University of Louisville

ThinkIR: The University of Louisville's Institutional Repository

Electronic Theses and Dissertations

8-2014

\title{
Critical thinking structures for business ethics.
}

Brian G. Barnes

University of Louisville

Follow this and additional works at: https://ir.library.louisville.edu/etd

Part of the Arts and Humanities Commons

\section{Recommended Citation}

Barnes, Brian G., "Critical thinking structures for business ethics." (2014). Electronic Theses and Dissertations. Paper 73.

https://doi.org/10.18297/etd/73

This Doctoral Dissertation is brought to you for free and open access by ThinkIR: The University of Louisville's Institutional Repository. It has been accepted for inclusion in Electronic Theses and Dissertations by an authorized administrator of ThinkIR: The University of Louisville's Institutional Repository. This title appears here courtesy of the author, who has retained all other copyrights. For more information, please contact thinkir@louisville.edu. 


\title{
CRITICAL THINKING STRUCTURES FOR BUSINESS ETHICS
}

\author{
By
}

\author{
Brian G. Barnes \\ B.A., Hanover College, 1995 \\ M.A., University of Louisville, 1997
}

\begin{abstract}
A Dissertation
Submitted to the Faculty of the

College of Arts and Sciences of the University of Louisville

in Partial Fulfillment of the Requirements

for the Degree of
\end{abstract}

\section{Doctor of Philosophy}

Department of Humanities

University of Louisville

Louisville, Kentucky

August 2014 
Copyright 2014 by Brian G. Barnes

All rights reserved 

CRITICAL THINKING STRUCTURES FOR BUSINESS ETHICS

By

Brian G. Barnes

B.A., Hanover College, 1995

M.A., University of Louisville, 1997

A Dissertation Approved on

April 18, 2014

by the following Dissertation Committee:

Dr. Osborne Wiggins, Professor Emeritus

Department of Philosophy

Dr. Patty Payette, Executive Director

Ideas 2 Action

Delphi Center for Teaching and Learning

Dr. Lynn Boyd, Associate Professor and Chair of Management College of Business

Dr. Al Futrell, Professor and Chair

Department of Communication 


\section{DEDICATION}

This dissertation is dedicated to my parents,

Larry Barnes,

an award-winning journalist,

and

Mary Barnes,

an award-winning teacher.

I also dedicate this dissertation to my wife,

Mithuiel Barnes,

without whom

much would have been lost

and

all would be diminished. 


\section{ACKNOWLEDGEMENTS}

My thanks to Kendall-Hunt Publishing, particularly David Mattaliano,

Glenn Hammersmith, and Thalia Cutsforth for working with me to publish the textbook portion of this dissertation. Deep thanks go to the good friends, colleagues, and mentors who have helped me work through various issues in this text: John Ahrens, Mith Barnes, Phyllis Barnes, Angie Carlson, Rush Cosgrove, Phil Dowdle, Linda Elder, Stephen Fabian, Rob Frederick, Al Futrell, Matthew Hawthorne, Gary Heine, Mark Hogg, Elizabeth Irish, Paul Johnson, Mike Mays, Justin Mog, Matt Partin, Richard Paul, Joe Segree, Bill Smith, Osborne Wiggins, Bob Urekew, Steve Vice, and Vaughn Zeller. I couldn’t have compiled this material or taught this course without you.

Thanks to Bob Kimball from the U of L Philosophy Department for the continued support as this course has developed over the last nine years. Many thanks to my colleagues at the University of Louisville, including those in the Philosophy Department, on The Sustainability Council, and at the College of Business; at Bellarmine University in Philosophy and the Interdisciplinary Core; at Indiana University Southeast in the Philosophy Department and on their Sustainability Council; in the Philosophy Department at Jefferson Community and Technical College; and at Northwood and Strayer universities in 
Louisville. You have all helped me understand this material in deeper and clearer ways, and I'm grateful. Thanks to the Ideas to Action Institute at U of L and The Foundation for Critical Thinking in Dillon Beach, CA, for their help in the development of my thinking about this material. Many thanks to my contributors for answering the central question: Phil Dowdle, Gary Heine, Mith Barnes, Sondra Powell, and Matthew Hawthorne. Special thanks to Gary Heine for outlining his ethical journey as an entrepreneur for the text. I appreciate the many others who considered answering the central question or contributing their ethical journey to the text. Thanks to Richard Wilcke from the University of Louisville's College of Business and the many other contributors of material to the text. Of course, deep gratitude must go to my students, without whom this project would be irrelevant and who, at the end of day, have made this exploration of business ethics and critical thinking great fun. To those whom I have inevitably forgotten, my thanks and my apologies.

This document is submitted as a portion of my requirements for the $\mathrm{PhD}$. in Humanities at the University of Louisville, and, so, many thanks to veterans of my dissertation committees: Annette Allen, Mark Blum, Lynn Boyd, Al Futrell, Patty Payette, and, as Chair, Osborne Wiggins. Thank you all for helping me with this process.

Special thanks to my wife, my editor, and the aesthetic salvation of all of my projects, Mithuiel Barnes. Thank you for all of your support, encouragement, criticism, and knowledge of what really matters. This document would 
never have come together without your tireless efforts. To my son, Iain

Barnes, I offer thanks for your constant support. I also apologize for all of the times I was writing when I really should have been doing something with you.

I hope, when you look back, I really was more present after I finished my dissertation, as promised. 


\title{
ABSTRACT \\ CRITICAL THINKING STRUCTURES FOR BUSINESS ETHICS
}

\author{
Brian G. Barnes
}

Apr 18, 2014

This dissertation is an original synthesis of the critical thinking system developed by Richard Paul ("Paulian CT") and business ethics classroom teaching in the discipline of Philosophy. The project offers a full textbook for a 16-week college course in business ethics taught through the lends of Philosophy. This textbook is intended to teach business ethics in a critical manner, something often claimed by Philosophy textbooks but, according to this dissertation's literature review, never delivered upon. This textbook is the first business ethics textbook structured for criticality, to teach in ways that are supported by critical approaches, which set up the conditions for readers to teach themselves to think through the material to arrive at original, evidencebased conclusions, as opposed to didactic approaches, which merely tell the reader what to think. The goal of my text is to teach readers to identify and reason through ethical issues in business. The textbook is also deeply interdisciplinary and teaches its readers to reason in an interdisciplinary way. 
Of the critical structures in the textbook, many are made explicit to maximize a student thinking through the content. Others are hidden, however, since the student is meant to focus upon the content of the course, while getting much of the critical thinking accomplished along the way by doing the work requested of the textbook. These hidden critical structures are brought out in the dissertation, which analyzes the structural features of the text to provide a key for using it with maximum effectiveness for criticality. The dissertation also justifies the textbook's existence with a literature review of recent textbooks and scholarly articles published in Philosophy, Economics, and Critical Thinking, and it helps readers understand the shift from didactic to critical educational paradigms for teachers. 


\section{TABLE OF CONTENTS}

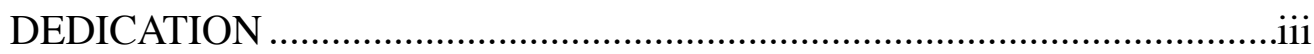

ACKNOWLEDGEMENTS ........................................................................iv

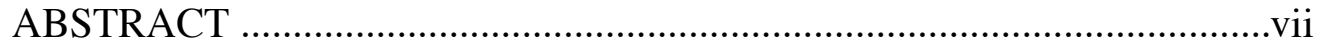

SECTION 1

INTRODUCTION TO THE PROJECT[..................................................

SECTION 2

KEY TO CRITICAL STRUCTURES AND PEDAGOGY in textbook .......25

\section{SECTION 3}

TEXTBOOK:

“THE CENTRAL QUESTION:

CRITICAL ENGAGEMENT WITH BUSINESS ETHICS” .....................74

Preface: Approaching the Question .....................................................

The Central Question .............................................................81

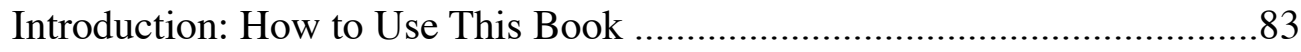

Notes on Devices in the Text .......................................................83

Six Learning Modalities: For Students and Teachers .......................84

Central Question: For Students ...................................................86

Fundamental and Powerful Concepts: For Students and Teachers ....87

Basic Paulian Critical Thinking Theory for Business Ethics ............89

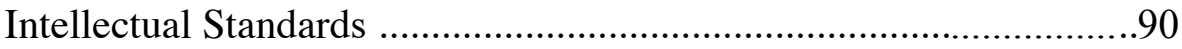

The Elements of Thought ........................................................91

Why write

Taking a Critical Approach Seriously: For Students .........................96 
Questions to Consider Before Reading:.........................................98

Critical Thinking for Business Ethics............................................98

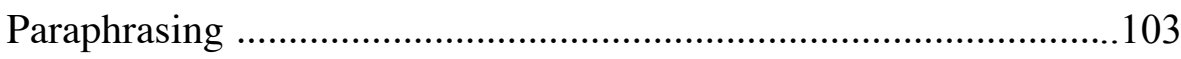

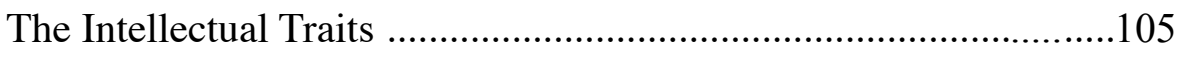

Egocentric and Sociocentric Thinking ......................................108

CHAPTER 1

INTERDISCIPLINARY THINKING:

THE MILGRAM EXPERIMENTS

CHAPTER 2

HOW TO IDENTIFY A BUSINESS ETHICS ISSUE

CHAPTER 3

ETHICAL EGOISM AND THE MYTH OF GYGES

CHAPTER 4

ENRON: A PARADIGM CASE

CHAPTER 5

SHAREHOLDER THEORY

CHAPTER 6

CONTRACTARIANISMS

CHAPTER 7

UTILITARIAN AND DEONTOLOGICAL THINKING

ABOUT BUSINESS ETHICS

CHAPTER 8

SMITH AND MARX

CHAPTER 9

CORPORATE PERSONHOOD

CHAPTER 10

ANTI-CORPORATE ACTIVISM

.210

CHAPTER 11

SUSTAINABILITY FOR BUSINESS ETHICS 216

SECTION 4 
Table 1: Review of Critical Thinking Texts.....................................241

Table 2: Review of Business Ethics Texts .....................................243

Table 3: Summary of Database Research for

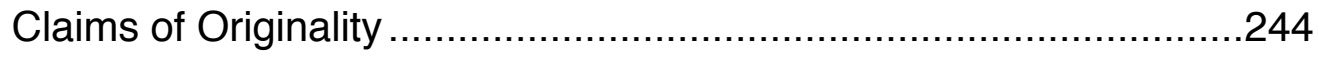

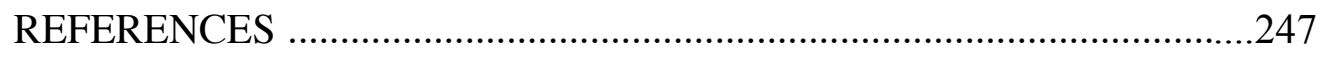

APPENDIX 1 (for textbook artifact)

LOOKING AHEAD FROM HERE

APPENDIX 2 (for textbook artifact)

ANSWERS TO THE CENTRAL QUESTION .276

APPENDIX 3 (for textbook artifact)

PODCAST RESOURCES

APPENDIX 4 (for textbook artifact)

“SUSTAINABILITY VILLAGE” MODEL PROPOSAL ...............................291

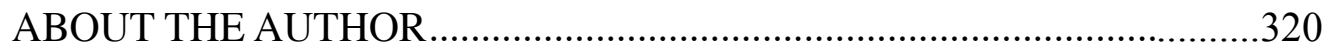

Appendix A

A REVIEW OF CRITICAL THINKING APPROACHES AS

REPRESENTED IN PHILOSOPHY TEXTBOOKS

Appendix b

A REVIEW OF THE BUSINESS ETHICS FIELD AS

REPRESENTED IN PHILOSOPHY TEXTBOOKS .348

appendix c

CLAIMS OF ORIGINALITY .362

Business Ethics Claims .366

APPENDIX E COB ETHICS FRAMEWORK PROPOSAL .405

APPENDIX F

COPYRIGHT and copyright PERMISSION TO REPRINT

"THE CENTRAL QUESTION: CRITICAL ENGAGEMENT

WITH BUSINESS ETHICS" 


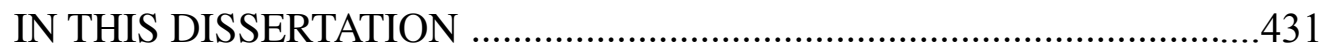

Copyright information for this textbook: .....................................431

DOCUMENTATION OF COPYRIGHT PERMISSION ..................432

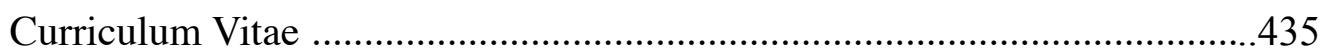




\section{SECTION 1 \\ INTRODUCTION TO THE PROJECT}

The purpose of this dissertation is to demonstrate to readers how to use Paulian Critical Thinking Theory ("Paulian CT") to construct a textbook that will teach users to reason critically and ethically about problems that arise in a capitalist marketplace. Paulian CT has been developed by Richard Paul, founder of The Foundation for Critical Thinking and Emeritus Professor of Philosophy at Sonoma State University in California. This project should be used by others as a model to construct a textbook in their own disciplines that teaches the content to readers through a critical thinking pedagogical processes, which is a central feature of Paulian CT.

"Instructional design involves a teacher thinking about instruction in both structural and tactual ways. Overall structural thinking - for example, about the concept for the course - can help free a teacher from the Didactic Model into which we have been conditioned and the ineffective teaching that invariably accompanies it. Simple and complex tactical thinking can provide the means by which we can follow through on our structural decisions in an effective way. Our teaching will not be transformed simply because we philosophically believe in the value of critical thinking. We must find practical ways to bringing it into instruction, both structurally and tactically."'

The textbook project that is at the heart of this dissertation is de-

${ }^{1}$ Linda Elder and Richard Paul. Critical Thinking: Basic Theory and Instructional Structures.

The Foundation for Critical Thinking Press, 1999. 5. 
signed to follow Paulian structures over the course of its use with students and to employ Paulian tactics throughout, in order to create an organized approach for helping students internalize the content of business ethics and to learn to think about their own thinking. This is the critical thinking goal of the work. The dissertation provides context and explains the ways structures and tactics interact to produce student learning and to promote the development of critical thinking ideas in the students that can be carried from the business ethics course across other disciplines.

First, a brief outline of the textbook project completes this general Introduction. Following the Introduction is an explication of "The Logic of" the textbook written for and being used as the object of deep analysis in this dissertation. The textbook provides an example of an explicitly interdisciplinary approach for infusing critical thinking into business ethics instruction in such a way that the content is delivered to the students in a way that maximizes their potential for learning it. This integration between content and pedagogy is a central feature of Paulian CT. In $A$ Thinker's Guide on How to Improve Student Learning, Richard Paul states in his chapter, "Recommended Design Features," that teachers should,

"Design instruction so that students engage in routine practice in internalizing and applying the concepts they are learning (and in evaluating their understanding of each). For students to learn any new concept well, they must initially internalize the concept, then apply the concept to a problem or issue so that they come to see the value of understanding the concept. At the same time, they need to evaluate how well they are internalizing and applying the concepts they are learning. If students are to ac- 
quire understandings and skills, we need to provide many opportunities for them to 1) internalize the key concepts in the subject, and to 2) apply those concepts to problems and issues (in their lives or in their coursework)." ${ }^{2}$

For Paul, the connection between learning the content and the way the teacher teaches is never broken in good instruction. Without an organized method on the part of the instructor for giving the students opportunities to connect theory with practice, understanding will not occur.

"It is only when students apply what they are learning to actual situations or problems that they come to see the value in what they are learning. And only when they see the value in learning the content will they be internally motivated to do so." ${ }^{3}$

This dissertation will explain one process of educational design that explicitly captures in textbook form Richard Paul's vision for a critical pedagogy. The textbook artifact for this dissertation is designed with these considerations in mind, and the dissertation will demonstrate that the pedagogy within the textbook is a critical pedagogy in the style of Richard Paul, the developer of Paulian Critical Thinking Theory. The dissertation will also demonstrate that a textbook designed explicitly to emulate the Paulian model has never been published in business ethics; this is the main original contribution of this dissertation to the discipline of Philosophy and its sub-disciplines of business ethics and critical thinking.

2 Richard Paul. A Thinker's Guide on How to Improve Student Learning. Foundation for Critical Thinking Press, 2011. 4.

${ }^{3}$ Ibid. 
This dissertation project begin with this Introduction, which discusses the various connections between textbook structural decisions and the Paulian pedagogy they are meant to reinforce. These decisions are explicated in greater detail in Section II with explicit reference to aspects of the textbook.

Following these two sections, the textbook artifact itself is revealed. The textbook was published in advance of this dissertation by Kendall-Hunt Publishers in December, 2013, and is entitled, The Central Question: Critical Engagement with Business Ethics. The textbook is the product of an original synthesis of business ethics and Paulian CT, and teaches both critical thinking skills and ethical reasoning skills for undergraduate business students.

The textbook trains beginning students to recognize, analyze, and assess the ethical aspects of business autonomously, has a mappable, logical progression to it, and it helps readers learn to apply ethical reasoning to business with an interdisciplinary method. The methods in the textbook are modeled on the dissertation author's own Business Ethics classes at The University of Louisville (PHIL 225); this textbook model advocates for and supports the classroom structures found in those courses.

Foundational to the book's structure is Richard Paul's critical thinking theory, perpetuated and disseminated by The Foundation for Critical 
Thinking. ${ }^{4}$ Due to the dual facts that this style of critical thinking stems

from Philosophy and that the approach to Business Ethics being used is a sub-discipline in Philosophy, the discipline of Philosophy is core to this dissertation. The textbook is written for use in a business ethics class taught from a philosophical point of view, as opposed to the business ethics points of view from Psychology, Management, or some other areas of the academy.

Likewise, there are many theoretical positions and concepts in the text that are selected for their relevance to business activities, though they may be unrelated to Philosophy. Working with these materials creates the interdisciplinary nature of the textbook, a feature which is required for dissertations in The School of Interdisciplinary and Graduate Studies at the University of Louisville, which is the governing body for this dissertation. Further, a text of this type demands examples from the world of business that apply simultaneously to critical thinking and ethics, which are provid-

4 "Paulian Critical Thinking Theory" is the body of critical thinking, education reform, and moral critique developed by Richard Paul since the late 1960s. This material has been collected into around 50 published works, several dozen video workshops and lectures, several dozen academic papers, and an annual International Conference on Critical Thinking is held in Berkeley, CA, to train scholars in this material. The conference is in its 34th consecutive year in 2014. Paulian Critical Thinking theory emphasizes a metacognitive approach to analyzing, evaluating, and improving a person's own thinking, particularly being sympathetic to the value of questions in a person's own reasoning and to hidden areas of bias within the thinker that are leading to poor thinking. It refers to the highest form of critical thinking, which contains an explicitly ethical component, as "strong sense critical thinking." 
ed. ${ }^{5}$ By reason of this connection, Business is also an important discipline for this dissertation.

Since the textbook claims to be multidisciplinary and interdisciplinary, there are a number of relevant theories and examples used in the textbook from across the academic realm: Psychology, Meteorology, Communication, History, English, Film Studies, Economics, Sociology, and others. These examples and theories have been assembled in a way that celebrates the interdisciplinary and multidisciplinary understandings required for real-world discussions of business ethics and its applications. Since business occurs in a marketplace unrestricted by dogmatic disciplinary orthodoxy for most consumers, a multi-faceted approach of this type demonstrates real-world relevance in so many business contexts when decisionmaking is required.

Following the textbook itself are several appendices, briefly outlined here. Appendix A is a literature review of Critical Thinking textbooks. Appendix B is a literature review of Business Ethics textbooks. Appendix C is a demonstration of claims of originality for this dissertation. Appendix D discusses the author's development as an educator in ways relevant to criti-

\footnotetext{
5 The purposes of the dissertation and the textbook are to raise and explore issues of learning and reasoning within the business ethics context. The goal is not to catalogue any specific business ethics examples, to provide knowledge about industry-specific business ethics problems, or to provide any sort of encyclopedic understanding of business ethics history and literature. This approach is about learning to think within business ethics by using the methods of Paulian Critical Thinking. All examples are only intended to accomplish these goals.
} 
cal pedagogy. Appendix $\mathrm{E}$ is a pedagogical primer for faculty wishing to incorporate business ethics into their classes. Appendix F is copyright permission from Kendall-Hunt Publishers for using the published textbook in the dissertation.

Appendix A offers a literature review of the Critical Thinking (CT) field within Philosophy. The section begins with an explanation of the main line in philosophical critical thinking theory, which is typically referred to as "Informal Logic." The main analysis of sources in this section supports and explains why this field should begin leaning toward a Paulian conception of CT, as opposed to the current state of the art.

Appendix B is a literature review of the Business Ethics field in Philosophy. The section begins with an explanation of the main line of business ethics pedagogy for beginning thinkers in the field. The section includes an explanation for why the traditional way of doing Business Ethics in this area deserves an update in line with the Paulian approach to CT.

Appendix $\mathrm{C}$ demonstrates and supports various claims of originality in the text. This is accomplished through a review of the relevant published literature.

Appendix D outlines the author's educational background and teaching history for the purposes of explaining why the critical approach to teaching is preferable to other ways of inhabiting the teaching role. 
Appendix E is a document the author created that teaches business school faculty about business ethics and suggests how it could be effectively incorporated into any class.

Appendix F contains the required statements and citations for reformatting and publishing the already-published textbook in this dissertation.

For understanding the pedagogy employed in the dissertation, it is important to distinguish the didactic mode of teaching and learning from the critical. Richard Paul outlines "didactic instruction" in Critical Thinking:

What Every Person Needs to Survive in a Rapidly Changing World.

"Didactic Instruction [is] teaching by telling. In didactic instruction the teacher directly tells the student what to believe and think about a subject. The students' task is to remember what the teacher said and reproduce it on demand. In its most common form, this mode of teaching falsely assumes that one can directly give a person knowledge without that person having to think his or her way to it. It falsely assumes that knowledge can be separated from understanding and justification. It confuses the ability to state a principle with understanding it, the ability to supply a definition with knowing a new word, and the act of saying that something is important with recognizing its importance."'6

So, the didactic approach to teaching involves students being told exactly what to think, whether it's in a lecture or in a textbook. There is no emphasis on promoting the development of autonomous intellectual processes within the thinker; the thinker is merely used as a repository for stor-

\footnotetext{
6 Paul, Richard. Critical Thinking: What Every Person Needs to Survive in a Rapidly Chang-
} ing World. The Foundation for Critical Thinking, 1990. 547. 
ing and repeating data, not for robustly processing it into thinking that is original with that thinker. A traditional didactic textbook gives students the reasoning for all conclusions and relies upon the student to internalize that material without encouraging him or her to know why and how the reasoning leads to the conclusions being offered. While the evidence is certainly offered in such texts, but student may not always know how to intellectually connect the evidence to the conclusions in ways that will lead to deep learning. Textbooks in the didactic style will often offer methods to be followed for students to reach an exercise's goal, but they won't encourage students to do much thinking about the method being followed, per se; students are merely encouraged to do what is being asked in order to finish the exercise. This is a decidedly un-Socratic method and promotes rote memorization and regurgitation, not original thinking within the subject. At its worst, a didactic approach to education creates discipline-bound sycophants that are immediately willing and able to regurgitate material in support of some entrenched position without knowing what the deep meaning behind that material might be for themselves or the discipline at large. If students are expected to be able to reason ethically in business situations after a course in business ethics, mere memorization and repetition of cases or lists of principles will not supply the necessary education for original thinking in the marketplace, according to Paul's distinctions above: The ability to state a principle in business ethics is not synonymous with understanding that 
principle in any practical way, the ability to supply a theory or idea in business ethics is not the same as knowing that idea in a way that it can be translated into action, and simply saying that an idea in business ethics is important does not actually mean that the thinker recognizes that importance for any actual practice of business.

In the frontispiece for $A$ Thinker's Guide for Those Who Teach on How to Improve Student Learning (2011), Paul offers a vision of the critical educational approach:

"This list of instructional ideas is based on the goal of teaching all subjects so that, as a consequence, students take ownership of the most basic principles and concepts of that subject... They are based on a vision of instruction implied by critical thinking and an analysis of the weaknesses typically found in most traditional didactic lecture/quiz/test formats of instruction. We begin with two premises: That to learn a subject well, students must master the thinking that defines that subject, and that we, in turn, as their instructors, must design activities and assignments that require students to think actively within the concepts and principles of the subject. Students should master fundamental concepts and principles before they attempt to learn more advanced concepts". ${ }^{7}$

So, critical thinking instruction is contained in the content of whatever is being taught, and it seeks to provide thinking opportunities for students that will promote deep learning beyond mere memorization. The principles of critical thinking are the mechanism that leads to the internalization of the concepts being studied. The business ethics textbook at the core of

${ }^{7}$ Richard Paul and Linda Elder. A Thinker's Guide for Those Who Teach on How to Improve Student Learning. The Foundation for Critical Thinking Press, 2011. 1. 
this project does that, and it does so by focusing on fundamental and powerful ("f \& p") concepts for business ethics at the beginning of each chapter and building upon those $\mathrm{f} \& \mathrm{p}$ concepts within each chapter to more advanced concepts, as Paul recommends above. Gerald Nosich explains f \& p concepts in Learning to Think Things Through.

"A fundamental and powerful concept is one that can be used to explain or think out a huge body of questions, problems, information, and situations. All fields have $\mathrm{f} \& \mathrm{p}$ concepts, but there are a relatively small number of them in any particular area. They are the most central and useful ideas in the discipline... if you can understand the $f \&$ p concepts in a deep way, you are in a position to understand a great deal of the rest of the course. You need to learn to think in terms of the fundamental and powerful concepts, to use them to think through any new problem or question that arises." $" 8$

So, The Central Question organizes these $\mathrm{f} \& \mathrm{p}$ concepts for business ethics in such a way that they can be used for deep and organized thinking about that discipline. This example of Nosich's method can be copied for other disciplines.

The Central Question is also organized within the logic of building an understanding of the relevance of ethics for business from the first page to the last, since the textbook's content progresses in complexity as the reader moves forward, not just within each chapter. Later chapters in the textbook rely upon the readers' understanding of earlier chapters. This progression exemplifies Richard Paul's approach:

${ }^{8}$ Gerald Nosich. Learning to Think Things Through: A Guide to Critical Thinking Across the Curriculum. Pearson Education: Upper Saddle River, NJ, 2009. 105-6. 
"Make the point that the content is a SYSTEM of interconnected ideas. Explain that this system is used, by professionals, to ask questions, gather data or information, make inferences about the data, trace implications, and transform the way we see and think about the dimension of the world that the subject represents.... Each idea is explained in terms of other ideas. The ideas together form an interrelated system."

Also within this critical thinking approach, it is much more important to know why you are thinking what you are thinking, and how your thinking got there, than it is to merely be able to regurgitate information and ideas without insight. This is indicative of the Socratic approach to learning.

"In the final analysis, we want students to learn the discipline of Socratic questioning, so that they begin to use it in reasoning through complex issues, in understanding and assessing the thinking of others, and in following-out the implications of what they, and others, think." 10

It is a particularly appropriate approach for business ethics teachers who want to develop thinkers, as opposed to mere memorizers. This echoes Paul's intentions above, that "we, in turn, as their instructors, must design activities and assignments that require students to think actively within the concepts and principles of the subject."11

Business students should learn approaches from their college classes that promote critical thinking in the same ways that they are being taught to

9 Richard Paul. A Thinker's Guide on How to Improve Student Learning. The Foundation for Critical Thinking Press, 2011. 30.

${ }^{10}$ Richard Paul. The Thinker's Guide to the Art of Socratic Questioning. The Foundation for Critical Thinking Press, 2007.2.

${ }^{11}$ Richard Paul. A Thinker's Guide on How to Improve Student Learning. The Foundation for Critical Thinking Press, 2011. 30. 
reason masterfully within other systems relevant to business: finance, logistics, marketing, management, etc. Each of these systems address outcomes that are most easily achieved if the person using them can learn to apply the system to his or her life in important ways. Richard Paul has articulated some of the important ideas about how critical thinking can apply to life.

"...focus on the important pay-offs of critical thinking... The proof of any approach to critical thinking is given in how clearly, accurately, precisely, relevantly, deeply, broadly, logically, significantly, and fairly it lends itself to practical use in the full range of human situations which call for critical analysis, critical assessment, or critical judgment," 12

and

"the quality of our life and that of what we produce, make, or build depends precisely on the quality of our thought. Shoddy thinking is costly, both in money and in quality of life."13

Barry Beyer offers a related assessment when he writes,

"Whenever we evaluate our own cooking, someone else's performance of a task, the accuracy of a newspaper or TV account, a work of art, or a researcher's conclusion, we are applying criteria to make a judgmentwe are engaged in critical, or criterial, thinking." 14

It is precisely this kind of thinking that makes our lives rich and that links the different aspects of our lives together to provide meaning and val-

12 Richard Paul. "Reflections on the Nature of Critical Thinking, Its History, Politics, and Barriers, and on Its Status across the College/University Curriculum Part II." Inquiry: Critical Thinking Across the Disciplines. 27:1. Spring, 2012. 6.

${ }^{13}$ Richard Paul and Linda Elder. The Miniature Guide to Critical Thinking Concepts and Tools. Foundation for Critical Thinking Press, 2008. 2.

${ }^{14}$ Barry Beyer. Critical Thinking. Phi Beta Kappa Educational Foundation: Bloomington, 1995.9. 
ue to each of us. We can use our minds to do it well, or we can do it poorly.

Critical approaches, by virtue of causing students to think about deep reasons behind their thinking, will foster an attitude of deep learning that leads to action. "For critical thinking, it is not enough to know how to seek reasons, truth, and understanding; one must also be impassioned to pursue them rigorously," 15 and "critical thinking [arises] from the... sentiment to overcome ignorance, to theist the distorted against the true, [and] to ground effective human action in an accurate sense of social reality." 16 Students should develop techniques that prompt metacognitive, precise, deep understanding early during the process of their business educations, so that the necessary skills for real-time ethical decision-making can be developed. Burbules and Berk suggest this ethical dimension in critical thinking. "The object of thinking critically is not only against demonstrably false beliefs, but also those that are repressive, partisan, or implicated in the preservation of an unjust status quo." ${ }^{17}$ Richard Paul also believes that ethical thinking and critical thinking are intertwined:

"Paul believes that, because critical thinning allows us to overcome the sway of our egocentric and sociocentric beliefs, it is 'essential to our

\footnotetext{
15 Nicholas C. Burbules and Rupert Berk. "Critical Thinking and Critical Pedadgoy: Relations, Differences, and Limites." Critical Theories in Education: Changing Terrains of Knowledge and Politics. Thomas Popkewitz and Lynn Fendler, editors. Routledge: London. 1999. 51.

16 Ibid., 53.

17 Ibid., 51.
} 
role as moral agents and as potential shaper os our own nature and destiny." "18

Paulian critical thinking theory helps the thinker develop precisely this kind of masterful and flexible use of content, and so it is an appropriate base for business ethics reasoning.

The textbook is designed as an application of Paulian critical thinking theory for maximum student engagement, development of critical thinking skills, community engagement, and development of the skills needed to fully incorporate ethical aspects of business into thinking about business practice. Due to the emphasis on appreciating multiple points of view and developing intellectual empathy, development of Paulian critical thinking skills can cultivate awareness of the multiplicity of ways ethical issues arise within business. These skills also provide evaluative tools for any inquiry, robust intellectual and ethical standards for living, and a good foundation for understanding systematic thinking, including the mechanics of ethical reasoning. This is the attitude, for example, of Peter Facione, author of Critical Thinking: A Statement of Expert Consensus for Purposes of Educational Assessment and Instruction. Research Findings and Recommendations. In two places in the report, Facione cites Richard Paul to make the point that there is an important connection between strong sense critical thinking and the learning of values and ways of living with others in the world.

18 Ibid., 50. 
"There is a very great difference between skills and attitudes... Richard Paul has taught us most effectively [that] there is, or should be, a causal relation between skill and disposition such that the disposition might/ should elicit, motivate, and work as side-constraints for the skills." ${ }^{19}$

Those constraints and motivations might very well be ethical, if that is the motive sought by the thinker. Facione also cites Paul when making explicit connections between $\mathrm{CT}$ and ethics.

"If thinking is disciplined to serve the interests of a particular individual or group, to the exclusion of other relevant persons and groups,... it is sophistic or weak sense critical thinking. If the thinking is disciplined to take into account the interests of diverse persons or groups, it is fair-minded or strong sense critical thinking.--Richard Paul." ${ }^{20}$

The strong-sense critical thinking approach, which is explicitly concerned with ethical reasoning as part of its process, is at the core of The

\section{Central Question.}

Specific goals of the textbook are enumerated below. Methods within the text for meeting those goals are then provided, and this approach is expanded in Section 2. First, this textbook is intended to provide an alternative to other business ethics texts currently available. ${ }^{21}$ Many business ethics texts ignore the development of skills that enable students to actively engage in applying ethics in favor of a didactic march through cases and legal-

\footnotetext{
19 Peter Facione. Critical Thinking: A Statement of Expert Consensus for Purposes of Educational Assessment and Instruction. Research Findings and Recommendations. American Philosophical Association, 1990. 103.

20 Ibid., 102.

21 see Appendix B.
} 
ities. ${ }^{22}$ The Central Question's approach develops skills for applied ethics, broadly, and also applies those skills to business contexts. The dissertation's critical approach should be contrasted with an approach that focuses only on the content needed for addressing very narrow issues in business. The critical approach to learning involves self-reflective reading, writing, listening, and speaking about the content. This approach to learning is shared by Paulian theory and The Oxford Tutorial. ${ }^{23}$

The Oxford Tutorial is a system of learning developed at Oxford University in Cambridge, England, and used around the world.

"Tutorials take place at least once a week and it's up to you to research and prepare for them. Then you meet your tutor, perhaps with one or two other students, to discuss an essay or solutions to set problems. The aim is to review your answers or theories and explore ideas that arise in discussion...A tutorial relies on the exchange of ideas between you, your tutor and other students. You need not be experienced in debating, you just need to be ready to present and defend your opinions, accept constructive criticism and listen to others." 24

The tutorial creates opportunities for students to read material, speak about that material, write about the material as a matter of preparation, listen to colleagues and the tutor speak about the material, and to consider the material deeply. All of these skills correspond directly with Paulian CT's criti-

\footnotetext{
${ }^{22}$ see Appendix B.
}

${ }^{23}$ Rush Cosgrove. "Critical Thinking in the Oxford Tutorial: A Call for an Explicit and Systematic Approach." Higher Education Research \& Development, 30: 3, 343-356.

${ }^{24}$ http://www.ox.ac.uk/admissions/undergraduate/why-oxford/studying-at-oxford/tutorials 
cal modalities.

"Where communication becomes part of our educational goal is in reading, writing, speaking and listening. These are the four modalities of communication which are essential to education and each of them is a mode of reasoning." 25

Cosgrove points out that,

"It was in the area of essay writing that [Oxford] tutors' and students' conceptions of critical thinking converged most. All participating tutors and students interviewed mentioned that the first task when writing an essay was to clarify the question asked by precisely articulating the meaning behind key concepts, as well as identifying the assumptions underlying their use." 26

Writing is a key area in the Oxford Tutorial and for Paulian CT; both

of the methods also emphasize practice in reading, listening, speaking, though Cosgrove didn't discuss those at a deep level in his study. Linda Elder makes even more explicit connections between Paulian modalities and the Oxford Tutorial in her essay about the similarities between the two approaches.

"Both traditional Oxford Tutorial and emergent Critical Thinking approaches emphasize:

1) Teaching with a Socratic Spirit (teaching that emphasizes the student taking ownership of content through actively thinking it through). In this mode of teaching, the inquiry process is more important than the answer, while rote memorization is accorded little [value];

2) Teaching with intellectual standards (students are expected to adhere to clarity, accuracy, precision, relevance, depth, breadth, logic,

25 Richard Paul. "Reflections on the Nature of Critical Thinking, Its History, Politics, and Barriers, and on Its Status across the College/University Curriculum Part II." Inquiry: Critical Thinking Across the Disciplines. 27:1. Spring, 2012. 6.

${ }^{26}$ Rush Cosgrove. "Critical Thinking in the Oxford Tutorial: A Call for an Explicit and Systematic Approach." Higher Education Research \& Development, 30: 3, 348. 
and significance in their academic discourse). In this mode of teaching, intellectual discipline and rigor is expected and fostered;

3) Teaching that encourages students to identify key structural components in thinking (purposes, questions at issue, information and data, inferences and interpretations, concepts and theories, assumptions and presuppositions, implications and consequences, points of view and frames of reference);

4) Teaching that requires students to read, write, listen, and speak (critically);

5) Teaching that is dialogical (wherein the student learns to question the thinking of others and to expect his or her thinking to be questioned by others);

6) Teaching that encourages students to think for themselves while exercising intellectual humility and intellectual empathy; and

7) Teaching that locates ultimate intellectual authority in evidence and reasoning, rather than in authority figures or "authoritative" beliefs or texts... Through these processes, students learn how to read, write, speak, and listen in a new way (critically). Most importantly, they learn how to learn, using disciplined reading, writing, speaking, and listening as modalities essential to learning., ${ }^{27}$

Second, the textbook applies Paulian Critical Thinking Theory to emphasize a classroom model that advocates providing students with limited top-down commentary from the textbook author, while offering the raw materials for that author's reasoning on a relevant subject. In this way, fresh perspectives and new material are offered to students for their thinking without using class time to convey that information or by reverting to a heavily didactic approach.

"One of the most important qualities of the critical thinking teacher is the ability to 'coach' students in thinking, to becomes facilitators of learning rather than 'givers of information'... The students should see the class

${ }^{27}$ Linda Elder. http://www.criticalthinking.org/pages/international-fellows-academy/1193. Foundation for Critical Thinking website, 2014. 
principally as a place for active engagement in a disciplined performance." 28

So, students need some material to prepare for class, but class should be a place where that material is discussed and shaped, not disseminated. To merely give students information, for this approach, is to undermine their ability to understand it and internalize it for themselves.

Further, this approach blends nicely with the central question technique.

"A course in a field has a central question that it revolves around. It is the unifying question, and everything in the course fits into that question. The way to understand every item in the course, to see how it all fits together, is to understand it in terms of that central question." 29

The Central Question serves as an example of the central question system's usefulness to make explicit the process of organizing a college course with a central question at its core, to provide methods for maximizing learning with a central question-based approach, and to provide that framework in an easily accessible way to motivated students, teachers, and business ethics practitioners of all types.

Third, the textbook brings together a contemporary body of business ethics exercises and examples for students to work through that are organized so that students will discover for themselves central concepts and

${ }^{28}$ Richard Paul. A Thinker's Guide on How to Improve Student Learning. Foundation for Critical Thinking Press, 2011, 31.

${ }^{29}$ Gerald Nosich. Learning to Think Things Through: A Guide to Critical Thinking Across the Curriculum. 3rd ed. Upper Saddle River, NJ: Pearson Prentice Hall, 2009, 111. 
methods within the discipline. For classroom applications, the e-book platform makes that content available on student digital devices in a format that can be easily accessed and is linked to critical methods and a limited amount of commentary from the textbook author.

Fourth, students should learn to recognize and identify ethics in business contexts; motivated students of this approach will be able to successfully and usefully apply ethical theories to business situations outside of class contexts. It seems logical that these skills, once developed, would transfer easily to other areas of applied ethics.

In order to facilitate these four goals, the textbook offers a variety of critical pedagogical devices. For example, each chapter provides $f \& p$ concepts that can be related directly to the central question, and the chapter is organized so that students will immediately connect $f \& p$ concepts to the chapter by attempting to answer the provided questions. The $f \& p$ concepts serve as a bridge between the chapter's content and the textbook's central question.

Nosich recommends the following ways to connect important concepts in the course with the central question.

"Formulate the central question of the course as a whole. Break it down into two or three subsidiary questions. Then figure out how they fit together within the central question. Look at every topic in the course and ask, 'How does it fit into the central question? How does that topic con- 
tribute to answering the central question?"'30

The concept that connects all of the purposes of the textbook to one another is the development and consideration of good questions. Critical Thinking theorists across the board highlight the value of good questions for learning. Richard Paul writes, "To think well within a discipline, you must

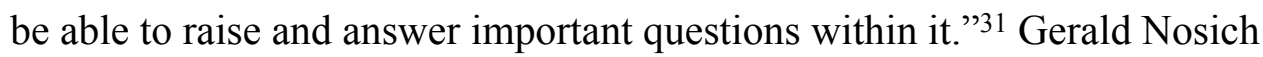
offers that, "Critical Thinking begins with asking questions... Thinking critically about solving a problem... begins with asking questions about the problem and about ways to address it." 32 Peter Facione suggests that, "Critical thinking instruction should focus on how students approach a question and reason about it." ${ }^{33}$ Psychologist Diane Halpern states that, critical thinking is "an assessment process in which all assumptions are open to question." ${ }^{34}$ Finally, the American Dental Education Association Commission on Change and Innovation in Dental Education suggests that core to enhancing critical thinking skills should be "frequent use of questions by

${ }^{30}$ Ibid., 114.

${ }^{31}$ Richard Paul. The Thinker's Guide for Students on How to Study and Learn. Foundation for Critical Thinking Press, 2007, 33.

${ }^{32}$ Nosich, Learning to Think Things Through..., 6.

${ }^{33}$ Peter Facione. Critical Thinking: A Statement of Expert Consensus for Purposes of Educational Assessment and Instruction. Research Findings and Recommendations. American Philosophical Association, 1990, 5.

${ }^{34}$ DF Halpern. Thought and Knowledge: An Introduction to Critical Thinking. Hillsdale, NJ: Lawrence Erlbaum, 1989. 
instructors that require students to analyze problem etiology, compare alternative approaches, provide rationales for plans of action, and predict outcomes. ${ }^{35}$ The textbook artifact for this dissertation is loaded with questions that build a relationship between the material in the chapter at hand and the central question. There are even special questions that reinforce that relationship at the end of each chapter. The textbook bases its questions not only upon theory, but also upon real business examples, which are placed throughout the book. Part of the critical design is that readers will discover the answers to these questions for themselves; the answers are rarely provided in the text, and then they are only given when it serves a pedagogical purpose, like when Shareholder Theory is evaluated in Chapter Five.

The textbook contains many exercises that will serve as examples of critical thinking exercises for classes of any size. Detailed instructions can be modified for any size classroom, and the text contains activities to promote community engagement, as well as suggestions about how teachers can modify those activities for their local communities, which could make the activities more meaningful for their students. Each chapter also suggests media research at various points.

The textbook conveys a huge amount of content through Internet links embedded in the text. Permissions have been obtained for using this

35 William Hendricson, et al. "Educational Strategies Associated with Development of Problem-Solving, Critical Thinking, and Self-Directed Learning." Journal of Dental Education. 70:9. 2006. 932. 
material by the textbook's publisher, Kendall-Hunt, so potential copyright pitfalls have been averted with regard to using the source material in this format ${ }^{36}$. Students can interact with the links embedded in the text and read expert opinions about the specific areas that, together, demonstrate and articulate business ethics reasoning. There is also a selection of podcasts from multiple disciplines that explore connected business ethics issues. In continuing within an interdisciplinary spirit, there are also examples, exercises, readings, or theories from disciplines not usually linked with business ethics.

In order to promote the critical thinking paradigms of Paulian theory, language and theory from that framework are developed with business ethics in mind throughout the text. In keeping with that educational approach, the text cultivates opportunities for students to think, read, write, speak, listen, and role-play with regard to the content, all of which has been demonstrated above to perpetuate deep thinking about that content.

${ }^{36}$ Permission has also been obtained to reprint the textbook as part of the dissertation. See Appendix E for more information. 


\section{SECTION 2}

\section{KEY TO CRITICAL STRUCTURES AND PEDAGOGY IN TEXTBOOK}

The following document serves as the pedagogical key to the critical structure of, and critical structures in, the Business Ethics textbook, The Central Question: Critical Engagement with Business Ethics. The textbook is intended to simultaneously promote student-driven, self-reflective, interdisciplinary thinking in business ethics reasoning and critical thinking in the Paulian tradition. The textbook builds an understanding of how to reason through business ethics problems by dissection of ethical theories and deep examination of the reader's own thinking about ethical issues in business. Much of this occurs through case studies and various other pedagogical vehicles in the textbook, discussed below. By the end of the textbook, students are able to reason in a flexible and informed way through various business ethics positions. The text is not inclusive of all important business ethics ideas, theories, or cases, but it uses a number of important concepts, typically articulated as " $\mathrm{f} \& \mathrm{p}$ concepts" at the beginning of each chapter, to guide students along in their thinking about the ethical aspects of business. 
Preface: Approaching the Question and Introduction: How to Use This Book

The text begins with a guide to how to use the book, since my assumption is that readers will be unfamiliar with both ethical reasoning and critical thinking in general, and with Paulian Theory in particular. Likewise, the Oxford tutorial methods (six learning modalities) are worth explaining for both teachers and students using the text, since all textbook activities explicitly employ one or more of them. The text is organized around a central question, and that method's usefulness needs to be explained to readers, along with the value of using fundamental and powerful concepts for anchoring their learning to the central question. The Foundation for Critical Thinking (FCT) advocates reprinting key material in the text for readers to easily access. This is why there is so much critical thinking theory minutely presented in these two sections, eliminating the need for an additional text on critical thinking alone.

The connecting features of the Paulian central question method, wherein all of the material in the course finds its way back to the central question by a definable path, brightly lit by the fundamental and powerful concepts at the head of each chapter, should be brought to the reader's attention, so that is accomplished early in the text. This structure is the skeleton of the course in business ethics that the textbook augments, and the textbook is designed to provide this trail of breadcrumbs back to the central question for all readers. The Preface also introduce the idea that there should 
be engagement with the community from the users of this book, which connects with methods and exercises later in the text that promote learning outside the classroom and in the world around the university.

As mentioned, the Introduction also includes the basic Paulian CT material that will be referred to and augmented throughout the text and the classroom experience. An additional part of the point of providing all of this material early in the text is so that readers can begin noticing critical thinking connections in their reading, and classroom students can be introduced to the language in context. In other words, anyone can begin using these critical thinking ideas, from the first pages of the text, immediately after exposure to them. While it is possible that readers may already be using critical thinking implicitly for their learning, one goal of Paulian Theory is to make the implicit in thinking processes explicit. By giving people the vocabulary to talk about the kind of autonomous reasoning humans might use informally and implicitly all the time, readers can grab onto that thinking and improve it, when needed. To know which aspects of thinking to grasp and which to let go, students must be certain about what is being discussed. Such certainty is accomplished by precise reference to the artifacts and inferences that have been made explicit by a thinker's process.

1: Interdisciplinary Thinking: The Milgram Experiments 
To make the process of interdisciplinary thinking explicit, the Milgram experiments are used to introduce readers to the idea that they might be giving up their own free choices about how to treat others without intending to do so. Humans might give up agency to employers, if care is not taken, because workers in corporations often believe in the work that they are doing, just like the participants in Milgram's experiments believed in the value of those experiments. Tuning students into this point of view causes them to consciously confront their own assumptions about the role of authority in their decision-making. By causing them to do this intellectual work, the textbook is promoting one of its major goals, which is to cause readers to seriously investigate their own thinking about key concepts that are at play when they think critically about business ethics.

The $f \& p$ concepts for this first chapter are Agency (free will), Authority (self's, the boss's or others'), Obedience (which is expected at work), and Power (the means by which humans try to gain control over their lives and the world around them, often including the autonomy of others.) All of these features are present in the Milgram Experiments, too, and so there is a nice analogy created between the concepts and the content of the chapter. By using $f \& p$ concepts in the book, the reader is prompted to reflect upon those concepts as keys to understanding his or her own thinking in any particular chapter. The textbook encourages readers to incorporate considerations of these $\mathrm{f} \& \mathrm{p}$ concepts into their own thinking 
about the material. From Paulian CT's point of view, readers can't incorporate concepts into their thinking without doing the intellectual work on their own.

"To generalize, students often do not sufficiently think about information they memorize in school sufficient to transform it into something meaningful in their mind. Much human information is, in the mind of the humans who possess it, merely empty words (inert or dead in the mind). Critical thinkers try to clear the mind of inert information by recognizing it as such and transforming it, through analysis, into something meaningful." 37

The first question set on page 34 highlights the analogy between the Milgram experiments and the business environment with questions like, "Do business activities that harm people ever occur without the consent of those who are harmed?" and "How much of a role does authority play in your decision making?" So, the question set bridges the gap between the decision-making in the experiments and that present in the workplace, which is a key to this approach.

This set also creates opportunities to get students reading, writing, and thinking about the material on their own or in class, depending on how the instructor has set up the evaluation structure. A reader going on his or her own, based upon the Introduction and Preface, may decide to use those methods that are explicitly suggested in the earlier sections. Classroom conversations (using the modalities discussed at the end of Section I.) will

${ }^{37}$ Richard Paul. http://www.criticalthinking.org/pages/critical-thinking-distinguishing-between-inert-information-activated-ignorance-activated-knowledge/488. 
also encourage students to use various tools from the critical thinking framework to analyze, assess, and/or improve their own thinking about the questions. The questions are all worded in ways that cause the reader to self-reflect prior to answering. For example, questions 1, 3, and 5 directly confront the reader's intellectual position. Questions 2 and 4 ask people to directly confront their own assumptions, which causes them to engage in analysis using the Elements of Thought.

Next, there are three web links. These external links are intended to provide the voices of outside experts to give the students information necessary for them to build the logic of their own answers into the question sets later in the chapter. Since the articles are all from Psychology, this creates an interdisciplinary learning opportunity, since students are being asked to explicitly use tools from Psychology to address Business concerns. A best practice might be for the class leader to make much of this interdisciplinarity, indicating how evidence is used and produced differently, how the important concepts and problems in the psychological approach connect with those raised in business ethics, and the way that theoretical material is presented in another discipline. The textbook presents these as explicit goals of using material from other disciplines. In this way, providing this material to students ahead of time provides raw material to be refined and discussed during class, completing the flipped-classroom model. Using this approach also shifts the point of view from the textbook author's to a dif- 
ferent author that is saying similar or dissimilar things, providing either support or contradiction from the primary text of the book. The connections between the textbook's ideas and those of the outside authors are connected in the first reading by overt reference to ethical ideas beyond the experiment itself. Those readings also give lots of information about the original experiments and those that followed for three decades, all of which are important for student understanding.

The second link is central for getting to the value of the Milgram Experiments for business ethics. It discusses the research of Thomas Blass, who wrote a biography of Milgram and assembled metadata from the worldwide Milgram experimental protocols conducted at dozens of universities. His research shows that the results of the original experiments are replicated by 25 years of metadata; this conclusion demonstrates that outcomes should be deeply impactful for readers who are following the text. This point of view is further reinforced by the third question of the next question set, and the third linked essay in that section is about the power of authority, which ties the concerns about that f \& p concept, "authority," to the experiments. While the textbook labels this final link as "optional," the potential impact of that information for students is powerful. After the next question set, which links ideas from the three readings, from the $f \& p$ concepts, and from the text, there is an introduction of "clarity" as a concept and a recognition of how to cultivate that as a reader and a writer in busi- 
ness ethics.

The Community Engagement Exercise is an opportunity for students to take their reflections upon the Milgram Experiments and try to interact with others in a surreptitious, though non-invasive, experiment ala Milgram. This exercise can be written or reported upon orally, and it brings the motivations of strangers into sharp focus for participants. This added step, if the exercise is completed, will help with deep understanding of the implications of the experiments for any of us navigating society daily. This exercise prompts deep reflection toward the motives of others that participants encounter in the world outside the classroom, which is another interdisciplinary cross-over skill for business ethics. It is also a great way to get students working through on reading, writing, listening, and speaking exercises, since they all would have had similar experiences to share and discuss.

The next part is an Application Exercise, which features media about Bernie Madoff. Each of the pieces of media portrays Madoff through his own words, and his actions are outlined by the reporters. The goal is to get students to connect Madoff's activity though the notions of power, authority, obedience, and agency. The question set reinforces that, and oral discussions contextualizing the material will help further. Students already have an understanding of Madoff that probably is not in line with these $f \&$ $\mathrm{p}$ concepts, and so the textbook shakes students out of their fixed under- 
standings of that situation in order to create flexibility in their points of view. This kind of flexible thinking is required for interdisciplinary work; students should possess some intellectual empathy for another viewpoint and promoting intellectual courage helps students explore a new idea or perspective at all that they might have otherwise ignored.

This progression leads the reader to an interdisciplinary training exercise. This exercise links ideas from Psychology, Sociology, Physics, Meteorology, and Ethics. Students use the different links and the classroom methods outlined in the Introduction to make the connections between the Milgram Experiments, Lorenz's Butterfly Effect, and Milgram’s Small World Experiment. What students should arrive at is something along the lines of The Small World Experiment demonstrating that contemporary humans are not so far apart from one another as is immediately apparent through the senses; the Milgram Experiment's conclusion suggests that anyone could harm someone else without intending it, even though that person was really trying to help or when following what seems to be an appropriate authority; finally, The Butterfly Effect's central idea is that very small actions can have huge, unintended consequences. All of these ideas, which can be further shaped in class, help students arrive at the business ethics conclusion that even the most well-meaning actions in business might have unintended, unforeseen, and harmful consequences, so business people should learn to reason deeply about motives and products in busi- 
ness environments in order to avoid undesired outcomes. This exercise is important, because it demonstrates that non-business ethics content can help anyone reason to business ethics conclusions, further demonstrating the power of interdisciplinary reasoning.

Each chapter contains a "Find the Ethical Aspect!" prompt, which encourages students to bring in an article, preferably from a newspaper (in order to support the perpetuation of print media for democratic purposes), so that students can see how ethical ideas from the chapter are showing up in the real world and playing out around them. This prompt creates an automatic opportunity for a written assignment that ties the chapter's material into contemporary media. If students can make original connections between this business ethics text and some pieces of current media that relate directly to each chapter's ideas, they might become more capable of making real-world business ethics connections outside of the classroom.

Finally, each chapter ends with some questions that relate the ideas and examples in the chapter back to the central question of the course and the text. The central question is, "When is it acceptable to profit from harm to others in business?" Since the text intends to provide students the ability to recognize and reflect upon potential and real harms as a result of their own and others' business activities, this recurring question set directs students to the core points in each chapter. By highlighting these questions, instructors can force students to do their own work to create those connec- 
tions in ways that the traditional written summary at the end of the chapter fails to do. Giving students the answers to self-reflective, complex questions is not required in the Paulian conception: "It is in virtue of 'discoveries' and insights... - which we must think through for ourselves to truly grasp them as knowledge - that our view... is transformed." ${ }^{38}$ Students must do the thinking for themselves and discover answers for themselves in line with the evidence.

\section{2: How to Identify a Business Ethics Issue}

Once students have been exposed to the potential implications and consequences of others' motives in business, they should have some direction regarding how to identify and classify a business ethics issue. This methodology has to be put at the beginning of the text, so that readers can then apply this rubric to exercises throughout the text. Being able to identify a business ethics issue is a key prerequisite for doing the work of business ethics.

The $f \& p$ concepts are evidence (which is key to identifying issues under this method), judgment (which is determined from the point of view of the ethical theory at hand), and axiology (an archaic word for the study of our freely-chosen values; the value systems of aesthetics, economics, and

${ }^{38}$ Richard Paul. http://www.criticalthinking.org/pages/critical-thinking-distinguishing-be$\underline{\text { tween-inert-information-activated-ignorance-activated-knowledge/488 }}$ 
ethics have fragmented, and so there is no contemporary replacement word).

The first section of the chapter relates ethical problems and their identification to relationships, not merely to isolated actions or particular types of people. In this way, students can learn to focus on relationship dynamics to locate ethical problems and motives. For this method of identifying business ethics issues, it is important that students learn to associate the ethics with the relationship. By the time Enron comes up in the text (see the box on page 60 of the textbook), the understanding that conflicts of interest are about relationships will be firmly in place if established here, and so the linking of upcoming conflicts of interest with a relationship, instead of an action or an individual, will be a simple maneuver.

Once a reader can identify the location of the business ethics issue in a relationship, the reader can link that relationship to the idea of responsibility, which is what the two questions accomplish. This is followed by the method of identifying an ethical theory, which involves a three-step approach that readers will find really useful in helping distinguish between secular ethical theories (the focus of the textbook) and theories that are not based in secular ethics, though they may address right and wrong in some direct way. There is significant difference in reasoning processes from ethical, religious, economic, and legal realms, and these are canvassed in the chapter, along with discussions of the pitfalls encountered by reasoning 
within these systems while claiming to be reasoning within ethics. Certain common errors can be made, which are articulated in the text. Students and readers, after they internalize this method, will be able to use it in each chapter of the textbook.

At the end of the chapter, students are encouraged through the questions to find ethical relationships that can be connected to the text from the point of view of the methodology presented above. Students can use the newspaper exercise, for example, to find examples of ethical reasoning in the media, but they could also locate pseudo-ethical reasoning. The questions that reflect upon the central question are directly related to the methodology and the consequences associated with failing to use those methods.

\section{3: Ethical Egoism and the Myth of Gyges}

One of the oldest and easiest to understand ethical theories is ethical egoism. Not all easy value theories fit the methodology in Chapter Two, but ethical egoism does. Subjectivism fails upon criterion 2, and relativism fails upon criterion 3 . The author would do well to add these common theories of right and wrong to the textbook in a later edition. Psychological egoism is highlighted as a behavioral theory that is often confused with an ethical theory, clearly failing the first criterion from Chapter Two. By using ethical egoism in this way, the students should see the difference between a theory 
that conforms to Chapter Two's methodology and a theory that does not. The fundamental and powerful concepts all directly relate to the conflict between similar theories and the methodological analysis in Chapter Two. So, psychological egoism is set against ethical egoism, though both of them promote self-interest as the good, and both of them are opposed to altruism as a good. In at least these simple ways, the $f \&$ p concepts all directly relate to the text.

The $\mathrm{f} \& \mathrm{p}$ concepts are also supposed to directly relate to the central question. If humans make profit from business, they are engaging in selfinterested behavior. If students believe that humans have no choice but to engage in self-interest, and if the business activity, which is self-interestedly engaged in profit, ends up creating harm, then many people would like to take responsibility out of the equation for the businessperson who caused the harm. He or she had no choice but to maximize self interest, remember? So, by raising the distinction between ethical egoism and psychological egoism, a motivation appears that allows readers to promote the pursuit of their own self-interest through free choice, as opposed to without it. In this way, readers can decide to embrace their responsibility, if they are convinced of the importance of autonomy (criterion 1) from Chapter Two. If it's possible to choose whether or not to act in one's self-interest, it may also be possible to genuinely act in the interests of others. This is the connection made through altruism. 
Using Plato's Republic introduces readers to the idea of intrinsic value in a way that links it directly to Philosophy as a discipline. The text offers a helpful link that explains the Theory of the Forms in a way that is relatable to its presentation in Book II of Republic. The entirety of the relevant text is reprinted for three main reasons: first, students get this first big section of text in the book to see how long it is (in order to plan study and reading time.) Secondly, students can refer to the text directly whether they have read it or not (by just looking at the book in class), and, third, so students can get a sense of why there are so many links (printing all this stuff is expensive!) These reasons are intended to encourage them to follow the links elsewhere in the book and get what is probably a lot of text (from their point of view), that they did not have to pay for in the book. Reprinting this one early, important source in its entirety allows the instructor using this book in class to continually make the case for the electronic format to readers. Finally, Plato's Republic is often cited in Business Ethics texts in small pieces, so that the point about self-interest is made, but the students are not provided the opportunity to make their own conclusions from the text, since it's not included for them. Students should be prompted to see the value of a long and complete selection of text (a technique which is often replicated behind links in this book) in order that the nuances of the reasoning can be digested, along with robust and helpful counter-arguments. 
The move of setting ethical egoism (an ethical theory) against psychological egoism (a behavioral theory with its roots in Plato's Republic, the primary reading in the chapter) highlights the interdisciplinary nature of the reasoning that happens within business ethics, and this is ultimately reinforced by question one on page 54. Students and readers must choose to embrace their personal responsibility for their actions in order to use this method. The text and class commentary demonstrate the value of comparing views from competing disciplines in order to arrive at truths. The method of comparing claims in a theory to one's lived experience is presented in the text as the chief method of overcoming psychological egoism in favor of ethical egoism in class. When students make a decision through following the text, they will be deciding something about their own lived experience as interpreted through ethical lenses from opposed disciplines. In doing so, they will simultaneously determine, due to the logic built into psychological egoism, whether altruism is even possible. This will highlight a new feature for thinkers following along with the text, which is that there are often logical consequences of adopting a theoretical position about ethics (or anything else) that are unintended and, in some cases, undesirable. Those consequences of the logical position cannot merely be set aside as a matter of preference, though; illogical positions must be avoided, due to their implications in the real world.

The first question set on page 49 provides direct links to the kinds of 
thinking that will be highlighted in the reading, like whether intrinsic value is more than an abstraction, and whether a person should always consider his or her own benefit before benefit to others. Following the reading, the same ideas are presented from Glaucon's point of view in Republic, and these are contextualized for business with the final question in the set. After readers have been able to get at the core conflicts between altruism, psychological egoism, and ethical egoism in this way, the theories are explained in order to make connections between the text and the ethics theories articulated within it.

Once students have seen the differences in these theories, and can differentiate them as theoretical positions, question two on page 54 prompts them to go to their own business disciplines to identify positions and thinkers that relate to ethical or psychological egoism. Readers should provide evidence during this process, which reinforces the critical thinking approach that asks them to reflect upon their thinking and then justify it, while being willing to reassess. These exercises can be used for both written and oral evaluation.

In preparation for the writing from the exercises and the business ethics question that follows, three central concepts from Paulian CT are introduced here. Each is selected to address the same potential problem in reader thinking at this point: he or she may disagree with some theory or position. Students should be sure that their interpretations at this point are 
accurate, that they are conscious of the relevance of multiple points of view for their position, and that they are representing the ideas that they've just encountered fair-mindedly in their own thinking. Each of these ideas is contextualized for a generic business environment, but there is also direct language that points back to the conflicts at hand regarding ethical egoism, psychological egoism, and altruism.

After this introduction, the same Madoff links from Chapter One are reintroduced. This time, there is a paragraph that asks students to consider the material already reviewed with a fresh point of view, this time thinking about it through the lens of self-interest, as opposed to that of authority. This creates a flexibility in point of view (intellectual empathy) that this course finds necessary.

An optional reading makes a great interdisciplinary connection between J.R.R. Tolkien's fiction novels, and their film equivalents, and this material. By learning that there is a connection between these familiar fictional works and the class material, readers get yet another pass at the material from earlier in the chapter. Multiple chances to touch the same content is important to Paulian CT's classroom interactions.

As usual, there is an urging for students to find connections between the theories from the chapter and contemporary media, preferably from a newspaper. The final question set relates the $f \& p$ concepts back to the central question, mainly focusing on the relationships between the 
chapter's concepts and the concept of harm.

\section{4: Enron, a Paradigm Case}

This chapter relies heavily upon the students being able to watch The Smartest Guys in the Room or their ability to review all of the links on page 60 about Enron. These are the two primary sources of content in this chapter. The film is automatically slanted, due to the anti-Enron point of view of the film studio and director, but the accuracy of facts is hopefully balanced by the other media from PBS and The Houston Chronicle on page 60 . The bias in the film inevitably comes up in class, so it's a great opportunity to revisit egocentric and sociocentric biases from the Introduction. It also creates an opportunity for students to evaluate sources and to decide for themselves what criteria they think are truly important in a credible source.

The chapter presents Enron as a paradigm case. A paradigm case of what? It's intended to be a paradigm case of ethical and critical thinking failures. So, the chapter presents material for students to digest that will illuminate the places that Enron stakeholders had key ethical and cultural decisions to make about responsibilities and conflicts of interest. The question set after the source links on page 60 begins this process. Readers are called upon the be self-reflective about their own analysis of the events at Enron. This creates immediate connections with chapters 
one and three. Enron as a paradigm case presents opportunities to see ethical theories applied in a business context.

Students get the opportunities to discuss the legal reactions to Enron's bankruptcy, but the text also provides lots of questions about individuals highlighted in the film and the links. This takes the personalization of the material out of the realm of fiction, self-reflection, and the solitary presence of Bernie Madoff, into a proliferation of flamboyant personalities from the film. In this way, students are prompted to consider multiple points of view on egoism, along with all of the trappings of full minds: assumptions, conceptual structures, and interpretive lenses. All of these can be discussed through Paulian theory, and some parts of that theory are invoked by the questions.

All of this ethical material about self interest, contextualized for business, leads to a natural discussion of the concept of greed. Milton Friedman, the subject of Chapter Five, has a short interview clip on YouTube about greed in business, and it brings the concept to the forefront of the students' thinking. The way this line of inquiry connects with the central question is along the lines of determining if there is anything like too much self-interest in business.

The critical thinking exercise focuses on Concepts, one of the Intellectual Standards. It encourages students to explore one character from the Enron scenario and map the concepts that are associated with that character. 
This concept map method ${ }^{39}$ helps students think deeply about the concepts that compose a point of view and how thinking can take a mind from one to another. The chapter ends, as usual, by looking for analogous business ethics problems in contemporary media and by considering questions aimed at the concepts in the central question.

\section{5: Shareholder Theory}

Chapter Five introduces Shareholder Theory, which is the ethical theory associated with Milton Friedman and the Chicago School of Economics. It is widely considered to be the most appropriate system of ethics for capitalism. This is the ethical system that is invoked continually by both Ken Lay and Jeff Skilling during the legal circus of the Enron bankruptcy; it is the mantra of headline makers from all walks of business. So, the concept of valuing, which is our chief study in this text, along with the shareholder/stakeholder distinction, and the idea of corporate social responsibility, are brought into full view in this chapter. It is time to do this, since readers have now gone from considering the power of authority, to a method for discovering ethical theories, to an examination of the role of self-interest in business, to a laboratory for examining the self-interest-

${ }^{39}$ Richard Paul and Linda Elder. The Thinker's Guide to How to Read a Paragraph, Third Edition. Foundation for Critical Thinking Press, 2014. 2-4.; Gerald Nosich. Learning to Think Things Through: A Guide to Critical Thinking Across the Curriculum, 3rd Edition. Prentice Hall, Upper Saddle River, NY, 2009. 109-111. 
based theories in the form of Enron, to now coming to a formal justification of Enron's behavior as voiced by its strongest advocates. That theory is Friedman's Shareholder Theory.

The structure of the chapter is built from years of classroom conversations by the author with students regarding this theory. First, the chapter defines who and what is being explored. Methodology is restated for convenience, and then there is discussion of Friedman's position. His essay from the New York Times Review in 1970 is used, instead of Chapter Eight of Capitalism and Freedom, because of the the conciseness of the argument in the former piece. The author presents quotes that have informed his own reasoning, and the conclusion of that reasoning is also presented. The connections between those premises and the conclusions are omitted, because the author wants the students to have the opportunity to use the same material he used to see how the conclusions offered were reached. This exercise models the relationship in much of the book between important text-based ideas and the embedded sources.

Friedman's theory fits the criteria for an ethical theory by the model in chapter 2. At the bottom of page 65 , students are directed to write out Friedman's theory in their own words. This move at paraphrasing is the first part of the SEE-I method from Paulian critical thinking theory. ${ }^{40}$ This

${ }^{40}$ Richard Paul and Linda Elder. The Thinker's Guide to How to Read a Paragraph, Third Edition. Foundation for Critical Thinking Press, 2014. 9-11; Nosich. Learning to Think Things Through. 33-37. 
exercise is inserted in the text here, because readers should internalize the meaning of Friedman's theory for reference in their business ethics training.

The next section of text introduces a few criticisms of Friedman's theory. Scholarly and popular criticisms range far and wide. In this section, two criticisms of the author's paraphrased formulation of Friedman's theory are offered. In the first approach, there is no law against the action in question; in my second approach, there is a law forbidding the business action. This sets the stage for students to think about both regulated and unregulated harms in business from the point of view of Shareholder Theory. The distinction also ties into upcoming theorists, like those from Thomas Hobbes, John Locke, and John Rawls. At the end of approach one, students are again asked to paraphrase this position, which is an important move for getting them to think about Shareholder Theory on their own. While the text doesn't mention the paraphrasing exercise again, instructors using the text many prompt students to use it during in-class quizzes and for their own understanding from this point forward.

After the author's criticisms of Friedman's theory, Rich Wilcke's essay, “An Appropriate Ethical Model for Business and a Critique of Milton Friedman's Thesis" ${ }^{\prime 1}$ is introduced. This essay criticizes Friedman in

41 Richard Wilcke. “An Appropriate Ethical Model for Business and a Critique of Milton Friedman's Thesis”. The Independent Review, 9:2, 2004. 187-209. http://www.independent.org/pdf/tir/tir 0922 wilcke.pdf 
different ways than the author does, which is useful for demonstrating the broad range of debate over Friedman's ethical theory. Wilcke's essay also criticizes the culture of teaching business ethics by philosophers untrained in business schools. His criticism of business ethics classes and professors is discussed in class here and, again, at the end of the semester to see if the text and the class was able to avoid Wilcke's anticipated classroom failures, or if this approach wasted everyone's time. The essay also affords readers a fine opportunity to approach Wilcke's essay with critical thinking tools, like Elements of Thought and Intellectual Traits, in order to clarify Wilcke's position for the purposes of business ethics.

Wilcke is also a fine introduction to a stakeholder model of business ethics, as opposed to a shareholder model. This distinction is explained next in the text, and Wilcke's essay and the question sets that accompany it are meant to bring out the distinctions between stakeholder and shareholder theories for thinkers in advance of an explanation in the text. This continues the critical paradigm of asking readers to do original thinking about the topic in advance of the reasoning being explained by the text, or even instead of that.

Stakeholder theory, and the several models that accompany it behind the links, show students alternatives to thinking about business ethics by the Shareholder Theory alone. Moving from Shareholder Theory, which the author assumes is already implicitly present in undergraduate business 
student thinking (see the Preface to the textbook for an explanation of this assumption) to versions of stakeholder theory is a logical shift and one that opens the door to reconsideration of ethics in business by readers. If it's possible for students to make the shift from Shareholder Theory to some stakeholder theory, they will be able to make the shift to utilitarianism, categorical reasoning, or anything else. It is this kind of theoretical flexibility in student thinking that the book is trying to cultivate.

After the presentation of several flavors of stakeholder theory, students are prompted to consider Intellectual Courage, a Paulian concept, ${ }^{42}$ since it is very relevant to opposing the dominant or traditional ideas in any sector of thinking. The author's experience is that students are usually very unsettled, but curious, at this point in the progression of business ethics. It is at this point that students are asked to locate even more contemporary and relevant evidence for ethical thinking in business by interviewing local business leaders. This exercise can be replicated anywhere the book is being used, and students can report on it orally, in writing, or as part of a multi-session project that involves small group work. The chapter ends with the opportunity to explore contemporary media for its ethical aspects, and it offers questions that relate the key conflicts between stake-

42 "Intellectual Courage" is one of the Intellectual Traits. These may be found in The Miniature Guide to Critical Thinking Concepts and Tools by Paul and Elder, pages 14-15, and the Paulian approach to Intellectual Traits is referenced in The Fannie Lou Hamer National Institute on Citizenship and Democracy: Engaging a Curriculum and Pedagogy Michelle D. Deardorff, Thandekile R. M. Mvusi, Leslie Burl McLemore, Jeffrey Kolnick The History Teacher, 38:4, 2005. 448. 
holder and shareholder responsibility to the central question.

\section{6: Contractarianisms}

By focusing on the social contractarian tradition from Hobbes to Rawls, the text teases out the thread of business regulation in society and explores its ethical implications. Hobbes, Locke, and Rawls are all very interested in the relationship between the individual and the group under the auspices of some kind of social contract. Before readers move more deeply into ethical considerations and varieties, they should deeply consider how much, if any, regulations should exist in the markets they want to participate in. Are there any good reasons to limit individual freedom within the group? This brings in earlier concepts of ethical egoism, altruism, authority, and stakeholder theory. These ideas in the text play off the concept of citizenship in order to help students arrive at their own understanding of their roles in the society they choose to live in and how far business can go to make profit in that setting. This last idea naturally ties directly back into considerations of the central question.

The chapter starts by pointing out how these strongly political theories can relate to ethical theories on the basis of structure by referring to the model from Chapter Two. Then the text introduces the three major theorists for the chapter and make small but direct connections between their approaches (which have not yet been introduced), and earlier ideas from the 
text. The chapter also introduces how the thinkers relate to one another in a very general way so that readers can see their relevance for a business ethics study and how their ideas connect for those purposes. After this brief introduction, a link to an essay about Thomas Hobbes from Stanford University that canvases in a very complete way the ethical implications of his political theory is offered. The text then discusses these ideas for business and markets, and then questions are offered that cause the reader to more fully explore the business ethics implications of Hobbes's ideas, alone or in a group. Locke is approached in an identical way, even with a similar essay from Stanford. This parallel approach creates continuity for the student between the two thinkers, which the author feels is appropriate, due to the way that Locke explicitly draws from and reacts to Hobbes in his writing. The chapter provides a little more contextualization for Rawls, and an essay is also provided for clarity, but this essay is from the Internet Encyclopedia of Philosophy, which has a slightly different tone than the Stanford University essays.

These sources each link political theorists with ideas for business ethics. This is a very common interdisciplinary move in business ethics textbooks, particularly with Hobbes and Locke. ${ }^{43}$ The author is not doing

${ }^{43}$ Business In Ethical Focus (Allhoff and Vaidya, 2008); Business Ethics: A Textbook with Cases (Shaw, 2005, 2008, 2011); Contemporary Reflections on Business Ethics (Duska, 2007); Perspectives in Business Ethics (Hartman, 2001); and An Introduction to Business Ethics (Desjardins, 2013) all use Hobbes and Locke. 
anything original by bringing Rawls, but using him does provoke a conversation with the students about which rights they think they actually possess and how they think societies should be ideally structured, which could be a great exploration for business ethics thinking and a nice springboard into very contemporary material later in The Corporation film and the Anti-Corporate Activism chapter. The text then emphasizes that these theorists are all being applied in an interdisciplinary way when they are brought into the service of a business ethics analysis, and so the standard contemporary media search is then invoked to help students find media that can be explained with one of these contractarian theories.

The discussion of Implications in the critical thinking box reinforces much of the earlier material from the chapter, since it expresses the idea that diverse cultures suggest diverse outcomes. The final question set relates various important ideas to the three thinkers from the chapter, in addition to linking their ideas to one another's, and the central question questions explore the concept of citizenship as it relates to the text's central question. Students should leave this chapter realizing that business happens within or with relation to markets set up by governments (or, conspicuously, outside them), and so the relationships between businesspeople, customers, and governments are always relevant.

7: Utilitarian and Deontological Thinking about Business Ethics 
At this point in the text, readers should be introduced to different ways of thinking about ethics. Utilitarian and deontological reasoning are two common approaches for applied ethics, and they are vital to understanding ethics, generally, in the western tradition. Business ethics benefits from thinking about these two broad categories of ethical reasoning. By exploring utility, duty, and dignity, the three $\mathrm{f} \& \mathrm{p}$ concepts for this chapter, students will be able to develop a richer understanding of what they think the right thing to do is in business and elsewhere. By this point in the semester, students have the tools and experience to navigate ethical theory in its own right and to learn to apply that theory to business situations. This chapter progresses chronologically through utilitarianism, because this helps show the development of the idea in the modern world, and its changes and challenges reflect the historical contexts of its champions. Taking a historical approach to presenting the ethical material also deepens the presentation along interdisciplinary lines. The text and the readings, from Epicurus forward, bring a set of broader cultural understandings to the conversation that would be lots without this interdisciplinary approach. This interdisciplinary move is also intended to give the reader a taste of the western intellectual heritage and to suggest that there may be deep historical and developmental roots in other ethical approaches. The question sets challenge students to confront the ideas for themselves, keeping the chapter squarely in a critical, rather than didactic, vein. 
The entire utilitarian movement is interdisciplinary, and so introducing students to thinkers like Popper and Singer broaden their understanding of the cultural conversation around ethics and some of the issues associated with it, as well as giving them alternate versions of utilitarian valuing and reasoning to explore (for example, Bentham reasons from quantity; Mill introduces levels of quality; Popper elevates suffering above utility; Singer extends utility to nonhuman animals. Each of these approaches is valuable for business ethics reasoning.) The early utilitarian method of hedonic calculus ties together with the later questions about cost-benefit analysis. There is much here for a person considering the good from a consequentialist view to explore, including for business.

The next section introduces and explains the ethical approach from Kant; it is based in recognizing and abiding by universalizeable, categorical duties. There is added value to this viewpoint, since it is from roughly the same time period as classical utilitarianism, so it gives readers an opportunity to consider (and discuss) Enlightenment values. Categorical reasoning is also useful because some students in class are already absolutists in their reasoning. Kant is also an absolutist, though of a much more complicated type than most undergraduate students. Providing this absolute position gives other styles of absolutists a great deal to consider about their own ethical positions, and it provides an opportunity to explore an inflexible approach to ethical reasoning, which is often difficult to locate in applied 
ethics.

A brief explanation of Kant's reasoning is offered in the text, but two hours of video from Harvard ethicist Michael Sandel is also included in the chapter. Sandel explains Kant's ethics with a number of interesting business examples at Harvard for all to see. Students also benefit from watching a Harvard classroom, in my opinion, and classes might spend a lot of time talking about what students have said in Sandel's classes, rather than spending so much time on Sandel's comments. Nonetheless, there is great value in having another voice take over the classroom approach for a little while, and one intention with requiring Sandel's videos is to give students an example of what a serious college classroom looks like when it pursues Socratic method. The readers of the textbook are provided an example of how class should be going at this point in this semester and how serious students work through the Socratic method with a professor. Students in class should have a lot to reflect upon by this point. The questions direct students to think from a duty-based point of view.

The interdisciplinary exercise asks students to find utilitarians and deontologists in their local business community as judged by information that has shown up in media about business ethics. Students are asked to make arguments using the evidence and judge from the point of view of the theory. This is a rather deep research assignment if students are going to do it well, and this exploration works great in multi-class small group ses- 
sions. This is also the assignment that gets to the baseline for competence in this material. Students should be able to do this, at a minimum, with all theories in the course. With regard to the goals discussed in the Preface and Introduction, this assignment exemplifies the basic set of skills students need to develop from working with this text.

The trait of Intellectual Perseverance is presented for readers to consider, since at least one of the approaches in the chapter should be new and difficult. The chapter ends with a bonus reading by Sandel which is directly relevant to the concerns of the class. Students are asked to form their own questions about that text, which is a task important to Paulian critical thinking (In fact, Richard Paul's dissertation, available on FCT's website, is all about forming good questions. ${ }^{44}$ ) This method, as with others, can be replicated easily from this point forward for any textbook exercise. The questions become a jump-start to large and small group work back in class. The chapter ends on the same note of attempting to locate media that reflects the material (in a slightly less demanding way than the prior assignment with the business leaders), and then there are questions that associate the positions in the chapter with the central question. The first question asks the reader to consider business ethics from the point of view of utilitarian reasoning, the second addresses intrinsic value in the corporate person (which will become a central topic in two chapters), and

${ }^{44}$ Richard Paul's dissertation is here: http://www.criticalthinking.org/files/Dissertation.pdf 
the third question addresses the central question from the point of view of deontology.

\section{8: Smith and Marx}

Nearing the end of the text, Adam Smith and Karl Marx are presented. These are used for business ethics in a more complex way than other explorations in the text, so students should already have a basic understanding of ethical reasoning before they begin to approach these thinkers. Smith's ideas are wrapped up primarily with economic thinking these days, but he primary training and writing was as an ethicist. The text highlights the interdisciplinary flavor of Smith's work, which is particularly important, since he isn't often used in an interdisciplinary way these days. Like Friedman, Smith is at the center of free market thought, and he has his own ideas about ethics in business, from the government down. In this way, all of the material about Smith can be tied back into any of the material from the text so far.

Marx should also be considered in an interdisciplinary light. He is overtly connected with unpopular economic theories here in the US, but he also present a useful critique of capitalism. Students should be exposed to these thinkers for their historical placement, their cultural influence, their political suggestions, and their ethical reasoning. All of their ideas tie right back into labor and markets, so students have the opportunity at this point 
in the semester to encounter two thinkers who are overtly interdisciplinary in their approaches, foundational for western culture's ideas about business, and explicitly concerned with ethics in business.

The $f \& p$ concepts reflect the focal issues for the section. The chapter begins with an essay that explicates the dark side of Smith's division of labor theory, a theory which he promises will bring great benefit to those who can usefully employ it. Book One, Chapter One, of An Inquiry into the Nature and Causes of the Wealth of Nations tells the tale:

"The greatest improvement in the productive powers of labour, and the greater part of the skill, dexterity, and judgment with which it is any where directed, or applied, seem to have been the effects of the division of labour." 45

Smith's assumption is that the human value of labor for the assembly line environment will be cared for through the processes of specialization and education; the essay argues for a different modern marketplace, and it raises the important issue of using market mechanisms to, perhaps, exploit others. While exploitation of the workforce was an aspect of Enron or even the egoisms of Chapter Three, those instantiations of exploitation were not made explicit in those chapters and are brought to the surface of student reasoning with this document. Readers are also directed to an academic essay on Smith's thought, since that will fill out much of the back-

45 Adam Smith. An Inquiry into the Nature and Causes of the Wealth of Nations. Edwin Cannan, ed. 1904. Library of Economics and Liberty. 14 July 2014. <http://www.econlib.org/library/Smith/smWN1.html>. 
ground material students need to begin thinking of Smith as a man in two worlds, as all people are: the economic and the ethical. This interdisciplinary character shift is useful for getting students to step outside their respective boxes and include the ethical aspect in their thinking. After students have dealt with preliminary ideas about Smith and the division of labor through the question set, the text gives them another essay that is even more explicit about the history and ideas that link Smith's ethics with his economics.

The text's discussion of the invisible hand is small, because the author assumes that business students already have some opinion about it. In case they do not, the text offers a robustly-arranged sketch of the invisible hand from Wikipedia and challenges students to articulate it through the question sets. Since Smith has slightly different versions of the invisible hand in his two major works, it's useful to consider them side by side. Students can easily find those references through the supporting material behind the links that have already been provided.

The information about Marx is very slim, but that's primarily because the author intends to hide his own slant about Marx, outside of an admiration for Marx's rational critique of capitalism. The text provides three provocative essays of Marxist thought and critique, the final one from Marx himself. The question sets associated with these readings are intended to get readers thinking about the human element in Marx's work, as op- 
posed to the institutional or political one.

Next, the text brings the important Marxist theory of dialectical materialism into sharp focus with a little explanation and a relevant link. The author then spends a good bit of time laying the dialectic out, but the text also alludes to ways that it fails in business contexts. In class, the instructor could discuss how dialectical financial risk assessment algorithms led to the US financial crash of 2008, as explained in All the Devils are Here. ${ }^{46}$ It is this kind of problem that prompts the need for a more fluid judgment system, like yawara. This is a brand new connection for business ethics, and students will not be familiar with it. It is a different way to think about solving problems, and it allows the insertion of ethical aspects into the reasoning process. This line of thinking is strongly influenced by Takuan Soho, the 17th century Japanese Zen Buddhist monk, and Chuang-Tzu, a Chinese Taoist from the 3rd century BCE. One classroom exercise is to expand these ideas to articulate the role of cooperation and yielding in business success. Thinking of yawara while practicing thinking causes students to see the limitations of a purely dialectical approach.

The chapter ends with the media exercise, to find examples of Smith's or Marx's thought in the contemporary media, which is not too challenging, though interesting when one locates what he or she is seeking. There are also questions for central question connections, and these relate

${ }^{46}$ Bethany McLean and Joe Nocera. All the Devils are Here. Penguin Group, USA, 2011. 
key ideas like flexible thinking, capitalist harm, and problem solving to the larger concern over when it is acceptable to profit from harm in business.

This chapter complicates and confuses much that has already come before in the text, and with a profoundly destabilizing effect in the classroom. This is an attempt at building yawara into the text. Students are confronted, probably for the first time, by familiar thinkers from other disciplines that are not characterized as they are usually found (so the author has been told by the College of Business students, but not as often by Philosophy majors, who wander through this course. The textbook's focus is on the Business students.) Students can be surprised and intellectually imbalanced by the information suggested here, and just when they thought they were starting to figure it out. This confusion causes them to seek meaning, which is when they should focus back on the central question through the chapter's f \& p concepts, which should bring the important issues in the text back into focus.

9: Corporate Personhood

Corporate personhood is a key feature of the modern capitalist system in the US. Examining the ethical implications of that status seems only 
natural, and it's been done by lots of strong thinkers. Many of them are included in one place through interviews and the case study method in the award-winning Canadian documentary, The Corporation. This film is heavily slanted toward the position of pointing out the same processes and flaws in capitalist theory (problems with division of labor, alienation, invisible hand, externalities, etc.) that were discussed in the prior chapter. Many of the situations and ideas presented here are made more concrete by the film. The film also uses powerful thinkers from both sides of the debate to frame the controversies around corporate ethics and personhood as they manifest today (or, at least, at the turn of the millennium.) The course builds up to being able to talk about each of the 23 distinct problems in this film with strict adherence to the ethical theories from the course. This film is presented for free on YouTube by is producers, so it's easily-accessible to readers of the textbook.

Questions about the value of corporate personhood orient readers to what the film offers. Three links are provided to the seminal court case in 1886 that gave formal US personhood to American corporations, and then the text offers a bit more background and a contemporary discussion with regard to the recent affirmation of corporate personhood by the US Supreme Court, a court case that is often referred to as Citizens United. ${ }^{47}$

${ }^{47}$ Citizens United vs. Federal Election Commission is found here: http://www.oyez.org/cases/ 2000-2009/2008/2008 $08 \quad 205$ 
The readings and the question set are intended to explore the idea of personhood for corporations as a separate issue from the treatment it gets in the film. Students stand to become much more engaged with the film if they fully understand the history and implications of corporate personhood before watching it.

The invitation to watch the film is followed by questions relating the film's content to the textbook's ethics content in order to link the ethical theories and positions already studied with the problems and personalities raised by the film. Ray Anderson of Interface Carpet is highlighted, since he comes up in the film and once again before the textbook is finished, with regard to his company's sustainability efforts. These are discussed in Chapter Eleven. Next, two or three readings for big topics in the film are discussed that students could find very relevant to their personal experience. Of course, students may bring other concerns from the film to the classroom, but this is a place to start with plenty of opportunity to add depth to the film's point of view.

The interdisciplinary exercise brings in the exercise from Paulian critical thinking called "The Logic of..." This exercise employs the Elements of Thought to fully explore a concept. ${ }^{48}$ Links to the ongoing Hobby Lobby religious opposition to contraceptive coverage under the Af- ford-

48 Richard Paul and Linda Elder. The Thinker's Guide to How to Read a Paragraph, Third Edition. Foundation for Critical Thinking Press, 2014. 9-10. 
able Care Act are then provided for teasing out "The Logic of..." the decision, Hobby Lobby's position, and other relevant material. There is also an exercise that asks students to synthesize materials they've already explored to make some determination, as the film does, about the mental state of a "person" who acts as "corporate persons" do. Each of the exercises hearkens back to Chapter Two and the material presented there, in addition to being designed to incorporate both critical thinking and ethical reasoning skills.

As a way of connecting with whatever kind of person a corporation ends up becoming, the text considers the trait of Intellectual Empathy. It's contextualized for connecting with other people affected by business actions in the marketplace and at work, but it also prompts students to reflect deeply upon the positions raised by the film. The chapter ends with the media grab; this assignment is really easy for students, since the weeks that don't have corporate personhood as a headline nearly always produce headlines about corporate malfeasance. Finally, the set of questions surrounding the central question relate the core concept, the propriety of harm in business, to the character of the business actor, be that an individual or a corporate person.

10: Anti-Corporate Activism

Anti-corporate activism follows The Corporation for two reasons. 
First, it deepens a topic raised at the end of the film about what can be done by showing a few things that have been done to fight corporate power and highlighting the reasoning behind those fights. The text is only trying to introduce sources on anti-corporate activism, not to offer much new theoretical material. The students should be able to use the reasoning methods from earlier in the text to do all of the work here. All of the small and large group activities, as well as any writing activities, can be used to tackle the material.

Secondly, empathically and courageously considering anti-corporate activism pushes business students way outside of their comfort zone. Since the text is focused on ethics, readers can ask questions about whether any kind of protest against corporate action is justified, all the way up to engaging in detailed discussion and writing about specific actions and actors. This causes students to engage critical thinking skills highlighted earlier, particularly the Intellectual Traits, and the controversial material provides motivation for business ethics students to figure out if some particular anti-corporate action or statement can be called "good" or "right" under some theory from class. Also, much of the material is satirical, and entertainingly so, which readers might enjoy. Since user-friendliness is a goal of the text, this helps achieve that goal.

As the text introduces Klein, Lasn, Bichlebaum, and Bonanno, it also reveals aspects of the author's personal journey as a teacher of busi- 
ness ethics. The text connect the concerns of these four thinkers with the author's in the brief text that accompanies their links, and the author creates a rough "Logic of..." his own reasoning about these thinkers and their artifacts for others to consider. In this way, the author hopes to soften what could seem like a difficult bunch of material for business students, and that approach also brings in the importance of personal narrative, another Paulian idea. Richard Paul states, "that the personal experiences of the student is essential to all schooling at all levels and in all subjects; that it is a crucial part of the content to be processed (applied, analyzed, synthesized, and assessed) by the student." ${ }^{49}$ By keeping personal narrative until the end of the text, more objective and logic-based approaches have already been constructed in the course of working through the textbook, and now students can introduce a layer of subjective reasoning on top of that, to augment it, rather than to become the foundation of their thinking about business ethics issues. The chapter ends in the usual way and for the usual reasons.

\section{Sustainability}

The sustainability chapter is at the end, because sustainability is an

${ }^{49}$ Richard Paul. "Reflections on the Nature of Critical Thinking, Its History, Politics, and Barriers, and on Its Status across the College/University Curriculum Part II." Inquiry: Critical Thinking Across the Disciplines. 27:1, 2012, 18. 
interdisciplinary approach in whatever specific discipline it manifests..$^{50}$

Because of this, students should have done preliminary work in disciplinespecific endeavors and in less rigorous interdisciplinary activities before landing here; the textbook's structure has facilitated this intellectual progression. Also, many of the community engagement and writing exercises in this chapter are located within a sustainability approach, and so students have an opportunity to come to the end of the course, or near the end of the course, working with sustainability ideas. This chapter also introduces an outside voice from the Louisville business community through Gary Heine's statement about his ethical journey through business. Since Gary's statement does not lead students through ethics material, they should already have a background in the theories and types of reasoning used in business ethics before they encounter a multi-disciplinary approach like Gary's and an interdisciplinary one like this chapter's topic conveys. Also, placing sustainability after The Corporation and the anti-corporate activism chapter provides readers access to a stakeholder theory that is being used around the world today to address some of the concerns that drive

\footnotetext{
${ }^{50}$ Richard Howarth promotes sustainability as "the interdisciplinary field... [described] as the 'science and management of sustainability,", in "An Overview of Land Economics", Defining Sustainability, 73:4, 1997, 445. Lauren Bettencourt and Jasleen Kaur criticize the development of the sustainability field as a science, due to its interdisciplinary profile. "It remains unclear how far the field has progressed as a scientific discipline, especially given its ambitious agenda of integrating theory, applied science, and policy, making it relevant for development globally and generating a new interdisciplinary synthesis across fields," in Proceedings of the National Academy of Sciences of the United States of America, 108:49, 2011, 19540 .
} 
anti-corporate activists and frustrated consumer/citizens. If someone is looking for action that builds up or creates, rather than breaks down and seeks to dissolve, as a reaction to corporate misgivings, sustainability may be a fine place to begin looking.

The chapter starts by contrasting some common assumptions about capitalism with some common sustainability solutions. This is the tenor of the text and the point of including a variety of sustainability sources in the beginning, like the controversial "Story of Stuff" and information from the international Transition movement. Since the text will probably be used primarily at $\mathrm{U}$ of $\mathrm{L}$, the author makes an effort to connect $\mathrm{U}$ of $\mathrm{L}$ students who are looking at this textbook with some sources for sustainability activism on campus, should they be interested in such a thing. This is the spirit with which the author offers the sustainability video in U of L's EcoReps video series.

The next three links directly address business attitudes toward sustainability and seek to change them. The first talks about corporate culture and manufacturing, the second talks about culture at large and design, and the third addresses the ethical problems associated with global labor. Each of these can be linked back to and discussed by reference to earlier ethical theories, political theories, and support theories. These three videos make strong arguments with good evidence, and students should find ways to grapple with them through the tools and techniques of the course. They 
are, in fact, prompted to do just that by the question set following the links.

Next, students are invited to come to U of L's Community Composting Project in order to see a sustainable system in action. This system could have been created by any business and management principles, but its organizers have choses to operate within sustainability parameters. As a result, student visitors have an opportunity to access claims about some sustainability processes at the site when they go to investigate for themselves. Potential visitors are given enough background material to know what to expect at the $\mathrm{U}$ of L Community Composting Project, and then the text suggests assignments that motivate them to spend a day working at the site. Afterward, they are required to write an ethical analysis of this socalled "sustainable system." For interested entrepreneurs, the author has also included "The Sustainability Village Proposal" that he developed and submitted to $\mathrm{U}$ of $\mathrm{L}$ last year as a plan to sustainably develop a potential land donation. The land wasn't secured by the university, but this proposal can be used to illustrate several closed-loop systems and other sustainability features for development of products, services, and rental space. Student entrepreneurs could be inspired to investigate and copy some of the easyto-create systems in the proposal, but the short term use is to give readers the option to dig deeper into both sustainable development or sustainable action, whichever is more appropriate for the class that semester. The pro- 
posal resides in an appendix, because it made the chapter too long, and it really is an optional piece for instructors.

Sustainability work in most sectors today entails standing against the crowd. Intellectual Autonomy is a necessary trait for continuing to think in original and creative ways, particularly when there is pressure against doing so. This trait also moves readers directly into the trash collection exercise, which is explicitly interdisciplinary. The pieces of trash, the systems they represent before they are trash, the systems that collect and store them, and those that re-engineer them, are all interconnected and different. They each require management teams, physics principles, historical precedents, business plans, and, somewhere in there, each is attached to a profit motive. So, the class can explore the trash from their group in a way that emphasizes the ethical aspects of the business choices that have gone into a particular piece of trash. Students can make relationships between the piece of trash and various ethical theories. Students can make ethical judgments about the companies that created the eventual trash. An explicit assignment shows how students can learn from the process of collecting trash.

As mentioned above, the last document is a personal essay from a local entrepreneur, Gary Heine, which highlights how ethics and sustainability can intersect in a for-profit business. The chapter ends as the others have, but these final ties to the central question are a bit more general in their 
scope than some others have been in order to capture the broad reach of business ethics thinking.

Appendices

The first three appendices (the fourth, The Sustainability Village Proposal, is explained above) are intended to provide additional resources for teachers and for the curious investigator of business ethics to learn more about the topic. The first appendix concerns alternate assignments that will provoke deep thinking about business ethics on the part of participants. These assignments have been useful for the author in the classroom and could be inserted at various places throughout the textbook. They were inserted in an appendix to make them appear more versatile than they might if contextualized in a specific chapter. The exercises incorporate an interdisciplinary approach. Charles Dickens is fiction, the interview series with and about Mike Daisey is performance art and journalism, "Bridging the Divide" is a local community activism report, and the whistleblowing media not only include a touring speaker series that students can find and interact with directly, but Ibsen's stage play, An Enemy of the People, is a classic example of failed whistleblowing, which is a very appropriate counterpoint to the American Whistleblowing Tour and can be approached with a number of interdisciplinary methods also advocated by critical thinking, 
like role play. ${ }^{51}$

The answers to the central question in Appendix Two are intended to help students connect with the central question from a real-world perspective. These answers also demonstrate answers from multiple disciplines: law, accountancy, coffee retailing, and graphic design. There is also an immediate community connection for $U$ of $L$ students reviewing this material, since all of the respondents are local.

Appendix Three assembles business ethics-related podcasts from around the Internet that can be connected with material in the chapters. These were not inserted in the chapters, because the author wanted to have a large repository of Internet media as a resource for students. Many of these episodes give insight into some particular business ethics practice or outcome, including those that support underground economies; students will be able to use theories and methods from the textbook to address these business ethics situations.

This section has highlighted the intellectual processes and structural thinking for the textbook. The text proceeds by focusing on interdisciplinary and critical thinking techniques. The text is organized to promote a progressive understanding of business ethics within various contexts that blend together from chapter to chapter and over the whole text in such a way as to

51 "Roleplay" is considered a learning modality at The Foundation for Critical Thinking. It is referred to in Richard Paul's and Linda Elder's The Thinker's Guide to How to Read a Paragraph, page 11. It is listed in that text as the fifth, and most complex, level of close reading. 
promote self-reflective and otherwise deep thinking about a student's own thinking about business ethics. 


\section{SECTION 3}

TEXTBOOK:

“THE CENTRAL QUESTION:

\section{CRITICAL ENGAGEMENT WITH BUSINESS ETHICS”}

\section{PREFACE: APPROACHING THE QUESTION}

I am confident that everyone who teaches Business Ethics has encountered a colleague or student who jokes that the class content is oxymoronic. The implication of that joke, of course, is that it's not possible to have ethical business; that these two words are in some ways irreconcilably contradictory. This textbook takes a different view: not only is the ethical aspect of business compatible with the pursuit of other, more commonly-

understood business goals, e.g. pursuit of profit, growth of assets, and the development of commercial relationships, cultivation of the ethical aspect of business is actually desirable. Desirable for whom? Cultivation of the ethical aspect of business is desirable for all stakeholders, from the owners to the customers, from employees to partners. The government has a stake in ethical business, and it should cultivate ethical aspects of the business community within its areas of influence, precisely because free markets demand honesty and integrity in business dealings in order to create a truly level playing field for commercial activity. 
My earliest memories of business are wrapped up in the ethical aspect. My grandfather was an executive with the Convenient Food Mart chain, which was later the Dairy Mart corporation, during the 1970s and 80s. At that time, the company controlled a chain of franchised and company convenience stores across the south and midwest. Papaw worked for this company in Florida and Kentucky, and he would sometimes take me with him as he traveled from store to store in his region, putting out fires and enforcing best practices.

As I rode along with him, Papaw would talk about what he was doing at the stores along his route. This person needed help with merchandising. That person needed help with the books. Sometimes we were helping out with a promotion. He always included comments about a person's character in his descriptions of their business acumen, and that stuck with me. These businesspeople, many of them entrepreneurs in their part of the state, were also people like us. They'd tell jokes, swap stories, and recount tragedies. Sometimes they were "good" people, and sometimes they weren't. Sometimes we'd end up at someone's home or around a dinner table with strangers. With my background growing up in church, these sorts of labels and communal activities made sense. All people, regardless of their occupation, had a moral side to them, an ethical aspect. In many ways, we respected that aspect by participating in community with them.

This textbook explores the ethical aspect of business. In fact, a chief aim of this book is to locate, illuminate, and explore the ethical aspects of business in a way that will help readers learn to do it on their own. I spend time discussing this idea throughout the book. This textbook is organized to be used in an introductory course in Business Ethics at the 
undergraduate level. It could also be used for a graduate program in business ethics or for classes in social justice of various types. The workload is broken up into what I consider to be manageable chunks for a traditional 16-week semester class meeting three days per week for 50 minutes. Throughout the text I provides readings and exercises for both inclass and homework applications. Teachers looking for extra work should see the appendices.

In truth, this may be a terrible example of a textbook. It has been suggested to me that this project is more appropriately a study guide or a course pack... maybe even a workbook. I suppose that this critique hinges upon what one expects from a textbook. So, let me address the critics of my approach here.

In the critical mode of teaching, one strategy is the "flipped classroom." In this model, students interact with new material outside of the classroom. Students will absorb new material at home, on the bus, or wherever they study. They should think about it, write about it, and they watch videos about it in order to gain material that would often otherwise be gained through classroom lecture. Students then come to class with the intention of discussing and writing about the material, among other interactive activities. Students have already considered the material for themselves, mentally, in writing, and maybe even in some interactive way, prior to ever coming to class. In this way, the professor can be an instigator for continuing the inquiry or the conversation, depending upon the level of power the professor wants to retain as the head of the classroom. I like to give up a great deal of power to my students, because I believe that this places more responsibility upon students to think for themselves and gives them practice designing a culture in 
which they want to work. So, my preference is that students take the material presented here as the basis for a larger period of conversation with periods of focused writing. I also have not put the entirety of my thought regarding the material into the text. I want to work through the material together with my readers, as a class, with this document and its links as the foundation of that work. Perhaps, then, this is more appropriately a "workbook”. Criticism accepted.

\section{Critical Engagement}

The title of the book includes the phrase "Critical Engagement." I strongly advocate the incorporation of both words in that phrase into your reading and interaction with this material. I strongly advocate the Paulian approach to critical thinking, which I introduce in relevant ways in this book. The Paulian approach was initiated by Richard Paul, founder of The Foundation for Critical Thinking, in the 1960s. Paulian theory gives us tools for analyzing our thinking and that of others, assessing the usefulness of that thinking for our goals, and it provides us with tools for improving our thinking process where it seems lacking. Readers should be approaching the material and exercises in this book critically, which is to say that they should not approach them didactically. While some professors are interested in the memorization of facts and text, and while memorization and regurgitation has its importance, I prefer that students and readers engage with this text in such a way that the examples and exercises provide the basis for meaningful individualized thought about the material. Further, I hope that this thinking leads to significant action in readers' lives. At all points, I suggest that readers think about their own thinking on these subjects; all of the exercises in this text are designed to be critical think- 
ing exercises about business ethics. They vary in scope and complexity, but all of them are intended to help readers develop their ability to think autonomously, deeply, broadly, and significantly about business ethics from a variety of points of view. More information on the Paulian critical thinking theory, and my association with it, can be found at Criti-

\section{calThinking.org}

\section{Engagement}

To lightly unpack the word "engagement," I hope teachers and students alike will see the value of treating business ethics as an activity to be observed and participated in, not merely to be examined at a distance or rendered as theory alone. I want students to get out of the ivory tower and into their communities in order to meet business leaders who want to talk about the ethical aspects of their journeys. I've been fortunate enough to include writings from a few of these people from my home in Louisville, Kentucky, as part of this book. The ethical aspect of business, as my grandfather suggested on those road trips decades ago, is always present in people. Some people do good, and others do not, but no one is truly liberated from the ethical aspect living, and no business is exempt from ethical judgments. This is because ethics, among other things, is inherently social, just as business is inherently social. We should learn to think about why we are making the judgments we are making. Others will see, or others will imagine, and others will judge. The question is, will their judgments be worthwhile? Will ours? How can we know the answer to either question? Both ethics and commerce are contextualized in a world of others. It only makes sense that students and professors would use some of their time in an applied ethics class, like the one this book outlines, to interact and communicate with 
the business communities in which they live. I provide several examples for community engagement in the introductions for teachers and students, and there are several exercises that promote engagement throughout the chapters.

So, to do "Critical Engagement" with business ethics is to interact and communicate with the local business community in order to understand the actions of the business community in a deep, significant way that goes beyond mere memorization and promotes applicable understandings. Readers using this course material should come away from it being able to talk about the ethical aspect of business with employers and colleagues and be able to judge business activities as being right or wrong, good or bad, using the available information. Of course, simple judgment is only a beginning point, a baseline. Students finishing this material should be able to think for themselves about the reasons for their ethical judgments about business actions and entities. There are no sacred cows in a critical approach, and readers should feel prompted to examine their own biases and assumptions in order to more easily recognize the truth of a business situation, to the extent that truth can be discovered at all.

As a trained philosopher, my choice of topics in the classroom tends toward the theoretical. Life is multidisciplinary and interdisciplinary in its scope, and success in complex and cosmopolitan societies demands a certain degree of engagement and criticality. Also necessary, however, is the ability to interpret our own thinking, to analyze important concepts in our lives, and to challenge our own assumptions, as well as to determine accurately the points of view of others. Success at these tasks necessitates an understanding of critical theory and its role in a person's own thinking and actions. 
When we have reactions to others' actions that cause us to judge them as good or bad people committing right or wrong actions, we have an easier time articulating the reasons for our judgments when we recognize the connections of our judgments to the ideas that inform them: theories. This text addresses a number of theories overtly: Paulian critical thinking theory, psychological and ethical egoism, altruism, utilitarianism, deontology, capitalism, Marxism, sustainability, and others. Due to my own training, however, there are other theories behind the music, as it were, that I'd like to acknowledge. I am sympathetic to existentialist and phenomenological thought, as well as having been trained as an adult in various eastern ways, including Zen Buddhism and classical bujutsu. I also have a great affinity for the thinking of Friedrich Nietzsche, Michel Foucault, and Naomi Klein. Experienced readers of these disciplines and theorists will recognize buzzwords and phrases from those approaches. I fully embrace my training in this regard, which may be foreign to some, just as I embrace my training in epistemology, logic, ethics, and cultural anthropology, which is likely more common.

Business activities are intimately tied up with employees and customers as individuals, but businesses are also necessarily entwined with governments and other kinds of stakeholders, like citizens, utilities, and nature. While I do not answer many of the important questions about these relationships from the ethical aspect, I do raise the questions and hope that readers of all types find in this text the tools to answer them on their own, just as I hope readers will learn to ask significant questions about the ethical aspects of business on their own as a result of this text. Students using this book for a course should 
attempt to answer all questions, and the questions will be tackled as part of classroom activities if I'm your professor.

\section{THE CENTRAL QUESTION}

This book uses a "central question", which is meant to orient readers, teachers, and students to the main point of the book. The central question technique ties students to the material through references in the text, reinforcement in the classroom, and by the presence of a question set at regular intervals in the text that prompts the reader to consider the central question in light of recent ideas presented in the text. I've found this technique to be a useful resource in many classes; more information on this technique can be found in this text by Gerald Nosich: Learning to Think Things Through. The central question of this business ethics course is, "When is it acceptable to profit from harm to others in business?"

I don't reprint every primary source in the pages this text. In fact, I rely heavily upon internet links to sources. While I know this makes full interaction with the course material awkward for those using a paper copy of the book, I am noticing that fewer and fewer students are choosing this option in my classrooms. By offering this first edition as an ebook only, I am hoping to accomplish several things at once. First, I hope to bring down the cost of this textbook by making it smaller. Offering the electronic format also addresses this concern. By making the book electronic, I want students to be able to have the text on a device and be comfortable using it. I've been impressed with students' ability to use technology in the classroom for direct research, but I have often been unim- 
pressed by their choice of sources. What this text tries to do is to get students using their phones, tablets, and laptops to focus them on the correct information, on good sources, and on relevant research. As a professor who has regularly banned electronics of any type from my classroom, I'm interested to see how this works out.

Much of my own interest in business ethics relates to corporate power and the ways markets influence democracy and individual decision making. A quote from the Introduction to The Money Men by H.W. Brands will focus many of those interested in placing me inside an ideological box: "[In the early United States], an inherent tension existed between [democracy and capitalism]. The driving force of democracy is equality; of capitalism, inequality." This product is an attempt to help readers, and myself, work through this tension, which has been present in my experience of living. 


\section{INTRODUCTION: HOW TO USE THIS BOOK}

\section{NOTES ON DEVICES IN THE TEXT}

The primary goal of this text, when combined with the classroom course for which it is written, is to give interested students the skills to perform business ethics analysis, including the ability to thematize and reflect upon their own thinking. The audience for whom this textbook is ideally intended is the undergraduate business major who has had a few basic business classes. This person will have already learned something about capitalism, about micro and macroeconomics, and about the goal of making profit. This person will know many basic definitions of business terms and will have some definite ideas about what's good and bad in terms of business practices from the purely economic viewpoint, which is to say, how profit is generated and maintained through commercial activity. On the other hand, the person reading this book need not have had any collegelevel courses in business, and it would be really great if entrepreneurs read this book. I even hope that other instructors can take something useful away from it. I often have undergraduates or graduate students in non-business disciplines taking my classes, and there is value in this material for them. Also, please be advised that this book is an introduction to Business Ethics, not an introduction to Business. In many cases, you will need to look 
up business terms you encounter. You could use an industry-specific source like Business

\section{Dictionary.com}

\section{SIX LEARNING MODALITIES: FOR STUDENTS AND TEACHERS}

The use of this text is intended to aid student learning. When I am thinking about student learning, I am thinking that classroom pedagogy is usually intended to engage in six learning modalities: you read the material, you think about the material, you write about the material, you speak about the material with others, and you listen to them speak about the material. You may also go farther in your understanding by engaging in role play with these ideas to try to internalize understandings and get directly at motivations through intellectual empathy. The goals of the exercises in this book are to get you to engage in these six modalities as often as possible. To that end, there are many questions in each chapter of the text.

One goal of this text for students is that you would be able to engage with the central question using the six learning modalities. These modalities can be engaged in any order, and a goal of this text and the critical approach to business ethics is to engage in at least five of the modalities at each meeting. So, for example, reading this information about the central question should prompt you to think about it. You could stop and write a few lines about it on a piece of paper. You could then share that written material with someone else through speaking about it, and then you could gain feedback from them through listening to their comments about what you have written. It is at this point that I suggest returning to your writing (and/or your thinking) and performing revision. Revising your 
own writing in light of other students' comments (part of a process called "peer review”) is a powerful way for you to update your thinking. You can engage in all of these approaches prior to ever having your thinking evaluated by your teacher. You can also come together in pairs or groups and role play interviewing the thinkers you have read. The students can take turns asking questions and being the writer or speaker. In this way, everyone can make efforts at internalizing the point of view of the material through this method.

One goal of this text for teachers is that you would learn to organize your classroom activities to maximize the impact of these learning modalities. If other modalities are apparent to you and easily incorporated, you should include them. Throughout the text, I present questions that can be tackled by students (and by teachers) in a written form, in a form that is spoken, in a form that is listened to, and in thought. Students can read on another's answers to get another pass at the material. Bear in mind that each time students interact with the material, there is an opportunity for learning and for the deepening of understanding. Making the learning modalities explicit in your instruction accomplishes much of that. Role play may also be included, but that should be added once students have worked heavily with material. By the end of this course in business ethics, students should be able to empathically enter into the point of view of important thinkers discuss since the beginning of the course. 


\section{CENTRAL QUESTION: FOR STUDENTS}

This text and the course I teach in Business Ethics is designed around a Central Question. The idea of using a central question, for example, "When is it acceptable to profit from harm to others in business?" is to keep the student oriented, no matter what is being explored in the course. At any point during the reading of this text, a reader should be able to relate the material being presented to the central question in a meaningful way. In fact, most chapters have questions at the end that relate the material in that chapter to the central question.

If you think that the process of considering the central question through six learning modalities is complicated, consider this example which may be familiar to many collegeaged learners. My son, when he was eleven, began playing an online video game called Terraria. He would play the game, and he would think about how he had been playing the game afterward. This self-reflection upon his process of gaming, as with many other gamers, caused him to improve his game play. Since there is a wealth of information online about the game, he would go to websites and read or watch information being presented about ways to successfully achieve the goals of the game. The aspects of the game that he would research would be related to the problems he had been thinking about solving within the game. So, he was thinking about the game and reading/watching about the game. So, often, when he was trying to solve a particular problem in the game, he would write down a note or a set of procedures to be implemented in the game later. This would reinforce or make concrete the suggestions he had researched. Lastly, since many of his friends played the game, he would speak with them about his concerns or progress and 
listen to their stories and suggestions. In this way, my middle-school-aged son was participating in five of the learning modalities I'm suggesting, and he would improve at the game through the effort. You, as a student, probably take a similar approach to learning about topics that are interesting or important to you. You should apply this approach to the material in the book. (By the way, he and his friends also role-played the characters in the game!)

\section{FUNDAMENTAL AND POWERFUL CONCEPTS: FOR STUDENTS AND TEACH-}

\section{ERS}

Each chapter starts with a line that tells readers what the Fundamental and Powerful Concepts are for the chapter. Like the central question, this is a way of focusing readers on what I'm really trying to convey for the purposes of teaching business ethics. Every exercise and reading in the chapter should directly relate to at least one of the fundamental and powerful concepts listed at the beginning of the chapter. So, when learners ask, "What's important?" The answer is that what is important is directly related to these Fundamental and Powerful Concepts.

I have chosen not to reprint every reading within the textbook. Many readings are linked to free sources for that reading on the Internet. In many cases, links in the text take a reader to a film or a slideshow hosted on a free Internet site. My intention for using this approach is threefold. First, I'm trying to keep the size of the book down, which lowers the ultimate cost to the student. This also accounts for offering the first edition in an electronic format only. Next, I'm trying to keep the density of the text down, which seems to 
help student understanding. While my own comments in the text might be quite dense, and I hope that none of them are particularly useless for learners, those comments aren't buried in or piled alongside a bunch of other dense text. This allows learners to take the reading in chunks: my own words introduce or contextualize the video clip or online reading, so learners can compartmentalize their own approach to the material. I've also tried to locate outside readings or videos that are intelligible and to the point. Finally, students of traditional college age like to use the Internet. They like online sources, particularly videos, many of which will have direct relevance to the material. By asking you, the student, to go out on the internet and mine popular websites, like YouTube or Ted.com, for relevant academic material, I'm turning electronic access and online material into a benefit, rather than allowing it to remain a barrier between student and teacher roles. In my view, we're all supposed to be learning together.

In many cases, this textbook presents links to related online material. In some cases, it'll be more material than you can reasonably digest prior to the next class. Also, the readings that are linked are often larger in scope than our very narrow conversation about business ethics. Why do I do this? Why not just give you the appropriate paragraph at the appropriate website and ask you to review that very narrow slice of material by itself? Why not just reprint that appropriate paragraph, cut away from its larger context? The answer is that students at the undergraduate level need practice at doing research, working through primary sources, and discriminating what is important about this text on their own. You have the central question. You have the fundamental and powerful concepts for the chapter. You have critical thinking tools and the class discussions. You should consid- 
er all of these and try to direct your thinking about the material in ways that are consistent with those devices provided to help you focus. This is one deep meaning of research, and many students aren't good at it, because lots of textbooks and teachers in your past have spoonfed you only the relevant pieces. We have to learn to do appropriate research for ourselves, and the teacher for the course should help you refine that process as you work your way through the text. If you leave this textbook or any course on business ethics unable to think through new material about business by considering the ethical aspects on your own and within your own thinking, you will be unprepared for the challenges of applying ethics to business situations on the ground, where you live, in contexts that matter for your life. Helping you develop this ability is one important goal of this textbook.

(If any links are broken or direct you to the wrong material, please type in the name of the material and search on your own; free links are often slippery.)

\section{BASIC PAULIAN CRITICAL THINKING THEORY FOR BUSINESS ETHICS}

Critical thinking is an important element of this textbook's approach, but it must be overtly approached, diligently expressed, and assiduously cultivated throughout the course of study to be as useful as possible. Critical thinking is more than mere thinking. Thinking can be done didactically, without deep consideration, conscious reflection, or overt connection to other ideas. Criticality forces students to incorporate the material, to work through it in a deep and inclusive way, and to connect the material at hand to other important ideas in the course, like the central question or the fundamental and powerful concepts. Students should use the critical thinking principles outlined in this chapter and 
investigate Critical Thinking.org for more detailed explications of Paulian critical thinking theory. Several critical thinking ideas are explicated in each chapter, and these exercises directly relate to the exercises, to your understanding of the text, and to your assessment, if you are taking a class with the author. At a basic level, students should become familiar with The Intellectual Standards, The Elements of Thought, and The Intellectual Traits, as well as Egocentric and Sociocentric Biases. All of this critical thinking material has been pioneered by Drs. Richard Paul, Linda Elder, and Gerald Nosich from The Foundation for Critical Thinking at Critical Thinking.org .

\section{INTELLECTUAL STANDARDS}

Intellectual Standards are used to assess thinking, and they are the standards that I use to assess the thinking of students in my Business Ethics courses. Students present this material in writing and in speech, which I can assess, but students should also be able to assess their own products, including their thinking, by reference to the intellectual standards. These are defined in the chapters as we progress, but the list you should be sensitive to is here:

Clarity, Accuracy, Precision, Relevance, Depth, Breadth, Fairness, Completeness, Logicalness, and Significance

For critiquing your own performance at a business presentation, for example, you should be able to use the Intellectual Standards for assessment. You might consider if you were as clear as you could have been. If not, you might take the opportunity to follow up with a clarifying note to the participants or to at least make your own notes for the next 
time you present this material. Were all of your facts accurate? Are you sure because you double-checked them? We should always be sure of the accuracy of the fact we pass to others. Was your presentation precise to the necessary level of detail to ensure sufficient understanding by your audience? Was the information in your presentation all relevant to getting your point across? Did you go into sufficient depth with the information? Did you make the necessary connections to convey breadth in your presentation? Did you treat all of the information your presented in an evenhanded way? Did you research sufficiently to ensure that you were presenting complete information? Were all of the points you made put together logically? Did you share with your audience something of significance by making your presentation? Did you get at the main issues? We can always ask any of these questions about ourselves or others, and the inquiry will always be useful. Arguably, we will always find ways to improve.

\section{THE ELEMENTS OF THOUGHT}

Everyone thinks; it is our nature to do so. But much of our thinking, left to itself, is biased, distorted, partial, uninformed, or downright prejudiced. Yet the quality of our life and of what we produce, make, or build depends precisely on the quality of our thought. Shoddy thinking is costly, both in money and in quality of life. If we want to think well, we must understand at least the rudiments of thought, the most basic structures out of which all thinking is made. We must learn how to take things apart. 
Thinking, then:

- generates purposes

- raises questions

- uses information

- utilizes concepts

- makes inferences

- makes assumptions

- generates implications

- embodies a point of view

\section{The Elements of Thought}

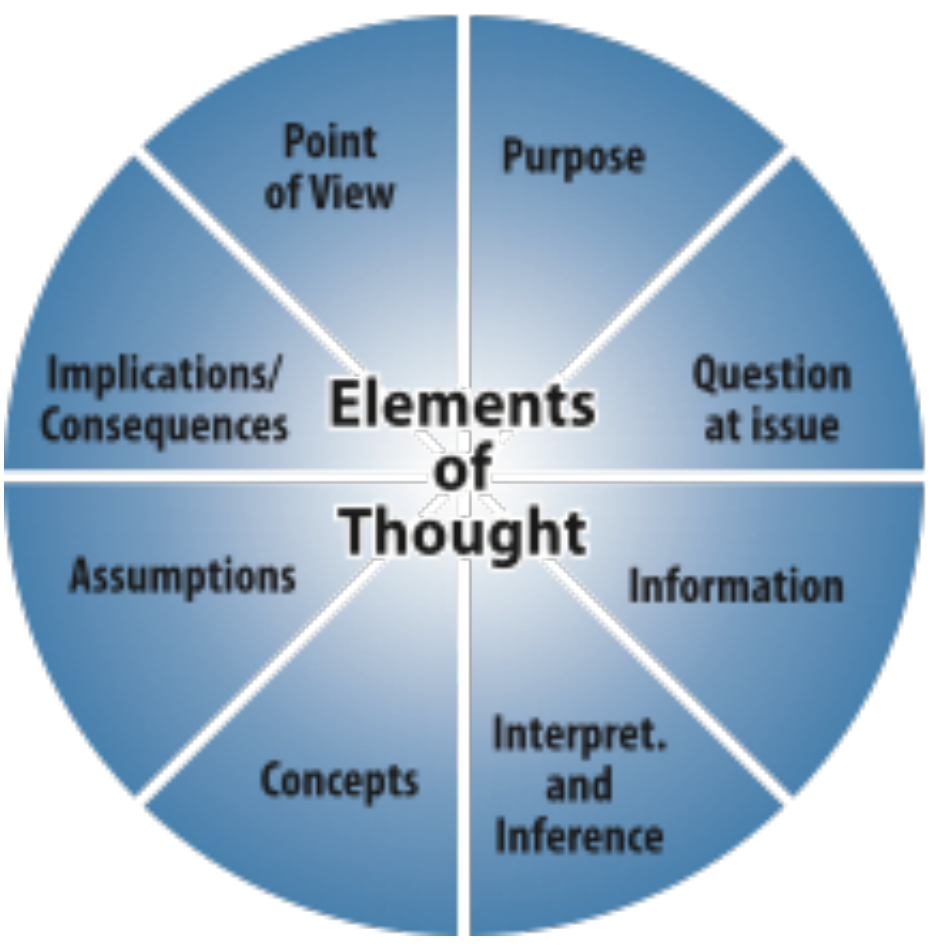

Each of these structures has implications for

the others. If you change your purpose or agenda, you change your questions and problems. If you change your questions and problems, you are forced to seek new information and data. If you collect new information and data... and so on.

All thinking is defined by the eight elements that make it up. Eight basic structures are present in all thinking: Whenever we think, we think for a purpose within a point of view based on assumptions leading to implications and consequences. We use concepts, ideas, and theories to interpret data, facts, and experiences in order to answer questions, solve problems, and resolve issues.

All thinking is done for a purpose. We have a problem that needs to be solved. This problem always entails important questions at issue that should be considered and an- 
swered in order to successfully fulfill the purpose. We all use information to help us know what to do with any given problem, and we each have an automatic, probably unconscious, process of interpreting that information when we encounter it. We aren't usually aware of the ways we interpret the information, but we all do, and sometimes our interpretation is unfair, inaccurate, or unrelated to the problem we are trying to solve. All of us think from some point of view that is always uniquely our own, and that point of view might clash with other relevant points of view on the problem at hand. Our points of view are populated by assumptions, ideas that we use for our reasoning but have not tested, and concepts, which are tried and true ideas that we use to help us understand the problem at hand. Finally, all of our reasoning leads to implications and consequences. The implications are the logical outcomes of our reasoning, and the consequences are the physical manifestations of our thinking. We engage in an analysis of our thinking, writing, or our speaking by using The Elements of Thought in any order and for any discipline.

These basic analyses are only the beginning, however. The Elements of Thought are useful when organizing a paper or speech, when planning out research, or when getting a handle on our own thinking. They may be used as the foundation of any organized process of writing or thinking. Many of the exercise sets suggest various applications for using The Elements, and more will be introduced in the main text or by the teacher. Some of these strategies include creating a "Logic of..." the problem, which involves identifying all Elements for that problem. We can assess the Logic of... by applying each Intellectual Standard to each Element we've identified in order to refine it, thereby raising the 
quality of our writing, speaking, or research. We may isolate certain elements in order to focus in on them and improve our thought by paraphrasing, roleplaying, and other types of traditional exercises. More detail on these methods can be found in literature from The Foundation for Critical Thinking, particularly the following:

\section{The Thinker's Guide to Analytic Reasoning}

The Thinker's Guide to How to Read a Paragraph

\section{The Thinker's Guide to How to Write a Paragraph}

These Thinker's Guides lay out various applications of The Elements of Thought for students and instructors.

\section{WHY WRITE?}

I advocate writing throughout the course. Many of the exercise sets in this textbook are intended to produce written products. It is important for students to engage in the writing modality about this material because they may not have thought deeply about the material until they are forced to construct sentences about what they believe. The material gathered here offers a new approach to students working on business ethics. They may never have thought about these ideas in the ethical realm before they begin working on it here. So, it is important that these ideas become incorporated deeply into students' consciousness. When students construct sentences, they make word choices. These choices help them formalize what they think; it allows their thinking to move from the vague and general to the precise and particular. Everyone, students and teachers alike, should want this to happen. When we are precise in our meanings, our knowledge grows more rapidly 
and in more impressive and useful ways than when we are vague and unfocused. Therefore, I encourage everyone to write out all of the exercises in this textbook that they choose to use for their learning.

Teachers will complain that regular writing creates undue stress upon their time due to added grading. It is not my intention that all writing practice be graded by the teacher. In fact, I advocate some degree of peer review in all of my classes. Students might write at home, their work based upon a reading or video, bring the document to class, and then pass it around to other students. Students read the peer writing, assess it using Intellectual Standards, Elements of Thought, or relevant theories from the chapter, and then pass it back to the owner for revision. Teachers might also decide that students should orally discuss their writings with one another in small groups, raise the writing to the whole class for comment, or even attempt rewrites themselves. The goal is to be sure that each piece of writing creates opportunities for peer interaction, hitting multiple learning modalities for the topic at hand, and a review of the material by its creator occurs multiple times during this process. All of these strategies are intended to counter a traditional lecture or other didactic approach to teaching, and they are fully laid out in various exercise sets throughout the text. For a full inventory of these techniques and how to begin using them, I recommend:

The Foundation for Critical Thinking's Strategies to Improve Student Learning Critical Thinking: Basic Theory and Instructional Structures 
See the following pages for more methodology and some examples of critical thinking theory for business ethics.

\section{TAKING A CRITICAL APPROACH SERIOUSLY: FOR STUDENTS}

You have to do the work. This is the case for true learning to occur in any area. Sadly, many students hold the opinion that some classes, maybe even this one, can be skated through with no effort. This point of view is in error. You will be required to learn the content of this course, but you'll also be required to learn a new way of interacting with the content. You will be able to use this method of interaction with any content in any course or area of study for your life and your academic career. This approach is the critical approach, and it is at the foundation of critical thinking. Critical approaches are able to turn the analytic gaze back upon the thinker in order to analyze the thinker's own processes and approaches to doing the work of thinking. This approach incorporates techniques for thinking, reading, writing, speaking, and listening. Students of this work are expected to participate in a way that will increase their ability with these skills.

If we were a basketball team, instead of a class, and I was the coach, instead of the professor, we might have a meeting at the first practice. I'd welcome you to the team, and then I'd lay out the expectations for the season. What if it went something like this? My assistant coaches would bring out clipboards and pens for each of you. The clipboard has a pad of paper attached to it. "Good afternoon, team. Congratulations on your success at making the team. We're gonna have a great season. Let me tell you how practices will work: At each meeting, I'm going to give you the chance to take notes on the things that 
I'm doing. I'll be the example. So, I'll run around the court from spot to spot to demonstrate various playmaking. I'll dribble, I'll work on layups and jump shots, and I'll talk about the basics of passing, defense, and all the rest. You will take very careful notes, and you'll review those notes at home. If you have some specific interest in basketball, you should find ways to practice on your own time, but none will be offered here. You are being given the opportunity here to learn from a master at the craft of basketball, me, and you should be honored to have this opportunity. Probably, none of you will ever have the understanding of basketball that I do, so you should take this opportunity to learn as much as you can while modeling my excellent moves on the court on your own time or at our testing times, which are this season's scheduled games."

Chances are that our basketball team would not be very successful under these conditions. In athletics, we understand that the abilities needed to perform the skills is most easily attained by attempting to perform the skills. Learners in athletics are encouraged to think about what they are doing and to self-correct. This skill is critical for success within an athletic endeavor. Modeling is important, but each learner makes the skills his or her own. This is the kind of learning I am trying to cultivate with the critical approach. Each of us should make the learning his or her own. We should practice the skills when we are together. We should provide feedback for one another. All of these things happen at the basketball practice. Think of class as a way to practice the skills you're working on. You can also practice with the questions in the book, and you need to have reviewed the material for the class day before class so that you'll be familiar with what we're working on 
today. Coach would ask you to review the playbook or some scouting reports before practice; please take this course as seriously as you might take your responsibilities on a team.

\section{QUESTIONS TO CONSIDER BEFORE READING:}

-What relationship does critical thinking have to business?

- What is it to be "critical" in the sense that "critical thinking" uses the word?

- Is there any value in altering your learning toward a critical mode?

\section{CRITICAL THINKING FOR BUSINESS ETHICS}

A good way to begin an analysis of any problem is by appealing to the Elements of Thought. The Elements of Thought are a valuable part of Paulian Critical Thinking Theory. Whenever we try to solve a problem, large or small, we use all eight aspects of The Elements of Thought, even if we aren't directly aware that we are doing it. Many of the associations made with the Elements of Thought wheel happen unconsciously, but any of them can be accessed by us in self-reflection upon our thinking process. This section will demonstrate how The Elements can be used for thinking about Business Ethics problems.

Let's use a sample problem for this introduction. We are trying to decide whether it is right or wrong that a CEO makes 500 times more in salary than his or her lowest-paid employee. Please bear in mind that The Elements are not a magic eight ball. They will not give you an answer. An answer to your question should present itself, however, based upon your analysis. This answer will be in some ways unique for every thinker. 


\section{Purpose}

Every time we try to work out a problem, we do so for a Purpose. Why are you thinking about this in the first place? Perhaps the CEO salary problem was given to you in class, so working it out for practice or a grade is your purpose. Perhaps your boss or your mentor posed this hypothetical, so your purpose is to demonstrate your reasoning to that person. Your purpose will dictate many aspects of your approach. Is your purpose wrapped up in a deadline? Is there a competitive element? Is some kind of payment associated with your answer? Your Purpose will help you decide how you should approach the issue at hand and what level of priority, rigor, or resources should be poured into your analysis of the problem. We should never move forward without understanding our purpose.

\section{Question}

There is always at least one important Question related to your reasoning process. Examples here include, What is the right balance between CEO and other workers' pay? Are there good reasons to value the CEO's compensation so much higher than another employee's compensation? What are the right rules to determine compensation for employees? There are other important Questions here, but these can get us started.

\section{Information}

We will decide the solution to our problem by reference to Information. The Information we use determines the outcome of our thinking, and the quality of that Information is directly related to the quality of our solution. In this instance, we have the difference be- 
tween the two salaries, and we might also have the actual numbers. We would also want information about the jobs performed, the sector, compensation packages and scales from other companies, the value of one job versus another for this company, and many other pieces of Information.

\section{Interpretation}

Information is always interpreted. This process of Interpretation, which often happens without our conscious awareness, leads to Inferences, which are the necessary connections that our thinking makes between different pieces of information. Each of us has an interpretive process that we engage in based upon our own training and our background. We automatically Interpret information to create Inferences, and we use these Inferences to progress in our thinking process. We can view our own Interpretations in self-reflection, but we must practice it to do so. In this case, how am I interpreting the information? When I learn about the numbers and the duties, what are my automatic reactions? Do

those reactions seem justified? When I put together my own thoughts about that information, is my interpretation being fair toward the information as I've discovered it?

\section{Point of View}

All reasoning happens from a Point of View, my own. Each of us possesses a Point of View that is unique and is constructed from our personal narrative and the thinking we've done in our lives. Often, my own history will influence the way I interpret the information, which is one aspect of Point of View. So, if I've been a CEO, or want to be one, maybe my Point of View is more sympathetic to the high salary gap than the Point of 
View of someone who has only worked as an employee on the low end of the salary scale. Perhaps my parents' employment is important to my Point of View. The danger is that we may not recognize the biases built into our own Points of View. As critical thinkers, we want to be aware of all biases we might bring into our reasoning process unintentionally, and we should be aware that these can often be attached to an unknowinglybiased Point of View.

\section{Assumptions}

Like point of view, Assumptions are often buried within our thinking process without our knowledge. Assumptions are untested ideas that we use to support and inform our thinking. Like points of view, assumptions often arise from our own biases and unexamined personal histories. We might be making assumptions about the value of money or the value of labor in our example. We might be assuming that there is a value difference between the CEO and the low-paid laborer, and we might not have examined it. We could be making unwarranted assumptions about relative workload, about the industry and its products, or about the character of the individuals in question. Any of these assumptions could bias our understandings of the situation and skew our problem solving.

\section{Concepts}

Whenever we reason about anything, we use Concepts. Concepts are background ideas that support our reasoning. They are usually well-tested, and we can often express them and their value for our understanding and solving of a problem. Our solution to this problem will be impacted by some economic concepts, some ethics concepts, and some 
concepts about society. We should be able to analyze our own understandings of relevant economic concepts, like trickle-down, the free market, and employment at-will. We should be able to analyze our own conceptions of what is right and wrong, an activity that is always relevant for business ethics. We should be able to self-reflect upon what we mean by a social contract, a fair marketplace for labor, or the degree to which governments should get involved with labor practices. All of these concepts are in play when we work through this problem, and we might find, upon self-reflection, that we are in error about some of these, unclear about others, and in need of clarification before we can use others. Recognizing the limitations in our own use of Concepts as necessary parts of our thinking process will allow us to improve upon the quality and effectiveness of our own thinking about this or any problem.

\section{Implications and Consequences}

All thinking leads to Implications and Consequences. The Implications are the logical outcomes of our thinking down the road, as one inference leads to another. The Consequences are the ways in which our thinking manifests itself in real-world outcomes. Whenever we reason through a problem, the solution we arrive at has both Implications for our future thinking and, potentially, Consequences for the ways that the thinking informs our own actions. Even if we don't create Consequences today, they are always available for our future selves. Since Implications can affect our future thinking, and since Consequences not only affect us, but also others, we should be sure that we have analyzed what those are. Do we want the Implications of our thinking to be support for 
the wage gap from the problem? Do we want our thinking to support actions in the world that will come from an acceptance of that thinking?

Do we want the Consequences of our thinking to be that our company loses a solid CEO to a competitor company in a wage battle? Are we comfortable with the hit that shareholders will take from this outcome?

New Paragraph: The Elements of Thought are always significant pieces of information for any inquiry. If students can identify the Elements for their own thinking about any topic, then they will have achieved knowledge worth having. Of course, it is also desirable for students to know ethical theories, historical connections, literary context, and discipline-specific standards in addition to Elements of Thought. Due to the ubiquity of the Elements for our thinking, however, their identification will be a useful starting point for any analysis in any discipline.

\section{PARAPHRASING}

One way of improving our writing is to attempt to capture someone else's words with our own word choices. Paraphrasing is the effort to capture someone else's idea or statement in your own words. I suggest that a useful way of learning important principles in business ethics is to paraphrase key business ethics ideas. We all have difficulty reacting to controversial ideas as stated. Students will spend much time reacting to their own impressions regarding what was said or written, but they often miss the actual meaning of the speaker or author. A way to be certain that we know what the other person is asserting 
is to practice putting those words from the other into our own words, and then critically comparing our paraphrase to the original.

Most students have probably been paraphrasing since elementary school, but not all kinds of paraphrasing have the same purpose. Much traditional paraphrasing has a strong bias toward didactic accuracy with the original statement. Once that correlation has been achieved, there is no longer any work to be done. While a bias toward accuracy is a useful thing for students, it is still a bias. Biases limit our ability to see unfamiliar aspects of what we are investigating; we assume that the value is in one area alone and, therefore, not in others. Our active thinking shuts down when we appeal to biases, especially when those biases are subconscious.

Critical paraphrasing has a different purpose. What the paraphraser is trying to do is capture, as closely as possible, the meaning of the speaker. While accurately picking words that are synonyms of the author's words is a fine exercise, sometimes a critical paraphrase can also enhance and highlight an author's point of view, the implications of the writing, or the assumptions of the piece. Certainly, though, not just anything can be a good paraphrase, and the paraphraser should be able to demonstrate how his or her paraphrase connects with the original statement through critical criteria, like The Intellectual Standards, which are discussed above. For more information on the Intellectual Standards, check out The Universal Intellectual Standards. 


\section{THE INTELLECTUAL TRAITS}

A critical approach also demands a goal for the thinker who is trying to improve his or her own thinking. This goal is partially articulated by The Intellectual Traits. These traits are characteristics that thinkers can develop which will improve the thinking process by their presence as positive habits of mind. A list is included here, and further information can be found at www.criticalthinking.org and throughout the course. How can you apply these intellectual traits to business decision-making? The list below comes from The Miniature Guide to Critical Thinking: Concepts and Tools by Richard Paul and Linda Elder, 2008.

Intellectual Humility (opposite is Intellectual Arrogance)

Having a consciousness of the limits of one's knowledge, including a sensitivity to circumstances in which one's native egocentrism is likely to function self-deceptively; sensitivity to bias, prejudice and limitations of one's viewpoint. Intellectual humility depends on recognizing that one should not claim more than one actually knows. It does not imply spinelessness or submissiveness. It implies the lack of intellectual pretentiousness, boastfulness, or conceit, combined with insight into the logical foundations, or lack of such foundations, of one's beliefs.

\section{Intellectual Courage (opposite is Intellectual Cowardice)}

Having a consciousness of the need to face and fairly address ideas, beliefs or viewpoints toward which we have strong negative emotions and to which we have not given a serious hearing. This courage is connected with the recognition that ideas considered 
dangerous or absurd are sometimes rationally justified (in whole or in part) and that conclusions and beliefs inculcated in us are sometimes false or misleading. To determine for ourselves which is which, we must not passively and uncritically "accept" what we have "learned." Intellectual courage comes into play here, because inevitably we will come to see some truth in some ideas considered dangerous and absurd, and distortion or falsity in some ideas strongly held in our social group. We need courage to be true to our own thinking in such circumstances. The penalties for nonconformity can be severe.

Intellectual Empathy (opposite is Intellectual Narrow-mindedness)

Having a consciousness of the need to imaginatively put oneself in the place of others in order to genuinely understand them, which requires the consciousness of our egocentric tendency to identify truth with our immediate perceptions of long-standing thought or belief. This trait correlates with the ability to reconstruct accurately the viewpoints and reasoning of others and to reason from premises, assumptions, and ideas other than our own. This trait also correlates with the willingness to remember occasions when we were wrong in the past despite an intense conviction that we were right, and with the ability to imagine our being similarly deceived in a case-at-hand.

\section{Intellectual Autonomy (opposite is Intellectual Conformity)}

Having rational control of one's beliefs, values, and inferences. The ideal of critical thinking is to learn to think for oneself, to gain command over one's thought processes. It entails a commitment to analyzing and evaluating beliefs on the basis of reason and evi- 
dence, to question when it is rational to question, to believe when it is rational to believe, and to conform when it is rational to conform.

\section{Intellectual Integrity (opposite is Intellectual Hypocrisy)}

Recognition of the need to be true to one's own thinking; to be consistent in the intellectual standards one applies; to hold one's self to the same rigorous standards of evidence and proof to which one holds one's antagonists; to practice what one advocates for others; and to honestly admit discrepancies and inconsistencies in one's own thought and action. Intellectual Perseverance (opposite is Intellectual Laziness)

Having a consciousness of the need to use intellectual insights and truths in spite of difficulties, obstacles, and frustrations; firm adherence to rational principles despite the irrational opposition of others; a sense of the need to struggle with confusion and unsettled questions over an extended period of time to achieve deeper understanding or insight.

\section{Confidence In Reason (opposite is Distrust of Reason and Evidence)}

Confidence that, in the long run, one's own higher interests and those of humankind at large will be best served by giving the freest play to reason, by encouraging people to come to their own conclusions by developing their own rational faculties; faith that, with proper encouragement and cultivation, people can learn to think for themselves, to form rational viewpoints, draw reasonable conclusions, think coherently and logically, persuade each other by reason and become reasonable persons, despite the deep-seated obstacles in the native character of the human mind and in society as we know it. 
Fairmindedness (opposite is Intellectual Unfairness)

Having a consciousness of the need to treat all viewpoints alike, without reference to one's own feelings or vested interests, or the feelings or vested interests of one's friends, community or nation; implies adherence to intellectual standards without reference to one's own advantage or the advantage of one's group.

Finally, we should not forget that critical thinking takes focus and hard work. We have to be self-reflective in order to know where we are making intellectual mistakes and in order to avoid our biases. The Paulian critical thinking theory recognizes two broad categories of biases, Egocentric and Sociocentric biases. The information on these biases below is also reprinted from The Miniature Guide to Critical Thinking: Concepts and Tools from Critical Thinking Press and The Foundation for Critical Thinking.

\section{EGOCENTRIC AND SOCIOCENTRIC THINKING}

Egocentric thinking results from the unfortunate fact that humans do not naturally consider the rights and needs of others. We do not naturally appreciate the point of view of others nor the limitations in our own point of view. We become explicitly aware of our egocentric thinking only if trained to do so. We do not naturally recognize our egocentric assumptions, the egocentric way we use information, the egocentric way we interpret data, the source of our egocentric concepts and ideas, the implications of our egocentric thought. We do not naturally recognize our self-serving perspective. As humans we live with the unrealistic but confident sense that we have fundamentally figured out the way things actually are, and that we have done this objectively. We naturally believe in our 
intuitive perceptions - however inaccurate. Instead of using intellectual standards in thinking, we often use self-centered psychological standards to determine what to believe and what to reject. Here are the most commonly used psychological standards in human thinking.

"It's true because I believe it." Innate egocentrism: I assume that what I believe is true even though I have never questioned the basis for many of my beliefs.

"It's true because we believe it." Innate sociocentrism: I assume that the dominant beliefs of the groups to which I belong are true even though I have never questioned the basis for those beliefs.

"It's true because I want to believe it." Innate wish fulfillment: I believe in whatever puts me (or the groups to which I belong) in a positive light. I believe what "feels good," what does not require me to change my thinking in any significant way, what does not require me to admit I have been wrong.

"It's true because I have always believed it." Innate self-validation: I have a strong desire to maintain beliefs that I have long held, even though I have not seriously considered the extent to which those beliefs are justified by the evidence.

"It's true because it is in my selfish interest to believe it." Innate selfishness: I believe whatever justifies my getting more power, money, or personal advantage even though these beliefs are not grounded in sound reasoning or evidence. 


\section{The Problem of Sociocentric Thinking}

Most people do not understand the degree to which they have uncritically internalized the dominant prejudices of their society or culture. Sociologists and anthropologists identify this as the state of being "culture bound." This phenomenon is caused by sociocentric thinking, which includes:

- The uncritical tendency to place one's culture, nation, religion above all others.

- The uncritical tendency to select self-serving positive descriptions of ourselves and negative descriptions of those who think differently from us.

- The uncritical tendency to internalize group norms and beliefs, take on group identities, and act as we are expected to act - without the least sense that what we are doing might reasonably be questioned.

- The tendency to blindly conform to group restrictions (many of which are arbitrary or coercive).

- The failure to think beyond the traditional prejudices of one's culture.

- The failure to study and internalize the insights of other cultures (improving thereby the breadth and depth of one's thinking).

- The failure to distinguish universal ethics from relativistic cultural requirements and taboos.

- The failure to realize that mass media in every culture shapes the news from the point of view of that culture. 
- The failure to think historically and anthropologically (and hence to be trapped in current ways of thinking).

- The failure to see sociocentric thinking as a significant impediment to intellectual development.

- Sociocentric thinking is a hallmark of an uncritical society. It can be diminished only when replaced by cross-cultural, fairminded thinking — critical thinking in the strong sense.

Students and teachers should learn to contextualize the critical thinking tools from this section for all aspects of the course. Effectively recognizing the ethical aspect of business takes practice and disciplined self-reflection, both of which can be developed through a critical approach. Look for more information and opportunities to practice with these tools throughout the text. A few more tools will be added as new chapters are processed. These are the foundational tools. 


\section{CHAPTER 1}

\section{INTERDISCIPLINARY THINKING:}

\section{THE MILGRAM EXPERIMENTS}

\section{Introduction to the Ideas in this Chapter:}

Chapter one orients us toward the problem: Harms occur all around us, even to us, and we are sometimes blissfully unaware, even in the midst of the action. The information in this chapter helps contextualize why this might happen. It may be that ordinary people can cause harms to those around them without really thinking of their actions as harmful. Maybe we just need to think more.

The Milgram experiments give us some background for understanding the problem. When we combine these experiments with the butterfly effect theory and suggestions from the small world experiments, we may find ourselves compelled to consider what harms we are unintentionally causing, or what harms are being perpetuated upon a consumer population that is not paying attention. We will be returning to this idea repeatedly in this text. 
Fundamental and Powerful Concepts:

\section{Agency, Authority, Obedience, Power}

\section{Why Start with Milgram?}

Why start a course in business ethics with The Milgram Experiments? Shouldn't a text like this start with a business ethics theorist or, perhaps, an economist? Maybe it should start with a noble entrepreneur or a crusading regulator. I begin with Milgram because you, the reader, needs to make some decisions early in this course on business ethics. How do you think people act at a baseline? What are the alternate ways to value things that could also be valued economically? Is there ever much more going on than economic valuing, anyway? If so, how do we recognize it? What role might such noneconomic valuing have in the business context?

So, my intention is not to highlight the initial experiment as a dramatic example of commercially-motivated greed leading to harms, though readers familiar with these experiments might suspect this approach. Sure, there was a commercial relationship involved: Milgram paid participants in his first experiment $\$ 4$ for an hour of their time in 1961 at Yale University. This is a trivial connection with business ethics, however, and is not my purpose. It's about time to introduce a particular bias of this textbook.

It is the author's position that economic valuation alone dominates the understandings of undergraduate business majors, to the detriment of their thinking and, potentially, an increase in harm as a result of their actions in their careers. In fact, American society at large elevates the economic consideration to not only the superlative level of value, but, 
indeed, the singular. Only economic considerations exist for many young thinkers about business $^{52}$.

It is with this bias, which I refer to in class as the economic highjack of our thinking, in mind that I refer to the \$4 payment as “trivial.” After all, in 1961 in Connecticut, \$4 was not trivial from an economic point of view. At the time of this writing, the relative updating of $\$ 4$ then to today's money results in buying power for participants of just over $\$ 20$ for an hour of their time. It is "trivial" because the economics of the situation are far less important, and far less illuminating for our purposes, than are the ethical aspects. Consider the idea that this unnoticed economic highjack of our thinking exists in lots of places in our society. Can you locate any other areas where it is obvious?

The Milgram Experiments are loaded with big ideas about how we value things. First of all, the world containing many of our university campuses appears friendly and safe. Many, though not all, students fail to encounter significant violence against their person while in college or prior to college. These students should consider, for their own safety and for their deeper understanding of the larger world, whether everyone who appears to be playing by the rules of society is actually doing so. How much faith can we put in others to respect our safety and our lives? I'm not trying to scare people or create panic in a crowded theatre. What I'm wondering is whether we are succumbing to a post hoc propter hoc fallacy in our daily activities. How much more is this the case at the office,

\footnotetext{
52 Many students have not yet been educated to think by using the ethical aspects of business. Much of the ethical thinking that is cultivated in western culture is harmful to the process of thinking through ethics; this kind of thinking is grounded in bowing to authority, religion, or law without thought, taking the standards found there as synonymous with truth. In fact, all value standards, including those presented in this text, are constructed and should be critically analyzed and assessed.
} 
when we are forced to interact with groups of strangers who may or may not have our interests at heart? What about when our co-workers or business leaders have no one's interests at heart, when their only interest is the making of profit without regard for others? How does this example help us understand how things get valued?

Secondly, The Milgram Experiments are no longer allowed, due to the ethics of informed consent. Medical ethics, among other areas of applied ethics, require experimental human subjects to be briefed about all of the things that could happen to him or her during experiments. Milgram, though, did not gain informed consent from his experimental subjects. Likewise, business actions regularly harm people who are not expecting to be harmed by the action, primarily because these people had not been made aware that they were caught up in a commercial enterprise that could cause harms. In many cases, business activities amount to experiments within the market that are designed to directly affect customers. Often, in order to maintain competitive advantage or in order to cultivate surprise or shock value from consumers, businesses disclose to the public few, if any, of the risks they are taking. This happens in all areas of commerce worldwide, though regulation and entrepreneurial preference provides much variation across markets.

These largely unintended (but often foreseeable) negative actions that harm consumers are often called externalities within the business community. In the 2004 Canadian documentary, The Corporation, Nobel Prize-Winning Economist Milton Friedman defines an externality as, "The effect of a transaction between two individuals on a third party who has not consented to or played any role in the carrying out of that transaction." Friedman admits in the same film that, "There are real problems in that area [of externali- 
ties]. There's no doubt about it." ${ }^{53}$ So, why are harms allowed through various externalities, while they are not allowed in areas like medical testing? Each could be hailed as being "for the common good," so what's the difference? Look for externalities as you review the experimental protocol and history for the Milgram experiments.

Third, The Milgram Experiments prompt us to consider the extent to which we support a purely economic consideration of business or whether there might be other aspects. Consider a situation in which someone instructs you to follow their authority at work, and you can foresee that harms will occur to others from the business activity at hand, but you are tempted to follow the order because of your own financial benefit. If you found yourself willing to go along with the harm in question, how much money would it take for you to do so?

Lastly, what can these experiments tell us about our own ability to make good choices in difficult situations? The capitalist business world is full of pressure to grow, to earn, to present a particular appearance, and to climb. To what extent do these pressures cause us to compromise our other values as we succeed under a capitalist model? In ethics, we use the word agency to identify that feature of human beings that allows us to choose what we want to do. European Enlightenment thinkers like John Locke and John Mill refer to this feature as liberty. We are all born free, and we represent our own interests, just like sports agents represent the interests of the athletes they work for. As long as we freely represent our own desires, we are free to act, and we are responsible for what we have

\footnotetext{
${ }^{53}$ http://www.youtube.com/watch?v=aCGTD5Bn1m0 Milton Friedman at 2:13.
} 
freely done. In ethics, a person whose agency is compromised, for example, through coercion, is no longer considered to be acting freely, and so may not be responsible for his or her own choices due to the loss of control over his or her agency.

\section{Questions to Consider Before Reading.}

1. How much of a role does authority play in your decision making?

2. Is it credible that a stranger in our society will kill another stranger from that same society simply because an authority figure told him or her to do so?

3. What is it about your personal experiences in the workplace that cause you to trust fellow workers to the extent that you do?

4. Do business activities that harm people ever occur intentionally, but without the consent of those who are harmed?

5. Does everyone have a price? If so, what's yours? If you don't have one, why can't you be bribed?

6. Are there any important market activities about which consumers should not ever be informed? Can you provide an example?

\section{Read about The Milgram Experiments}

Information about The Milgram Experiments is behind the following three links. Follow them to get information about the experiment.

The Milgram Experiment - Simply Psychology

The Man Who Shocked the World 


\section{Optional Reading}

\section{Milgram's Experiment on Obedience to Authority}

\section{Questions to Consider After Reading}

1. Do you think the explanations given for the participants' behavior are legitimate?

2. What would be conditions under which you could lose or give up control over your own agency?

3. What is Blass's most important statistic for understanding the broad relevance of The Milgram Experiments? Why do you think so?

4. What do you think is the most important idea for business ethics from these experiments?

\section{Critical Thinking Vocabulary and Application}

Clarity. Clarity is the gateway intellectual standard. If we are not clear about material we read or listen to, we will not fully understand it, and we will be unable to agree with it or oppose it in important and useful ways. Are you clear about the material that you've read? Some strategies for clarifying written material include writing the important ideas from the passage in your own words (paraphrasing), rereading slowly and intentionally, or creating questions from the text that may be answered by that same text. For everything you read in this class, you should ask if you understand it clearly. For everything you write, you should ask whether it is as clear as it can be for the reader. 


\section{Community Engagement Exercise}

Consider your community by viewing it from a different point of view. Spend an entire day on campus making eye contact, smiling at, and greeting everyone you see. Don't be suggestive, aggressive, or inviting. Just make eye contact and provide a genuine, and reasonably-sized, smile. Accompany this with the appropriate greeting for the time of day. Silently gauge the reaction or response of those with whom you interact. How does this activity help you think about those with whom you share time and space? If you already do this regularly, spend the day avoiding eye contact, erase your smile, and refrain from offering any polite social greetings for one day. Do not put yourself at risk!

\section{Application Exercise}

Please review the links below about Bernie Madoff.

http://www.nytimes.com/interactive/2009/06/29/business/madoff-timeline.html

http://www.thefiscaltimes.com/Articles/2013/02/05/Madoff-Makes-Millions-and-

Its-Legit.aspx\#page1

http://www.nbcnews.com/business/madoff-emails-jail-i-wish-i-hadnt-pleadedguilty-1C8391074.

\section{Questions:}

1. Do you believe that Bernie Madoff was coerced in any way by authority? 
2. To what extent was Bernie Madoff the authority figure? Can you apply Milgram to this case?

3. How do we stand against authority when that authority is successful?

Interdisciplinary Exercise

The Milgram Experiments are contained within the disciplines of psychology and sociology. What happens if we merge them with two other ideas, one also from social science, but the other from physics and meteorology?

Please read these two links, keeping in mind the important ideas for each.

Fundamental and Powerful Concepts: Connectedness, Communication

The Small World Experiments

Fundamental and Powerful Concepts: Complexity, Causation, Foreseeability

The Butterfly Effect

Now that you have explored The Milgram Experiments, The Small World Experiment, and the Butterfly Effect, consider how each of them fit together. Try this: Write down the most important ideas for each of the three theories in this chapter that you think relate to ethical business practices. Then, combine those ideas in such a way that they become evidence in an argument for a conclusion like, "Therefore, we should pay attention to the ethical aspects of business." Bring this written exercise to class for discussion. 


\section{Classroom Exercise Method}

Students should get into pairs to discuss their answers to the interdisciplinary exercise. One student should present his or her answer to the other. The other student should ask questions using Intellectual Standards (see the Introduction for a list). Perhaps the instructor could limit the questioner to only using questions of clarity, precision, and relevance. Students should switch roles after three to five minutes of questioning. The instructor could demonstrate to make sure everyone is clear on the technique and the kinds of questions desired.

\section{Find the Ethical Aspect!}

Mine the newspaper! For this assignment, please use a recognized news source. Locate the ethical aspect of some business activity reported in a news source during the week you are discussing this chapter's material. Try to make your story relevant to this chapter's fundamental and powerful concepts. You should look for evidence of any ethical theories from the text thus far. Bring your example to class for discussion. There is one of these exercises in each chapter, so please think about using a hardcopy newspaper for a few of the news research assignments this semester. Be sensitive to the differences you perceive between print versus digital media types; there's even an ethical aspect to that comparison! 
Relation of Some Key Ideas in this Chapter to the Central Question: When is it acceptable to profit from harm to others in business?

- If we are concerned about harms to others, then the Milgram Experiment highlights harms in pursuit of knowledge. Do you find this sort of tradeoff acceptable?

- Does the degree to which people might be closely connected or in close proximity change your understanding of acceptable harm in business?

- If our actions can cause unintended harm (externalities), then what responsibility do we have to foresee harms in business? 


\section{CHAPTER 2}

\section{HOW TO IDENTIFY A BUSINESS ETHICS ISSUE}

Introduction to the Ideas in this Chapter:

This chapter provides a necessary tool for doing business ethics. Students of this work need to understand when a theory is an ethics theory, as opposed to a theory from some other discipline. Readers should examine the material in this chapter and use it as a tool for identifying ethical theories that can illuminate the ethical aspects of business. This will be a useful tool throughout the textbook, and students will be expected to use it appropriately as the course progresses.

\section{Fundamental and Powerful Concepts}

\section{Evidence, Judgment, Axiology}

What are the necessary parts of an ethics theory?

It is crucial to doing business ethics that students are able to identify issues that are ethics issues related to business. Once an ethical issue is identified, an ethical theory 
should be selected to apply to the situation. So, how do we go about doing this? The process is pretty straightforward.

\section{Identifying Commercial Relationships}

First, students should locate a commercial relationship. Examples of commercial relationships include employer/employee, merchant/customer, manager/subordinate, supplier/purchaser, and many others. There should be a relationship, in some sense, that is based in business activity.

\section{Identifying Problems in the Relationship}

Once that relationship is found, the student should decide whether he or she can locate any problems with that relationship. One way to do this is to observe actions or attitudes in the relationship and ask if anyone is treating anyone else unfairly. Students can begin this process with an intuitive sense of what this lack of fairness means. Is a manager asking a subordinate to work off the clock, thus denying the worker fairly-earned wages? Is an owner asking an employee for sexual favors in order that the employee be allowed to keep his or her job? Is a supplier demanding non-contractual consideration, like concert tickets, in order to deliver upon his or her obligations? Is a grocery merchant selling out-of-date products to customers?

Certainly, other aspects of the business world have things to say about these situations. In many cases, these activities constitute breaking a law or a company rule in addition to being unethical. The conduct might also violate basic operating procedures for the companies involved or go against established industry standards. While it is true that 
these companies or individuals could focus on the legal, managerial, financial, or human resources aspects of the problem, they could also focus on the ethical aspect. The ethical aspect, once identified, has to be more precisely defined in line with a particular ethical theory. Students should not avoid a merely impressionistic identification of the ethical issue, but they need to do more for the purposes of business ethics. After a student indicates that something seems "wrong," the next step is to identify the ethical theory that makes it wrong.

\section{Questions to Consider}

1. Why is evidence important for establishing responsibility?

2. Can you think of a commercial relationship that involves ethics?

\section{Identifying an Applicable Theory}

The next step in the basic approach is to justify or criticize the action or issue by reference to some ethical theory. Some people will claim that there are always absolute "good" and "bad" ways of judging ethical outcomes. This course in business ethics does not take that position. While some actions can never be justified because of the harm they do to people (rape, genocide, and harm to children, for example), ALL actions must be justified in some way to be labeled as the right or wrong thing to do. This is a function of evidence-based thinking about ethics, which is the approach taken in this course on business ethics. For those who would like more extensive training in an evidence-based approach to ethics, please see Richard Paul's “Thinker's Guide to Ethical Reasoning." 
Before applying an ethical theory to the business situation at hand, it's important to know what makes a theory an ethics theory. There are plenty of theories out there that may be applied to real-world situations, including ethical theories. Each of the theories used for this course in business ethics is outlined in the following chapters, along with relevant support from the social sciences, physics, economics, and politics. An important question to consider in this sea of theory is what exactly the features of a theory are that makes it a candidate for being an ethical theory. In this course, I offer a three-part checklist.

\section{Checklist for an Ethical Theory}

1. Does the theory allow a person to act freely? (agency)

2. Does the theory use a process of evidence to build a correspondence between the appropriate use of this theory and the situation at hand? (evidence)

3. Does the theory make a determination about what is "good" or "bad" in the situation? (judgment)

Business ethics has a basic assumption that all of its actors make their moves freely. As is common in most ethical sub-disciplines, it is that freely-chosen action that makes it possible to hold the agent responsible for his or her action. The freely-chosen action is undermined when there is leverage or coercion against that individual that caused him or her to do something other than what would have been done without the coercion. It's important for the person choosing an ethical theory to explain behavior in order to know whether or not the actor has made the decision on his or her own. Often, business situa- 
tions apply pressure on the individual from above in a business hierarchy or laterally in the form of peer pressure. When the coercion becomes great enough, people are no longer said to be choosing on their own, and so the possibility of holding that person responsible for his or her action vanishes. Consider the Milgram Experiments.

Why use evidence? Why can't the theory just apply any old logic to the decision about why a situation is good or bad? The answer is that we live in a world where evidence matters. It simply is not acceptable to judge or hold another person responsible without good reasons for doing so. If a person isn't demonstrably to blame for an action, we find it unacceptable that they would be blamed anyway. Often, humans in society blame one another for actions without good reasons. In other words, we use impressionistic thinking, rather than evidence-based thinking, to make these decisions. We use intuition. We "go with our gut" on an issue. We make decisions based upon emotion, tradition, law, or religion. None of these decisions are appropriate for business ethics without the infusion of evidence. What would we think about an employer who hired and fired based upon "the way I've always done it" alone, without reference to evidence? How about the trader who decides upon moves in the market based upon emotions or biblical guidance? Would we want to trade with manufacturers who make decisions regarding the right price at which to purchase raw materials by reference to a passage from the their religious text? When we fail to use evidence, we fail to make decisions that engage reason as the primary source for the decision.

Without a method of reasoning through the evidence, we will be deciding an issue without reference to what a logical observer might call "good reasons." We will fail to 
think the issue through fully, which could result in disaster in areas where we are expected to hold ourselves accountable for our decisions. Not only that, in business, others will hold us accountable for our decisions, which means that our bosses, clients, and community will ask us why we did what we did and expect that our answers make sense within the cultural context in which we are operating.

Bear in mind, though, that the cultural context alone is not enough for good decisions. The reasons have to make sense in a world of evidence, whatever the cultural interpretation. If you are taking this course in business ethics from the author, please recognize that only reasonable, evidence-based theories will be acceptable. Many of these are outlined in the text. If you want to reason from a point of view not explicitly covered by this text, you should bring it up in class to see if that point of view meets the necessary criteria.

\section{About Religious Thinking}

For clarity, I will offer a brief word on religious thinking. Religious thinking, because of its lack of empirical foundation, is not evidence-based to our standard. It is not appropriate as a way to determine how a person should behave in business. While, in the author's experience, many businesspeople who are religious behave in highly ethical ways, they do not do so because of their reliance upon religious principles without reference to the world in which we live. Angels, demons, deities, deceased relatives, the power of rituals, prayer, and other religious mainstays are not evident as a function of evidence-based inquiry. These are matters of faith, not evidence. "Faith" is intensely personal and is not reasonable. If we have good reasons, we have evidence, not faith. As a result, referring to 
faith-based reasons for decisions about business decisions like buying, selling, hiring, firing, and promotion is inappropriate in most business contexts. Therefore, these are not useful for thinking about business ethics.

On the other hand, if a religiously-endorsed standard is simultaneously justifiable from a standard of relevant evidence, it is perfectly appropriate for business ethics decisions to rest upon it; the use of relevant evidence in our logical process is the key. What is not acceptable is to decide on matters for which experientially-based evidence is appropriate, but to instead use a standard that is based in the supernatural, fantastical, or illogical, particularly when that standard is elevated above any reasonable methods. Business decisions should not happen because the invisible, superlative, or infallible have told us to do something. Such standards are inconsistent with our human experience, and should be rendered to matters of religion, rather than the more practical realm of business.

\section{Further Clarifying What Makes an Ethical Theory}

Many theories we might use to explain the world do not pass judgment upon whether actions of actors are good or bad actions. Take gravity. If we use our agency to step to the left, and then we fall down, gravity is blamed for taking hold of the actor and pulling him or her toward the center of the earth. While the actor's use of agency in stepping that way might be judged in terms of a good or bad decision, as might the sidewalk, the cliff, or the person's shoes be noted as important in whether it was a good or bad thing to step over there, no one uses reference to gravity to make this decision. Gravity didn't make this a good or bad action, reference to the evidence of the situation and the actor's use of 
agency did. In fact, once gravity comes into play, these other ideas have probably already been vetted on the basis of the evidence they provide for the situation. Gravity is not where we pin the responsibility, because gravity is only incidental in the decision regarding where to step. It is not really a part of our judgment; we all know it will be in play, and we make our decision with it in mind, like other rules of physics.

Theories for business ethics must help us decide whether the actor did a justifiably good thing or a justifiably bad thing. Note the word "justifiably." This prompts us back to good reasons and evidence. We need to make reference to those for the purposes of linking the theory with an ethical judgment.

Bear in mind that ethics is not the only field that uses the terms good and bad. Ethics is part of a larger field of valuation philosophers call Axiology. Axiology is the study of the value judgments we make. Traditionally, axiology has contained economic and aesthetic reasoning, as well as ethical reasoning. When we reason about economics, we make judgments about good and bad while primarily considering money or profit. When we reason about aesthetics, we reason about whether or not something is beautiful, applying the terms good and bad to considerations that are often found in artistic appreciation of various types. Judging whether a song, a painting, a person's form, or a caress from a lover is good or bad is often largely decided with reference to aesthetic theories.

In ethics, good and bad refer to whether there is an action that can be identified from the point of view of whether benefit has been conferred or harm brought about by the actor. When we talk about doing the right thing from the point of view of ethics, we mean 
that we can identify whether the target of the action has been helped or hurt. While we could always characterize these in terms of economics, there are simply more ways that people can be helped or harmed than merely the economic. Aesthetics does not make reference to help or harm in terms of good and bad. So, for most thinkers in an introductory business ethics class, whenever we say good or bad, but we don't mean economic or aesthetic considerations, we are probably reasoning within ethics.

Of course, many of us have grown up with a shorthand for this kind of reasoning. We refer to right and wrong. Of course, right and wrong might purely be considerations of accuracy, but when we refer to the harm or aid of another, we are not usually referring to accuracy alone. We are referring to how that person has been treated by some actions against his or her well-being. Again, we will be speaking about issues beyond merely the economic, like mental and physical health, relationships, respect, etiquette, power, abuse, forgiveness, and loyalty. Candidates for the highest kinds of value will transcend (perhaps even defy) quantitative standards when they are evaluated.

A useful ethical theory will explain how a free agent reasons to considerations like these. Good and bad, right and wrong, are arrived at as a function of evidence. The quantitative and qualitative aspects of situations are observed and noted with reference to the reasons for identifying them as such. A person is not struck by a moving car because we think he or she should be. There are good reasons to make the statement that they have been struck. We then use the evidence and the way that evidence relates to outcomes for the situation to determine whether the situation was good or bad, he or she has been or right and wrong. 
Ethical theories provide the tools for making these judgments. Ethical theories define what it is to be right and wrong, or good and bad. We apply them to situations. So, an ethical egoist, a person who ascribes to the theory of Ethical Egoism, will define the right or good thing to do as the action that brings about the greatest benefit for the actor. The utilitarian thinker might define the good action as the one which brings about the greatest benefit for the greatest number of sentient creatures in the situation, but the ethical egoist's perspective, that the agent should get the benefit of every action, will be wrong for a utilitarian where other sentient beings are involved in the situation. Likewise, an altruist will define the good action as one that benefits others to the exclusion of the agent's own benefit. This approach will always be considered wrong for the ethical egoist.

\section{So, Who's Right?}

This text will canvas in other chapters the relative strengths and weaknesses of theories appropriate for business ethics. Students should remember that there is a three-step process: agency, evidence, and judgment. If a theory doesn't support any one of these three steps, it is not an appropriate theory for business ethics. So, for example, psychological (as opposed to ethical) egoism asserts that human beings are incapable of acting for the interests of others, that the only interests we consider $100 \%$ of the time are our own. This would apply to all people in all situations. This theory fails to recognize the value of agency for decision-making, and so it is inappropriate for explaining ethics. In another example, various religious theories fail to privilege evidence over impressionistic or traditional thinking, thus creating a bias that indicates we can know things without evidence. While many religious theories are quick to pass judgment on the actions of others, their 
judgments do not use evidence as a necessary arbiter of the rightness or wrongness of the situation. As a result of their tendency to minimize the role of evidence for decision-making, these theories are typically not appropriate for use in business ethics. Can a religious person engage in ethical business? Certainly! As Immanuel Kant points out in The Foundation of the Metaphysics of Morals, if the businessperson performs the ethical action in business from a mere loyalty to religious perspectives, he or she is not being critical in his or her thinking about business ethics, and so he or she is not considering the important ethical aspects, truly. Religious belief does not ask us to consider all of our actions in light of the evidence and with the consideration of our positions as people contextualized in a diverse world of others. It does not ask us to consider duty to principles of criticality and evidence in our ethical outcomes. This business ethics textbook, however, does.

Find the Ethical Aspect!

Mine the newspaper! For this assignment, please use a recognized news source. Locate the ethical aspect of some business activity reported in a news source during the week you are discussing this chapter's material. Try to make your story relevant to this chapter's fundamental and powerful concepts. You should look for evidence of any ethical theories from the text thus far. Bring your example to class for discussion. There is one of these exercises in each chapter, so please think about using a hardcopy newspaper for a few of the news research assignments this semester. Be sensitive to the differences you perceive between print versus digital media types; there's even an ethical aspect to that comparison! 
Relation of Some Key Ideas in this Chapter to the Central Question: When is it acceptable to profit from harm to others in business?

- Why should harm in business actions generally be avoided?

- How do different views of right and wrong potentially change the answer to the central question? Can you provide an example?

- What are the conditions that make harm in business attractive? 


\section{CHAPTER 3}

\section{ETHICAL EGOISM AND THE MYTH OF GYGES}

Introduction to the Ideas in this Chapter:

This chapter is an introduction to the ideas of self-interest and the interests of others. Readers encounter Plato's Myth of Gyges and consider some of the ideas that come out of it, like psychological egoism, which is labeled as a behavioral theory. The text also introduces ethical egoism and altruism, which are ethical theories. An exercise is provided for interdisciplinary thinking, and the text highlights three critical thinking tools: accuracy, point of view, and fairmindedness. These are powerful for use in thinking through business ethics issues.

The end of the chapter provides an example from recent headlines for practice in applying the ideas from the chapter. The text considers the case of Bernie Madoff and provides guidance for applying the theories from the chapter to that case. An optional reading introduces the relationship between the chapter's ideas and The Lord of the Rings trilogy, which is a helpful analogy. Finally, several core concepts from the chapter are linked to the central question of the course. 
Fundamental and Powerful Concepts:

\section{Psychological Egoism, Ethical Egoism, Self-Interest, Altruism}

\section{Success at What Cost?}

The overwhelming urge of businesspeople is to succeed. Everyone wants to do well in their business activities, because success at commerce is a major indicator of ease in life, of wealth, the ability to act upon your own intentions, and a degree of peer respect. Once we are successful, there is a belief that life is qualitatively better than prior to such success, which is often demonstrably true.

What is the value of that personal success, though? Should it come at any cost at all? Is gaining financial success the most important and most valuable thing in life, its attainment trumping all other considerations? Businesspeople, whether owners, managers, or staff, should all know how far they are prepared to go for financial success. Is it acceptable to harm others for that success? If so, are there any types of harm that are not acceptable for personal gain?

The main reading of this chapter is from Plato's Republic, arguably one of the most important books in the history of western civilization. People have read, translated, and deeply considered the various ideas in this ten-part exploration of ethics, politics, education, knowledge, and other key concepts for centuries. It was translated into Arabic as early as the first century of the common era (See Oliver Leaman's $\underline{\text { A Brief Introduction to }}$ Islamic Philosophy.) St. Augustine, 5th Century Bishop of Hippo, plagiarized it for his 
monumental City of God. As you'll read later, without Plato's Republic, we might not have ever had The Lord of the Rings trilogy.

The second book in Plato's Republic contains a presentation by Socrates (Plato's reallife teacher and the central character in nearly all of his writings) about what constitutes good or right action for human beings. Socrates advocates for an unchanging, absolute good, one that is superior in value to all other goods. When something is better than all the rest of its type and is, in fact, the most excellent example of the kind of thing that it is, we call it the superlative example.

The good that Socrates advocates for is not only superlative, however. It is also of the highest type, such that it is unchanging in its value. In ethics, we call this kind of value intrinsic value. Intrinsic value is carried within the thing itself and is not imposed upon it by an outside observer. Intrinsic value never changes, is always superlative, and endures for all time. In many ways, it is similar to many people's conception of perfection. Intrinsic value is contrasted with instrumental value (also called extrinsic value), which is the value that we give to things we use. Toasters, brooms, cars, and even money are all instrumentally valuable--their value is not absolute, is not fixed, and fluctuates from user to user. Intrinsically-valuable things would not have these characteristics.

There's more to the concept of Goodness than what is contained in this text. Much of what Plato means by a superlative, intrinsic good is wrapped up in his understanding of "The World of the Forms". You probably aren't familiar with that idea, but you might find it familiar if you read about it. Ask your teacher to help you understand the implica- 
tions of these ideas for business ethics, or, for deeper understanding, do some extra study yourself here:

\section{Plato's Theory of Forms}

\section{Questions to Consider Before Reading:}

- Is there such a thing as something that is always good and can never be corrupted? If so, can you provide an example? If not, why do you think that there is not?

- Should you always act in ways that benefit yourself first and others only after that?

- Are there good reasons for placing the benefits of others before benefits to ourselves?

The myth below tells the story of Gyges, a shepherd in the king's employ, who finds a ring that makes him invisible. Glaucon tells the story of Gyges to Socrates in reaction to Socrates' expression that people who know Goodness (in his perfect conception) will act in ways that reflect their knowledge. Any evil, therefore, is really just a mistake about what is good. See if you agree with Glaucon or Socrates (or neither). Since we're only reading a small portion of the text, it's reprinted below.

\section{The Myth of Gyges}

\section{From Plato’s Republic, Book II--translated by Benjamin Jowett}

They say that to do injustice is, by nature, good; to suffer injustice, evil; but that the evil is greater than the good. And so when men have both done and suffered injustice and have had experience of both, not being able to avoid the one and obtain the other, they think that they had better agree among themselves to have neither; hence there 
arise laws and mutual covenants; and that which is ordained by law is termed by them lawful and just. This they affirm to be the origin and nature of justice; --it is a mean or compromise, between the best of all, which is to do injustice and not be punished, and the worst of all, which is to suffer injustice without the power of retaliation; and justice, being at a middle point between the two, is tolerated not as a good, but as the lesser evil, and honored by reason of the inability of men to do injustice. For no man who is worthy to be called a man would ever submit to such an agreement if he were able to resist; he would be [insane] if he did. Such is the received account, Socrates, of the nature and origin of justice.

Now that those who practice justice do so involuntarily, and because they have not the power to be unjust, will best appear if we imagine something of this kind: having given both to the just and the unjust power to do what they will, let us watch and see whither desire will lead them; then we shall discover in the very act the just and unjust man to be proceeding along the same road, following their interest, which all natures deem to be their good, and are only diverted into the path of justice by the force of law.

[Here is an example.] The liberty which we are supposing may be most completely given to them in the form of such a power as is said to have been possessed by Gyges the ancestor of Croesus the Lydian. According to the tradition, Gyges was a shepherd in the service of the king of Lydia; there was a great storm, and an earthquake made an opening in the earth at the place where he was feeding his flock. Amazed at the sight, he descended into the opening, where, among other marvels, he beheld a hollow brazen horse, having doors, at which he, stooping and looking in, saw a dead body of stature, 
as appeared to him, more than human, and having nothing on but a gold ring; this he took from the finger of the dead and reascended.

[Some time later...] Now the shepherds met together, according to custom, that they might send their monthly report about the flocks to the king; into their assembly [Gyges] came, having the ring on his finger, and as he was sitting among them he chanced to turn the collet of the ring inside his hand, when instantly he became invisible to the rest of the company and they began to speak of him as if he were no longer present. He was astonished at this, and again touching the ring he turned the collet outwards and reappeared; he made several trials of the ring, and always with the same result-when he turned the collet inwards he became invisible, when outwards he reappeared.

Whereupon he contrived to be chosen one of the messengers who were sent to the court; where as soon as he arrived he seduced the queen, and with her help conspired against the king and slew him, and took the kingdom. Suppose now that there were two such magic rings, and the just put on one of them and the unjust the other; no man can be imagined to be of such an iron nature that he would stand fast in justice. No man would keep his hands off what was not his own when he could safely take what he liked out of the market, or go into houses and lie with anyone at his pleasure, or kill or release from prison whom he would, and in all respects be like a God among men. Then the actions of the just would be as the actions of the unjust; they would both come at last to the same point. 
And this we may truly affirm to be a great proof that a man is just, not willingly or because he thinks that justice is any good to him individually, but of necessity, for wherever any one thinks that he can safely be unjust, there he is unjust. For all men believe in their hearts that injustice is far more profitable to the individual than justice, and he who argues as I have been supposing, will say that they are right. If you could imagine any one obtaining this power of becoming invisible, and never doing any wrong or touching what was another's, he would be thought by the lookers-on to be a most wretched idiot, although they would praise him to one another's faces, and keep up appearances with one another from a fear that they too might suffer injustice. Enough of this.

Now, if we are to form a real judgment of the life of the just and unjust, we must isolate them; there is no other way; and how is the isolation to be effected? I answer: Let the unjust man be entirely unjust, and the just man entirely just; nothing is to be taken away from either of them, and both are to be perfectly furnished for the work of their respective lives. First, let the unjust be like other distinguished masters of craft; like the skillful pilot or physician, who knows intuitively his own powers and keeps within their limits, and who, if he fails at any point, is able to recover himself. So let the unjust make his unjust attempts in the right way, and lie hidden if he means to be great in his injustice (he who is found out is nobody): for the highest reach of injustice is: to be deemed just when you are not. Therefore I say that in the perfectly unjust man we must assume the most perfect injustice; there is to be no deduction, but we must allow him, while doing the most unjust acts, to have acquired the greatest reputation for justice. If he have 
taken a false step he must be able to recover himself; he must be one who can speak with effect, if any of his deeds come to light, and who can force his way where force is required his courage and strength, and command of money and friends. And at his side let us place the just man in his nobleness and simplicity, wishing, as Aeschylus says, to be and not to seem good. There must be no seeming, for if he seem to be just he will be honoured and rewarded, and then we shall not know whether he is just for the sake of justice or for the sake of honours and rewards; therefore, let him be clothed in justice only, and have no other covering; and he must be imagined in a state of life the opposite of the former. Let him be the best of men, and let him be thought the worst; then he will have been put to the proof; and we shall see whether he will be affected by the fear of infamy and its consequences. And let him continue thus to the hour of death; being just and seeming to be unjust. When both have reached the uttermost extreme, the one of justice and the other of injustice, let judgment be given which of them is the happier of the two.

And now that we know what they are like there is no difficulty in tracing out the sort of life which awaits either of them. This I will proceed to describe; but as you may think the description a little too coarse, I ask you to suppose, Socrates, that the words which follow are not mine. --Let me put them into the mouths of the eulogists of injustice: They will tell you that the just man who is thought unjust will be scourged, racked, bound --will have his eyes burnt out; and, at last, after suffering every kind of evil, he will be impaled: Then he will understand that he ought to seem only, and not to be, just; the words of Aeschylus may be more truly spoken of the unjust than of the just. For the 
unjust is pursuing a reality; he does not live with a view to appearances --he wants to be really unjust and not to seem only:--

His mind has a soil deep and fertile, out of which spring his prudent counsels. In the first place, he is thought just, and therefore bears rule in the city; he can marry whom he will, and give in marriage to whom he will; also he can trade and deal where he likes, and always to his own advantage, because he has no misgivings about injustice and at every contest, whether in public or private, he gets the better of his antagonists, and gains at their expense, and is rich, and out of his gains he can benefit his friends, and harm his enemies; moreover, he can offer sacrifices, and dedicate gifts to the gods abundantly and magnificently, and can honor the gods or any man whom he wants to honor in a far better style than the just, and therefore he is likely to be dearer than they are to the gods. And thus, Socrates, gods and men are said to unite in making the life of the unjust better than the life of the just.

\section{Questions to Consider Before Class}

- Do you agree with Glaucon's assessment of the way people act?

- Do you agree with Glaucon that it is better to be unjust than just?

- Do you agree with Glaucon that all powers unite to reward injustice more than justice?

- If you agree that Glaucon's arguments hold, does this also mean that you feel this way about all business activities? 
The perspective that Glaucon advocates, that any person who can get away with things that are harmful to others will do just that, and that all human beings will always seek their own advantage in any situation, is called psychological egoism (PE). Psychological egoism is NOT an ethical theory, since it lacks important features necessary for an ethical theory. To use our checklist from Chapter 2, PE does not recognize that humans could possibly do something for the good of others as a motivation, so that means that human beings under PE do not possess full agency. PE uses evidence to decide what is in the actor's best interest, as in step two, but it doesn't judge, as in step three, because humans could not choose any ways other than acting in their own interest. Since there are no options for other kinds of actions, the actors cannot be judged as having acted in good or bad ways; they simply act in the only ways they are able. This theory actually eliminates the ethical aspects of human interactions. Since humans can't choose, their freely taken actions can't be judged, at least, from Glaucon's point of view.

Please recognize that PE contains another distressing feature. If it is true, it is true for all people all of the time. Further, there is no possibility of altruism for the psychological egoist, since all actions are always taken in the actor's own interest. Altruism is an ethical theory that advocates that we should always act in the interest of others while minimizing or ignoring our own interests. There's a rather tricky problem here: When we look at our own human actions, including those in business, it seems like we sometimes do things for ourselves and sometimes for the benefits of others. While we certainly enjoy business write-offs from charitable contributions, what about the times when you've given without getting a receipt? Where's your self interest there? We tend to judge the actions of others 
(and ourselves) as sometimes "selfish." We use this idea of excessive, unthinking application of our own self interest as an example of a bad action precisely because we believe that it's possible to act otherwise.

What if I believe that I could act for the interests of others (against PE), but I feel like the right thing to do is always to act in my own interests (always against altruism)? In this instance, I would be acknowledging that I have freedom to act in any ways I want (condition 1), I could use evidence to decide whether I'm doing a good or a bad thing (condition 2), and I would be making the ethical judgment that the good is what is good for me, and the bad action is the action that is not in my interest. This adjustment to PE, which allows me to choose and allows me to judge actions, is called ethical egoism (EE). Ethical egoism states that the good action is always the action taken in my own self-interest, and the bad action is the action that minimizes or ignores my own best interests in favor of the interests of someone else. While EE is no less oriented toward satisfying individual desires and motives than is PE, EE as a motivation falls into the realm of ethics, as opposed to the realm of behavioral description. Just remember that to accept PE is to accept the idea that everyone, all the time, and for all time, is always interested in satisfying his or her own motives alone. If even one exception to PE exists, then EE becomes the only available option with a similar value structure.

\section{Interdisciplinary Exercises}

1. When you think in an interdisciplinary way, you are bringing in more than one academic point of view on a problem or a set of information. Different disciplines will ap- 
proach the "truth" differently. Which one is right? That's a difficult and problematic judgment to make, which we will discuss elsewhere in this text. The goal of interdisciplinary thinking is to synthesize different points of view together. In the exercise below, which should be written for maximum effect, try as closely as possible to represent the position of the writers you are using to answer the question. In your answer, avoid distorting their positions in any way. When you finally judge the positions by comparing them to the theory of PE, try as closely as possible to see their arguments from their own points of view in order to most accurately determine which advocate PE and which do not.

2. Read some articles or other writings from thinkers in your business discipline. Consider carefully the kinds of actions the writers advocate for members of the business community and individuals in society. Are these thinkers advocating Glaucon's position? Provide a detailed explication of the writings' positions through the lens of psychological or ethical egoism. Bring your analysis to class and role play the position for a group of classmates. Others should ask you questions about your position in order to determine whether you are or are not advocating one of these egoistic positions.

\section{Critical Thinking Vocabulary for Business}

Accuracy (Standard): Accuracy is the recognition of a correspondence between our statements or thoughts and the empirical, verifiable reality of things. When I am accurate, I am being faithful to my understanding of facts and data regarding an issue. In business, a well-considered transaction of any type involves the accurate use of data. 
Business is conducted based upon facts, and those facts require a correspondence to the real world where we live, the world of experience. Accuracy allows us to connect with the experiential world in a way that causes us to make correct assessments of economic value, timely transactions, and allows us to predict and control the consequences of our business actions.

Point of View (Element): Point of View is the position that I naturally take as a thinker. It is at least slightly different for each different thinker. So, if I am in a business meeting, there are at least two different points of view present at the meeting (one for each person present.) Sure, each thinker might be in accord with other thinkers on specific issues, but no one sees the world through exactly the same lens. This is due to personal experience, upbringing, and education, among other factors that make each thinker a unique thinker. In order to succeed in a negotiation, it is often vital that we consider the multiple points of view that are inevitably included in the business situation at hand.

Fairmindedness (Trait): Fairmindedness involves a recognition of the value of other people's points of view and a recognition of the need to accurately represent them in my thinking and for the purposes of understanding actions. While we may disagree with others, we should be careful to be sure we are opposing the actual position, rather than falling prey to our own biases. Each position should be heard and vetted on its merits, no matter who the speaker is or what their background or affiliations. To reject ideas on bias rather than reason is to be narrow-minded, the opposite of fairminded, and a problematic character trait for successful thinking in business. 


\section{Business Ethics Application}

What are the implications for the individual and for the market culture if a corporation or entrepreneur succeeds without scruples?

\section{Bernie Madoff Again?!}

Remember Bernie Madoff from Chapter One? Review the material on Madoff one more time. Did Madoff find the ring of power and wield it like Gyges? If you think so, did he have a choice? Would anyone in Madoff's position have done the same things?

\section{A Timeline of the Madoff Fraud}

Madoff Makes Millions...And It's Legit (February 5, 2013)

Madoff Emails From Jail: I Wish I Hadn’t Pleaded Guilty (February 14, 2013)

\section{Making the Connection}

If you read these accounts of the Bernie Madoff scandal, you are likely left with the idea that Madoff acted for his own interests while being uninterested in any harms he was bringing to others. Students should be able to analogize between Madoff's rise to power and Gyges' rise to power in Plato's Republic. If you were able to make connections from ethical egoism, psychological egoism, and altruism to the Myth of Gyges, and if you are able to see the analogous relationship between Gyges and Madoff, then you can connect the theories from the chapter to Madoff. You should do this in writing before the next class meeting in order to solidify your own ideas about these connections and how they should occur. 


\section{Optional Reading.}

We are not the first thinkers to consider these issues from Plato's Republic. J.R.R. Tolkien (1892-1973) was a classics scholar who read Republic in Greek while at Oxford University. His exploration of the ring of power and various personalities from his fictional Middle Earth can shed a great deal of light upon what we might or might not want to do for personal gain. Read this link for more insight:

The Rings of Tolkien and Plato: Lessons in Power, Choice, and Morality (From: Lord of the Rings and Philosophy: One Book to Rule Them All, By Eric Katz, Open Court Press, 2003)

\section{Find the Ethical Aspect!}

Mine the newspaper! For this assignment, please use a recognized news source. Locate the ethical aspect of some business activity reported in a news source during the week you are discussing this chapter's material. Try to make your story relevant to this chapter's fundamental and powerful concepts. You should look for evidence of any ethical theories from the text thus far. Bring your example to class for discussion. There is one of these exercises in each chapter, so please think about using a hardcopy newspaper for a few of the news research assignments this semester. Be sensitive to the differences you perceive between print versus digital media types; there's even an ethical aspect to that comparison! 
Relation of Some Key Ideas in this Chapter to the Central Question: When is it acceptable to profit from harm to others in business?

- Is it acceptable to harm others if you can definitely get away with it?

- How much power does one person or organization require for "success"?

- Is the avoidance of arbitrary harm an intrinsically valuable good or an instrumentally valuable one? 


\section{CHAPTER 4}

\section{ENRON: A PARADIGM CASE}

Introduction to the Ideas in this Chapter:

Enron was the darling of the financial world for nearly a decade in the 1990s. Its collapse and the accompanying scandal brought into question the rules markets should use, the market's reliance upon gatekeepers, the character of the players in the market, and even what the ultimate goals should be for market activity. At the end of the day, many people became aware that they did not know as much about the security of their finances as they'd thought.

If you have no background regarding Enron, please watch The Smartest Guys in the Room (2005). That will give you enough information to get started. The chapter contains links to news stories about Enron and the fallout from its bankruptcy. This case is set among discussions of Intellectual Traits and various questions to focus your thinking on the Enron affair. At the end of the chapter, you should have some definite opinions on the construction of corporate cultures and when corporations should disclose their problems. 
Fundamental and Powerful Concepts:

\section{Corporate Culture, Disclosure, Conflict of Interest, Whistleblowing}

\section{What is a "Paradigm Case?"}

A "paradigm case" is an example that illustrates some principle in a clear and easily understandable way. When we are trying to discuss business cultures that might create harm to employees and, eventually, to the market at large, a broad range of stakeholders, and its own shareholders, the Enron bankruptcy comes up as a clear and understandable case. In this chapter, I expect students to watch the documentary film and review the links for the two books mentioned in the paragraph below. At that point, even if you've never heard of Enron, you'll have enough information to consider the ethics of the situation. There is also a fine archive of Enron-related media at the Houston Chronicle's website. For those very interested, other good sources may be found online and in libraries.

The documentary film at the core of this chapter, The Smartest Guys in the Room, is based primarily upon two books. One is called $\underline{\text { Power Failure }}$ and the other shares its name with the film, The Smartest Guys in the Room. If you are taking this class for credit, or if you hope to get the ethical implications of the example, I recommend that you watch the film through a service (like Netflix) that will pay those involved in the film for their efforts. Do this in addition to watching information at the links below and reading the material behind others. Several questions will occur to you while you watch the film. Some will relate to agency, some to responsibility, yet others to honesty, and several of 
you will have questions about greed. One goal I want you to have is to try to figure out the following:

1. If anyone did anything wrong.

2. Exactly what they did wrong.

3. Why you think it's wrong.

4. Whether any harms that resulted from those wrong actions were acceptable.

When we are trying to do any applied ethics, like business ethics, it's important that we try to think about what the purpose might be for thinking in this way. What's the value of considering the ethical aspects of business when we could consider the financial or managerial aspects, for example? In any defensible business activity, part of the purpose has to be deciding what sorts of behaviors are acceptable and which are not. Is the correct action the one that considers the outcomes? Is the correct action the one that follows inflexible rules? Is the correct action the one that creates the most wealth? Is the correct action the one that results in the least harm? While there are many ways of arriving at rules for behavior, one other way is to think about the kind of people we want to create, ourselves included. Thinkers have recognized that our beliefs lead to our actions for centuries. So, do we want to advocate rules that lead to us performing actions that will cause harm, particularly in the name of profit?

Information about Enron:

Enron Timeline

Behind the Enron Scandal 


\section{Enron Creditors Recovery Corp}

\section{Questions to Consider}

- Do you think the Enron bankruptcy can be pinned on one person? If so, who and why?

- Can you identify the ethical motivation of any of the players in the Enron scandal?

- Is it possible to gain success in the business world and feel ashamed over the way to you gained that success?

- Would anything have changed at Enron without the whistleblower?

\section{Legislative Responses to Enron}

The US Congress responded to the Enron bankruptcy and other corporate scandals of the time by passing the Sarbanes-Oxley legislation in 2002.

$\underline{\text { A Guide To The Sarbanes-Oxley Act }}$

Sarbanes-Oxley Act of 2002 (US.GOV)

Sarbanes-Oxley: 10 Years Later: Boards Are Still the Problem

\section{Another View: Sarbanes-Oxley and the Legacy of Enron}

What do you think about the corporate culture Enron created? Should it be modeled by other companies? Enron's former president, Jeff Skilling, has recently struck a deal with prosecutors. Has he been punished enough? Should he have been punished at all? Enron's Skilling Strikes Deal for Shorter Sentence 


\section{Questions to Consider}

- Did Lou Pai do anything wrong, as it relates to the bankruptcy?

- Did Rebekah Mark do anything wrong with the Dabhol power plant deal?

- Was it ultimately a mistake to create a commodity market in natural gas?

- Were California's consumers harmed in any way that could be judged as "wrong?"

- Is there good evidence that any Enron executives demonstrated Intellectual Courage?

- If you watched the movie, were the filmmakers in any way unfair to Enron's executives?

Many people would argue that Enron should have disclosed at various earlier points. Do you agree? If so, when should it have disclosed its problems? Explain your answer.

\section{Greed as a Concept}

Watch this short video clip from an interview with Milton Friedman, whom we see more from in upcoming chapters:

\section{Milton Friedman on Donahue - Greed}

How does your view of our market economy and capitalist culture correspond with Friedman's position?

\section{Critical Thinking Vocabulary and Application}

As an in-class exercise, pick one character from the Enron story. Write down what the most important concept is for you understanding that person. Create a concept map of 
his or her character, starting with the central concept and expanding outward through additional business ethics concepts and critical thinking vocabulary. You should make some notes about how you are moving from concept to concept in your map. After you get ten concepts, explain your concept map to someone else, paying particular attention to the connections between concepts. Once you are both finished explaining your concept map, help one another expand, taking turns discussing ways to add one concept at a time to the other person's map until you are unable to continue. Did you gain any insight into the motivations of your Enron personality? How useful is this technique for gaining understanding of your Enron character's business ethics motivation?

\section{Find the Ethical Aspect!}

Mine the newspaper! For this assignment, please use a recognized news source. Locate the ethical aspect of some business activity reported in a news source during the week you are discussing this chapter's material. Try to make your story relevant to this chapter's fundamental and powerful concepts. You should look for evidence of any ethical theories from the text thus far. Bring your example to class for discussion. There is one of these exercises in each chapter, so please think about using a hardcopy newspaper for a few of the news research assignments this semester. Be sensitive to the differences you perceive between print versus digital media types; there's even an ethical aspect to that comparison! 
Relation of Some Key Ideas in this Chapter to the Central Question: When is it acceptable to profit from harm to others in business?

- Is it possible to do the wrong thing if you get rich in the process of doing it?

- Should concern over corporations harming others extend to shareholders?

- Is creating any harm ever so severe that it justifies suicide, even if you didn't know you were doing the wrong thing at the time? 


\section{CHAPTER 5}

\section{SHAREHOLDER THEORY}

Introduction to the Ideas in this Chapter:

This chapter explores Shareholder Theory as presented by Milton Friedman. The theory is demonstrated as an ethical theory, and it is currently the gold standard for ethics in free market societies. I then offer criticism of Friedman's theory, from myself and from other sources. This criticism is meant to upset the idea that we can rely upon Friedman's Shareholder Theory for our understanding of what is the right thing to do in business.

The chapter contains many relevant questions that will help you explore your own position on Friedman's Shareholder Theory. There are a couple of linked readings to scholarly articles, a little critical thinking vocabulary to consider, several community engagement exercises, and connections back to the central question.

Fundamental and Powerful Concepts:

Shareholders, Stakeholders, Corporate Social Responsibility, Valuing 


\section{The Free Market}

The free market, wherever we find it, is dominated by the owners of business entities and their agents. The dominant business ethics approach today, as indicated in countless corporate mission statements and corporate agendas, is most fully stated and elaborated upon by the late Milton Friedman, Nobel Laureate, friend and advisor to President Ronald Reagan, and an anchor scholar at the world-renowned Chicago School of Economics for decades. Friedman's theory, often referred to as "The Neo-Classical Model of Corporate Social Responsibility," is more commonly known as Shareholder Theory.

For the purposes of this course in business ethics, this theory will be considered the most common motivation for business ethics. It is a central job of the student taking this business ethics course to challenge this initial assertion and determine whether it is accurate based upon available evidence. Much of the evidence provided in this text seeks to support the idea that this is the most common capitalist motivation, and so, as the gold standard in our culture, it deserves critique and challenge. It is the job of the student to provide alternate evidence if this (or any) assertion in the text is suspected as being problematic. If the text does not provide adequate evidence for an assertion, you should email the author at brian.barnes@louisville.edu. Please put the word "textbook" in the subject line, and please cite the quote and page number in your question; apologies in advance if replies are not quick. 


\section{Friedman's Ethical Model}

In class, I like to articulate shareholder theory, derived from Friedman, in this way:

"The only ethical duty of any agent of the owners of a corporation is to make money for shareholders within the limits of the law or the ethical custom." You will not find that exact quote in the text below, but it is based upon the following three quotes from that text. In the classroom conversations and writing prompts that follow, these three quotes heavily support the author's contention that this is the most dominant business ethics theory used in free market societies today, and that it leaves much to be desired as an ethics theory.

"There is one and only one social responsibility of business-to use its resources and engage in activities designed to increase its profits so long as it stays within the rules of the game, which is to say, engages in open and free competition without deception or fraud."

"In a free-enterprise, private-property system, a corporate executive is an employee of the owners of the business. He has direct responsibility to his employers. That responsibility is to conduct the business in accordance with their desires, which generally will be to make as much money as possible while conforming to the basic rules of the society, both those embodied in law and those embodied in ethical custom."

"The key point is that, in his capacity as a corporate executive, the manager is the agent of the individuals who own the corporation... and his primary responsibility is to them." 
(From The New York Times, September 13, 1970. (C) 1970 The New York Times. All rights reserved. Used by permission and protected by the Copyright Laws of the United States. The printing, copying, redistribution, or retransmission of this Content without express written permission is prohibited.)

Note that Friedman's Shareholder Theory meets the three criteria for an ethical theory from earlier in this text. Friedman believes that:

1. People choose their own actions freely

2. He offers evidence for why this theory should be adopted, and

3. He articulates what is good (making money for owners within the rules) and what is bad (using the owners' money in ways not in line with the principles of capitalist entrepreneurship.)

So, business actions in this course can be explained using Shareholder Theory as the ethical theory.

Please take a little time to read the document at the following link. It is Milton Friedman's 1970 New York Times Review article from which the above three quotes were taken.

$\underline{\text { The Social Responsibility of Business is to Increase Its Profits }}$

Many of these ideas and others are provided in Friedman's classic Capitalism and Freedom, published in 1962. Chapter eight is directly relevant to the topic of social responsibility of business and echoes the linked article above. 
Please write Friedman's ethical theory in your own words. Create no more than three sentences, and don't use any examples.

The criticisms of Friedman's theory are easily located in scholarly journals and business media. This chapter doesn't attempt to examine every criticism. I merely want to point out that there are alternate points of view on this issue that should be considered carefully, since they raise significant difficulties with Friedman's theory. Before we move into readings about three alternative theories, I will suggest my own criticism.

Friedman's theory suggests that we should pursue profit for shareholders within the limits of 1) the law and 2) the ethical custom. These limitations are based in the culture of a place and time, and so they are not absolute; Friedman suggests that they are flexible to the degree that cultures reflect different laws and ethical customs from one another. The two limitations provide a check upon one another, as well. The law becomes the first check, but if the law fails to support what is commonly held as morally acceptable by the people in a particular time and place, the second criterion of an ethical custom comes in play, keeping the businessperson from acting in a way that would violate the unwritten rules of societal norms, keeping the unwary public from harm.

The problem with this approach is that our society has undermined it. It is not the case in today's business world that the ethical custom serves as a check upon the legal standard. When the legal standard is lacking, the ethical custom that's supposed to slip into place is the standard for the society. The standard for western, free market societies is Milton Friedman's standard. So, if the law is inadequate, how does Friedman's standard 
help us do the right thing and avoid unnecessary harms? There seem to be two approaches to answering this question.

\section{Approach 1}

When we go to the free market's ethical gold standard, we find that it asks us to put owner profits above all other considerations of business actions, even harms. The only two checks to these harms is the law, which limits many externalities, and our cultural ethical gold standard for business, which says that the right thing to do is to put profits before any other considerations (within the law).

However, this approach fails to provide a meaningful limitation on corporate action to prevent unnecessary harms to the public interest. We must acknowledge that not all harms are covered by the legal standard. Sometimes, particularly in cases of pollution and civil rights, the law has lagged behind the publically-recognized "right thing to do." But, as long as profit is being pursued, corporations can do whatever they want that doesn't break the law. So, the law becomes the standard. If the law doesn't cover the harm, the industry is free to harm legally, so that's unhelpful for preventing harm. Also, to the extent that the law is often collaborated upon by industry insiders and lobbyists that are paid to represent the interests of industry owners, not to mention the various soft and hard money approaches that corporations and their representatives take toward campaign finance and political control, the extent to which the law actually protects the public interest from externalities should be seriously evaluated and taken into account. 
So, if the problem falls outside the law, then we go back to the ethical custom. But if Friedman's standard is the ethical custom, we are just kicked back to the right thing to do being to make money for owners within the limits of the law... or the ethical custom... which is to make money within the limits of the law... so, we should make money within the limits of the law. Period. If the harm is not already covered by some law, then this approach to applying Friedman's standard is only an economic highjack of ethics and a loophole to ignore harms in favor of profits.

Now, paraphrase the criticism from Approach 1 in your own words.

\section{Approach 2}

We are still considering the idea that ethical business takes place within the limits of the law or the ethical custom. Our understanding of the law from Approach 1 has not changed. What about considering the ethical custom without Friedman's winning position of holding the ethical gold standard for our society? What if we make the ethics unrelated to Friedman's theory, but rather have them in line with the common practices of society? These might include, don't lie, don't cheat, don't steal, etc. Would we then find Friedman's ethical position useful in preventing harms? After all, society doesn't want people, including its corporate citizens, doing those things.

If society doesn't want people and corporations doing things that lead to the harming of others in society, then it would prohibit them by law or custom. This is Friedman's position. Everything else should be acceptable. The law is a punisher of those who do wrong. But, ethical custom also punishes the wrongdoer by making a pronouncement that 
the action in question should not be done. There are often cultural sanctions to go along with this idea of the action in question being wrong, even though the law does not currently prohibit it. So, in our culture, what is the common reaction to wrongdoing on the part of business entities?

In our culture, we support a "do the harm, pay the fine, repeat as needed" approach. We can clearly see this in the legal areas, where companies commonly break the law, are fined, and then commit the same crimes in the future, often for years on end, even hiring legal counsel and accountants to work on anticipated future fines. This action is supported by culture, as there is little obvious interest in changing the system. When there is not a law in place, the cultural norm seems to say that companies can ignore any position that is not legally-protected. So, the commonly accepted action becomes the cultural norm:

1. Do the harm if it will profit you

2. Pay the fine if it becomes an issue

3. Build future fines into your bottom line if it is profitable to continue the behavior

4. Continue the behavior until absolutely prohibited by law, at which time you might be able to continue your operation in another market with less regulation

This approach does not make any effort to avoid harms.

So, by Approach 1 and Approach 2, Friedman's model for ethics fails to provide any meaningful ethical limits for business actors, failing to help us know how to do the right thing and avoid unnecessary harms. It even short-circuits legal limits by supporting harmful behavior that is sanctioned by cultural lethargy. This analysis, and others in this chap- 
ter, indicate why we need a different approach to business ethics than the dominant Shareholder Theory.

\section{Wilcke's Ethical Model}

Dr. Richard Wilcke is a professor in the University of Louisville's College of Business. He knew Milton Friedman personally and has hosted Friedman at his home for dinner. Wilcke wrote an article critiquing Friedman's version of the Shareholder Theory:

An Appropriate Ethical Model for Business, and a Critique of Milton Friedman's $\underline{\text { Thesis }}$

In the article, Wilcke is not only critical of Friedman's CSR, he is also particularly concerned about the greenwashing effect that occurs in contemporary markets when companies adopt policies of CSR toward environmental issues.

\section{Questions}

1. What are Wilcke's main criticisms of Friedman? Do you agree or disagree with Wilcke? Explain your answer.

2. Do you believe that Wilcke's solution of focusing on customers over shareholders will improve the ethics of the business community?

3. What is Wilcke's specific critique of Friedman's focus on shareholders?

\section{Stakeholder Theories}

One alternative idea to consider is what is often called Stakeholder Theory. In stakeholder theory, there are multiple groups or issues that the organization values, and those 
groups or issues are given priority over profit. Friedman finds this approach to be problematic for long-term profitability and solvency of the corporation. Check out some of the distinctions in this piece by Elizabeth Redman:

\section{Three Models of Corporate Social Responsibility: Implications for Public Policy}

An alternate way to value stakeholders that seeks parity with profit is the triple bottom line. This idea ties directly into sustainability theory, which is highlighted in another chapter. There is a nice introduction to it here:

\section{Triple Bottom Line: It Consists of Three Ps: Profit, People and Planet}

\section{Questions to Consider Before Class}

What's the right way to view corporate social responsibility? Why?

\section{Critical Thinking Vocabulary and Application}

Intellectual Courage (Trait) (opposite is Intellectual Cowardice)--Having a consciousness of the need to face and fairly address ideas, beliefs or viewpoints toward which we have strong negative emotions and to which we have not given a serious hearing. This courage is connected with the recognition that ideas considered dangerous or absurd are sometimes rationally justified (in whole or in part) and that conclusions and beliefs inculcated in us are sometimes false or misleading. To determine for ourselves which is which, we must not passively and uncritically "accept" what we have "learned." Intellectual courage comes into play here, because inevitably we will come to see some truth in some ideas considered dangerous and absurd, and distortion or falsity in some ideas strongly held in our social group. We need courage to be true to our own thinking 
in such circumstances. The penalties for nonconformity can be severe. When we are at work, we have opportunities to explore new ideas. We might be encouraged to explore an alternate point of view on office politics, we might need to think about a competitor's approach, or we might need to consider scary ideas, like layoffs or bankruptcy. Intellectual courage is the habit that good thinkers use to consider those scary, absurd, or emotionally-charged ideas. Without it as a habit, we could reject some potentiallygood ideas without any serious consideration.

\section{Community Engagement Exercise}

Make appointments to ask managers of businesses in your town about their business's ethical stance. If the business or industry creates obvious harms, describe them for the manager in that industry and ask him or her to explain the justification for these harms. If there is no clear articulation of an ethical principle from your interviewee, share Friedman's shareholder theory with him or her and ask him or her to respond with how closely Friedman's theory represents the basic approach of the manager's company. Report on your interview to your classmates orally or on a blog.

\section{Find the Ethical Aspect!}

Mine the newspaper! For this assignment, please use a recognized news source. Locate the ethical aspect of some business activity reported in a news source during the week you are discussing this chapter's material. Try to make your story relevant to this chapter's fundamental and powerful concepts. You should look for evidence of any ethical theories from the text thus far. Bring your example to class for discussion. There is 
one of these exercises in each chapter, so please think about using a hardcopy newspaper for a few of the news research assignments this semester. Be sensitive to the differences you perceive between print versus digital media types; there's even an ethical aspect to that comparison!

Relation of Some Key Ideas in this Chapter to the Central Question: When is it acceptable to profit from harm to others in business?

- Are the interests of the owners of a company the most important interests to consider when making ethical decisions for business?

- When is it obviously okay to profit from harm? Provide examples.

- How much would you have to profit to be involved in serious harm to another person? 


\section{CHAPTER 6}

\section{CONTRACTARIANISMS}

Introduction to the Ideas in this Chapter:

This chapter introduces three important thinkers concerned with our rights and responsibilities as citizens and as human beings. Each of them is very concerned with how human beings should decide to come together into social groups. How are rules decided? What are the best practices, and what have been the realities, of human beings coming together in groups to form society? What implications can these choices have for markets?

First, I alter my tool for identifying an ethical theory so that it can work for identifying a political theory. There is some discussion of why political theories should matter for business ethics. The text then jumps into some brief contextualizations of the political and ethical thinking of Thomas Hobbes, John Locke, and John Rawls for business ethics concerns; there are also links to follow that give more detail about these three for your work away from class. Following this information there are plenty of questions, an interdisciplinary exercise, a little critical thinking, and a few questions to help us tie ideas about contractarianism to the central question. 
Fundamental and Powerful Concepts:

\section{Social Contract, Citizenship}

Business Ethics: A Web of Relationships

Business Ethics always involves relationships between individuals and governments, since individuals reading this book with the intention of applying it to commercial relationships are most often living within an environment dominated by governments. In other words, modern human beings are always and already political beings, wherever and whenever we find ourselves. It is possible that a businessperson will find him or herself in an environment without governmental oversight, but that rare and dangerous environment will be notable for its lack of governance. Also notable is the ubiquity of underground or informal markets alongside government-sanctioned ones.

Businesspeople always conduct business within a context of rules put together by governments. We cannot escape the political aspects of our decisions in these contexts any more than we can escape their ethical aspects, though our individual political actions often seem to have less immediate impact than our ethical ones. It is important for business ethics that students learn to recognize and use evidence to explain their relationship with governments. In the same way, we should recognize and use evidence to construct our relationships with others. To that end, I re-introduce my three-part system for identifying an ethics issue.

\section{Checklist for an Ethical Theory}

1. Does the theory allow a person to act freely? (agency) 
2. Does the theory use a process of evidence to build a correspondence between the appropriate use of the theory and the situation at hand? (evidence)

3. Does the theory make a judgment about what is "good" or "bad" in the situation? (judgment)

In this chapter, I alter that system to be used for political structures. Just like we need to think critically about our relationships with corporations, other people, and our world through ethical thinking, we also need to think about our relationships with governments through political thinking. Remember, without governments, there are no markets with any rules to streamline trade and protect both players and public from market actions that may externalize risk or harm to those unprepared to deal with it. If you truly believe that a Wild West-style market with exchange value governing all is the best way to go, then maybe this chapter will be uninteresting for you. I am asking that you consider important differences in political and ethical thinking for yourself, however, since it will both broaden your thinking about value and responsibility greatly, but also because you will most likely continue to live most of your life, and conduct most of your business, surrounded by a governmental context. So, please consider the following modifications.

\section{Does the theory allow a person to act freely? (agency)}

Number one remains the same in nearly every case. Both political systems in which free markets prevail and our own understandings of the world at large demonstrate that we are free actors, capable of directing our own lives and making our own choices. So, a political system that recognizes the agency of its citizens will be an appropriate system 
upon which to found an evidenced-based understanding of the relationship between individuals and their governments. Capitalist markets seem to require that governments treat their citizens as free actors.

2. Does the theory use a process of evidence to build a correspondence between the appropriate use of the theory and the situation at hand? (evidence)

Again, condition two is exactly the same. Markets and governments, if they are free in terms of business dealings and commercial relationships, must use evidence. The stock markets around the world use evidence to make predictions and establish positions. No one owns a piece of a company merely because he or she wants to, and not even if he or she has always owned a piece of that company. What matters is evidence, however that presents itself; a good theory of the relationship between government and its citizens, like the relationships between those citizens themselves, must be founded upon the information.

3. Does the theory make a judgment about what is a "good" relationship or a "bad" relationship between individuals and governments? (political judgment)

The important distinction here is that the theory should define what is good or bad for a relationship between government and governed. In this text and in my course, I offer only three theories of contractarianism, each with a very narrow perspective on what the relationship between government and governed should be. This is because of time constraints, and because I am trying to get students to think about their own roles and how the government should interact with their lives, not just to learn more theories for memo- 
rization. For each of these, there is a judgment about what the correct relationship is between humans and the government, between humans in society, and what the various rights, duties, and mechanisms of political life should entail for the individuals living it.

\section{Three Political Theories}

The three political theory options I am presenting are the social contractarianisms (SC) of Thomas Hobbes (1588-1679), John Locke (1632-1704), and John Rawls (1921-2002). I use these three to accomplish specific tasks in training thinkers about business ethics. Once students can accomplish these specific intellectual moves for these thinkers, they can translate those skills to other intellectual areas, strengthening students' ability to use theory generally. Each of these thinkers has broad theories that relate to a variety of philosophical issues. For each thinker, I will only be borrowing a small number of ideas, somewhat separated from their context in this text. You should follow the links in the paragraphs below for more information about each thinker and for the integration of their theories into your information about how to do business ethics, which is important to our purpose.

First, Thomas Hobbes's SC theory is based upon the idea that people always act in their own interests, what was labeled earlier as "psychological egoism." This is an expansion of the ideas presented in The Myth of Gyges. So, there is some continuity for the student who wants to think about how a highly individualistic ethical theory, like ethical egoism, might translate into a political theory focused upon individual benefits, like Hobbes's SC. 
Secondly, John Locke's SC theory is based, in large part, upon the SC theory of Hobbes. So, students can appreciate the continuity between the two thinkers and the distinctions that arise as Locke attempts to develop aspects of Hobbes' ideas and expand them into different directions. Locke is convinced that human beings can cooperate for the good of the group, potentially subverting ethical or psychological egoism.

Third, Rawls is reacting against both Hobbes and Locke. He wants citizens to think about the social contract in a completely different way, and he wants to criticize his predecessors' approaches while doing so. In this way, students can begin to think about their governments not only in the mold of the thinkers that shaped the important thinkers for the American project, but also in ways that are counter to the ways they've been thinking about governments all of their lives. It is my hope that readers will learn to truly think about governments and the roles of citizens for themselves as a result of this exercise. Since the US government is so oriented toward commercial relationships and successes, it is important that American readers think about the importance of why the rules and relationships that govern our lives are in place... and whether they should continue to be.

\section{Hobbesian Social Contractarianism:}

Read the link about Hobbes here:

\section{Hobbes's Moral and Political Philosophy}

Hobbes believed that human beings had joined together in groups primarily out of fear. Life in Hobbes' state of nature, prior to the social contract, was hard and dangerous, and human beings lived in fear of a violent death. Hobbes believed that, at some point in 
history, humans decided to come together into groups for mutual defense. They used a rational approach to determine the rules for these societies, which involved the giving up of some natural rights, like the right to take anything a person wanted, in exchange for some measure of safety. Hobbes felt like there should be an absolutely powerful leader, chosen from among the people, who could punish anyone who broke the social contract by harming others. Hobbes thought the power of this monarch should include capital punishment. Under Hobbesian SC, the rules of society limit behavior. Rational, self-interested individuals seeking their own advantage, which Hobbes thinks describes everyone, will always be looking for loopholes in the law to gain greater benefit for themselves. As long as a harm is not covered by the rules, the rational, self-interested actor can hardly be blamed for taking advantage of this kind of failure of government to protect the public.

So, Hobbesian SC creates certain relationships and a particular set of rules for society and the markets that operate within them.

\section{Questions to Consider Before Class}

- What is the relationship between governments and citizens for Hobbes?

- How might corporate actors fit into such a scenario?

- What are the implications for business ethics if we agree with Hobbes's position on how human beings behave?

- Can you think of market examples that support Hobbes's view?

-What are some other important questions that Hobbes's position raises in your mind? 


\section{Lockean Social Contractarianism}

John Locke updates Hobbes's position. He agrees with the historical state of nature and the fact that humans enter the social contract of their own free will, but he also considers that there is cooperation on the part of humans to come together and form society, much moreso than humans coming together over fear of a violent death. Locke also believes that God is quite strongly in play and that many of our natural rights are wrapped up in His will for us. You can read more about Locke's full position here:

John Locke: The Social Contract Theory (see especially sections 4.3 and 4.4).

Locke is also more explicit about rights and duties than Hobbes. Human beings have the natural rights to their own life, liberty, and some measure of property. We have liberty until it infringes upon another's liberty without good reasons, or until it would result in us giving up our own life or liberty, which is typically not acceptable for Locke. We can also mix our own labor with natural resources to end up with a property right, but Locke insists that we don't really own that property. We are stewards of that property for God, and, as such, we don't have a right beyond the claims of our own needs and the necessity of resource balance in society. The result of this idea, for Locke, is that we are unable to hoard property; we must leave "as much and as good" for others who would like a similar property right to ours. Labor rights, for Locke, are not absolute. The central ideas of cooperation and stewardship create different implications for a business ethics environment under the Lockean social contract than what we may have noticed under Hobbes. 
Locke also thinks that governments have important powers that can trump the liberty and the right to life for individuals.

\section{Questions to Consider Before Class}

1. Do you think governments should have such rights, like the right to force citizens to defend it during wartime, risking their own lives in the process?

2. Do you think citizens interact with governments as Locke describes?

3. Do you believe that you have "natural rights"?

4. If so, what are they? Are they limited?

5. Did Locke get his ideas of rights right?

6. What are the implications of Locke's position for taxation? How about imminent domain?

\section{Rawlsian Social Contractarianism}

John Rawls thinks that the entire social contractarian tradition, building heavily off of Hobbes and Locke, is deeply flawed. If the goal is justice-as-fairness, Rawls suggests, then we have to find ways of including everyone in society, not just those who are privileged enough to find themselves born into the wealthier, more educated classes. Government, particularly democracy, is supposed to be for everyone, but the rules that dominate democracy are always made, Rawls points out, by those who are in charge of society--the wealthy, the educated, the men, etc. These are always the people in the room when documents are created. Rawls thinks that, no matter how well-intentioned these men have 
been throughout history, their documents were created with biases against certain sectors of society in favor of others. Mainly, the biases were created to perpetuate power in the control of those who were like the people who had power at the time the rules were being made. Rawls thinks that these biases, which result in varying levels of power, are unavoidable and hidden from most of us. If we truly want justice-as-fairness in society, we need to overcome these limitations.

Rawls thinks that the way to build fairness into society is by starting at a fair place. His suggestion is hypothetical, and it creates a set of thinkers operating without complete knowledge of themselves. These thinkers are operating in "the original position," free from bias, behind "a veil of ignorance," which is to say that they know nothing of their own gender, age, race, sexual orientation, economic status, or other personal indicators that would lead to biased rulemaking in favor of them and people like them. In order to facilitate their job, the deciders would know basic things about ethics, politics, governance, economics, physics, and the other large bodies of knowledge within society. These deciders know that they will be thrust back into the diverse society from which they came after their rules are created, so Rawls thinks each person will arrive at rules that will be fair to everyone, since the deciders don't know what their personal interests actually are. It's an impractical solution, for sure, but it should eliminate the kinds of bias Rawls is concerned with. Since we can't actually have a Rawlsian veil of ignorance, however, we can only pursue Rawls's suggestions by engaging in a thought experiment about what a truly just society might look like. 
Rawls thinks that such a society only has a few rules. Read the information behind the link to learn more about his process and the expected outcomes for this new kind of social contract:

John Rawls: A Theory of Justice

\section{Questions to Consider Before Class}

1. What is the foundational idea for people living in society with others?

2. Do you agree with any of the three theorists in this section regarding any particular points?

3. Which human characteristics are most important for successful living with others?

4. Do any of the motivations in this chapter for entering into social contracts seem correct in light of the fact that you have probably never signed such a contract?

\section{Interdisciplinary Exercise}

Find an example of some aspect of Hobbes's political thought in some recent piece of media. In a short essay, discuss the aspects of correspondence between Hobbes's theory and the real world case. Then, discuss the ways the case would have to be different to support Locke's thinking. Identify meaningful differences. If you're feeling particularly interested in this topic, explore how the foundational concepts of society would have to change to accommodate a Rawlsian understanding of social contract. How would those changes affect the real world case you've been considering in this exercise? 


\section{Critical Thinking Vocabulary and Application}

Implications (Element)--When we trace the reasoning in our thinking to its logical outcome, we are identifying the implications of that thinking. Implications are the rational and foreseeable end points of our thinking on any issue. We often consider implications when we are concerned about the consequences of our thinking. In this chapter, implications of one theory of social contract lead to different ways of thinking about citizenship and the role of governments for everyone in society. Implications manifest in the real world as consequences, so we should keep that in mind, especially when we know that the consequences are not for the individual thinker alone. We should also remember that one of the implications of reasoning about social issues is that we create beliefs that will be acted upon when conditions are right.

\section{Discussion Questions}

- How do each of the three theories relate to the necessary parts of a political theory, as presented at the beginning of the chapter?

- What role does agency play in each of the three theories?

- Which aspect of each thinker's ideas is relevant to business ethics? How?

- What are the important differences between Hobbes's and Locke's thought on issues relevant to business ethics?

- Does Rawls succeed in improving upon Hobbes's and Locke's version of the social contract? 
Find the Ethical Aspect!

Mine the newspaper! For this assignment, please use a recognized news source. Locate the ethical aspect of some business activity reported in a news source during the week you are discussing this chapter's material. Try to make your story relevant to this chapter's fundamental and powerful concepts. You should look for evidence of any ethical theories from the text thus far. Bring your example to class for discussion. There is one of these exercises in each chapter, so please think about using a hardcopy newspaper for a few of the news research assignments this semester. Be sensitive to the differences you perceive between print versus digital media types; there's even an ethical aspect to that comparison!

Relation of some key ideas in this chapter to the central question: When is it acceptable to profit from harm to others in business?

- Does the government have the right to harm citizens of its own country if that harm increases profit for domestic businesses?

- Does the government have the right to harm citizens of other countries if that harm increases profit for domestic businesses?

- Do individuals have rights that governments cannot remove? If so, what are they? If not, why not? 


\section{CHAPTER 7 \\ UTILITARIAN AND DEONTOLOGICAL THINKING \\ ABOUT BUSINESS ETHICS}

Introduction to the Ideas in this Chapter:

This chapter introduces two types of ethical thinking that have been powerful in the western intellectual tradition: utilitarianism and deontology. Each of these theories provides us with a different way to approach what is good and bad or right and wrong. I present several utilitarian thinkers, mainly focusing upon the points in their thinking that are directly relevant to business ethics. There are certainly other applications. When we get to deontology, the same approach is taken. Follow the links for all thinkers to get more information about their ideas and more ability to flexibly apply their theories. The chapter also contains lots of questions, an interdisciplinary exercise, a critical thinking connection, and some questions relevant to the central question. Finally, there is a bonus essay from Michael Sandel at Harvard University. 
Fundamental and Powerful Concepts:

\section{Utility, Duty, Dignity}

\section{Bentham's Utilitarianism}

In the first part of this chapter, I'm trying to display utilitarian thinking in its diversity and show how this approach might be useful for business ethics. Jeremy Bentham [17481832] is the father of utilitarianism. The word utility refers to the benefit that will come to a person from some activity. For some 18th century thinkers who use this word in the same way Bentham does, like Adam Smith, for example, the utility, or benefit, from an action was not measured with only financial metrics. People want lots of things including, sometimes, utility for others, for the group at large, or for non-human stakeholders like the environment or other animal species.

For Bentham, the way to value utility was by reference to the two natural foundations for all of our behavior, pursuing pleasure and avoiding pain. Bentham thought that all of our action was motivated by the amount of pleasure and pain that would be brought to ourselves or other sentient creatures affected by the action. Bentham thought that we could make a determination about these actions by reference to a mathematical formula, explained in detail in this video: Philosophy Core Concepts: Bentham, The Hedonic Cal$\underline{\text { culus }}$

One of the important thinkers Bentham leaned upon was the ancient Greek, Epicurus (341-270 BCE). Epicurus made some important distinctions between simple pleasureseeking (hedonism) and what Bentham conceived as the core of utilitarian thought. Epi- 
curus's "Letter to Menoeceus" contains much of his thinking on this matter. Epicurus thought that correct human action and thinking goes beyond merely focusing on the short-term consequences, and he also put together the idea that goods are not fixed in their value, but that the value of various things called "good" varies with culture and use.

For our study, we are wondering if good things in business might be measured by pleasure and pain in the ways that Bentham suggests. The study of business ethics suggests different ways of valuing what is right and what is wrong. Students should decide if they think, with the utilitarians, that the right way to value things in business is to value them along the lines of the greatest utility, what is commonly referred to as "the greatest good for the greatest number." When we make decisions in business with reference to the ethical aspect, should our ethical valuing be along the lines of producing the most pleasure and avoiding the most pain for the greatest number of stakeholders? Note that utility is defined by Bentham as being greater than merely the economic aspects of the situation. Note, also that utilitarian business ethics reasoning goes beyond the interests of shareholders alone. For Bentham and other utilitarians, we must consider the interests of all rational, free, utility-seeking creatures for the problem we're considering. Thus, ethical egoism and utilitarian reasoning are incompatible. Since utilitarianism thinks people can legitimately choose in the interests of others, it is likewise incompatible with psychological egoism. Also, since utilitarian reasoning considers the interests of all stakeholders equally, it is incompatible with strict altruism. 


\section{Questions to consider before class}

- Do you think interests other than those of investors should be considered in business decision making? What should those interests be?

- Do you think the economic aspects are the only aspects that should be considered for "good" business decisions?

- Can business be profitable and still strive for the greatest good for the greatest number of stakeholders?

\section{Other Utilitarians}

For some thinkers, utilitarian approaches are reasonable, but the strict mathematical nature of the hedonic calculus fails to represent, for them, the way human beings live their lives and make decisions. John Stuart Mill (1806-1873), another famous utilitarian, is one of these thinkers. (You can see an annotated selection of Mill's thought in this PDF: Mill: Utilitarianism, Ch. 2) He made a few updates to Bentham's utilitarianism that many may find compelling. Information concerning Mill's utilitarian approach and how it reflects Bentham's approach are here: Utilitarianism: Bentham \& Mill. One of the things that Mill suggests is that there are certain pleasures which will always be qualitatively better than other pleasures. Do you agree with this statement, based upon your own experience? How can you apply some of the ideas you've read from Mill to your understanding of utilitarian thinking for business ethics? Be prepared to discuss these with a group.

Negative Utilitarianism is a compelling update to classical utilitarian thought that avoids the problem of justice often leveled at Bentham. In a move that would make a 
buddha proud, this theory promotes alleviation of suffering over maximization of pleasure. So, it flips the basic utilitarian principle of promoting the greatest good first. Or, if you like, it determines that the greatest good for humans is the alleviation of suffering. You can find out what you think about Karl Popper's (1902-1994) reasoning on this theory by reading $\underline{\text { Karl Popper and Negative Utilitarianism. }}$

1. In what ways do you consider the alleviation of suffering, as a particular human good, to be an appropriate goal for business?

2. If you find it inappropriate, what would have to change to make it more useful as an idea for business ethics?

3. What would a cost-benefit analysis look like if it was created from Popper's negative utilitarian point of view?

For a utilitarian approach to non-human species, consider a brief introduction to the thought of Peter Singer (b.1946) in Greg Neale's article "Peter Singer: Monkey Business." More relevant material by Singer is available online. If you are beginning to think about the use of non-human animals in commerce, utilitarian thought is a nice place to start. You could find your own sources for animal activism or for ending testing or commercial uses of animals on the Internet. Do some research and bring to the class your understandings of where some utilitarian logic and the logic of these animal activists overlap. 


\section{Deontology}

The ethics work of Immanuel Kant (1724-1804) is called "deontological theory." With a name based upon Greek roots for the study of duty, deontology is linked to the notion that our correct ethical behavior relies upon knowing what we must and must not do (our "duties"), and then acting accordingly. This is tied to the basics of our humanity. Human beings are special kinds of creatures, according to Kant. We have freedom (autonomy) and we possess the ability to reason (rationality). These two characteristics cause us to have the highest sort of value: intrinsic value. Intrinsically valuable things, like Kant's human beings, are always of the highest value, and they should be treated as such. Human beings should not be used merely for the benefit of others, and this idea makes Kant a valuable thinker for business ethics. Kant does not want any human beings to be used as instruments or tools only, since these uses are beneath the dignity of these highly valuable, free, rational creatures. Kant is also opposed to utilitarian thinking, since he feels that boiling value down to pleasure trivializes human dignity. Human beings for Kant, by the way, have value far in excess of non-human animals, which may be used instrumentally without those actions being "wrong” for Kant.

Kant has two central phrases that we can focus on for our own thinking about business ethics. The first is called "the categorical imperative." It states that, "In all of our actions, we must act so that the value of our actions can be made into a universal law."1 Let me break that down a little. So, Kant is saying that our principles for acting, at their most basic level, are principles that should apply to anyone trying to make a decision in our situation. He is talking about all of our actions. He is is saying that we must act, not 
for individual outcomes, but so that the ideas driving our actions (the value of our actions), can be made into rules that apply to everyone (universal law). So, for Kant, it is not acceptable for us only to think about the benefit to ourselves or only for our shareholders, unless benefit to self or shareholders is actually what a person should be deciding in this situation. The other central phrase from Kant will provide clarity.

Kant felt like there was an immediate inference that arose from a deep understanding of the categorical imperative. He called this immediate understanding the first corollary to the categorical imperative, and it is the second central phrase for Kant' ethics. It states that, "A human being must always be treated as an end, and never as a means, only." 2 So, for Kant, human beings are too valuable to only be used as we would use tools, for means only. This idea has relevance for labor rights and human resources concerns. How should we treat our employees? What kind of culture should we be participating in at work? Is it ever acceptable to discriminate against others? What about social and product experimentation on customers in the open marketplace? For Kant, the most obvious expression of the ideas of duty and dignity in the categorical imperative is its first corollary, prohibiting the treatment of human beings as means only.

Check out the links here to get a good explication by Michael Sandel of Kant's ideas on ethics. The subsequent episode has a really good discussion of more of Kant's ideas relevant to business ethics.

$\underline{\text { Justice with Michael Sandel: Episode } 6}$

$\underline{\text { Justice with Michael Sandel: Episode } 7}$ 
Fundamental Principles of the Metaphysic of Morals by Immanuel Kant, pg. 31

Fundamental Principles of the Metaphysic of Morals by Immanuel Kant, pg. 30

\section{More Questions to Consider Before Class}

- Do you think it makes sense that there are ideas about ethics that are always right and always wrong?

- Do you think that any human characteristics make us more ethically valuable than other creatures? If so, which characteristics?

- Are you familiar with other systems of ethics that suggest absolute rights and wrongs? How does Kant's system differ from those systems?

\section{Interdisciplinary Exercises}

Discover ways that Utilitarian theory and Kant's ideas have been used in your local business community. Use print media and online accounts of business actions to locate champions of each position. Then, make some judgment as to which corporate actor did the best thing from your point of view, highlighting the value of one ethical theory over another and supporting your use of it by reference to evidence.

\section{Critical Thinking Vocabulary and Application}

Intellectual Perseverance (Trait) — When your community and your training fail to support your view of business ethics, what should you do? One approach is to continue to explore your ideas with humility, courage, and fairmindedness. Intellectual Perseverance entails us pushing past obstacles to attain clearer understandings, to discover more 
about the accuracy of the facts we use, to always be as precise in our meanings as possible, to ensure that important controversies in business ethics remain at the front of the conversation, to take the extra time to be deep and broad in our assessments of business ethics ideas, to enforce the logicalness of our reasoning about business ethics at every turn, and to always be certain that we recognize the significant ethical aspects of a situation, not the trivial, even when others oppose our efforts.

\section{Bonus Reading}

Check out this fine essay by Michael Sandel, which is relevant to our central question.

\section{"How Markets Crowd Out Morals"}

If you read this essay for class, please take the extra step of forming three business ethics-related questions that you construct from the text. Please bring these questions to class (on the appropriate date listed on the syllabus) and initiate a discussion about the essay.

\section{Find the Ethical Aspect!}

Mine the newspaper! For this assignment, please use a recognized news source. Locate the ethical aspect of some business activity reported in a news source during the week you are discussing this chapter's material. Try to make your story relevant to this chapter's fundamental and powerful concepts. You should look for evidence of any ethical theories from the text thus far. Bring your example to class for discussion. There is one of these exercises in each chapter, so please think about using a hardcopy newspaper 
for a few of the news research assignments this semester. Be sensitive to the differences you perceive between print versus digital media types; there's even an ethical aspect to that comparison!

Relation of some key ideas in this chapter to the central question: When is it acceptable to profit from harm to others in business?

- Is it sometimes okay to harm others in business if the profit affects more people than the associated harms?

- Are some industries so important that it's okay for them to profit as a result of harm to others?

- If there are some actions that are always right, does that mean that harming people as a result of those actions is acceptable? 


\section{CHAPTER 8}

\section{SMITH AND MARX}

Introduction to the Ideas in this Chapter:

Much tension in capitalism is captured by the contrasting views of Adam Smith (1723-1790) and Karl Marx (1818-1883). Smith is largely known for his foundational work on the economics of the free market, An Inquiry into the Nature and Causes of the Wealth of Nations (1776, 1778, 1784, 1786, and 1789.) Smith taught Moral Philosophy at The University of Glasgow, and it was during this time that he published his work on ethics, The Theory of Moral Sentiments (1759, 1761, 1767, 1777, 1784, and 1790.) These works, particularly the former, have been fantastically important to the development of contemporary market thought.

Karl Marx is focused on the rights of workers. His activism brings about the publication of A Manifesto of the Communist Party in 1848, a year of revolution across Europe. Marx has many important concerns about the ways in which capitalism hurts workers. 
Many of his ideas can be seen in contemporary critiques of market structures throughout the world, as some of the readings demonstrate.

While many thinkers in our culture reject Marx out of hand as the enemy of markets, his articulation of the dangers of capitalism cannot be ignored. As you read this chapter, consider the links, consider the questions, and work through the exercises with the idea that you will be exploring something new, even if you've worked with this material before. Marx's decision-making approach, the dialectic, is discussed at the end of the chapter with a new twist.

\section{Fundamental and Powerful Concepts:}

\section{Division of Labor, Invisible Hand, Alienation, Dialectic}

\section{Adam Smith}

For business ethics purposes, we will focus on only three pieces of Adam Smith's theory: Division of labor, true value of labor, and the invisible hand. Smith points out in book one of Wealth of Nations that division of labor is a great benefit, using his famous example of the pin factory. The division of labor, when it leads to specialization, is a great benefit to industry and workers in Smith's view. In book five, however, when Smith again discusses division of labor, he points out that the amount of money given for labor is not the true value of the labor, since owners will always negotiate for the lowest labor costs. This situation, arguably, leads to harms. To check out these sections for yourselves, see this version of The Wealth of Nations. 
The implications of division of labor are not always to the benefit of the workers, as noted here: Why making a Chipotle burrito or a McDonald's Big Mac should be considered manufacturing. In the contemporary world, many jobs offer neither opportunities for workers to advance, nor the ability to improve their skills to eventually get a better job. In fact, the process of division of labor in a manufacturing system like fast food is to teach workers kitchen skills that will probably not transfer well to other types of restaurant kitchens, keep their wages lower than other market sectors, and ultimately to devalue the relationships between workers, since productivity and efficiency are often opposed to relationship-building at low-end jobs. Read the next two links to determine if you think Adam Smith would have intended this kind of outcome for his market theories.

Information about Smith's ethics can be found here:

\section{Adam Smith's Moral and Political Philosophy}

\section{Questions to Consider}

1. What is one main idea from Smith's ethics that can be directly applied to business?

2. What is Smith's view of rules?

3. Can you explain the connection of Smith's ethics to a theory of nature?

4. What is one problem with Smith's ethical theory, from your point of view? Can you look at your own thinking and discover which important principles for you that Smith contradicts? 
This link will help connect ethics and economics through Smith:

\section{Recovering Adam Smith's Ethical Economics.}

\section{Questions to Consider}

1. According to this reading, what is "liberty" for Smith?

2. How does the gaining of national wealth benefit the poor for Smith?

3. Can you explain the connection between autonomy and free markets for Smith?

There is a fine explication of the concept of the invisible hand in Smith and the limited textual sources for each at the Wikipedia page on the subject: Invisible Hand. For class exercises, be sure you are able to distinguish between the two sources for this important free-market concept. It's useful to realize that markets are not found in nature, and so the invisible hand is only as "natural" as the human relationships that contain it. Of course, Smith believes that humans have a natural tendency to enter into commerce; does that seem credible to you as an idea?

\section{Questions to Consider}

1. What important distinctions are there between the two versions of Smith's invisible hand?

2. Are you able to explain the idea of the invisible hand in your own words?

3. Can you provide an example of evidence of the invisible hand at work in your own life? 
4. Which ethical theories from the text so far can you link with the idea of the invisible hand?

5. At what point do you think the concept of the invisible hand ceases being relevant for business ethics?

\section{Karl Marx}

Business ethics thinkers should concern themselves with Marx, among other reasons, because Marx was concerned about securing good conditions for workers. A few of the key ideas that make Marx important for contemporary capitalist critique are contained in this blog post: Was Marx Right. Marx is also important for a larger understanding of the cultural concerns leading to business ethics as a serious topic of discussion. Some of those ideas appear here: The Revenge of Karl Marx.

\section{Questions to Consider}

1. Can you explain one of Marx's concerns about capitalism?

2. To what extent do you believe that your own circumstances in life are based upon material concerns?

3. Can you relate one of Marx's critiques to an ethical theory from this text?

Read a little of Marx for yourself here: Estranged Labour. 


\section{Questions to Consider}

1. Is Marx's explanation of how workers are alienated from their labor logical to you? Can you provide a contemporary example?

2. Do you see the identify of workers being linked to their wages?

3. Can you explain how people become alienated from themselves through capitalism?

\section{Dialectical Thinking}

Marx is completely invested in an idea known as the dialectic. The dialectic is the principle of opposition that logically exists whenever there is conflict. For Marx, conflict is always present in society and in relationships. Due to the ubiquitous nature of dialectical relationships, Marx believed that all of our choices are based around this idea of conflict, which is based in the need to overcome the other. Marx called his idea dialectical materialism: Dialectical Materialism.

Dialectical decision making is based in conflict of ideas. The opposing ideas are judged according to some criteria, and that criteria causes one idea to be valued more highly than another. Thus, one idea (or object) is elevated, while another idea is found to be lacking. Dialectical decision making, even if we don't recognize the name, is an important cultural pattern in American society and for free markets. This is because dialectical processes use evidence to make judgments, as does business. The two processes work well together, since business decision making requires the best evidence. 
Often, however, dialectical processes are unable to keep up with problems that occur in real time. Take the situation in the kitchen where the cook is creating pasta sauce. If a mistake is made in the recipe, the cook has to contend with the passing of time in the real world if he or she wants to salvage the sauce. As the clock ticks, heat is being applied to the ingredients on the stove. Cooking is happening, and transformation is underway. If the cook is too rigid in his or her application of a decision making process, seeking to set up a new dialectic for analysis before taking action, the sauce will be unsalvageable.

The dialectic is particularly rigid. In dialectical decision-making, thinkers are encouraged to work within certain sets of conditions that will allow for dialectical judgments. What happens, though, when the system is spinning out of control? If dialectical processes are in use, those models have to be reset in order for a judgment to take place. In real time, however, there is often no time to reset the dialectic. As with our sauce above, there will be no opportunity to fix whatever is broken if new conditions have to be identified before judgments can occur. This kind of deciding potentially needs to occur for ethics as well as other business areas. I advocate for a different kind of decision-maker to navigate the dialectic flexibly.

What is needed is a system of deciding that avoids rigid models, thereby retaining the ability to operate fluidly in real time. One model for this is contained in the central teaching of the Hontai Yoshin Ryu (link to Hontai Yoshin Ryu), a system of Japanese martial arts (bujutsu) from the 17th century. In the central teaching, a willow tree is metaphorically set against an oak tree. A dialectal relationship emerges in which the willow tree and 
the oak tree both encounter conflict in the form of a storm. The oak tree is broken by the high wind, but the willow tree remains intact.

One way to spin this story for our purposes is to use the oak tree as an example of stiff decision-making in the dialectical mode. When the conflict arises, there is no way for the oak tree to re-evaluate; it cannot bend, and so it breaks. The willow tree, however, is able to give with the high wind and snap back. This principle of yielding and flexibility is called yawara in Japanese, and it is at the core of the improvisational control exhibited in high level judo, aikido, jujutsu, and other Japanese body arts.

When a problem develops in business decision-making, whether about ethics or anything else, that problem might be too complex to be solved by reference to dialectical models. This approach could be linked to the recent poor decisions evident in the financial crises that began in 2008. Those who need to make decisions are often locked into ways of deciding that are not open to any flexibility or fluidity. These thinkers cannot work with the situation at hand to create new possibilities in real time. Sometimes, however, this is needed.

I'll close this section with a surfing analogy. The surfer needs to have strong skills in balance, board control, and other characteristics in order to stay on the wave. When the wave changes, the surfer can't oppose the wave; he or she has to work with it, which is what yawara implies. Without the ability to bend in real time, the surfer will wipe out. Without yawara, the cook might lose the sauce. 
Business ethics decision making takes thinking through the problem in real time, with that thinking based upon good fundamentals. Ultimately, though, many of our decisions, have to be navigated by those with lots of experience and practice in the area. These people will be in the best positions to improvise a solution that works in real time, takes the evidence into account, and masterfully bends in order to locate solutions. When situations are complex, when much is at stake, and when conditions on the ground are constantly changing, the best thinkers will improvise.

\section{Group Exercise}

- Get into groups of three.

- One person explain to the other two what the value of one idea from Smith or Marx might be for business ethics.

- One other in the group should ask questions related to Intellectual Standards, and the other should ask questions based upon Elements of Thought.

- The original speaker should seek the deepest understanding possible for his or her position.

- Once the business ethics connection has been fully explored, partners should switch roles.

\section{Find the Ethical Aspect!}

Mine the newspaper! For this assignment, please use a recognized news source. Locate the ethical aspect of some business activity reported in a news source during the week you are discussing this chapter's material. Try to make your story relevant to this 
chapter's fundamental and powerful concepts. You should look for evidence of any ethical theories from the text thus far. Bring your example to class for discussion. There is one of these exercises in each chapter, so please think about using a hardcopy newspaper for a few of the news research assignments this semester. Be sensitive to the differences you perceive between print versus digital media types; there's even an ethical aspect to that comparison!

Relation of some key ideas in this chapter to the central question: When is it acceptable to profit from harm to others in business?

- How are harms created by capitalist processes?

-What sorts of harms can be introduced by inflexible thinking in business ethics?

- When is it acceptable to ignore solutions to problems in order to receive benefit? 


\section{CHAPTER 9}

\section{CORPORATE PERSONHOOD}

Introduction to the Ideas in this Chapter:

This chapter leans heavily upon the Canadian documentary, The Corporation, from 2004. The documentary explores, through interviews with important thinkers in many market-related areas, a good sampling of the ethical problems and challenges relevant to the modern business corporation. This chapter offers extra media that relates to many of the ideas in the film, and it also explores the central question of the film, which is relevant to our central question: If a corporation is to be treated like a person, what kind of person is the corporation?

Fundamental and Powerful Concepts:

\section{Corporate Personhood}

\section{The Claim and The Question}

This film explores the idea of corporate personhood in a particular way. The film notes that the idea of corporate personhood is an important one in our American democ- 
racy, and it's also particularly important for free market economies around the world. Corporations in the US are considered to be "US persons", which is to say that the corporate structure itself has all of the legal rights and protections of naturally-born US citizens. The film asks, "Having acquired the legal rights and protections of a person, the question arises, what kind of person is the corporation?"54

Explore the history of how the corporation became a legal US person at these links:

$\underline{\text { Santa Clara County V. Southern Pacific Railroad Company }}$

What is the Basis for Corporate Personhood?

\section{Corporate Personhood Challenged}

\section{Questions to consider:}

-What are the implications of corporate personhood for ethics in business?

- Does it matter if corporations are considered people when deciding if they have done the right or wrong thing?

- What are the important elements for understanding corporate personhood as presented at each of the three links above?

- Does it matter if The Supreme Court didn't actually approve the idea that corporations can be legal persons?

54 at 12:15 in The Film 


\section{The Corporation Documentary}

There is a free version of the film on YouTube (The Corporation). If you don't want to watch it in 23 parts, find it on Netflix or borrow it from the library.

Questions to Consider after watching the film:

- Do you think it's reasonable, given the evidence presented, to label the modern business corporation as a psychopath?

- What responsibilities, if any, should a business entity have when it foresees harm to human beings?

- Do corporations have any responsibilities to the natural environments surrounding the areas where they operate?

- Do corporations have responsibilities to any stakeholders beyond the limits of law or the ethical custom? Can you provide an example?

- Are there any ethical responsibilities of business when it comes to the development of future technologies? Are there any products, as Ray Anderson suggests in the film, that shouldn't be made at all?

- Does it makes sense to you that corporations should be allowed to break the law, pay the fine, and repeat without limit? Clearly, this is not all corporations. Why are some allowed to do this and others not?

Additional Reading on paradigm cases from the film:

General business cases: 
Should Companies Obey the Law If Breaking It Is More Profitable?

$\underline{\text { IBM } \text { and the Holocaust: The Strategic Alliance Between Nazi Germany and Ameri- }}$ ca's Most Powerful Corporation

Growth hormones:

Sustainable Table: rBGH

Banned in 27 Countries, Monsanto's rBGH Inhabits Many U.S. Dairy Products

Monsanto's positions on labeling and regulation (PDF document)

The legality of truthtelling in the media:

The Media Can Legally Lie

A Law Against Lying on the News: Why Canada has one and the U.S. doesn't

$\underline{\text { Society of Professional Journalists Code of Ethics }}$

Advertising:

The Nag Factor: How do children convince their parents to buy unhealthy foods?

The Commercial Campus ("Please follow the NYTimes link on this page.)

Undercover Marketing:

Undercover Marketing Uncovered

Stealth marketing: When you're being pitched and you don't even know it!

Corporate Crime: 
The Top 100 Corporate Criminals of the 1990s

The Ten Worst Corporations of 2004

Corporate Crime Reporter

\section{Interdisciplinary Exercises}

1. Demonstrate how you bring together ideas from different disciplines to make a case for the corporation being a psychopath or failing to qualify as a psychopath. Be sure to demonstrate the standards you are using to make your judgment.

2. Demonstrate "The Logic of..." one of the topics from the Additional Readings. See information on "The Logic of..." in Chapter 2.

3. Read these links and write out "The Logic of..." seeing the corporation as a person for religious purposes.

Court Rules Hobby Lobby Can Be Considered a Religious 'Person'

Hobby Lobby Won't Have To Pay Millions In Fines As It Challenges Obamacare

Birth Control Mandate

Federal Appeals Court Rules in Favor of Hobby Lobby

Court: Hobby Lobby can challenge health care law - Yahoo! News

\section{Critical Thinking Vocabulary and Application}

Intellectual Empathy (Trait) — To practice Intellectual Empathy is to see a thing from another person's point of view. Intellectual Empathy is a partially imaginative exercise that entails putting yourself into the most accurate mental position of someone else that 
is possible. This involves paying lots of attention to others, noting similarities and differences, and being highly self-reflective when comparing. Since free market business ethics positions must take into account corporate personhood, we as students of the market should be able to empathically enter the point of view of a corporation-as-person and see the world, to some degree, as this entity sees it. That way, we can begin to learn what its motivations are and, as our film asks, what kind of person the modern business corporation really is.

\section{Find the Ethical Aspect!}

Mine the newspaper! For this assignment, please use a recognized news source. Locate the ethical aspect of some business activity reported in a news source during the week you are discussing this chapter's material. Try to make your story relevant to this chapter's fundamental and powerful concepts. You should look for evidence of any ethical theories from the text thus far. Bring your example to class for discussion. There is one of these exercises in each chapter, so please think about using a hardcopy newspaper for a few of the news research assignments this semester. Be sensitive to the differences you perceive between print versus digital media types; there's even an ethical aspect to that comparison!

Relation of some key ideas in this chapter to the central question: When is it acceptable to profit from harm to others in business?

- Does it say anything about a person's character if harm to others is not an important thing to avoid? 
- Are corporations compelled to cause harm, or do they have some choice in their behavior?

- Is corporate harm more acceptable than interpersonal harm? Why or why not? 


\section{CHAPTER 10}

\section{ANTI-CORPORATE ACTIVISM}

Introduction to the Ideas in this Chapter:

Some people feel that corporate structures and rules about corporate power and personhood are central to many of the problems of human life. Many of these people oppose corporate power in many ways, directly and indirectly. The following pieces of media are examples of activist thinkers and their thinking about the problems surrounding capitalism, corporations, and commercial culture. You should follow the links, consider the ideas, and then write about your position. Do you accept any of these arguments? Are there other important negatives about business that are not reflected here? Is all of this just a smear campaign, a way of the weak attacking and vilifying the successful because of their own lack of financial or commercial success? Read on and judge by answering questions at the end of the links.

What follows is a short essay concerning the author's own encountering of these sources, what they are good for to help our study, and why they might matter, even if you don't care much about the discipline of business ethics. 
Fundamental and Powerful Concepts:

\section{Resistance, Exploitation, Obfuscation, Activism}

\section{No Logo}

Naomi Klein first brought my attention to concerns about advertising. I'd already been managing a grocery department in a Wild Oats grocery store for a few years by the time I found No Logo in an internet search for films I could show my Business Ethics class, which I had begun teaching one night per week at $\mathrm{U}$ of L. The full film of $\underline{\text { No } \log O}$ is available online

Klein talks about the power of branding and the ways it impacts our societies. Could branding lead to harms? She talks about advertising having real social capital. She talks about exploitation of labor. I hadn't thought as much about these things then as I probably should have, and many of her assertions began making themselves clear to me as I began traveling to Panama City, Panama, once or twice each year, to teach a two-week Business Ethics course to international students. While Panama City is a lot like the US, there are interesting places where the techniques regarding manipulation of customers and labor from last generation in the US show up there. You just have to know where to look, and Klein helped me see what I was looking at.

I suppose I wasn't yet adept at seeing the ways advertising and other kinds of commercial speech and action did things like encroaching upon our pubic spaces and causing us to value one item in the marketplace, or one relationship in our lives, over another. The suggestions were everywhere. I started to look around for earlier advertising, to see if it 
was as manipulative. Much of what I found caused me to rethink a lot of what I thought I'd known about early advertising and its effects upon culture. Of course, maybe it's a reflection. Is it both? Can ads like these lead to harms? Consider this list of 25 Vintage Ads That Would Be Banned Today.

As I started to become interested in these issues of advertising, a friend bought me a subscription to Adbusters Magazine. There is a whole subculture of groups and individuals that seek to peel the curtain back from the injustices of the marketplace. Adbusters covers the people and events that shake up the power structures in North America and abroad. They make arguments and support ad campaigns against corporations and governments that support oppression, duplicity, and corruption. Sometimes you'll agree, and sometimes you won't, but there is a lot to think about at the website above.

A few years later, Naomi Klein released The Shock Doctrine, which outlined the ways free market structures can lead to harms of many types. Klein outlines a doctrine she called "disaster capitalism," which she says is particular to the free market and that creates shocks to societies in order to stimulate markets. The revelations in that book were particularly shocking to me, since much of her criticism is levied at the US government for which I used to work, and under the same administration. If you are interested in seeing a great interdisciplinary analysis that tells completely different stories about free markets and the US government's involvement in them around the world, check it out. There is a documentary film based upon this research, also called The Shock Doctrine. 
The Yes Men are two activists, Andy Bichlbaum and Mike Bonanno, who travel the world trying to right the wrongs caused by bad corporate actions and the rules that let bad actors off the hook. Mainly, The Yes Men stage fake public relations events and falsely represent corporations as spokesmen in a number of official contexts. You must see them for yourself in their films, linked at their website http://theyesmen.org/faq. There is a great deal of free footage on the internet, as well.

"Kalle Lasn is the founder and publisher of Adbusters magazine, highlighted above. Lasn is also the author of a fine text concerning reasons for anti-corporate activiites. It's

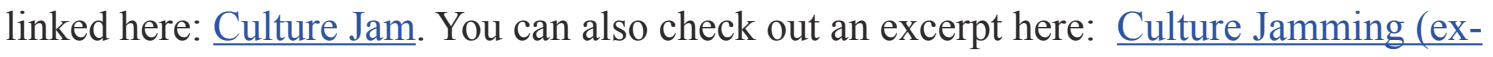
cerpt). Lasn is also the person who suggested that the disenfranchised occupy Wall Street, and his call spawned the Occupy movement. Occupy's Louisville chapter had its manifesto presented to Metro Council by Foundation for Critical Thinking Fellow Rush Cosgrove.

I have found good reasons to question the motives of many corporate actors, though I am still considering whether corporations are certain to harm because of the kinds of things they are. Whatever the answer to that concern, we are all affected by corporate culture, since we are consumers. The corporations supply the goods and services that promote our ways of life, and they also seem to shape our desires for those goods and services. Of course, serious self-reflection about our desires and feelings, while using a robust critical process like Paulian critical thinking theory, can really help us avoid mistakes and pitfalls. 
A few things seem relatively certain: Corporations are not identical to living people. Corporations cannot "die" like living persons can; corporations can be immortal. Corporations are not subject to shocks from the natural world like people are; corporations can be resilient in ways humans cannot. The idea that corporations should be given identical rights and protections to living human beings is an idea that should be seriously examined, unless we want to create immortal, highly adaptable, super-wealthy, largely unaccountable mega-beings. Is that the best thing for democracies or for free markets? What other questions related to this issue are you considering?

\section{Find the Ethical Aspect!}

Mine the newspaper! For this assignment, please use a recognized news source. Locate the ethical aspect of some business activity reported in a news source during the week you are discussing this chapter's material. Try to make your story relevant to this chapter's fundamental and powerful concepts. You should look for evidence of any ethical theories from the text thus far. Bring your example to class for discussion. There is one of these exercises in each chapter, so please think about using a hardcopy newspaper for a few of the news research assignments this semester. Be sensitive to the differences you perceive between print versus digital media types; there's even an ethical aspect to that comparison!

Relation of some key ideas in this chapter to the central question: When is it acceptable to profit from harm to others in business?

- Are there good reasons corporations should be opposed in this country? 
- Do you believe that there is something intrinsically harmful about corporations? If so, why? If not, can you reconstruct such a position?

- Is it a good thing to criticize corporate actions, or does doing so create an undesirable crisis in society's confidence regarding business? 
CHAPTER 11

\section{SUSTAINABILITY FOR BUSINESS ETHICS}

Introduction to the Ideas in this Chapter:

Sustainability is a powerful idea in business ethics today. In fact, it is a paradigm changer for many corporations and is, in many ways, creating a cultural shift for entrepreneurs. Sustainability as a concept is more than just a business ethics theory, but there are ways to position it in that way, too. Students should try this exercise, using the tools from earlier chapters, to make their case whether sustainability is an ethical theory or not. If it is, how should it be applied in the free market?

The chapter uses a variety of media, from The Story of Stuff to a University of Louisville Eco-Reps training video, from TED Talks to composting primers; there is a mix of disciplines and contexts here. Use your critical thinking skills, your business ethics tools, and your interdisciplinary skills to contextualize sustainability in reference to the central question. Note the interdisciplinary exercise with your own trash, the critical thinking connection, and the entrepreneurial exercise with other peoples' trash. 
Fundamental and Powerful Concepts:

\section{Sustainability, Waste, Consequences, Limits}

\section{Sustainability}

Sustainability is a way of preserving what one has. As such, it is an inherently conservative concept. When we are trying to sustain something, we are trying to help it do what it does at the level it is currently doing it. Sustainability, in the abstract, is not really interested in growth, because sustainable systems do not demand growth. More important than putting resources into growth, sustainable systems put resources into protecting against shocks to the system that could create a need for extra resources for rebuilding. It's most important that sustainable systems optimize themselves toward little risk and maximum resilience.

Capitalism is, of course, interested in growth. Capitalism is also interested in taking managed risks in order to enhance that growth. Many free-market approaches seem willing to sacrifice resilience for growth. So, there seems to be an inherent conflict between the concepts of sustainability and capitalism. In our free market model of capitalism, growth is supposed to be perpetually possible. As Annie Leonard points out in The Story of Stuff, however, we can't really grow perpetually, since our system has inherent limits. Her suggestion is to embrace a mindset of conservation and sustainability in our economic and social models.

The chapter explores a few approaches to sustainability. We may need to seriously examine this concept if Leonard's contention is correct. If we will need to seriously con- 
sider a switch to sustainable systems within one generation's lifespan, our own, we will need models to get us started. One is demonstrated by the University of Louisville EcoReps program video "What is Sustainability?" Another very robust approach that emphasizes the concept of resilience in our communities as a response to climate change is the Transition Movement. Transition US's website is at www.transitionus.org. Other approaches are suggested in the links below. Please review each of the links and consider the questions that follow.

"The Business Logic of Sustainability" is by Ray Anderson, the founder and CEO of Interface, Inc. Anderson argues that reorganizing your business toward sustainability is a way of pursuing profit, protecting the environment, and doing the right thing for future generations.

\section{"Cradle to Cradle Design" by William McDonough. McDonough argues that we} should be more thoughtful about the kinds of things we are creating on this planet. He believes that incorporating principles of sustainability into business is a way of improving the real purpose of creation in business, which includes improving our time on this planet and preserving it for others who will spend time on it.

"Making Global Labor Fair" by Auret van Heerden. Van Heerden argues that global supply chains cause us, the consumers, to be accessories to exploitation after the fact. He suggests that governments should get involved in markets to ensure that commitments to sustainability worldwide are met. 


\section{Questions to Consider:}

- Does it makes sense that global markets should aspire toward reducing harms?

- Do future generations figure into your sense of right and wrong action?

- Should sustainability be embraced or ignored in certain industries? Provide examples.

- Is the exploitation of a person on the other side of the world a good reason to avoid purchasing a product?

- Do you see a way that your current or future industry could embrace sustainability principles?

- What responsibilities do you think multinational corporations should have for the human rights of their workers or subcontract employees?

\section{Entrepreneurial Exercise}

What do sustainable systems look like for business? Here is an example of a closed loop start-up business that anyone could get going. (For more insights, see it in action at

\section{$\underline{\mathrm{U} \text { of L Eco-Reps Advanced Video on Urban Composting }}$}

Use trash from local businesses to make compost. A basic outline of the process can be found at Composting Basics. This part of the business will take about six months from inception to your first batch of compost (assuming that the startup takes no longer than three months.) 
Use that compost to feel red wiggler worms. This process is called "vermicomposting." Vermicomposting makes super soil that is just as potent as commercial fertilizers and chemical amendments. When the worms eat the compost, they poop out vermicompost. The crystalline structure of the dried mucous around the worm turd holds minerals that are beneficial for growing plants.

Once you have compost and vermicompost, you could sell each of them. You could also sell the worms, which reproduce every couple of months. This isn't the real opportunity, however. Growing Power, an urban farming leader in Milwaukee, Wisconsin, is the pioneer of this program, which Will Allen, the CEO, calls "live soil." With the live soil technique, pots containing crop plantings are placed on a water table which is attached to an aquaponics system. Each pot contains $80 \%$ compost and $20 \%$ vermicompost. There are live worms in the soil, and the plant, soil, and worms are all watered by holes in the pot, as water from the aquaponics system circulates. Water leaving the crop area carries nutrients to farmed fish in the bottom of the system. Will Allen introduces the idea in the video "Will Allen Talks Us Through Growing Power: Aquaponics." Allen primarily grows tilapia and lettuces in the systems in the video, but all sorts of crops can be farmed aquaponically with the live soil technique.

The system closes the loop on waste. Trash is composted, and then that compost is converted into food for worms, which produce nutrients for fish in their runoff, which in turn provides nutrients for the worms through the fish waste. Depending on the system, some amendments should be made with the fish's diet, and you'll need electricity to operate your pump, but it's mainly a closed-loop system that uses waste to grow food. A 
system with few inputs requires less to operate it. As long as it's also designed to be resilient and work with the other systems supporting it, this kind of aquaponics system is sustainable.

Now, use your own business skills to write a proposal for funding this kind of project. Do the research. Prepare the marketing plan. Map out logistics. Run the numbers. Work in groups of three or four students to design a closed-loop urban composting system. Want to go a further step? Decide upon a strategy for selling your produce and/or fish locally (fish-friendly systems can be created). Want to do more? Find some investors and make it happen!

Appendix 4 in this book presents a larger proposal that uses aquaponics and composting as one aspect of a "Sustainability Village." Check it out and bring your questions to class. What would it take to make this happen at your university? What about your city or town?

\section{Critical Thinking Vocabulary and Application}

Intellectual Autonomy (Trait) - We should be the kinds of people who want to think for ourselves. After all, we do just that each day. We make our own decisions, large and small, all the time. We should be sure that the decisions are coming from us and not from our training, our biases, or our traditions. We should be sure we have good reasons for the decisions we're making; we should not feel like we're being pressured by others to make decisions that go along with certain ideologies or political slants. We are independent thinkers, and we should be thinking independently about issues related to 
our consumerism, our commercial activities, and our roles as employees, managers, and citizens. This is intellectual autonomy.

\section{Interdisciplinary Exercise}

According to a well-known statistic, North Americans produce 4.5 pounds of trash per person per day, and 2.5 pounds of that is compostable waste. For this assignment, students should collect their personal trash for one week in a heavy-duty trash bag. These can be purchased from hardware stores; the bags should be a thickness of 6 millimeters or greater. We need thick bags, because students will be required to transport these bags to class during the week of the collection in order for everyone to see how one another's bags are growing. Students will lose points if their bags are not present in class. Bags should also have some sort of easily-openable closure, so that smells in the bag do not float out. All personal trash should be collected. This generally includes everything that is not liquid or meat. You should exclude used toilet paper, and any other trash that you already recycle or dispose of in some special way (like in a toilet) should be handled as you normally do. Don't include anything that's going to cause legal or relationship problems for you, since bags will be opened and inspected, as well as being weighed, in class. Students should pool their money to buy enough bags for everyone with a few extra leftover. It would be great if departments could provide the bags. Some students will need multiple bags. The teacher will need a scale to weigh the outcome of the class's work. 


\section{Assignments}

Ask students to write about the experience of carrying around their own trash for a week. Ask students to combine items in the bag to reuse them as something else; the photo at the right is a working lamp that a Panamanian student made by reusing her week's trash. Ask students to combine trash from multiple bags to create useful items. Ask students to write a research paper in which they trace the lifecycle of one item in the bag from creation to ending up in the bag. Ask students to write a research paper in which they describe what would have happened to their chosen piece of trash if it had not ended up in the bag. I find it's useful to tell students what the assignment is after they've already been carrying the bag for a few days. Otherwise, trash selection sometimes occurs on the part of the students, which can defeat some purposes of the assignment.

\section{Bonus Essay}

A Louisville native and entrepreneur, Gary Heine has been a business ethics inspiration for many people around this town. Gary was kind enough to share some aspects of his ethical journey through business in the document which follows, wherein you will also find direct connections between his understanding of business ethics and the concept of sustainability.

\section{The Development of My Business Ethics}

\section{By Gary Heine}

In 1992, I started Heine Brothers' Coffee as a small espresso cart in a Louisville, KY, grocery store. I thought it seemed like a good idea because Espresso drinks and tasty, lo- 
cally roasted specialty coffee were popular in Seattle and in some larger cities. And my hometown, Louisville, KY, which I was getting ready to move back to with a wife and two small children, didn't have any great, fresh-roasted coffee.

It seemed that the investment to get into business on this relatively small scale would be manageable and be a quick source of income for our growing family. I had always loved espresso and tasty coffee and knew others did, too. I didn't know what else to do.

So I started this espresso cart coffee business and it got a lot of attention because my fresh-roasted coffee was really tasty and nothing else like it was available in Louisville at the time. I had no real idea of what my business ethics were; it never even occurred to me to think about it. I suppose my ethics were that I wanted to provide an excellent product with my name on it - to let people know the "buck stops with me."

This new business enveloped my life completely, took me away from my family, nearly bankrupted me, was a big reason for the end of my marriage many years later, and stressed me, my family, and my dog, Arnold, beyond belief.

I mention all this because I think many businesses start like this. And there's not much time to think of business ethics when you're struggling for survival. And I didn't, either.

In 1994, I restarted Heine Brothers' Coffee with a business partner and we opened an actual store. It was an "overnight” success. So a small, but regular, amount of salary started coming in for us and after a year or so, money anxiety eased significantly. It's when you are living your passion in business and have some breathing room, when you 
aren't in survival mode, that ethics can begin to be something you have the time and energy to think of. At least, that's how my path seems to have worked.

My parents were ethical people and I suppose it rubbed off on me. But I never actually thought about myself in those terms. My business partner and I talked about what sort of coffee business we wanted to create:

A place where people (our customers) could come and feel like they were seen and appreciated. A place where we would show our customers our gratitude for doing business with us. The opportunity for people to enter a retail establishment and feel valued was becoming more scarce in our city, and across America.

A company where our staff would be treated with respect and dignity. Where those working with us could be themselves while being an important part of the company.

So this is how we started. My business partner and I worked behind the counter every day for the first year or two, and so we got to know our customers by name. People come to trust you when you know their names. One of the things we noticed early on was how much recyclable waste we were producing and throwing in the dumpster - cardboard, office paper, plastic milk cartons, aluminum cans, paper cups, newspapers and magazines.

Although there was residential recycling in our city, there was no business recycling for many years to come. Gradually, my business partner and I started to think that it was, in fact, our personal and business responsibility to reduce our waste as much as possible and to recycle our waste on our own, government pickup or not. The truth, it seemed to us, was that it was OUR waste and we were responsible to recycle it. 
So we started using both sides of our fax pages that were sent and received every day between our two stores, our office, and our coffee roastery. We started to pay our employees to break down our recyclable waste as part of their daily jobs and collect them at each store, the office, and the roastery, so that other paid employees could pick them up twice a week. Then these employees would fill up our delivery van with boxes of recyclables and bring them to the recycle stations and unload the van into the recycling bins there.

Doing this helped me begin to realize how the small choices I make every day can have much larger impacts on the world. A couple of years in, we had heard about organic, fair trade coffee and were interested in bringing some to our company, roasting it, and selling it to our customers. But in the mid-90s, it was difficult to find. We would get some organic coffee from time to time to taste, but we felt like the quality wasn't anything near to the quality of the non-organic coffee we were selling. We believed in organic coffee, but not if our customers had to drink a poorer quality coffee. Anyway, that's what we thought then.

We found one company that would sell us a few bags of fair trade, organic coffee from Nicaragua. So we brought it to Louisville, roasted it, and let our customers taste it. They really liked it. So we started buying this single fair trade, organic coffee a few bags at a time and roasting it for our customers. We paid more for this green coffee than our other non-organic, non-fair trade coffees but thought it was a worthwhile experiment. 
A couple years later, around 1998, a couple of us went to Washington, D.C., to the First Sustainable Coffee Congress, where the ground work was set to grow demand and distribution for organic, fair trade coffees in the United States. The interesting idea at the heart of it was that the billions of U.S. songbirds who wintered in Central America preferred to winter in the small organic coffee farms in the mountains of the coffee growing countries. So, by promoting the purchase of organic, fair trade coffees from small, sustainable coffee farms in the mountains, this could save U.S. songbird habitats (and, thus, our birds). And the millions of bird lovers in the U.S. could fuel the demand for these sustainable coffees. This would, in turn, save these small coffee farms.

Then a friend who owned a small coffee company in Georgia got the idea to start a cooperative of several small coffee companies in the U.S. and Canada to purchase organic, fair trade green coffees directly from coffee farmers in the growing countries. Well, this was a crazy idea and nothing like it existed. So six small coffee companies, including Heine Brothers' Coffee, put in $\$ 1,000$ each and promised to purchase at least ten percent of our coffees from Cooperative Coffees, as we called the cooperative.

So all of a sudden, our small coffee company from Louisville, Ky, was helping create the world-wide conversation around organic and fair trade coffee growing, production, and sale. And there was a great need for an ethical viewpoint such as the viewpoint of those in Cooperative Coffees. So, over a few years, I went from little knowledge of organic, fair trade coffee to selling 100\% organic, fair trade coffee in our stores. 
The organic, fair trade coffees we bought cost more than other non-organic, non-fair trade coffees that were available through coffee distributors. But we thought it was the right thing to do to support growing healthy and sustainable coffees that were good for the earth, air, and water of the coffee-growing countries. And it was good for the health and sustainability of the coffee farmers, their families, and communities.

To become a $100 \%$ organic, fair trade coffee company, we had to quit selling some of our most popular (and my favorite) coffees, because we couldn't get them in fair trade and organic versions. For example, we stopped roasting and selling Kenya AA coffee and our Yemen Mocha Mattari (my favorite coffee.)

The great lesson I learned over these years was that we could all take small steps in our lives every day that could change the world for the better. This idea has been at the heart of my life ever since.

In 2006, we realized we were producing 50 tons of coffee grounds each year from all of our stores. And we were throwing this into the dumpsters at our stores to be landfilled! So I started experimenting to see if red worms would eat the grounds and turn them into worm compost, a rich soil amendment that could enrich the soil of our city. I found that the worms' favorite food was a blend of coffee grounds and food waste from a local grocery store. So, I'd take 5-gallon buckets of coffee grounds from our stores and go dumpster diving to get 5-gallon buckets of food waste from a local grocery, then mix them for the worms to munch on. 
It turned out that the worms began to produce worm compost, and so we started using it to enrich the soil in all the plants we had in our stores. But it quickly became clear that we had a big project in front of us. We had proved we had a mini-model to compost our grounds and other local food waste. But to create a composting model for our 50 tons of grounds a year was a big leap from 5-gallon buckets of coffee grounds and food waste from the grocery store.

To compost all of our coffee grounds, we'd need to bring additional food waste from local sources and add it to our coffee grounds. We'd have to pick up the grounds from our stores and bring it to our composting space several times a week. We'd need a much larger, outdoor composting space to handle the 75-100 tons of total compostable materials we'd be dealing with. We'd need a truck and someone to drive it and pick up and unload materials. We'd need a new business!

But we already had our coffee business, and my partner and I were working full time. However, once we knew we could create a product from our waste that could help heal our community, we couldn't just forget about it. We had to do it.

So we created a non-profit called Breaking New Grounds. Using Growing Power in Milwaukee as a mentor and model, our idea was to create compost and create sustainable jobs for people working with the compost. And we had hoped to grow food to feed hungry people, as well as teach others how to grow food to feed themselves. So that's the road we went down, and it was an adventure that lasted seven years until Breaking New Grounds closed. It closed for some of the reasons that non-profits close - burned out vol- 
unteers, not being able to find the right leadership to move it forward, and difficulties finding money.

In those seven years, however, the organization motivated, inspired, empowered and gave hope to hundreds of local volunteers who worked with us. The organization helped to create the local conversation around growing a local food economy, which is gaining powerful traction here in Louisville. So, it was a magical gift that we were able to start Breaking New Grounds, as well as a sad day when it closed.

What I learned from starting this non-profit was that a few people with an idea and a story can create powerful change in the world. Even if you don't know how to get from the idea to the reality, that's okay - you just start by sharing your story with others. So, this is what my business ethics came to be and continues to be - make a difference when you can, share your story with others, and keep taking small steps each day to make it happen, to make the world a better place. To help make all of us better. Now, this is the only way I'll do business.

More information on Gary's story can be found here:Breaking New Grounds Documentary Part 1.

\section{Find the Ethical Aspect!}

Mine the newspaper! For this assignment, please use a recognized news source. Locate the ethical aspect of some business activity reported in a news source during the week you are discussing this chapter's material. Try to make your story relevant to this chapter's fundamental and powerful concepts. You should look for evidence of any ethi- 
cal theories from the text thus far. Bring your example to class for discussion. There is one of these exercises in each chapter, so please think about using a hardcopy newspaper for a few of the news research assignments this semester. Be sensitive to the differences you perceive between print versus digital media types; there's even an ethical aspect to that comparison!

Relation of some key ideas in this chapter to the central question: When is it acceptable to profit from harm to others in business?

- Should exploitation of others be sufficient reason to limit profits?

- Should the consideration of future generations be sufficient to limit profits?

- Are there good reasons to limit growth now?

- Should any limitations on growth be left to the individual?

- Could harms caused by individual actors have effects that reach far beyond the intended consequences?

- What is the power of imagination for avoiding harms in business? 


\section{SECTION 4}

\section{CONCLUSIONS}

What has been accomplished? The textbook has demonstrated a synthesis between Paulian Critical Thinking Theory and Business Ethics, which was its overt goal. It has also explained how to utilize the various methods of design within the textbook to get students working together and engaging with the content and with their communities. This larger dissertation has demonstrated the candidate's knowledge of the fields of Business Ethics and Critical Thinking for the purposes of establishing the necessary expertise in those fields for writing this dissertation. Suggestions have been offered for the upgrading of both disciplines through more assiduous connection with and use of Paulian CT. Those two sentences are demonstrated in Appendix A for the Buiness Ethics literature review and in Appendix B by the Critical Thinking literature review. Claims of originality for sixteen separate pieces of this project are demonstrated in Appendix C by reference to a comprehensive and expansive literature and database search. Appendix D explains the choice of using the Paulian Theory and how it fits in with the candidate's teaching and experience, along with why it's a good fit for 
what the textbook attempts for classroom students. Section Two explained and justified the choices of source, structure, and critical exercises in the textbook, along with explaining the relevant pedagogical and critical ideas associated with the ordering of the chapters and ideas in each. That section also demonstrates the explicitly interdisciplinary nature of this project.

The consistent interdisciplinary layering used for the textbook can be best described by the metaphor of a body. The construction began with a spine, represented by the central question technique, and then chapters derived from various ethical approaches were built off of that spine like a skeleton. The development of such a process can benefit greatly from a concept map for any textbook that reflects this structure. To make each set of bones functional and useful for the reader, the muscles of specific ethical theories and critical thinking tools, like Elements of Thought or Intellectual Traits, were arranged and attached. The sinews and ligaments are mainly individual pieces of the larger critical thinking tools and parts of ethical theories, like agency or conflict of interest, but there are also specific interdisciplinary theories, which might be called the minor muscles, that work together with the major ethical theories and critical thinking structures to create movement and flexibility at the connective points, which might be the joints, that connect each chapter. Examples of minor muscles include the butterfly effect, the invisible hand, and yawara.

The body metaphor will break down with detailed observation, as 
any analogy will, but the basic form of the project is uniquely interdisciplinary in the way it is structured. Of course, that body needs to move for a purpose, and various discrete exercises can be practiced by students through the individual questions in the chapter. Complex tasks for testing the movement possibilities of the whole structure are included as intellectual activities that contain many parts, like the food desert exercise in Appendix 1 of The Central Question. These exercises are intended to help the reader gauge the value of the textbook structure for real-world functionality and business ethics learning. Since the setting of any business ethics exploration can and will change, from the safe laboratory environment of the easy chair or classroom to the more challenging environment of the real business world, new experiments are always required for practicing even the most basic theoretical movements for the thinker about business ethics, even if these have already been mastered in contexts with lower stakes.

So, the interdisciplinary model constructed here is a living, flexible thing, and it is capable of helping students navigate a wide range of actions through the lens of ethical reasoning and critical thinking. The construct only promotes self-reflection if the student will care to do it, but the student can watch the movements he or she commands the body to conduct, can watch the way the connective concepts support and direct the major theories, and how those large, powerful bodies of knowledge shape and give 
specific character to the simple or complex tasks at hand, even if he or she doesn't want to see the personal value in these machinations. Based upon the student's understanding of the value of his or her experiment, this modern prometheus can be re-directed, re-examined, and re-deployed for a variety of learning experiences in any capitalist society, all of which are business ethics laboratories.

\section{Implications for Future Research}

This project has implications for the discipline of Business Ethics. It is very clear from this study that Business Ethics needs some kind of intellectual process that will help learners think through conclusions. There is a need, since business students, like all others, come into their training with biases and misconceptions that get in the way of good thinking about the ethical aspects of business. It is clear that a robust system of critical thinking that encourages fairmindedness, the Polarities, self-reflection, and systematic intellectual processes is badly needed for the literature, unless the Business Ethics discipline at large believes students learn such a method in areas of study other than Philosophy. If some other system of intellectual self-critique and improvement can be brought to business ethics, then that would suffice. To date, such a system to replace critical thinking has not been located.

For Critical Thinking, one implication of this study is that another piece of work is added to Paul's, Elder's, Nosich's, and Cosgrove's. The 
research demonstrates that the available literature in Philosophy lacks a text-based method to teach students critical thinking in a useful way that will actually lead to outcomes for any discipline. Another important implication for Paulian CT is that this is the first discipline-specific textbook that uses Paulian theory to create a course structure. Another implication is that these methods could be refined further, copied, and improved upon by other scholars and teachers concerned with critical instruction.

The main implication for faculty is that there is now a business ethics textbook that uses critical thinking in an integrated way to teach students both the critical thinking theory and the business ethics reasoning process. In addition, this dissertation outlines the methodology used to create that textbook, which can be replicated for any discipline. This is an innovative approach which teachers trained in didactic methods may not immediately understand, but the textbook also provides the opportunity for teachers to teach themselves critical thinking while they are leading students through the content. All of the basic Paulian CT theory is in the text already, so teachers can draw upon it for business ethics applications and other applications in their research, teaching, or administration without the need for additional texts at the beginning stages. This textbook will also integrate with all other Paulian CT materials in ways that will allow faculty beginning with this text to transition their own training into more robust study through other materials available through The Foundation for Critical 
Thinking and their varied training opportunities.

Implications for future research include synthesis of all of the excellent suggestions received for the second edition of The Central Question, and immediate work from this project is focused toward making those updates. The second edition will offer students an additional option of a physical textbook, along with a website, so that the linked media may be more easily managed. In addition, a new publication or series of articles in educational journals could synthesis and distill the principles for making a textbook in this style, to complement the initial writings on the subject.

Other implications involved the pursuit of the publication of several literature reviews and the conclusions implied by them. There is a need for Paulian CT to be perpetuated broadly in the discipline of Business Ethics, and publication of the Business Ethics literature review contained in this document in order to demonstrate that there is a gap in students' intellectual training would be useful as a contribute to the discipline's academic literature. Some additional peer-reviewed papers that bring people's attention to the problems of informal logic as a system for critical thinking might also be useful.

There are implications for using the central question to develop a training tool for corporations to interact with ethics. Such development could eventually lead to a variety of products and trainings designed to help leaders and workers in corporations learn to recognize the ethical aspects of 
their actions and to learn to think it through for their work and their lives. Training seminars and conferences could bring together individuals interested in business ethics locally, and some of the textbook's contributors and sustainability partners have expressed interest in presenting their ideas at such an event.

This critical approach to business ethics also has implications locally for helping students and other local stakeholders understand how to recognize ethical problems in Metro. In collaboration with U of L faculty and partners, there are already efforts underway to research the development of a series of business ethics paradigm cases locally. Some topics include the development of Rubbertown, the local penchant for coal, various local industries' resistance against sustainability approaches, and contextualized praise for the power of U of L's sustainability initiatives, along with their hidden ethical costs, for example. There is also the possibility of applying this business ethics paradigm to the ethics of underground economies domestically and abroad; Panama, for example, has already been researched heavily with this application in mind. This business ethics research could be applied to ethical aspects of some shadow industries, like illegal labor, gambling, and drugs. There is an analysis to be written of business ethics implications for the emerging marijuana industries domestically and worldwide.

Perhaps this project will provide a springboard for other partnered 
writing projects. In addition to the aforementioned work-in-progress with Dr. Cosgrove at The Foundation for Critical Thinking, The Foundation for Critical Thinking could develop a Thinker's Guide to Business Ethics, perhaps, or even a Critical Thinking textbook that uses Business Ethics examples and reasoning, inverting much of the paradigm offered here.

Lastly, there is an immediate opportunity for connecting Paulian Critical Thinking Theory and Business Ethics reasoning explicitly in the operating documents of a new business, Derby City Flavor, LLC ${ }^{55}$., a Kentucky company, which manufactures flavorful liquids for e-cigarette vaporizers. Like Thales believed at the beginning of the western philosophical tradition, practical matters should be addressable with the tools of deep inquiry ${ }^{56}$. The author is creating an entrepreneurial laboratory to explore the issues of modern business through this company. For example, hardware for that business has been ordered from Shenjhen, China, a place known for exploiting human labor in exchange for lower costs. The business is also

55 www.derbycityflavor.com

56 Thales of Miletus (620 BCE to 546 BCE): Thales's reputation for wisdom is further enhanced in a story which was related by Aristotle. (Politics, 1259 a 6-23). Somehow, through observation of the heavenly bodies, Thales concluded that there would be a bumper crop of olives. He raised the money to put a deposit on the olive presses of Miletus and Chios, so that when the harvest was ready, he was able to let them out at a rate which brought him considerable profit. In this way, Thales answered those who reproached him for his poverty. As Aristotle points out, the scheme has universal application, being nothing more than a monopoly.

There need not have been a bumper harvest for the scheme to have been successful. It is quite likely that Thales was involved in commercial ventures, possibly the export of olive oil, and Plutarch reported that Thales was said to have engaged in trade (Plut. Vit. Sol. II.4). Internet Encyclopedia of Philosophy, "Thales of Miletus", http://www.iep.utm.edu/thales/. 
operating in an industry that poses some human health concerns but is currently lightly regulated ${ }^{57}$. Other real business ethics issues, from employees to transportation to packaging, will all be there for exploration in this company and with other business opportunities on the horizon. There is much more to be discovered surrounding the central question.

${ }^{57}$ Food and Drug Administration's position on Electronic Cigarettes, as of July 16, 2014: "Ecigarettes have not been fully studied, so consumers currently don't know:

the potential risks of e-cigarettes when used as intended, how much nicotine or other potentially harmful chemicals are being inhaled during use, or whether there are any benefits associated with using these products. Additionally, it is not known whether e-cigarettes may lead young people to try other tobacco products, including conventional cigarettes, which are known to cause disease and lead to premature death."

"Only e-cigarettes that are marketed for therapeutic purposes are currently regulated by the FDA Center for Drug Evaluation and Research (CDER). Currently, the FDA Center for Tobacco Products (CTP) regulates cigarettes, cigarette tobacco, roll-your-own tobacco, and smokeless tobacco. FDA has issued a proposed rule that would extend the agency's tobacco authority to cover additional products that meet the legal definition of a tobacco product, such as e-cigarettes. FDA's Extending Authorities to Additional Tobacco Products webpage offers more information on the proposed rule, including how to submit comments." 
TABLE 1: REVIEW OF CRITICAL THINKING TEXTS

\begin{tabular}{|c|c|c|c|c|c|c|c|c|}
\hline $\begin{array}{l}\text { Author/ } \\
\text { Year }\end{array}$ & Explicit & Global & $\begin{array}{l}\text { System- } \\
\text { atic }\end{array}$ & Socratic & $\begin{array}{l}\text { Liberat- } \\
\text { ing }\end{array}$ & $\begin{array}{l}\text { Ordin- } \\
\text { ary } \\
\text { Lan- } \\
\text { guage }\end{array}$ & $\begin{array}{l}\text { Integ- } \\
\text { rated }\end{array}$ & $\begin{array}{l}\text { Judg- } \\
\text { ment }\end{array}$ \\
\hline $\begin{array}{l}\text { Bassh } \\
\text { am } \\
2011\end{array}$ & Yes & Yes & Yes & Yes & No & No & No & $\begin{array}{l}\text { Didacti } \\
\mathrm{c}\end{array}$ \\
\hline $\begin{array}{l}\text { Boss } \\
2010\end{array}$ & Yes & Yes & No & Yes & No & No & No & $\begin{array}{l}\text { Didacti } \\
\text { c }\end{array}$ \\
\hline $\begin{array}{l}\text { Boylan } \\
2010\end{array}$ & No & No & No & Yes & No & No & No & $\begin{array}{l}\text { Didacti } \\
\text { c }\end{array}$ \\
\hline $\begin{array}{l}\text { Cohen } \\
2009\end{array}$ & No & No & No & Yes & No & No & No & $\begin{array}{l}\text { Didacti } \\
\text { c }\end{array}$ \\
\hline $\begin{array}{l}\text { Damer } \\
2009\end{array}$ & Yes & No & Yes & Yes & No & No & Yes & $\begin{array}{l}\text { Weak } \\
\text { Hybrid }\end{array}$ \\
\hline $\begin{array}{l}\text { Hughe } \\
\text { s } 2008\end{array}$ & Yes & No & No & No & No & No & No & $\begin{array}{l}\text { Didacti } \\
\mathrm{c}\end{array}$ \\
\hline $\begin{array}{l}\text { Martin } \\
2011\end{array}$ & No & No & No & No & No & No & No & $\begin{array}{l}\text { Didacti } \\
\mathrm{c}\end{array}$ \\
\hline $\begin{array}{l}\text { Moore } \\
2012\end{array}$ & Yes & No & No & Yes & No & No & No & $\begin{array}{l}\text { Didacti } \\
\mathrm{c}\end{array}$ \\
\hline $\begin{array}{l}\text { Nosich } \\
2009\end{array}$ & Yes & Yes & Yes & Yes & Yes & Yes & Yes & Critical \\
\hline $\begin{array}{l}\text { Ruggie } \\
\text { ro } \\
2008\end{array}$ & Yes & Yes & No & Yes & No & No & No & $\begin{array}{l}\text { Didacti } \\
\text { c }\end{array}$ \\
\hline $\begin{array}{l}\text { Ruggie } \\
\text { ro } \\
2012\end{array}$ & Yes & No & No & Yes & Yes & No & No & $\begin{array}{l}\text { Didacti } \\
\mathrm{c}\end{array}$ \\
\hline $\begin{array}{l}\text { Salmo } \\
\text { n } 2013\end{array}$ & No & No & No & No & No & No & No & $\begin{array}{l}\text { Didacti } \\
\mathrm{c}\end{array}$ \\
\hline $\begin{array}{l}\text { Schick } \\
2008\end{array}$ & Yes & Yes & No & Yes & Yes & No & No & $\begin{array}{l}\text { Strong } \\
\text { Hybrid }\end{array}$ \\
\hline
\end{tabular}




\begin{tabular}{|c|c|c|c|c|c|c|c|c|}
\hline $\begin{array}{l}\text { Author/ } \\
\text { Year }\end{array}$ & Explicit & Global & $\begin{array}{l}\text { System- } \\
\text { atic }\end{array}$ & Socratic & $\begin{array}{l}\text { Liberat- } \\
\text { ing }\end{array}$ & $\begin{array}{l}\text { Ordin- } \\
\text { ary } \\
\text { Lan- } \\
\text { guage }\end{array}$ & $\begin{array}{l}\text { Integ- } \\
\text { rated }\end{array}$ & $\begin{array}{l}\text { Judg- } \\
\text { ment }\end{array}$ \\
\hline $\begin{array}{l}\text { Schick } \\
2011\end{array}$ & Yes & Yes & No & Yes & Yes & No & No & $\begin{array}{l}\text { Strong } \\
\text { Hybrid }\end{array}$ \\
\hline $\begin{array}{l}\text { Vaugh } \\
\text { n } 2013\end{array}$ & No & Yes & Yes & Yes & No & No & Yes & $\begin{array}{l}\text { Strong } \\
\text { Hybrid }\end{array}$ \\
\hline
\end{tabular}


TABLE 2: REVIEW OF BUSINESS ETHICS TEXTS

\begin{tabular}{|c|c|}
\hline Author/Date & Classification \\
\hline Allhoff (2008) & Didactic \\
\hline Allen (2004) & Strong Hybrid \\
\hline Beauchamp (2009) & Weak Hybrid \\
\hline Ciulla (2007) & Weak Hybrid \\
\hline DesJardins (2007) & Didactic \\
\hline DesJardins (2003) & Strong Hybrid \\
\hline Ghillyer (2007) & Strong Hybrid \\
\hline Gini (2009) & Didactic \\
\hline Hartman (2011) & Weak Hybrid \\
\hline Hill (2010) & Weak Hybrid \\
\hline Hosmer (2008) & Strong Hybrid \\
\hline Lasn (2000) & Weak Hybrid \\
\hline Leonard (2011) & Weak Hybrid \\
\hline Martin (2010) & Didactic \\
\hline McKibben (2008) & Didactic \\
\hline Newton (2008) & Didactic \\
\hline Newton (2012) & Didactic \\
\hline RIchardson (2008) & Didactic \\
\hline Sandel (2010) & Didactic \\
\hline Shaw (2013) & Didactic \\
\hline Shiva (2007) & Didactic \\
\hline
\end{tabular}




\section{TABLE 3: SUMMARY OF DATABASE RESEARCH FOR}

CLAIMS OF ORIGINALITY

\begin{tabular}{|c|c|c|c|c|c|}
\hline Claim & $\begin{array}{l}\text { Search } \\
\text { Terms }\end{array}$ & & total & $\begin{array}{l}\text { pursued } \\
\text { for } \\
\text { commenta } \\
\text { ry }\end{array}$ & $\begin{array}{l}\text { claim } \\
\text { demonstra } \\
\text { ted? }\end{array}$ \\
\hline 1 & $\begin{array}{l}\text { "critical } \\
\text { thinking", } \\
\text { "business } \\
\text { ethics" [limi } \\
\text { ted to } \\
\text { books] }\end{array}$ & $\begin{array}{l}\text { JSTOR/ } \\
\text { Google } \\
\text { Books/ }\end{array}$ & $58 / 4,020 /$ & $9 / 10$ & Yes \\
\hline 2 & $\begin{array}{l}\text { "central } \\
\text { question } \\
\text { technique" } \\
\text { "business } \\
\text { ethics" }\end{array}$ & $\begin{array}{l}\text { EBSCOhos } \\
\text { t/Amazon } \\
\text { Books/ } \\
\text { Google } \\
\text { Books }\end{array}$ & $0 / 1 / 0$ & 0 & Yes \\
\hline 2 & $\begin{array}{l}\text { "central } \\
\text { question" } \\
\text { "business } \\
\text { ethics" }\end{array}$ & $\begin{array}{l}\text { Google } \\
\text { Books }\end{array}$ & 766 & 6 & Yes \\
\hline 3 & $\begin{array}{l}\text { "business } \\
\text { ethics" } \\
\text { "milgram } \\
\text { experiment } \\
\text { s" }\end{array}$ & $\begin{array}{l}\text { Google } \\
\text { Books/ } \\
\text { Amazon } \\
\text { Books/ } \\
\text { EBSCOhos } \\
\mathrm{t}\end{array}$ & $4020 / 200 / 3$ & 12 & Yes \\
\hline 4 & $\begin{array}{l}\text { "oxford } \\
\text { tutorial" } \\
\text { "business } \\
\text { ethics" }\end{array}$ & $\begin{array}{l}\text { Amazon/ } \\
\text { EBSCOhos } \\
\text { t/Google } \\
\text { Books/ } \\
\text { Google } \\
\text { Scholar/ } \\
\text { ProQuest }\end{array}$ & 0 & 0 & Yes \\
\hline 5 & $\begin{array}{l}\text { demonstrat } \\
\text { ed by } \\
\text { existing } \\
\text { search data }\end{array}$ & $\mathrm{N} / \mathrm{A}$ & $\mathrm{N} / \mathrm{A}$ & 0 & Yes \\
\hline 6 & $\begin{array}{l}\text { "business } \\
\text { ethics" } \\
\text { "business } \\
\text { plan" } \\
\text { "business } \\
\text { proposal" }\end{array}$ & $\begin{array}{l}\text { EBSCOhos } \\
\text { t/JSTOR }\end{array}$ & $775 / 92 /$ & $0 / 7$ & Yes \\
\hline
\end{tabular}




\begin{tabular}{|c|c|c|c|c|c|}
\hline Claim & $\begin{array}{l}\text { Search } \\
\text { Terms }\end{array}$ & & total & $\begin{array}{l}\text { pursued } \\
\text { for } \\
\text { commenta } \\
\text { ry }\end{array}$ & $\begin{array}{l}\text { claim } \\
\text { demonstra } \\
\text { ted? }\end{array}$ \\
\hline 7 & $\begin{array}{l}\text { "When is it } \\
\text { acceptable } \\
\text { to profit } \\
\text { from harm } \\
\text { in } \\
\text { business?" }\end{array}$ & All & 0 & 0 & Yes \\
\hline 8 & $\begin{array}{l}\text { "business } \\
\text { ethics" } \\
\text { "The } \\
\text { Corporation } \\
\text { " } \\
\text { "document } \\
\text { ary" or } \\
\text { "film" }\end{array}$ & $\begin{array}{l}\text { Amazon/ } \\
\text { Google } \\
\text { Scholar/ } \\
\text { Google/ } \\
\text { JSTOR }\end{array}$ & $\begin{array}{l}0 / 20 / 4100 / \\
91\end{array}$ & 0/0/6/0 & Yes \\
\hline 9 & $\begin{array}{l}\text { "milgram } \\
\text { experiment } \\
\text { s" "butterfly } \\
\text { effect" } \\
\text { "small } \\
\text { world } \\
\text { experiment } \\
\text { " }\end{array}$ & $\begin{array}{l}\text { Amazon/ } \\
\text { EBSCOhos } \\
\text { t/Google } \\
\text { Books/ } \\
\text { Google } \\
\text { Scholar/ }\end{array}$ & 0/0/0/0/3 & 0/0/0/0/1/ & Yes \\
\hline 10 & $\begin{array}{l}\text { "food } \\
\text { desert" } \\
\text { "student } \\
\text { film" }\end{array}$ & $\begin{array}{l}\text { Amazon/ } \\
\text { EBSCOhos } \\
\text { t/Google } \\
\text { Books/ } \\
\text { Google } \\
\text { Scholar/ } \\
\text { ProQuest }\end{array}$ & 0/0/0/0/0 & 0 & Yes \\
\hline 11 & $\begin{array}{l}\text { "Milton } \\
\text { Friedman" } \\
\text { "ethics" } \\
\text { "equivocati } \\
\text { on" }\end{array}$ & JSTOR & $\begin{array}{l}2,537 / 1,33 \\
9\end{array}$ & 52 & Yes \\
\hline 12 & $\begin{array}{l}\text { "Collecting } \\
\text { trash" } \\
\text { "business } \\
\text { ethics" }\end{array}$ & $\begin{array}{l}\text { Google } \\
\text { Books/ } \\
\text { Google } \\
\text { Scholar/ } \\
\text { JSTOR/ } \\
\text { ProQuest/ } \\
\text { EBSCOhos } \\
\mathrm{t}\end{array}$ & 0/0/0/0/12 & 0 & Yes \\
\hline
\end{tabular}




\begin{tabular}{|c|c|c|c|c|c|}
\hline Claim & $\begin{array}{l}\text { Search } \\
\text { Terms }\end{array}$ & & total & $\begin{array}{l}\text { pursued } \\
\text { for } \\
\text { commenta } \\
\text { ry }\end{array}$ & $\begin{array}{l}\text { claim } \\
\text { demonstra } \\
\text { ted? }\end{array}$ \\
\hline 13 & $\begin{array}{l}\text { "contributio } \\
\text { ns from } \\
\text { local" } \\
\text { "business } \\
\text { ethics" }\end{array}$ & $\begin{array}{l}\text { Google } \\
\text { Books/ } \\
\text { EBSCOhos } \\
\text { t/Amazon } \\
\text { Books/ } \\
\text { ProQuest }\end{array}$ & 0/0/0/0 & 0 & Yes \\
\hline CT1 & $\begin{array}{l}\text { "Richard } \\
\text { Paul" } \\
\text { "business } \\
\text { ethics" }\end{array}$ & $\begin{array}{l}\text { EBSCOhos } \\
\text { t/ProQuest/ } \\
\text { Google } \\
\text { Scholar/ }\end{array}$ & $0 / 0 / 14$ & 2 & Yes \\
\hline СТ2 & $\begin{array}{l}\text { demonstrat } \\
\text { ed by } \\
\text { existing } \\
\text { search data }\end{array}$ & N/A & $\mathrm{N} / \mathrm{A}$ & 0 & Yes \\
\hline СТ3 & $\begin{array}{l}\text { "Richard } \\
\text { Paul" } \\
\text { "Japanese } \\
\text { art" }\end{array}$ & $\begin{array}{l}\text { Amazon/ } \\
\text { EBSCOhos } \\
\text { t/Google } \\
\text { Books/ } \\
\text { Google } \\
\text { Scholar/ } \\
\text { ProQuest }\end{array}$ & 0/0/3/0/0 & 0 & Yes \\
\hline
\end{tabular}




\section{REFERENCES}

Achbar, Mark, Jennifer Abbot, and Joel Bakan. "The Corporation: Chapter 4." Big Picture Media Corporation, 2013. Posted by The Corporation. http:// www.youtube.com/watch? $\mathrm{v}=\mathrm{aCGTD} 5 \mathrm{Bn} 1 \mathrm{~m} 0$. (accessed November 23, 2013).

Achbar, Mark, Jennifer Abbot, and Joel Bakan. "The Corporation Website." Big Picture Media Corporation, 2013. http://www.thecorporation.com/index.cfm?page_id=46. (accessed November 23, 2013).

Ahmed, Mohamed M., Kung Young Chung, and John W. Eichenseher. "Business Students' Perception of Ethics and Moral Judgment: A Cross-Cultural Study." Journal of Business Ethics 43, No. 1/2 (2003): 89-102.

Ahrens, John, and Brian Barnes. "Eco-Reps Advanced Video on Urban Composting." University of Louisville Sustainability Website, 2013. Posted by Brian Barnes. http://www.youtube.com/watch?v=dWDAXQW9EWw. (accessed November 22, 2013).

Allen, Anita. The New Ethics: a Tour of the 21st-Century Moral Landscape. New York: Miramax Books, 2004.

Allhoff, Fritz, and Anand Vaidya. Business in Ethical Focus: An Anthology. Calgary: Broadview Press, 2008.

Ardichvili, Alexandre, James A. Mitchell and Douglas Jondle. "Characteristics of Ethical Business Cultures.” Journal of Business Ethics, Vol. 85, No. 4 (2009): 445-451.

Allen, Will. “Growing Power Webpage.” Growing Power, 2010. http://www.growingpower.org. (accessed November 22, 2013).

American Institute of CPAs. "The Sarbanes-Oxley Act." AICPA, 2006. http:// www.soxlaw.com/. (accessed November 23, 2013).

Anderson, Ray. "The Business Logic of Sustainability." Ted Conferences, 2009. Uploaded by TED. https://www.youtube.com/watch?v=iP9QF_1BOyA. (accessed November 21, 2013). 
Armaline, William, et. al. Human Rights in Our Own Backyard: Injustice and Resistance in the United States. Pittsburgh: University of Pennsylvania Press, 2011.

Axelrod, Paul. Values in Conflict: The University, the Marketplace and the Trials of Liberal Education. Montreal: McGill-Queen's University Press, 2002.

Banach, David. "Plato's Theory of Forms." St. Anselm College, 2006. http:// www.anselm.edu/homepage/dbanach/platform.htm. (accessed November 23, 2013).

Barker, David. "Ethics and Lobbying: The Case of Real Estate Brokerage." Journal of Business Ethics, Vol. 80, No. 1 (2008): 23-35.

Barnes, Brian. The Central Question: Critical Engagement with Business Ethics. Dubuque, IA: Kendall Hunt Publishing Company, 2013.

Barnes, Mithuiel. “Answer to the Central Question.” Personal statement requested by author. Louisville, KY, 2013.

Bassham, Gregory, et. al. Critical Thinking: A Student's Introduction. 4th ed. New York: McGraw-Hill Higher Education, 2011.

"Behind the Enron Scandal." Time, Inc., 2013. http://content.time.com/time/ specials/packages/0,28757,2021097,00.html. (accessed August 5, 2014).

Beauchamp, Tom, Norman Bowie, and Denis Arnold. Ethical Theory and Business. New York: Pearson Press, 2009.

Betttencourt, Lauren, and Jasleen Kaur. Proceedings of the National Academy of Sciences of the United States of America, 108:49, 2011, 19540-19545.

Beyer, Barry. Critical Thinking. Phi Beta Kappa Educational Foundation: Bloomington, 1995.

Birch, Eugenie, and Susan Wachter. Growing Greener Cities: Urban Sustainability in the Twenty-First Century. Pittsburgh: University of Pennsylvania Press, 2011.

Black, Edwin. "IBM and the Holocaust Website." Edwin Black, 2013. http:// www.ibmandtheholocaust.com/. (accessed November 23, 2013).

Blass, Thomas. "The Man Who Shocked the World: Thomas Blass Probes into the Life of Stanley Milgram, the Man who Uncovered Some Disturbing 
Truths about Human Nature.” Psychology Today, 2002 http://www.psychologytoday.com/articles/200203/the-man-who-shocked-the-world. (accessed November 23, 2013).

Block, Melissa. "What is the Basis for Corporate Personhood?" All Things Considered, 2011. http://www.npr.org/2011/10/24/141663195/what-is-thebasis-for-corporate-personhood. (accessed November 23, 2013).

Bored Panda. "25 Vintage Ads that would be Banned Today." Bored Panda, 2013. http://www.boredpanda.com/vintage-ads/. (accessed November 22, 2013).

Boss, Judith A. Think: Critical Thinking and Logic Skills for Everyday Life. New York: Mc- Graw-Hill, 2010.

Bouckaert, Luk, and Rita Ghesquiere. "Dostoyevsky's Grand Inquisitor as a Mirror for the Ethics of Institutions" Journal of Business Ethics, Vol. 53, No. 1/2 (2004): 29-37

Boylan, Michael. Critical Inquiry: The Process of Argument. Boulder, CO: Westview Press, 2010.

Bradley, Larry. "Chaos and Fractals: The Butterfly Effect." Space Telescope Science Institute, 2010 http://www.stsci.edu/ lbradley/seminar/butterfly.html. (accessed November 23, 2013).

Brands, H.W. "The Money Men: Capitalism, Democracy, and the Hundred Years' War Over the American Dollar." New York: W. W. Norton, 2006.

Brock, Walter. "Breaking New Grounds, Part 1." Walter Brock, 2009. Uploaded by BNGLouisville. https://www.youtube.com/watch? v=5na5jYppfL8. (accessed November 22, 2013).

Burbules, Nicholas C., and Rupert Berk. "Critical Thinking and Critical Pedadgoy: Relations, Differences, and Limites." Critical Theories in Education: Changing Terrains of Knowledge and Politics. Thomas Popkewitz and Lynn Fendler, eds. Routledge: London. 1999

“Business Dictionary.com Website.” WebFinance, Inc., 2013. http:// www.businessdictionary.com/. (accessed November 23, 2013).

Carson, Thomas. "Does the Stakeholder Theory Constitute a New Kind of Theory of Social Responsibility?" Business Ethics Quarterly, Vol. 3, No. 2 (1993): 171-176. 
Cassidy, Charlene, and Bob Kreitner. Supervision: Setting People Up for Success. Boston: Cengage Learning, 2009.

Cassidy, Charlene, Bob Kreitner, and Susie VanHuss. Administrative Management: Setting People Up for Success. Boston: Cengage Learning, 2013.

Chew, Donald, and Stuart Gilligan, eds. U.S. Corporate Governance. New York: Columbia University Press, 2009.

Ciulla, Joanne, Clancy Marting, and Robert Solomon. Honest Work. New York: Oxford University Press, 2007.

Clegg, Stewart and Carl Rhodes. Management Ethics: Contemporary Contexts. New York: Routledge, 2006.

Cohen, Elliot D. Critical Thinking Unleashed. Lanham, MD: Rowman \& Littlefield Publishers, 2009.

Cohn, Scott. "Madoff Emails from Jail: I Wish I hadn't Pleaded Guilty." NBCNews.com, 2013 http://www.nbcnews.com/business/madoff-emailsjail-i-wish-i-hadnt-pleaded-guilty-1C8391074. (accessed November 23, 2013).

Common Sense Capitalism. "Ronald Reagan Describes Milton Friedman." Uploaded by Common Sense Capitalism. http://www.youtube.com/watch? v=F7HtZtwyn_c. (accessed November 24, 2013).

Corporate Crime Reporter. "Corporate Crime Reporter Website." Corporate Crime Reporter, 2013. http://www.corporatecrimereporter.com/. (accessed November 23, 2013).

Cosans, Christopher. "Does Milton Friedman Support a Vigorous Business Ethics?" Journal of Business Ethics, Vol. 87, No. 3 (2009): 391-399.

Cosgrove, Rush. "Critical Thinking in the Oxford Tutorial: A Call for an Explicit and Systematic Approach." Higher Education Research \& Development, Vol. 30: 3 (2011): 343-356.

Cosgrove, Rush, and Occupy Louisville. "Occupy Louisville Manifesto.” October 13, 2011. Uploaded by diworewww. https://www.youtube.com/ watch? $\mathrm{v}=6 \mathrm{~B}-19 \mathrm{D} 2 \mathrm{KpCs}$. (accessed November 22, 2013).

Cragg, A.W. "Business, Globalization, and the Logic and Ethics of Corruption.” International Journal, Vol. 53, No. 4 (1998): 643-660. 
Cragg, Wesley. "Business Ethics and Stakeholder Theory." Business Ethics Quarterly, Vol. 12, No. 2 (2002): 113-142.

Cruz-cruz, Jose. Business Ethics. Hoboken, NJ: Blackwell Press, 2009.

Damer, T E. Attacking Faulty Reasoning: A Practical Guide to Fallacy-Free Arguments. Belmont, CA: Cengage Learning, 2009.

C.W. "Capitalism and Freedom by Milton Friedman Review" Ethics, Vol. 74, No. 1 (1963):70-72.

Danley, John R. "Polestar Refined: Business Ethics and Political Economy." Journal of Business Ethics, Vol. 10, No. 12 (1991): 915-933.

Deardorff, Michelle D., et. al. The Fannie Lou Hamer National Institute on Citizenship and Democracy: Engaging a Curriculum and Pedagogy. The History Teacher, Vol. 38, No. 4 (2005): 441-453.

Denver Urban Gardens. “Composting Basics.” Denver Urban Gardens, 2010. http://dug.org/composting-basics. (accessed November 21, 2013).

Dickens, Charles. “A Christmas Carol.” Elliot Stock, London, 1890. http:// www.stormfax.com/dickens.htm. (accessed November 20, 2013).

Dickens, Charles. "Hard Times.” The World Wide School, November 1997, Seattle. http:/www.worldwideschool.org/library/books/lit/charlesdickens/ HardTimes/Chap1.html. (accessed November 20, 2013).

De George, Richard. "The Status of Business Ethics: Past and Future.” Journal of Business Ethics, Vol. 6, No. 3 (1987): 201-211.

DesJardins, Joseph. Introduction to Business Ethics. Columbus, OH: McGraw Hill Higher Education, 2003.

DesJardins, Joseph. Business, Ethics, and the Environment. Columbus, $\mathrm{OH}$ : McGraw Hill Higher Education, 2007.

Dobson, John. "Is Institute Shareholder Wealth Maximization Immoral?" Financial Analysts Journal, Vol. 55, No. 5 (1999): 69-75.

Donahue, Phil. "Milton Friedman on Donahue--Greed." Critical Commons, 2012. http://www.criticalcommons.org/Members/fsustavros/clips/miltonfriedman-on-donahue-greed/view. (accessed November 23, 2013).

Dowdle, Philip. “Answer to the Central Question.” Personal statement requested by author. Louisville, KY, 2013. 
Dubois, Alice, Gregory Roth, Jay Davies, Kelly Couturier, and Joshua Brustein. "A Timeline of the Madoff Fraud." New York Times Company, 2009. http://www.nytimes.com/interactive/2009/06/29/business/madofftimeline.html. (accessed November 23, 2013).

Dunfee, Thomas W., and Thomas Donaldson. "Contractarian Business Ethics: Current Status and Next Steps.” Business Ethics Quarterly, Vol. 5, No. 2 (1995): 173-186.

Duska, Ronald. "Business Ethics: Oxymoron or Good Business?” Business Ethics Quarterly, Vol. 10, No. 1 (2000): 111-129.

Dyer, Linda. Critical Thinking for Business Students. Concord, ON: Captus Press, 2006.

Ebeling, Richard. "Milton Friedman and the Chicago School of Economics." Foundation for Economic Education, 2006. http://www.fee.org/the_freeman/detail/milton-friedman-and-the-chicago-school-of-economics\#axzz2Xhp4FAwL. (accessed November 24, 2013).

Evans, Jocelyn, and Hefner, Frank. "Business Ethics and the Decision to Adopt Golden Parachute Contracts: Empirical Evidence ofConcern for All Stakeholders." Journal of Business Ethics, Vol. 86, No. 1 (2009): 65-79.

Elder, Linda and Richard Paul. Critical Thinking: Basic Theory and Instructional Structures Handbook. Tomales, CA: Foundation for Critical Thinking, 2000.

Elder, Linda, and Richard Paul. Universal Intellectual Standards. Foundation for Critical Thinking, 2013. http://www.criticalthinking.org/pages/universal-intellectual-standards/527. (accessed November 23, 2013).

Elder, Linda. http://www.criticalthinking.org/pages/international-fellows-academy/1193. 2014.

Encina, Gregorio. "Milgram's Experiment on Obedience to Authority." The Regents of the University of California, 2004. http://nature.berkeley.edu/ ucce50/ag-labor/7article/article35.htm. (accessed November 23, 2013).

Enron. "Enron Credit Recovery Corporation Website." Enron, 2007. http:// www.enron.com/. (accessed November 23, 2013).

Epicurus. "Letter to Menoeceus." Epicurus and Epicurean Philosophy, 1996. http://www.epicurus.net/en/menoeceus.html. (accessed November 23, 2013). 
Facione, Peter. Critical Thinking: A Statement of Expert Consensus for Purposes of Educational Assessment and Instruction. Research Findings and Recommendations. American Philosophical Association, 1990.

Finnis, John. Fundamentals of Ethics. Washington, DC: Georgetown University Press, 1983.

Fisher, Josie. "Social Responsibility and Ethics: Clarifying the Concepts." Journal of Business Ethics, Vol. 52, No. 4 (2004): 391-400.

Fleischacker, Samuel. “Adam Smith's Moral and Political Philosophy.” Stanford Encyclopedia of Philosophy, February, 2013. http://plato.stanford.edu/ entries/smith-moral-political/. (accessed November 23, 2013).

Fleming, John. "Authorities in Business Ethics." Journal of Business Ethics, Vol. 6, No. 3 (1987): 213-217.

Fogelin, Robert J. Understanding Arguments: An Introduction to Informal Logic. Harcourt Brace Jovanovich, 1978

Food and Drug Administration Statement Regarding E-Cigarettes. July 16, 2014. www.fda.gov.

Free Dictionary.com. “Superlative.” Farlex, Inc., 2013. http://www.thefreedictionary.com/superlative. (accessed November 23, 2013).

Freeman, R. Edward, Jeffrey Harrison, and Andrew Wicks. Managing for Stakeholders: Survival, Reputation, and Success. New Haven, CT: Yale University Press, 2007.

Friedman, Milton. "What All is Utility?" The Economic Journal, Vol. 65, No. 259 (1955): 405-409.

Friedman, Milton. "The Social Responsibility of Business is to Increase its Profits.” New York Times Company, 1970. http://www.colorado.edu/studentgroups/libertarians/issues/friedman-soc-resp-business.html. (accessed November 23, 2013).

Friend, Celeste. “John Rawls' A Theory of Justice." Internet Encyclopedia of Philosophy, October, 2004. http://www.iep.utm.edu/soc-cont/\#H3. (accessed November 23, 2013).

Gabriel. "The Smartest Guys in the Room by Bethany McLean and Peter Elkind." Handful of Sand, 2009. http://www.handfulofsand.com/blog/ archives/006633.html. (accessed November 23, 2013). 
Ghillyer, Andrew. Business Ethics Now. Columbus, OH: McGraw-Hill Publishers, 2003.

Gick, Evelyn. "Cognitive Theory and Moral Behavior: The Contribution of F. A. Hayek to Business Ethics." Journal of Business Ethics, Vol. 45, No. 1/2 (2003): 149-165.

Gini, Al, and Alexei Marcoux. Case Studies in Business Ethics. New York: Pearson, 2009.

Government Accountability Project. "The American Whistleblower Tour." Government Accountability Project, 2013. http://www.whistleblower.org/ action-center/american-whistleblower-tour. (accessed November 21, 2013).

GRACE Communications Foundation. "rBGH." Grace Communications Foundation. http://www.sustainabletable.org/797/rbgh. (accessed November 23, 2013).

Grant, Colin. "Friedman Fallacies." Journal of Business Ethics, Vol. 10, No. 12 (1991): 907-914.

Gray, Cody. "Can a Person be Psychological Egoist and Ethical Egoist at the Same Time?” Philosophy Stack Exchange, 2013. http://philosophy.stackexchange.com/questions/159/can-a-person-be-psychological-egoist-andethical-egoist-at-the-same-time. (accessed November 23, 2013).

Grote, Jim, and John R. McGreeney. Clever as Serpents: Business Ethics and Office Politics. Collegeville, MN: Michael Glazer, 1997.

Gotzsch, Josiena. Designing for a Better World: A Critical Approach: Integrating Ethics Across the Business World. New York: Routledge Publishing, 2012.

Gucciardi, Anthony. "Banned in 27 Countries, Monsanto's rBGH Inhabits Many U.S. Dairy Products.” Infowars.com, 2011. http://www.infowars.com/banned-in-27-countries-monsanto $\%$ E2\%80\%99s-rbgh-inhabits-manyu-s-dairy-products/. (accessed November 23, 2013).

Halpern, D.F. Thought and Knowledge: An Introduction to Critical Thinking. Hillsdale, NJ: Lawrence Erlbaum, 1989.

Haque, Umair. “Was Marx Right?” Harvard Business Review Blog, September 7, 2011. http://blogs.hbr.org/2011/09/was-marx-right/. (accessed November $23,2013)$. 
Harrington, L. Katharine. "Ethics and Public Policy Analysis: Stakeholders' Interests and Regulatory Policy." Journal of Business Ethics, Vol. 15, No. 4 (1996): 373-382.

Hartman, Laura, and Joseph DesJardins. Business Ethics: Decision Making for Personal Integrity and Social Responsibility. Columbus, $\mathrm{OH}$ : McGrawHill, 2011.

Hausman, Daniel, and Michael McPherson. "Taking Ethics Seriously: Economics and Contemporary Moral Philosophy." Journal of Economic Literature, Vol. 31, No. 2 (1993): 671-731.

Hawthorne, Matthew. "Answer to the Central Question." Personal statement requested by author. Louisville, KY, 2013.

Heal, Geoffrey. When Principles Pay: Corporate Responsibility and the Bottom Line. New York: Columbia Business School Publishing, 2008.

Heath, Joseph. "Business Ethics without Stakeholders." Business Ethics Quarterly, Vol. 16, No. 4 (2006): 533-557.

Heine, Debra. "Federal appeals Court Rules in Favor of Hobby Lobby." Breitbart, 2013. http://www.breitbart.com/InstaBlog/2013/06/28/Federal-Appeals-Court-Rules-In-Favor-Of-Hobby-Lobby. (accessed November 23, 2013).

Heine, Gary. "My Ethical Journey Through Business." Unpublished memoir. Louisville, KY, 2013.

Heine, Gary. "Answer to the Central Question." Personal statement requested by author. Louisville, KY, 2013.

Hendricson, William, et al. "Educational Strategies Associated with Development of Problem-Solving, Critical Thinking, and Self-Directed Learning." Journal of Dental Education. 70:9. 2006. 932.

Hill, Austin, and Scott Rae. The Virtues of Capitalism: A Moral Case for Free Markets. Chicago: Northfield Publishing, 2010.

Hitchens, Christopher. "The Revenge of Karl Marx: What the Author of Das Kapital Reveals About the Current Economic Crisis.” The Atlantic, 2009. http://www.theatlantic.com/magazine/archive/2009/04/the-revenge-of-karlmarx/307317/. (accessed November 23, 2013). 
Hobbes, Thomas, and J C. A. Gaskin. Leviathan. Oxford: Oxford University Press, 1998.

Hoffman, W. Michael, and Jennifer Mills Moore. "What Is Business Ethics? A Reply to Peter Drucker." Journal of Business Ethics, Vol. 1, No. 4 (Nov., 1982), pp. 293-300.

Hosmer, La Rue. The Ethics of Management. McGraw-Hill Publishing, 2008.

Howarth, Richard. "An Overview of Land Economics", Defining Sustainability, 73:4, 1997.

Hughes, William, and Jonathan A. Lavery. Critical Thinking: An Introduction to the Basic Skills. 5th ed. Peterborough, ON: Broadview Press, 2008.

Husted, Bryan W., and David B. Allen. "Is It Ethical to Use Ethics as Strategy?” Journal of Business Ethics, Vol. 27, No. 1/2 (2000): 21-31.

Ibsen, Henrik. An Enemy of the People. Farquharson Sharp, Trans. Project Gutenberg, (1882) 2007. http://archive.org/stream/anenemyofthepeop02446gut/aeotp10.txt. (accessed November 21, 2013).

“Idea: Triple Bottom Line.” Economist.com, 2009. http://www.economist.com/node/14301663. (accessed November 23, 2013).

Independent Lens. "Enron: The Smartest Guys in the Room." ITVS Interactive, March, 2007. http://www.pbs.org/independentlens/enron/. (accessed November 23, 2013).

Inoue, Kyoichi. "Hontai Yoshin Ryu Website.” Hontai Yoshin Ryu, 2013. http://www.hontaiyoshinryu.com. (accessed November 23, 2013).

Internet Encyclopedia of Philosophy, “Thales of Miletus", http://www.iep.utm.edu/ thales/.

Internet Movie Database. "The Insider (1999)." http://www.imdb.com/title/ tt0140352. (accessed November 23, 2013).

Internet Movie Database. "The Smartest Guys in the Room (2005)." http:// www.imdb.com/title/tt1016268/. (accessed November 21, 2013).

James, Jr., Harvey S., and Farhad Rassekh. "Smith, Friedman, and Self-Interest in Ethical Society." Business Ethics Quarterly, Vol. 10, No. 3 (2000): 659-674. 
Jensen, Larry, and Steven A. Wygant. "The Developmental Self-Valuing Theory: A Practical Approach for Business Ethics." Journal of Business Ethics, Vol. 9, No. 3 (1990): 215-225.

Jirásek, Jaroslav A. "Two Approaches to Business Ethics.” Journal of Business Ethics, Vol. 47, No. 4 (2003): 343-347.

Johnson, Ralph H., and J. Anthony Blair. "Informal Logic: The Past Five Years 19781983”. American Philosophical Quarterly, 22:3, 1985. 181

Jones, Frederick D., and Cristen Dutcher. Business Ethics: Developing Analytical and Critical Thinking Skills. Dubuque, IA: Kendall-Hunt Publishing, 2013.

Kant, Immanuel. Fundamental Principles of the Metaphysics of Morals. Project Gutenberg, (1785) 2010. http://www.gutenberg.org/catalog/world/ readfile?fk_files $=3275637 \&$ pageno $=31$. $($ accessed November 23,2013$)$

Kaptein, S.P. Ethics Management: Auditing and Developing the Ethical Content of Organizations. New York: Springer, 1998.

“Karl Popper and Negative Utilitarianism.” Utilitarianism.org, 2013. http:// utilitarianism.org/karl-popper.html. (accessed November 23, 2013).

Katz, Eric. "The Rings of Tolkien and Plato: Lessons in Power, Choice, and Morality.” TheOneRing.net, 2007. http://archives.theonering.net/perl/ newsview/8/1059512515. (accessed November 23, 2013).

Kemerling, Garth. "Utilitarianism.” The Philosophy Pages, 2011. http:// www.philosophypages.com/hy/5q.htm. (accessed November 23, 2013).

Killinger, Barbara. Integrity: Doing the Right Thing for the Right Reason. Montreal: McGill's Queen's University Press, 2010.

Klein, Naomi. "No Logo.” Media Education Foundation, 2003. Uploaded by ChallengingMedia https://www.youtube.com/watch?v=uI0itS3gQFU. (accessed November 23, 2013).

Klein, Naomi. "The Shock Doctrine: The Rise of Disaster Capitalism." NaomiKlein.org, 2005. http://www.naomiklein.org/shock-doctrine. (accessed November 22, 2013).

Klein, Sherwin. "Don Quixote and the Problem of Idealism and Realism in Business Ethics.” Business Ethics Quarterly, Vol. 8, No. 1 (1998): 43-63. 
Kline, William. "Business Ethics from the Internal Point of View." Journal of Business Ethics, Vol. 64, No. 1 (2006): 57-67.

Kolstad, Ivar. "Why Firms Should Not Always Maximize Profits." Journal of Business Ethics, Vol. 76, No. 2 (2007): 137-145.

Kubasek ,Nancy. The Legal Environment of Business: A Critical-Thinking Approach. Upper Saddle River, NJ: Prentice Hall, 1999.

Lasn, Kalle. "Adbusters Website.” Adbusters Media Foundation, 2013. https:// www.adbusters.org. (accessed November 22, 2013.)

Lasn, Kalle. "Culture Jam: The Uncooling of America." Excerpts published in The Guardian, April, 2000. http://www.guardian.co.uk/books/2000/apr/10/ extract. (accessed November 22, 2013.)

Lattman, Peter. “Enron's Skilling Strikes Deal for Shorter Sentence.” The New York Times Company, May 8, 2013. http://dealbook.nytimes.com/ 2013/05/08/enrons-skilling-strikes-deal-for-shorter-sentence/. (accessed November 22, 2013.)

Flynn, Gabriel, ed. Leadership and Business Ethics. New York: Springer, 2008.

Leaman, Oliver. A Brief Guide to Islamic Philosophy. Hoboken, NJ: Wiley, 1999

Lee, Dwight R., and Richard B. McKenzie. "Corporate Failure as a Means to Corporate Responsibility." Journal of Business Ethics, Vol. 13, No. 12 (1994): 969-978.

Leonard, Annie. "The Story of Stuff." Tides Foundation and Funders Workgroup for Sustainable Production and Consumption, 2007. Uploaded by storyofstuffproject. http://www.youtube.com/watch?v=9GorqroigqM. (accessed November 22, 2013.)

Leonard, Annie. The Story of Stuff: The Impact of Overconsumption on the Planet, Our Communities, and Our Health-And How We Can Make It Better. New York: Free Press, 2011.

Leung, Rebecca. "Undercover Marketing Uncovered: Hidden Camera Capture Salespeople Secretly Pitching Products." 60 Minutes, 2004. http:// www.cbsnews.com/news/undercover-marketing-uncovered-22-07-2004/. (accessed November 22, 2013.) 
Lloyd, Sharon, and Susanne Sreedhar. "Hobbes's Moral and Political Philosophy.” Stanford Encyclopedia of Philosophy, 2008. http://plato.stanford.edu/entries/hobbes-moral/. (accessed November 22, 2013.)

Louisville Community Farm Alliance. "Bridging the Divide: Growing SelfSufficiency in our Food Supply."Louisville Community Farm Alliance, 2007. http://www.communityfarmalliance.org/BridgingTheDivide.pdf. (accessed November 22, 2013.)

Lowe, Graham. Creating Healthy Organizations: How Vibrant Workplaces Inspire Employees to Achieve Sustainable Success. Toronto: University of Toronto Press, 2010.

McDonald, Gael M., and Gabreil D. Donleavy. "Objections to the Teaching of Business Ethics." Journal of Business Ethics, Vol. 14, No. 10 (1995): 839853.

Machold, Silke, Pervaiz K. Ahmed, and Stuart S. Farquhar. "Corporate Governance and Ethics: A Feminist Perspective." Journal of Business Ethics, Vol. 81, No. 3 (2008): 665-678.

Martin, Kristen E. "Internet Technologies in China: Insights on the Morally Important Influence of Managers.” Journal of Business Ethics, Vol. 83, No. 3 (2008): 489-501.

Martin, Clancy, Wayne Vaught, and Robert Solomon. Ethics Across the Professions: A Reader for Professional Ethics. New York: Oxford University Press, 2010.

Martin, Robert M. There Are Two Errors in the the Title of This Book: A Sourcebook of Philosophical Puzzles, Problems, and Paradoxes. Peterborough, ON: Broadview Press, 2011. Print.

Marx, Karl. “Estranged Labour.” Karl Marx Internet Archive, 2013. http:// www.marxists.org/archive/marx/works/1844/manuscripts/labour.htm. (accessed November 23, 2013).

Masek, Lawrence. "The Doctrine of Double Effect, Deadly Drugs, and Business Ethics.” Business Ethics Quarterly, Vol. 10, No. 2 (2000): 483-495.

MBA Program Journey Blog. "Shareholders and Stakeholders Theory." Living MBA, 2010. http://livingmba.wordpress.com/tag/shareholders-theory/. (accessed November 24, 2013). 
McDonough, William. "Cradle to Cradle Design." Ted Conferences, 2005. Uploaded by TED https:/www.youtube.com/watch?v=IoRjz8iTVoo. (accessed November 21, 2013).

McKibben, Bill. Deep Economy: The Wealth of Communities and the Durable Future. New York: St. Martin's Griffin Press, 2008.

McLean, Bethany, and Joe Nocera. All the Devils are Here. New York: Penguin Group, USA, 2011.

McLeod, Saul. “The Milgram Experiment.” Simply Psychology, 2007. http:// www.simplypsychology.org/milgram.html. (accessed November 23, 2013).

Mill, John. "Utilitarianism, Chapter 2: What Utilitarianism Is." John Ahrens' Webpage, 2013. http://vault.hanover.edu/ ahrens/texts/Annotated_Texts/ Annotated_Mill_Util_II.pdf. (accessed November 23, 2013).

Mishan, E. J. “Capitalism and Freedom: Problems and Prospects (Proceedings of a Conference in Honour of Milton Friedman) by Richard T. Selden." Economica, New Series, Vol. 44, No. 174 (1977): 197-198.

Mog, Justin, and Brian Barnes. "U of L Eco-Reps Webpage.” University of Louisville Office of Sustainability, 2011. http://louisville.edu/sustainability/operations/eco-reps/eco-reps.html. (accessed November 23, 2013).

Mokhiber, Russell, and Robert Weissman. "The Ten Worst Corporations of 2004.” 2004. http://www.multinationalmonitor.org/mm2004/122004/ mokhiber.html. (accessed November 23, 2013).

Mook, Laurie, Jack Quarter, and Sherida Ryan. Researching the Social Economy. Toronto: University of Toronto Press, 2010.

Morningstar Document Research. "Monsanto Company 2009 Form 10-K." Monsanto Company, 2009. http://www.monsanto.com/investors/Documents/Pubs/2009/10-K.pdf. (accessed November 23, 2013).

Moore, Brooke N, and Richard Parker. Critical Thinking. 10th ed. New York: McGraw-Hill, 2012. Print.

Mulligan, Thomas. "A Critique of Milton Friedman's Essay 'The Social Responsibility of Business Is to Increase ItsProfits'." Journal of Business Ethics, Vol. 5, No. 4 (1986): 265-269. 
Multinational Monitor. "The Top 100 Corporate Criminals of the 1990s." Multinational Monitor, 1999. http://www.multinationalmonitor.org/ mm1999/99july-aug/crime1.html. (accessed November 23, 2013).

Neale, Greg. "Peter Singer: Monkey Business: The Father of the Animal Rights Movement Upsets Activists, Pro-Lifers, and Disability Groups Alike.” Utilitarianism.com, 2006. http://www.utilitarianism.com/petersinger.html. (accessed November 23, 2013).

Newton, Lisa. Taking Sides: Clashing Views on Business Ethics and Society, 11th Edition. New York: McGraw-Hill, 2008.

Newton, Lisa, Elaine Englehardt, and Michael Pritchard. Taking Sides: Clashing Views on Business Ethics and Society, 12th Edition. New York: McGraw-Hill, 2012.

Nobelprize.org. "The Sveriges Riksbank Prize in Economic Sciences in Memory of Alfred Nobel 1976". Nobel Media AB 2013. http://www.nobelprize.org/nobel_prizes/economic-sciences/laureates/1976/. (accessed November 23, 2013).

Nosich, Gerald M. Learning to Think Things Through: A Guide to Critical Thinking Across the Curriculum. Upper Saddle River, NJ: Pearson Prentice Hall, 2009.

Nunan, Richard. "The Libertarian Conception of Corporate Property: A Critique of Milton Friedman's Views onthe Social Responsibility of Business." Journal of Business Ethics, Vol. 7, No. 12 (1988): 891-906.

Nussbaum, Martha. Not for Profit: Why Democracy Needs the Humanities. Princeton University Press, 2012.

Osterhout, Jacob. "Stealth Marketing: When You're Being Pitched and You Don’t Even Know It!” NYDailyNews.com, 2010. http://www.nydailynews.com/life-style/stealth-marketing-pitched-don-article-1.165278. (accessed November 23, 2013).

O’Sullivan, Patrick, Mark Smith, and Mark Esposito. Business Ethics: A Critical Approach: Integrating Ethics Across the Business World. New York: Routledge Publishing, 2012.

Oyez: U.S. Supreme Court Media. "Santa Clara County versus Southern Pacific Railroad, 1886, Summary.” Chicago-Kent College of Law, 2013. http:// www.oyez.org/cases/1851-1900/1885/0. (accessed November 23, 2013). 
Oyez: U.S. Supreme Court Media. "Citizens United vs. Federal Election Commission." 2008. http://www.oyez.org/cases/2000-2009/2008/2008 08205.

Paul, Richard. "The Critical Thinking Polarities." Keynote Address, 33rd International Conference on Critical Thinking and Education Reform. Berkeley, California: July, 2013.

- A Glossary of Critical Thinking Terms and Concepts. Tomales, CA: Foundation for Critical Thinking, 2009.

— "Reflections on the Nature of Critical Thinking, Its History, Politics, and Barriers, and on Its Status across the College/University Curriculum Part I." Inquiry: Critical Thinking Across the Disciplines. 26:3. Winter, 2011.

— "Reflections on the Nature of Critical Thinking, Its History, Politics, and Barriers, and on Its Status across the College/University Curriculum Part II.” Inquiry: Critical Thinking Across the Disciplines. 27:1. Spring, 2012.

- A Thinker's Guide for Those Who Teach on How to Improve Student Learning. Tomales, CA: Foundation for Critical Thinking, 2011.

— Critical Thinking: What Every Person Needs to Survive in a Rapidly Changing World. Tomales, CA: Foundation for Critical Thinking, 1990.

- $\underline{\text { http://www.criticalthinking.org/pages/critical-thinking-distinguishing-be- }}$ tween-inert-information-activated-ignorance-activated-knowledge/488.

Paul, Richard, and Linda Elder. A Miniature Guide for those who Teach on How to Improve Student Learning. Tomales, CA: Foundation for Critical Thinking, 2006.

- Critical Thinking: Concepts and Tools. Tomales, CA: Foundation for Critical Thinking, 2009.

- Critical Thinking Website. Tomales, CA: Foundation for Critical Thinking, 2013. http://www.criticalthinking.org. (accessed November 23, 2013).

— The Thinker's Guide to Analytic Thinking. Tomales, CA: Foundation for Critical Thinking, 2007.

— The Thinker's Guide to the Art of Socratic Questioning. Tomales, CA: Foundation for Critical Thinking, 2007.

— The Thinker's Guide to Ethical Reasoning. Tomales, CA: Foundation for Critical Thinking, 2006. 
- The Thinker's Guide to How to Improve Student Learning. Tomales, CA: Foundation for Critical Thinking, 2011.

- The Thinker's Guide to How to Write a Paragraph: The Art of Substantive Writing. Tomales, CA: Foundation for Critical Thinking, 2007.

Peregrine, Michael. "Another View: Sarbanes-Oxley and the Legacy of Enron." The New York Times Company, 2011. http://dealbook.nytimes.com/2011/11/25/another-view-sarbanes-oxley-and-the-legacy-of-enron/. (accessed November 23, 2013).

Picchi, Aimee. "Madoff Makes Millions... and It's Legit." The Fiscal Times, 2013. http://www.thefiscaltimes.com/Articles/2013/02/05/Madoff-MakesMillions-and-Its-Legit\#page1. (accessed November 23, 2013).

Pieklo, Jessica. "Court Rules Hobby Lobby can be Considered a Religious Person.” RH Reality Check, 2013. http://rhrealitycheck.org/article/ 2013/06/27/court-rules-hobby-lobby-can-be-considered-a-religiousperson/. (accessed November 23, 2013).

Planet Money. "Episode 266: A Former Crack Dealer on the Economics of Drugs." National Public Radio, 2013. http://www.npr.org/blogs/money/ 2012/10/05/162383174/episode-266-a-former-crack-dealer-on-the-economics-of-drugs. (accessed November 23, 2013).

Planet Money. "Episode 403: What Can we Do with our Shell Companies?" National Public Radio, 2013. http://www.npr.org/blogs/money/ 2012/09/18/161358307/episode-403-what-can-we-do-with-our-shell-companies. (accessed November 23, 2013).

Planet Money. "Episode 408: How to Hide Money from your Spouse." National Public Radio, 2013. http://www.npr.org/blogs/money/ 2012/10/09/162580794/episode-408-how-to-hide-money-from-yourspouse. (accessed November 23, 2013).

Planet Money. "It's Legal to Sell Marijuana in Washington. But Try Telling that to a Bank." National Public Radio, 2013. http://www.npr.org/blogs/ money/2012/11/16/165245222/its-legal-to-sell-marijuana-in-washingtonbut-try-telling-that-to-a-bank. (accessed November 23, 2013).

Planet Money. "A Billion-Dollar Bet Against Weight-Loss Shakes.” National Public Radio, 2013. http://www.npr.org/blogs/money/ 2013/01/18/169719749/episode-431-a-billion-dollar-bet-against-weightloss-shakes. (accessed November 23, 2013). 
Plato. "The Republic, Book II." The Internet Classics Archive, 2009. http:// classics.mit.edu/Plato/republic.3.ii.html. (accessed November 23, 2013).

Pocock, Jennifer. "How Vermicomposting Works." How Stuff Works, 2013. http://home.howstuffworks.com/vermicomposting1.htm. (accessed November 23, 2013).

Poitras, Geoffrey. "Shareholder Wealth Maximization, Business Ethics and Social Responsibility." Journal of Business Ethics, Vol. 13, No. 2 (1994): 125-134.

Powell, Sondra. "Answer to the Central Question.” Personal statement requested by author. Louisville, KY, 2013.

Professional Exam Review. The Mortgage Broker and Loan Officer Core Education. Mason, OH: Cengage Learning, 2010.

Project Censored. "Number 11. The Media can Legally Lie." Project Censored, 2015. http://www.projectcensored.org/top-stories/articles/11-themedia-can-legally-lie/. (accessed November 23, 2013).

Project Censored. "Number 13. Corporate Personhood Challenged." Project Censored, 2010. http://www.projectcensored.org/top-stories/articles/13corporate-personhood-challenged/. (accessed November 23, 2013).

Radcliffe, Dana. "Should Companies Obey the Law if Breaking it is More Profitable?" Huffington Post, 2013. http://www.huffingtonpost.com/danaradcliffe/should-companies-obey-the-law_b_1650037.html. (accessed November 23, 2013).

Redman, Elizabeth. "Three Models of Corporate Social Responsibility: Implications for Public Policy." Elizabeth Redman, 2004. http://files.meetup.com/1325336/Three\%20Models\%20of\%20CSR.pdf. (accessed November 23, 2013).

Reeves, M. Francis. "An Application of Bloom's Taxonomy to the Teaching of Business Ethics." Journal of Business Ethics, Vol. 9, No. 7 (1990): 609-616.

Reilly, B.J., and M.J. Kyi. "Economics and Ethics." Journal of Business Ethics, Vol. 9, No. 9 (1990): 691-698.

Reynolds, Scott J., and Norman Bowie. "A Kantian Perspective on the Characteristics of Ethics Programs.” Business Ethics Quarterly, Vol. 14, No. 2 (2004): 275-292. 
Richardson, John. Annual Editions: Business Ethics. New York: McGrawHill, 2011.

Rogers, Mark. "Sarbanes-Oxley 10 Years Later: Boards are Still the Problem." Forbes, 2012. http://www.forbes.com/sites/frederickallen/2012/07/29/sarbanes-oxley-10-years-later-boards-are-still-the-problem/. (accessed November 23, 2013).

Ruggiero, Vincent R. Thinking Critically About Ethical Issues. 7th ed. Boston: McGraw-Hill Higher Education, 2008.

Ruggiero, Vincent R. Beyond Feelings: A Guide to Critical Thinking. 9th ed. New York: McGraw-Hill, 2012.

Sadler, Gregory. "Philosophy Core Concepts: Jeremy Bentham, The Hedonic Calculus." November, 2012. Uploaded by Gregory B. Sadler. http:// www.youtube.com/watch?v=5MAygHXUwtk. (accessed November 23, 2013).

Saldana, Dave. "A Law Against Lying on the News: Why Canada has One and the U.S. Doesn't.” Positive Futures Network, 2011. http:// www.yesmagazine.org/people-power/a-law-against-lying-on-the-news. (accessed November 23, 2013).

Salmon, Merrilee H. Introduction to Logic and Critical Thinking: Instructor's Edition 6th ed. Boston: Wadsworth, 2013.

Sandel, Michael, and others. "Forum: How Markets Crowd Out Morals--A Forum on the Corrupting Effects of Markets." Boston Review, 2012. http:// www.bostonreview.net/forum-sandel-markets-morals. (accessed November 23, 2013).

Sandel, Michael. "Justice: What's the Right Thing to Do? Episode 6." The President and Fellows of Harvard College, 2011. http://www.justiceharvard.org/2011/02/episode-06/. (accessed November 23, 2013).

Sandel, Michael. "Justice: What's the Right Thing to Do? Episode 7." The President and Fellows of Harvard College, 2011. http://www.justiceharvard.org/2011/02/episode-07/. (accessed November 23, 2013).

Sandel, Michael. What Money Can't Buy: The Moral Limits of Markets. New York: MacMillan, 2012.

Schaefer, Brian P. "Shareholders and Social Responsibility." Journal of Business Ethics, Vol. 81, No. 2 (2008): 297-312. 
Schick, Theodore, and Lewis Vaughn. How to Think About Weird Things: Critical Thinking for a New Age. 5th ed. Boston: McGraw-Hill Higher Education, 2008.

-How to Think About Weird Things: Critical Thinking for a New Age. 6th ed. Dubuque, IA: McGraw-Hill, 2011.

Shaw, Bill. "A Reply to Thomas Mulligan's "Critique of Milton Friedman's Essay 'The Social Responsibility of Business to Increase Its Profits."” Journal of Business Ethics, Vol. 7, No. 7 (1988): 537-543.

Shaw, William. "Marxism, Business Ethics, and Corporate Social Responsibility." Journal of Business Ethics, Vol. 84, No. 4 (2009): 565-576.

Shaw, William. Business Ethics: A Textbook with Cases. Mason, OH: Cengage Learning, 2010.

Shaw, William, and Vincent Barry. Moral Issues in Business. Mason, OH: Cengage Learning, 2013.

Shepard, Jon M., Jon Shepard, James C. Wimbush and Carroll U. Stephens. "The Place of Ethics in Business: Shifting Paradigms?" Business Ethics Quarterly, Vol. 5, No. 3 (1995): 577-601.

Sims, Ronald. Teaching Business Ethics for Effective Learning. Westport, CT: Praeger, 2002.

Smith, Adam. "An Inquiry Into the Nature and Causes of the Wealth of Nations, First Edition.” The Electronic Classics Series, 2005. http:// www2.hn.psu.edu/faculty/jmanis/adam-smith/wealth-nations.pdf. (accessed November 23, 2013).

Smith, Adam. "The Theory of Moral Sentiments, 6th Edition." The Liberty Fund, 2000. http://www.econlib.org/library/Smith/smMS.html. (accessed November 23, 2013).

Smith, David. "An Introduction to Ethics for Business People Making the Right Decision: Ethics for Managers by William D. Hall" Business Ethics Quarterly, Vol. 5, No. 1 (1995): 157-161.

Society of Professional Journalists. "SPJ Code of Ethics." Society of Professional Journalists, 2013. http://www.spj.org/ethicscode.asp. (accessed November 23, 2013). 
"Corporate Advertising and Commercialization on College Campuses." Sociological Cinema, October 15, 2011. www.thesociologicalcinema.com/1/ post/2011/10/corporate-advertising-and-commercialization-on-collegecampuses.html. (accessed November 23, 2013).

Stuff You Should Know Website. "How Corporate Personhood Works." Discovery Communications, 2013.http://www.stuffyoushouldknow.com/podcasts/how-corporate-personhood-works/Chapter 8. (accessed November 23, 2013).

__ "How Money Laundering Works." Discovery Communications, 2013. http://www.stuffyoushouldknow.com/podcasts/how-money-launderingworks. (accessed November 23, 2013).

"How Satire and Greenwashing Provide us an Easy Ticket Back to our LaZ-Boys.” Discovery Communications, 2013. http://www.stuffyoushouldknow.com/blog/23928. (accessed November 23, 2013).

"What Exactly is the Peter Principle?" Discovery Communications, 2013. http://www.stuffyoushouldknow.com/podcasts/what-exactly-is-the-peterprinciple/. (accessed November 23, 2013).

_ “What's the Ultimatum Game?" Discovery Communications, 2013. http:// www.stuffyoushouldknow.com/podcasts/is-a-free-market-free-if-its-regulated/. (accessed November 23, 2013).

This American Life. "Mr. Daisey and the Apple Factory." The Internet Archive, 2012. http://archive.org/details/thisamericanlife-misterdaisey. (accessed November 23, 2013).

_ "Retracting Mr. Daisey and the Apple Factory." National Public Radio, 2012. http://www.thisamericanlife.org/radio-archives/episode/460/retraction. (accessed November 23, 2013).

Transition United States. "Transition US Webpage.” Transition US and International Transition Network, 2013. http://transitionus.org/. (accessed November 23, 2013).

U.S. Securities and Exchange Commission. "Sarbanes-Oxley Act of 2002." U.S. Securities and Exchange Commission, 2013. http:/www.sec.gov/ about/laws.shtml\#sox2002. (accessed November 23, 2013).

Uzgalis, William. “4.3. [John Locke's] Social Contract Theory.” Stanford Encyclopedia of Philosophy, 2012. http://plato.stanford.edu/entries/locke/\#. (accessed November 23, 2013). 
Van Heerden, Auret. "Making Global Labor Fair." Ted Conferences, 2010. Uploaded by TED. https://www.youtube.com/watch?v=okQXrB7y_Aw. (accessed November 23, 2013).

Vandana, Shiva, ed. Manifestos on the Future of Food \& Seed. Brooklyn: South End Press, 2007.

Vaughn, Lewis. The Power of Critical Thinking: Effective Reasoning About Ordinary and Extraordinary Claims: Instructor's Edition. New York: Oxford University Press, 2013.

Werhane, Patricia H. "Business Ethics and the Origins of Contemporary Capitalism: Economics and Ethics in theWork of Adam Smith and Herbert Spencer." Journal of Business Ethics, Vol. 24, No. 3 (2000): 185-198.

Vaidhyanathan, Siva. The Googlization of Everything (And Why We Should Worry). Los Angeles: University of California Press, 2012.

"Vermicomposting." Vermicomposting, 2009. http://vermicomposting.com/. (accessed November 23, 2013).

Verschoor, Curtis C. "A Study of the Link between a Corporation's Financial Performance and Its Commitment toEthics." Journal of Business Ethics, Vol. 17, No. 13 (1998): 1509-1516

Wake Up World. "Will Allen Talks us through Growing Power: Aquaponics." 2011. Uploaded by Wake Up World. http://www.youtube.com/watch? v=JOaS5OtIsbs. (accessed November 23, 2013).

Walton, Douglas N. Informal Logic, A Handbook for Critical Argumentation. Cambridge University Press, Cambridge, 1989.

Watkins, Sherron, and Mimi Swartz. "Book Discussion on Power Failure: The Inside Story of the Collapse of Enron.” C-SPAN Video Library, 2003. http://www.c-spanvideo.org/program/176149-1. (accessed November 23, 2013).

Wells, Thomas. "Recovering Adam Smith's Ethical Economics." The Philosopher's Beard, 2012. http://www.philosophersbeard.org/2011/10/recovering-adam-smiths-ethical.html. (accessed November 23, 2013).

Werhane, Patricia H., et. al. Obstacles to Ethical Decision-Making: Mental Models, Milgram, and the Problem of Obedience. Cambridge: Cambridge University Press, 2013. 
Wicks, Andrew C. "The Business Ethics Movement: Where Are We Headed and What Can We Learn from Our Colleagues in Bioethics?" Business Ethics Quarterly, Vol. 5, No. 3 (1995): 603-620.

Wikipedia. "Dialectical Materialism.” Wikimedia Foundation, Inc., 2013. http://en.wikipedia.org/wiki/Dialectical_materialism. (accessed November 23, 2013).

__ "Invisible Hand.” Wikimedia Foundation, Inc., 2013. http://en.wikipedia.org/wiki/Invisible_hand. (accessed November 23, 2013).

__ “Post Hoc Ergo Propter Hoc.” Wikimedia Foundation, Inc., 2013. http:// en.wikipedia.org/wiki/Post_hoc_ergo_propter_hoc. (accessed November 23, 2013).

_ “Small-world Experiment." Wikimedia Foundation, Inc., October, 2013. http://en.wikipedia.org/wiki/Small-world_experiment. (accessed November 23, 2013).

Wilcke, Richard. "An Appropriate Ethical Model for Business and a Critique of Milton Friedman's Thesis.” The Independent Review, 2004. http:// www.independent.org/pdf/tir/tir_09_2_2_wilcke.pdf. (accessed November 23, 2013).

Wishloff, Jim. "The Land of Realism and the Shipwreck of Idea-ism: Thomas Aquinas and Milton Friedman on the Social Responsibilities of Business." Journal of Business Ethics, Vol. 85, No. 2 (2009): 137-155.

Woermann, Minka. On the (Im)Possibility of Business Ethics: Critical Complexity, Deconstruction, and Implications for Understanding the Ethics of Business. New York: Springer, 2013.

Wood-Wright, Natalie. "The Nag Factor: How do Children Convince their Parents to Buy Unhealthy Foods?" Johns Hopkins Bloomberg School of Public Health, 2011. http://www.jhsph.edu/news/news-releases/2011/ borzekowski-nag-factor.html. (accessed November 23, 2013).

Wyatt, Kristen. "Court: Hobby Lobby can Challenge Health Care Law.” Huffington Post, 2013. http://news.yahoo.com/court-hobby-lobby-challengehealth-care-law-175533290.html. (accessed November 23, 2013).

“Hobby Lobby won't have to Pay Millions in Fines as it Challenges Obamacare Birth Control Mandate.” Huffington Post, 2013. http://www.huffingtonpost.com/2013/06/27/hobby-lobby-birth-control-mandate_n_3511445.html. (accessed November 23, 2013). 
Yglesias, Matthew. "America's Food Factories: Why Making a Chipotle Burrito or a McDonald's Big Mac should be Considered Manufacturing." The Hive: Collective Wisdom, 2013. http://hive.slate.com/hive/made-americahow-reinvent-american-manufacturing/article/americas-food-factories (accessed November 23, 2013).

Yovanovich, Gordaria, ed. New World Order: Corporate Agenda and Parallel Reality. Hoboken, NJ: McGill Queen's University Press, 2003.

Zimmerman, Michael. "Intrinsic vs. Extrinsic Value.” Stanford Encyclopedia of Philosophy, 2010. http://plato.stanford.edu/entries/value-intrinsic-extrinsic/>. (accessed November 24, 2013). 


\section{APPENDIX 1 (FOR TEXTBOOK ARTIFACT) LOOKING AHEAD FROM HERE}

Introduction to the Ideas in this Appendix:

This appendix offers suggestions for exploring ethical ideas in assignments. As a result of several of these assignments and applications, I elected to include them for interested teachers, students, and researchers in a preface. More applications will be added in subsequent editions of this textbook. Those wishing to contribute their applications and assignments for future editions of this text should email their material directly to the author at brian.barnes@1louisville.edu. Please include "textbook" in your subject line and your telephone and snail mail contact information in the email.

\section{A Christmas Carol}

Use Charles Dickens' A Christmas Carol as the basis for exploring business ethics. In Louisville, the local Actors Theater of Louisville presents a theatrical version of the novella annually, and many in Louisville engage in the tradition of seeing this show with 
families, friends, and school groups. It's not a long piece of writing; someone could very reasonably read it to a group annually. The original printing is available online.

Dickens was an outspoken critic of the exploitation of the poor by the wealthy. Much

of this exploitation occurred against the 19th century backdrop of the European Industrial Revolution in Dickens's works, where the exploitation of workers was apparent. While the exploitation on the part of the Scrooge, the main character in A Christmas Carol, is not as serious as in, say, Hard Times (the first chapter is available online), Dickens paints a character that is isolated and miserable, despite his wealth. This presents an opportunity to talk about the potential social consequences of operating only with profit in mind. While one might hope that many students will find Scrooge to be a caricature, there are worthwhile aspects of the text for application to business ethics theories, thus supporting the goals of this text. With reference to the central question, we might ask who Scrooge is harming, if anyone.

\section{Mr. Daisey and the Apple Factory}

Mike Daisey is a storyteller who achieved national fame through his National Public Radio show about his visit to China and his observations of the labor conditions there. His show is moving, and it causes us to think about foreign labor in some very powerful ways. Listen to the audio of his program, Mr. Daisey and the Apple Factory. There are profound implications for our consumer-driven lifestyles and our individualisms 
There is more to the story, though. This American Life, the show that aired Daisey's presentation, found that there were questions about his methods, his facts, and, possibly, the conclusions he drew. They aired a second episode to explore all of that.

Business ethics students can certainly examine the labor issues involved with this study. Do human beings deserve more dignity than Daisey suggests they are getting in the Apple factory? Kant might think so. Who is benefiting the most from the situations he describes? Bentham or Mill might have something to say about that. Did Daisey himself operate only for his own interests? What kind of a society is being built for the sake of our stuff? Teachers can come up with plenty of other assignments related to journalism ethics, manufacturing ethics, regulation, disclosure, and on and on.

\section{Bridging the Divide}

In 2007, The Community Farm Alliance in Louisville released a report called Bridging the Divide: Growing Self-Sufficiency in Our Food Supply. This report identified three areas of the Louisville metropolitan area that it classified as food deserts, according to federal guidelines. Since that report, many steps have been taken, mainly by government, but also by private interests, to address the various problems raised in the report. Teachers using this text may be aware of similar problems with food deserts in their own areas.

I send students into the food deserts to locate the areas where problems were identified in the report I ask them to make their own short films, typically 3-5 minutes, which I ask them to post to YouTube. Many of the films are about tying business ethics theories to the situations as they exist at the time of the investigation. Other videos investigate 
whether there is or should be updating to the food desert problem. Others address ways to apply business ethics ideas, like sustainability, to the problem as it exists. In all cases, the videos should tie in some business ethics theories and data from Bridging the Divide. There are samples out there for teachers and students wanting to try this assignment. Searching YouTube for "Louisville" and "Business Ethics" should produce a healthy number of student videos. Others can be found if you search "Panama" and "Business Ethics;" many of those videos address problems of trash pollution in that city.

All of my student videos, in addition to the ethics component, contain strong critical thinking content. I typically ask students to include interviews, a central question of their own, and other class-specific features, in addition to what has already been mentioned. A more detailed assignment for video projects will produce better videos, in my experience. I often offer this assignment as a group project.

\section{Whistleblowing}

An excellent way to explore whistleblowing is through media like the 1999 film The Insider with Russell Crowe and Al Pacino. There is also the whistleblowing that is the catalyst for Enron's downfall in The Smartest Guys in the Room and its whistleblower, Sherron Watkins. Get more information on whistleblowing and its heroes from the Government Accountability Project's American Whistleblower Tour.

If time permits, teachers could explore an excellent play, called An Enemy of the People from the 19th century playwrite, Henrik Ibsen. In it, Dr. Thomas Stockman discovers that the water at the baths he supported his town in building for the tourist trade 
have become contaminated. The polluted water will be harmful to human health. As Stockman tries to blow the whistle on this problem, he is opposed from all sides. Ambitious students might decide to produce the play with contemporary struggles of similar type. It could be a great semester project from many points of view. 


\section{APPENDIX 2 (FOR TEXTBOOK ARTIFACT)}

\section{ANSWERS TO THE CENTRAL QUESTION}

Introduction to the Ideas in this Appendix: When is it acceptable to profit from harm to others in business?

This is the central question for my course on business ethics at the university level. Students using this text for that course will answer this question at the beginning of the class without having any training, and they will answer it again at the end of the course. At the time of this writing, the first answer is worth $5 \%$ of the course grade, and the last answer is worth $20 \%$. These answers are typically written in class without benefit of notes. By the end of the course, I expect that students have something significant to say on the topic they have been studying for some weeks.

The answers below are not from students in my business ethics classes, though each of them has discussed business ethics with me at some length. These writers are all involved in some kind of business in the Louisville area, and each of them has significant things to say in response to the question. I offer these answers to provide discussion ma- 
terial for the class as we all consider the question, "When is it acceptable to profit from harm to others in business?"

\section{Matthew Hawthorne}

My initial response was a simple "never." Giving it a bit more thought, I realize that's overly simplistic, but it still serves as a good baseline position.

What got me thinking a bit more in depth on it was health care - I can see health care as profiting from harm to others (not harm caused by the people profiting, at least not in any direct sense, but still profiting from harm to others). And while I firmly think that hospitals and insurance should be non-profit (at least - preferably public, too), I also can't argue against paying the providers well (though perhaps less well than they are currently paid - sorry to my physician friends). Likewise, I can see business models that are actually meant to do well out of solving other people's problems - lawyers, for example, especially personal injury/tort lawyers, get paid only because someone else was harmed.

So using those examples as a bit of a brief guide, it basically comes down to only being acceptable to profit from harm to others when you are 1) not the cause of that harm, 2) only if you are assisting the others to recover from that harm, and 3) only if that profit is reasonable (and that's * really* undefined, but best I have right now).

I still believe the response to harm of others should be simple compassion. Your response does have to be balanced with a need to live your own life, though. I'm still thinking on it, but I don't see, right now, a situation where I see it as acceptable to profit from harm to others that doesn't fulfill the three things above. 
Matthew's Bio:

Matthew Hawthorne, J.D., M.B.A., received his BA in Philosophy from Hanover College in 2002, his J.D. from the University of Louisville in 2005, and his M.B.A. from the University of Louisville in 2011. He has worked in the Office of Technology Transfer at the University of Louisville since 2003, and currently handles all aspects of software and other copyright disclosures, including evaluation, marketing, valuation and licensing; as well as engaging in agreement drafting and negotiation and assisting various offices of the Office of the Executive Vice President for Research and Innovation in assuring compliance with UofL's IP policy.

\section{Phil Dowdle}

It is not acceptable to profit from harm to others. In those simple terms that seems perfectly obvious; however, the realities of commerce, modern technology, and the comforts and conveniences to which the developed world has become accustomed have resulted in tremendous harms and inequalities in both the developed and developing worlds. These amenities do require sacrifices, and it would seem that those could be borne in an equitable way. The modern choice ignores the necessity of that sacrifice and the presumptive delayed rewards. One specific example of this harmful modern choice is the prevalence of "NIMBY-ism". Until such attitudes are reconciled with commerce and the common good, the reality of some gaining profit through harm to others will undoubtedly continue.

Phil's Bio: 
Philip R Dowdle holds a BSc in Environmental Science, Policy, and Management: Soil Environment from UC Berkeley and an Advanced Accounting Certificate from Bellarmine University in Louisville, KY. He spent several years investigating the microbial transformation of selenium, arsenic, and mercury as a team member in the National Research Program of the US Geological Survey and contributed to several articles published in the journals of the American Society of Microbiology, American Chemical Society, and American Geophysical Union. He subsequently rose through a management training program with Wild Oats Markets, purveyor of natural and organic food. He currently is the controller at a start-up hoping to revolutionize 3D printing systems and expedite processes in nanotechnology and also advises individuals and small businesses. He lives in Louisville, KY, with his wife and two sons.

\section{Gary Heine}

This is an interesting question. I can't say I ever thought of this idea in this particular way. You'd think most people would say, "It's never permissible to profit from harm to others in business." Yet, our society is set up to run on profits being created while doing harm from to others. Look at mountain-top coal removal, for example. This important component of our energy production makeup is keeping us warm in the winter and cool in the summer. It is lighting our schools and running our factories. And at the same time, it is destroying million-year-old mountains, their ecosystems, and the people and communities living on and around them. 
This sort of harm happens on a small scale all the time in our businesses, and in the one I ran for many years. For example, most companies that provide goods and services for us all and that employ us also throw away their waste, from paper to manufacturing scrap, from food waste to coffee grounds. Here in Louisville, it has taken many years for business recycling collection to be undertaken by the city. But it's too easy to blame city government for not picking up our recyclable waste, for example. As if it's the government's responsibility.

In the early days of Heine Brothers' Coffee, say around 1994-95, we threw our recyclable waste away in the dumpster. No one was really talking about business recycling in those days (it was 2010 before a small pilot project for business recycling was started in the city.) In those early days, residential recycling pickup was happening in the city, although less than $50 \%$ of residents actually took advantage of the program.

My business partner and I could see the amount of cardboard, office paper, plastic milk cartons, aluminum cans, paper cups, newspapers and magazines that we were throwing out in the dumpster every day. We shared our dumpster with the bookstore next door, so could see the double accumulation of their huge paper recycling waste - unsold books and magazines and empty cardboard boxes - and ours filling up this dumpster twice a week. We had to switch to a larger dumpster to "take care" of the waste.

We tried getting the bookstore next door to break down its empty cardboard boxes so there would be more room in the dumpsters. As if that was the problem. Gradually, my business partner and I started to think that it was, in fact, our personal and business re- 
sponsibility to reduce our waste as much as possible and to recycle our waste on our own, government pickup or not. The truth was, it seemed to us, was that it was our waste and we were responsible to recycle it. It would be great if the city would pick it up. But they weren't, and who knew when they might start such a collection.

So we started using both sides of our fax pages that were sent and received every day between our two stores, our office, and our coffee roastery. We started to pay our employees to break down our recyclable waste as part of their daily jobs and collect them at each store, the office, and the roastery for other paid employees to pick up twice a week. Then these employees would fill up our delivery van with boxes of compostables, bring them to the recycle stations, and unload the van into the recycling bins there.

It worked well and made us feel better. Our staff and customers liked that we did this, too. Did we save money because we filled up our dumpsters less or needed smaller dumpsters at our stores? Perhaps, we never really calculated this. More likely, in the short term, we paid more to recycle it than it cost us to dump it when you factor in the cost of paying employees to pick it up and the cost of the vehicle to take the recycling to the collection site.

But the problem with these sorts of calculations is that you don't figure in the longerterm harm to the environment to throw our recycling in the landfill. You don't figure in the cost of the landfill's methane gas despoiling our air or runoff polluting our water or contaminants from the garbage harming our soil. Too often, we just calculate our personal 
costs as if that's all there is to think about. We don't think about the harm we do to others, the environment, and ourselves in the long run, by running our businesses.

Anyway, this is just a small example from my experience to help illuminate the question asked. So, when is it permissible to profit from harm to others in business? In my opinion, never. But we do it anyway because we don't think about it. Fortunately, more and more people are taking steps towards greater clarity in their thinking around this. But we need much more clear thinking and focused action around this subject - to consider all the effects our businesses have on each other, our communities and the environment, and to make these considerations a primary building block in our business practices.

Gary's Bio

Gary Heine is the former co-owner of Heine Brothers' Coffee, a fair trade, organic coffee company in Louisville, KY. He has cofounded several non-profits. One, Cooperative Coffees, was the world's first cooperative that purchased fair trade, organic green coffee from coffee farmers around the world. Another, Breaking New Grounds, composted the coffee grounds from his company with other local food waste to create worm compost to help rebuild the community's soils. Another, 15 Thousand Farmers, taught people how to grow food simply in their back or front yards.

\section{Mith Barnes}

I don't think it is ever acceptable to profit from doing harm to others, in business or anywhere. And I count lying as harm. I spent years in the advertising industry, and it took most of those years before I got around to considering this question. In working on adver- 
tising for a variety of clients and products or services, I'm not aware of any instance when we lied outright. Most of my career was spent working on wine accounts, and barring legality and responsibility warnings, we were largely trying to sell a feeling. Carefree, relaxed, gourmet, sophisticated, laid-back - it depended on the brand. While there was the inherent deception involved with suggesting that a bottle of wine will make your troubles melt away, I didn’t feel bad about my work on those accounts.

When my outlook on my work really changed was when I moved to a new company, and was assigned to a large (though local) corporation that ran almost a dozen nursing homes. Let me be clear, nursing homes are awful (something I observed firsthand when relatives entered some of the homes run by my client). They may serve a vital function in the care of the aging, but they really are awful. Yet I spent almost three years gathering images of happy, smiling senior citizens, friendly-looking nurses, and glowing sunlit moments, all so we could help this company make millions convincing people nursing homes were happy, wonderful, dignified places. After a while, I realized that I wasn't helping seniors, I was helping the corporation continue to run substandard facilities while covering it up with a veneer of pretty pictures. I was also helping ease the guilt of adult children whose parents were entering nursing care, but it was a lie. No, that's not clear enough. I was enabling and disguising real harms to seniors.

Not only was the corporation profiting from harm to others (its residents), our agency was profiting from our own choice to propagate the lie about what those residents really experienced. I came to realize then that advertising is almost always a lie. Putting out facts doesn't sell product. The entire mechanism of advertising is all about convincing as 
many people as possible that this product or that service will make their lives better, will make THEM better, smarter, funnier, more popular, more cultured, happier.... It's really not much different than a pusher on a street corner. Come on, just a hit and you'll feel so much better. And if we admit that the pusher does harm, then so does the advertiser.

The consumer isn't utterly uninvolved in this fleecing, any more than the addict is wholly a victim, of course. Consumers want to believe that something they buy will make them or their lives better. Consumers, I learned, rarely want facts; they want a dream, a fantasy. Facts are boring. Then again, who trained up the current crop of utterly pitch-able conspicuous consumers? Us advertisers, madly scrambling to keep our clients on top, and of course, to keep ourselves on top. After all, we sell ourselves, too, and convince CEOs and Marketing Managers that we will make their company better, smarter, funnier, more popular....

That's when I realized I couldn't keep spending my days convincing people to buy more stuff, that nursing homes are happy places, that a bigger car will make them popular, and so on. I couldn't be a pusher. Not and look my young son in the eye. That's when I got out. I certainly can’t say I am not a consumer. But by using critical thinking, staying on top of what's really going on in the corporate world, and looking at facts, not fantasies, I do my best not to propagate the machine that lies and deceives, keeping society hooked on the drug of consumerism.

Mith's Bio: 
Mith Barnes spent over a decade in the advertising industry in Louisville and San Francisco before deciding to leave the industry altogether. Having earned a Master of Arts in Humanities from the University of Louisville, she is now a professor of Humanities at Bellarmine University. These days, her scholarship and teaching is dedicated to educating a more aware, critical, and globally minded generation.

\section{Sondra Powell}

To run a successful coffee business, we have to find the best quality product at the best prices for our customers. Opening our business, it didn't enter my mind that I might harm others when I would make a profit. "I just want to make some coffee, and coffee makes everyone happy." But then: How do you define "harm?" And how do you define "others?"

When I think of harm in business I envision an antebellum plantation with an enslaved workforce- harm in the physical sense. Of course, I would never do a thing like that! But where do coffee beans come from? Who are the coffee farmers and the workers and historically what that relationship had been like between the two? Coffee is grown predominately in developing countries; however it is consumed mostly in industrial countries. Growing coffee is a very labor-intensive crop grown by both small farm and large plantations. The coffee cherries ripen at different times and men and women of all ages pick the crops. (The idea of Juan Valdez is not a stretch of the imagination.) The raw coffee cherries are transported to central processing plants where they are sorted and readied for shipment by container to countries. There are few labor laws or unions in the coun- 
tries where many beans come from, and in the past the middle men in the industry have been notoriously exploitive to the small farmers, garnering the nickname "coyotes."

My company buys coffee through reputable importers who buy from farms that are paying at or above fair trade prices to combat this potential harm, today. I believe this is a way to combat the potential harm to the farmers. I also believe the coffee industry overall has been proactive in getting farmers a fair price for their crops.

But fair trade pricing isn't necessary a living wage. And the wages paid to the workers are not what we are accustomed to in this country. So while I try to do everything I can to ensure that the coffee I buy is cruelty free in every sense, it's hard to know what is really going at these foreign farms.

Apart from the laborers, the business includes other parties who are the sources for other needed goods. We have preferred sources for almost everything: from our green coffee, packaging or paper products or even dairy and drink mixes.

Most people would not even consider taking business away from one supplier and giving it to another as harm. But most typically make the final decision based on the bottom line. In a free-market society, this is understood to be acceptable and expected. Nonetheless, my business makes up a large share of some of the smaller companies I work with. They may have selected inventory specifically for us that may be harder to sell to other customers. If we stop buying from them, and switch to a larger suppliers to work with their business and even livelihoods could suffer. 
And would it be considered harm to profit from other business' failings? For example, to save on cost, it was a smart business move to purchase almost all of our roasting equipment at auction from companies that didn't survive. And perhaps we also profit from an acceptable harm when a new business starts up with a similar concept to ours, and we protect our own interests and customer retention through increased promotions and demos, all directly "inspired" by competing business.

Assessing harm also requires examining the practices of businesses we work with and how we compete. We are constantly working to expand and grow; oftentimes this means taking existing business in the form of customers or grocery store shelf space away from another coffee company. Does taking business away from the competition constitute harm? Although coffee roasters overall are a pretty civil bunch, we have established "gentleman's agreements" with other roasters in the city not to go after each other's established accounts in restaurants or stores. But we still need to be aggressive in business, which means we make sure we are where we need to be when we need to be there. For example we want to make sure we are at able to get our product in to potential customer's hands and in their memories. We need to be at eye level on grocery store shelves and handing out samples on the busiest demo days.

The easy answer is to say it is never acceptable to profit from harm to others in business, at least the physical harm of others. But in our society we profit from harm to others because of the way businesses operate in the free-market system. It takes the form of one company taking business from another and protecting and growing business interests. For our business, we try to cause as little harm as possible within the constraints of capitalist 
society. I believe that a business can offset and reconcile any perceived harm caused by good corporate citizenry. Our business works to stay involved in the neighborhood where we operate. We serve on the neighborhood board, volunteer for cleanups and donate to the picnics in the adjacent parks. We also do our best to be involved by donating to and volunteering with many nonprofits and charities. Being a small company does not inhibit us from trying to make a difference-everything from events for abused animals to visiting jails to mentor incarcerated women.

\section{Sondra's Bio}

Sondra Powell is the owner of Red Hot Roasters, a Kentucky Proud, organic coffee roaster located in Louisville, Kentucky. Learn more about her business at http:// www.redhotroasters.com/wordpress/.

Approximately forty other corporations, NGOs, government leaders, and businesspeople were asked to answer the question, but no other answers were received. 


\section{APPENDIX 3 (FOR TEXTBOOK ARTIFACT) PODCAST RESOURCES}

Introduction to the Podcasts in this Appendix:

Appendix 3 contains podcasts relevant to Business Ethics. There are many more out there; these are just samples from National Public Radio's Broadcasting and a few others. Chapters where they may be most relevant are noted after each link. Thanks to Elizabeth Irish for tracking down these podcasts.

Stuff You Should Know Podcasts

How Corporate Personhood Works

Is a free market "free" if it's regulated?

What's the ultimatum game?

What exactly is the Peter Principle?

$\underline{\text { How Money Laundering Works }}$

Money and Ethics channel

How Satire and Greenwashing Provide us an Easy Ticket Back to our La-Z-Boys 
Planet Money Podcasts

\#266 - A Former Crack Dealer on the Economics of Drugs

\#403 What we can do with our Shell Companies?

\#408 - How to Hide Money from Your Spouse

\#420 - The (Legal) Marijuana Business

\#431 A Billion Dollar Against Weight-Loss Shakes 


\section{APPENDIX 4 (FOR TEXTBOOK ARTIFACT) “SUSTAINABILITY VILLAGE” MODEL PROPOSAL}

University of Louisville Sustainability Village Project Proposal

Conceived and Developed by Brian Barnes, Philosophy Department

Submitted September 12, 2013

Introduction to the Sustainability Village Project

The 8-acre plot of the Henry Vogt manufacturing facility at 7th and Magnolia could be transformed into a Sustainability Education and Innovation Center, designed to function as The University of Louisville's Sustainability Village ("SV"). The property, controlled and offered by local philanthropist Henry Heuser, is being developed for local management of sustainability initiatives that will ultimately benefit Metro Louisville. The site would be owned and directed by $\mathrm{U}$ of $\mathrm{L}$, while its operations will serve the entire Metro community. The property is particularly situated to serve West-end neighborhoods where food insecurity is a reality and where sustainable systems, particularly those designed with low-income communities in mind, can be particularly useful. This site has 
enough room to showcase various sustainable systems in a permanent way, as well as becoming a model of sustainable agriculture (Mr. Heuser has indicated that the land is free of harmful contaminants), sustainable business, sustainable innovation, sustainable manufacturing, sustainable art, sustainable education paradigms, sustainable environmental research, and other sustainable systems development. The SV would become the premier destination for education about urban sustainability regionally, and the leadership of each area, all university and Metro partners, would be available to educate any and all stakeholders about the systems they use at the site. This proposal outlines various systems and models that could be part of U of L's Sustainability Village.

It has been strongly suggested that the project will be funded for the first five years with a university endowment. To develop its long-term sustainability, the project will sell composting memberships to local businesses and consumers, hold sustainability education workshops, collect consulting fees from corporations and other educational organizations, and manufacture and sell products like vermicompost, herbs, produce and fish from aquaponics, beekeeping products, and native plant cultivation. The director will write grants to secure additional funding for the organization. By the end of 30 months of operation, the aforementioned revenue streams will pay salaries and allow SV to redirect its university support in aid of other sustainability organizations that will spread resilient, replicable, reasonable, nature-based paradigms locally and regionally. 
Current Property Configuration

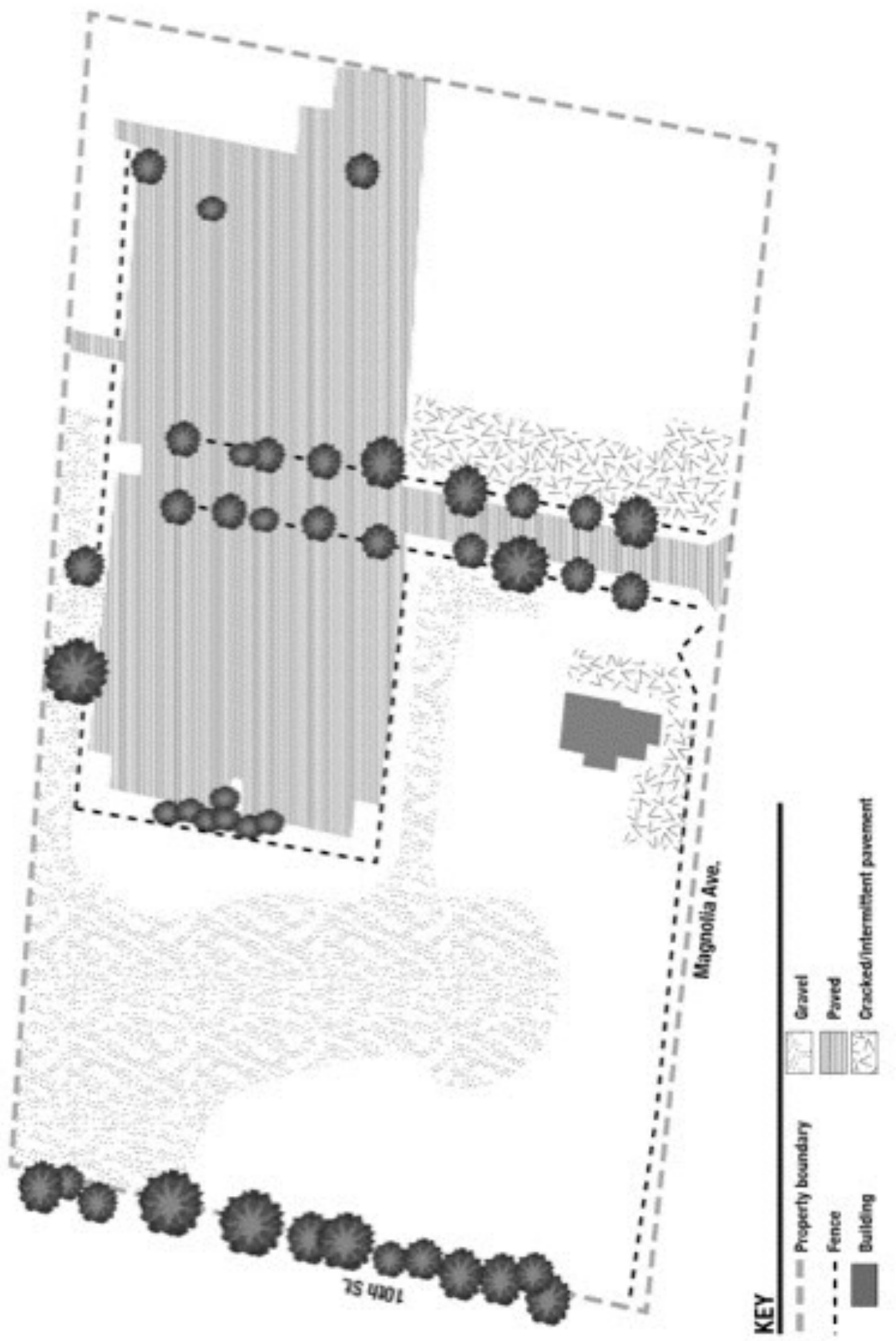




\section{The U of L Composting Project}

The Sustainability Village project is an outgrowth of the U of L Food Waste Composting Project, founded in 2010 to answer a question: "Is it possible to compost the majority of the food waste at $\mathrm{U}$ of $\mathrm{L}$ under a low-cost model, using human labor and handson composting methods?" Other important questions involved what to do with the compost, what the labor sources would be, and what support would be provided by the university, among other partners. Ultimately, this project began as a way to prove a concept about composting on an institutional scale without big, expensive machines. With a lowcost model of sustainable growth, using volunteer labor and inspiring community partners along the way, the Composting Project has proved its concept. U of L began composting the lion's share of its waste with Blue Skies Recycling in 2012, and The Composting Project has been finding niches of untapped compostable waste for its composting and vermicomposting projects since then. A partnership with The Root Cellar, which has been composting its waste with The Composting Project since The Root Cellar opened, blossomed after this transition. Josh Orr, an employee at The Root Cellar, began working to find partners to make a community composting operation in an urban setting. With his help, the Project has also accomplished that goal, as the project is increasing its penetration and visibility throughout the Highlands, Old Louisville, and West Louisville.

The project has composted over 110,000 pounds of waste to produce large amounts of compost and worm castings using a low-cost, human-labor-based model. The U of L Composting Project has used roughly 1,700 volunteer hours to accomplish this task and 
has made every effort to be as sustainable as possible. The only fuel-driven machine, for example, is the van used to pick up compostables from partners.

The project has given compost away to nearly 20 community garden projects across Louisville and augmented the planting projects of around 80 individuals from the $\mathrm{U}$ of $\mathrm{L}$ community and Metro since 2010. The compost and vermicompost are used annually in the garden beds at U of L's Garden Commons, and the new garden behind Urban Planning and Public Affairs was begun with this soil.

As an educational resource, The Composting Project brings over 150 students per year to the site from U of L, IUS, Bellarmine University, and JCTC to learn about sustainability and various aspects of the system. In addition, a dozen to twenty new community members visit the site to volunteer each year, and the Project has begun getting organizational labor through the Eco-Reps initiative. For example, Eco-Reps sponsored 40 SOUL volunteers from U of L in August of this year. The Project currently has two (2) volunteer assistant managers, one of whom is a graduate student, Angie Carlson, and one of whom is a non-university employee at The Root Cellar, Josh Orr. There is also one paid coordinator, Brian Barnes, who receives a stipend and is a part-time faculty member in the Philosophy Department.

As a community engagement endeavor, Angie Carlson has designed and is implementing a system to compost the waste from Miller Residence Hall. The Project already picks up coffee grounds from Ekstrom Library's coffee shop, The Tulip Tree. It also takes waste from a number of community partners: The Root Cellar, Quills Coffee (2 
locations), Sunergos Coffee (2 locations), Day's Coffee, Farm to Fork Catering, Luv-It Landscaping, and the Limerick Community Garden. It has established compost donation sites for community members to pick up empty 5-gallon buckets and drop off the full buckets of compostables, as suggested in the plan here, at Bluegrass Green on East Market Street and at Sunergos Coffee on Preston Street, near campus. The Composting Project provides compost to the two gardens on campus at Garden Commons and Urban Planning and Public Affairs. During the last twelve months, the Project has also supplied compost to the New Directions Housing Corporation for its community gardens and the Limerick Community Garden.

\section{Community Composting: Introduction}

One central process at the Sustainability Village is to create soil for community gardens and residential users. This product could be sold, and it could simultaneously be the foundation for a membership community. SV would provide donors of raw materials with some portion of finished compost or vermicompost, or they could direct their share to a community group. This is a new approach that will create excitement in the local gardening community. The model closes the loop between trash, soil, and produce, and the final model should be sustainable, scalable to different-sized operations, and replicable for all stakeholders (with some modifications.) Compost is made from trash. Good compost is a medium that can be used for planting crops in this region. SV can make that compost from trash donated by community partners. The Sustainability Village education and community missions are supported by the composting and other sustainability projects at SV. 


\section{The Community Composting System}

SV needs regular, high quality sources of nitrogen and carbon compostables in order to make its compost. In addition to these trash elements, other important needs for composting include time, which can be managed to some degree; heat, which is also manageable and determines the nature of the process and how long it takes; and water, which is available at the site and will be augmented by rainwater capture systems of various types and purification technology from WaterStep. Nitrogen compost will come from community partners; these could be businesses (or other groups) or individuals. SV has a separate protocol for getting waste from each type of partner.

Typically, individual partners will pick up 5-gallon buckets with "Feed the Dirt" stenciled on the side from the SV location. These buckets will be stored in a kiosk outside the Magnolia St. entrance; a staff member is not needed to facilitate the donation of buckets, nor to receive the compostables. A video camera will monitor the kiosk from the operations building inside the fence. Individuals will take one or two buckets with lids for their home or small office operations and return the buckets, when full, to the donation point next to the kiosk. Staff will process the buckets from there. Individuals may return and swap full buckets for empty ones at any time. It will be checked daily for full buckets to be processed and for refilling of the supply. Individuals can fill out an online form at SV's website to become part of the organization and have a bucket placed in the kiosk for them.

The buckets will be emptied into a composting dumpster or composting windrow by staff or volunteers. They will be rinsed with water at a station fed by rainwater collection, 
and the station will recapture the graywater for reuse. They will then be stored at a pallet house or other sustainably-constructed structure for drying and redistribution. This system will be developed within the first year.

Business partners will have their waste picked up at their business by SV staff, which could be university work-study students, some of whom would need drivers' licenses. The operation can use the Composting Project's van for pickups, though an additional van donated from surplus would need to be located as SV grows. Staff will swap clean buckets for the full buckets at the time of pick up, and a system will be developed for each business partner that will include their pick up day(s) and approximate time(s) each week.

During the first phase, any monies associated with the pickup and processing of the waste from business partners will be covered by university support. Near the end of the first two year period, business partners will be asked to begin paying a scaled fee for services, resulting in a donation from them. There are challenges with collecting this fee, since those businesses could always throw their waste into the landfill via normal curbside pickup. This program should produce enough benefits over the first two years for those businesses to recognize the value in paying the membership fees, which should include advertising for the businesses and access to various discounts and services for the development of any business partner's own sustainability characteristics. As mentioned above, donors will also receive a portion of the finished compost or vermicompost made from their waste, or they will have some ability to suggest which charitable organizations get their share of soil. 
The project will need at least four part-time (20-25 hours each) student workers to make the composting and vermicomposting happen each week, and another three to four part-time students for development and maintenance of the other systems. There should also be at least one full-time (salaried) manager. The buckets should be donations, the transportation will be the current decommissioned university vehicle being used for compost pickups, and its gas, insurance, and maintenance should be calculated by the university. The composting project currently spends around $\$ 30$ per month in gas for pickups. Structures used for the project are low-cost pallet and cobb buildings at this stage of the operation, which can be improved later as funds allow and needs arise.

SV will also be set up to accept donations of compostable material from community partners who are seeking a way to compost large, one-time sources of compostable waste. The composting management will make the decision about whether and where the system as a whole is able to process compostable wastes from a single, large donation. One-time waste donors will also be asked for a contribution to the project to cover labor, processing, and transportation costs, in addition to their waste donation.

$\mathrm{SV}$ is intends to provide consulting services for large and small sustainability projects. Community partners who do not want to use Sustainability Village's existing services, but who do want to compost their wastes by using a community model, can seek help in setting up a composting system at their site within parameters desirable to all stakeholders. This would be a for-fee consultancy that would fund the project and could happen at SV or at the business location. 
Carbon Sources will come from partnerships with U of L, local arborists, MSD clean up crews, and donations of carbon-based sources of waste. This kind of waste is primarily old tree limbs and leaves, including wood pulp products like cardboard and paper. Currently, $\mathrm{U}$ of $\mathrm{L}$ groundskeeping provides carbon material for the Composting Project. The university or other local partners would be identified for carbon sources. Accepting this kind of donation will entail the need for an industrial wood chipper as an early infrastructure addition. If dense wood pieces are not chipped, they will not contribute positively to the composting process, and composting will not occur within a reasonable timeline. SV could also develop a similar donation program to the nitrogen bucket program above by using 25-gallon trash cans for untreated paper or cardboard waste that has already been shredded. This shred could be managed for blending with nitrogen waste to make compost. This process could use U of L's shred or shred from other community partners. This waste material is likely to be readily available locally. Partners who wish to set up this system will have the cost of 25-gallon buckets built into their fees to SV.

SV will use two methods of composting: windrow composting and dumpster composting. SV will have windrows of compostable materials mixed and decomposing at the eastern side of the property. There are no community partners here (SEE MAP), and the land is open enough to compost in the field and to compost on the asphalt. Composting on the asphalt creates an opportunity to reduce Louisville's notorious heat island effect. SV will need two skid-steers (see Materials section) for regular windrow maintenance. This process, called "turning", is necessary for any actively-managed composting project of any size. Turning oxygenates the compost, which is desirable, since the primary bacte- 
ria that actively decompose the majority of the material are aerobic bacteria. Oxygenating of the material by exposing buried material to the air is the essence of this activity. Without at least one, but preferably two, pieces of heavy equipment for turning, this work will be untenable at this scale.

Using the backhoe attachment for the Bobcat (see materials), SV can turn the compost in dumpsters. In this way, SV can experiment with different compostables to create "small-batch composts", a product made of specific materials that can be offered at a premium price point to community partners. Composting in repurposed dumpsters is a method proven at the U of L Composting Project. Dumpsters will have catchment systems, and small solar pumps made of recycled materials will recirculate their liquid.

Water

Louisville water is available at the site, but SV will also capture rainwater to water the compost, recycle graywater from our cleaning processes, create an artificial wetland filtration system for blackwater from plumbing in the existing structure, and utilize WaterStep technology to connect water purification and aquaponics to innovate humanitarian disaster relief. The majority of human waste can be dealt with through the creation of dry composting toilets at the site made of reclaimed and donated materials. The waste from these toilets can be processed into vermicompost in a process separate from the site's commercial vermicomposting operations. Rainwater capture systems will be made with containers donated from Brown-Forman and other partners. 
WaterStep, the only local organization (and just one of two in the US) to be included in the Sustainia-100 publication, will partner at the site. WaterStep is a world leader in water purification and health and hygiene education, and it will provide its technology, brain power, and experience to help develop aquaponics systems at the site using innovative, low-cost, sustainable water purification technology. There are great opportunities to partner with U of L's engineering programs here, since WaterStep already operates a weekly engineering think tank with leaders from the Louisville Water Company and General Electric. This team can innovate aquaponic gardening for disaster relief and urban renewal in ways that only having such a laboratory as Sustainability Village can provide.

The leadership at SV will work with WaterStep leadership to develop aquaponics systems that will work with our soil and vermicompost. WaterStep will be developing innovative tools surrounding disaster relief and aquaculture; SV will be supporting that innovation in order to apply sustainable systems to the local food desert problems. Clean water technology, particularly derived from rainwater capture, is key. New technologies resulting in the partnership will lead to patents, intellectual property, and profit-sharing for U of L's Sustainability Village and for WaterStep.

\section{Sustainability Village's Educational Mission: Introduction}

Sustainability Village's educational mission will immediately target the university community, JCPS, and general sustainability education and innovation research around the Metro community. SV will have permanent learning stations around the property, but 
it will also require that all leadership at SV provide opportunities for stakeholders to learn directly from them: every operation on site must be explicitly attached to some sustainability principles, and those using the systems must be able to explain their use and their sustainability characteristics to any interested audiences. SV will host regular workshops as revenue-generating and community-building events, and it will eventually develop meeting space for other groups' educational events and for its own sustainability conference, which will also generate revenue for SV. That conference could not be developed until the end of the first five-year period.

Historical mapping could be developed at the site by educational projects through History and Urban Planning and Public Affairs. Anthropology could help identify cultural artifacts and the methods for preserving them as the site is developed. Biology could help develop soil testing protocols on-site, a service which could be extended to other partners. Education, Biology, and UP\&PA could help develop the permanent outdoor learning stations in order that all visitors will have the opportunity to teach themselves about various sustainability principles as they are applied to the site. A ready example might be ways the site promotes and demonstrates resilience.

The site will also have permanently-constructed building stations that will allow stakeholders to turn raw materials into artifacts for sustainable living. Examples include rain barrel preparation (in which a fixture would hold the barrel while another aspect of the fixture cuts the barrel, all in a safe way and by using some simple, human-powered machines incorporated into the station. There would then be methods for creating a top and various outlets on the rain barrel, all affixed to the station. It's like the do-it-yourself 
bike repair stations we have across campus.) Other examples include vermicompost bin preparation, raised bed building, small wind turbine construction, and native handicrafts (perhaps at a multi-station). Visitors would purchase the materials from SV or bring their own materials and pay a small service fee for use of the equipment.

Another educational area will involve asphalt destruction training for the community. One alternating section of asphalt will be destroyed in training sessions using various tools. Most would-be de-pavers have no idea how much work this activity actually takes with hand tools. These sessions will be videotaped for online training modules (a regular practice across SV), but SV will also hold regular for-fee workshops to teach people what is entailed in breaking up asphalt. These on-site and virtual trainings could directly impact Louisville's heat island effect as the methods are applied elsewhere in the urban area.

To generate sustainable power, Sustainability Village will feature recycled solar panel reconstruction. SV will create solar panels that operate at $60-70 \%$ efficiency by applying a method of assembling the panels out of recycled photovoltaic cells. The process was developed at U of L by the RE3 group from The Speed School. Technical advice and support can be obtained from the LVL1 Hackerspace on Broadway, also begun through U of $\mathrm{L}$ and the creators of the first solar panels designed using this process.

Labor for these projects will emphasize hands-on education and will be recruited from student volunteers, members, RSOs, Greek organizations, Brian Barnes's (and other faculty's) sustainability-themed classes from U of L and Bellarmine University, a partner- 
ship with former offenders from Dismas Charities, neighborhood groups, Louisville Timebank members, and any other motivated, interested groups.

\section{Learning Stations}

SV will build three hoophouses for the housing of aquaponics systems made from reclaimed materials and for growing various kinds of sustainable, year-round agriculture. SV will use sustainable methods for all building projects. SV will ask Urban Planning and Public Affairs to assist in the design of the area, including the laying of pathways and design of discrete work spaces. These aquaponics systems will be displayed, in part, as educational tools for visiting aquaponics researchers.

With the help of local partners like Alex Udis at The Americana Community Center, SV will create education gardens and fixed infrastructure to support the educational missions of the gardens. The goals of these gardens include feeding students, educating youth, and re-educating the community about how to successfully grow food plants in an urban setting.

In addition, SV will work with Ekstrom Library staff and university departments to develop historically-relevant maps and local narratives surrounding the site. This will tie the site directly in the neighborhood as a landmark and enduring cultural treasure, and it will drive groups interested in local history and education to the site, following the model of organizations like The Muhammed Ali Center and The Kentucky Center for African American Heritage. SV could also connect with local historical organizations, like The Filson Historical Society, to create more community engagement around the project. 


\section{Sustainable Systems}

In addition to the composting operation and the educational mission, Sustainability Village will offer a variety of sustainable systems for agriculture, infrastructure improvement, product development, and community engagement. These systems will all be fully available to the community after 30 months of operation, though many will be functional within the first year.

Vermicompost: SV will produce worm castings for community partners, for its own uses, and for sale. SV will innovate low-cost systems, add machinery to U of L's existing process where it makes sense and is sustainable, and will innovate vermiculture for this level of operation in such a way that U of L's program will set a new paradigm of efficiency and awareness of the multiple ways worm castings can be valuable to the community and for sustainable development.

Existing Structure: The development of the house on the property into an office and demonstration space for sustainable infrastructure, building updating, and indoor agricultural practices will be a priority during the first two years of the project. A full inspection of the building has not yet occurred, as of September 11th, 2013. This project has had a partnership offer from Tony Ellis, owner of Bluegrass Green, a local sustainable home

improvement store on East Market Street, for help in sustainably rehabilitating the building. http://www.bluegrassgreenco.com/page/home.

Cobb and Pallet Houses: Cobb houses can be built on the property by local partners familiar with the techniques. These are very low cost by comparison to traditional struc- 
tures, and they can be built in this region out of reclaimed and readily-available materials. Pallet houses can be built out of reclaimed materials donated by partners in the industrial zone adjacent to the property. After the shipping pallets are donated, SV leadership will design and build pallet houses that are appropriate for needs on the property. These structures can house various projects or demonstration spaces within Sustainability Village. The project will still need to purchase fixtures, assembly hardware, windows, and roofing materials for these dwellings. One recommendation for using the sustainable buildings is that SV could engage the community through bicycle repair classes, and another sustainable building could be outfitted for classes in sustainable redesign and biodiesel conversion of cars and trucks.

Rain water capture: Capturing rainwater in various vessels and for various applications will be a mainstay of the Sustainability Village. SV will teach others to do this, will showcase various methods, and will combine traditional and unconventional capture and irrigation systems with sustainable, local technology from WaterStep. By the end of the first year, one goal will be that all captured rainwater on the property is drinkable from any tap. Primary materials for building rain catchment systems are available locally as donations from Brown-Forman Distillers. Fixtures will need to be purchased and platforms constructed for the systems.

Hoophouses: Hoophouses will be built with grants obtained from local and federal sources for agricultural and urban renewal applications. SV should have no problem gaining grants that will pay for the entire cost of two hoophouses of 40' x $20^{\prime}$ each. One other hoophouse will likely need university support in the neighborhood of $\$ 3000$ for materials 
and labor. Two hoophouses will hold aquaponics systems, and the other will be available to community growers for year-round application with a labor-sharing or profit-sharing model, negotiable annually.

Chickens: Sustainability Village will have a flock of chickens that will produce eggs for sale or trade with community partners. The chickens will be moved from place to place on the property with a mobile chicken coop ("chicken tractor"), a design for which SV will adapt to the needs of the property. The chickens will fertilize the soil, eat insects, and provide educational and research opportunities. This project will also need to build a chicken coop, which can easily be accomplished with reclaimed materials or grant funding within the first year.

Bees: SV will keep bees on the property with the help of local beekeepers. The beekeepers will help SV create educational events and sustainable manufacturing around honey and beeswax. This will lead to a line of $U$ of L-branded bee and honey products (candles, soap, honey, etc.)

Mushrooms: The site has access, on its northern border, to an underground garage. Mr. Heuser has made it clear that the garage is expected to go unused by the new owners. SV would contact Eric Osbourne, a local mycoculturist, to help set up a sustainable, education-oriented growing room for high-value mushrooms and/or university research projects surrounding mycoculture. There are a variety of product lines available from mushroom cultivation, particularly the mushrooms themselves going to outlets like The Root Cellar for retail sale in the community. 
Native species planting: SV will cultivate a plethora of organically-grown native herbs and flowering plants for sale and study at the site. This would create other revenue streams for the site, like packaged teas, potpourri, or even the growing of boutique herbs and other crops for direct sale to university partners or through The Root Cellar and other community partners. 
University of Louisville Sustainability Village - Map
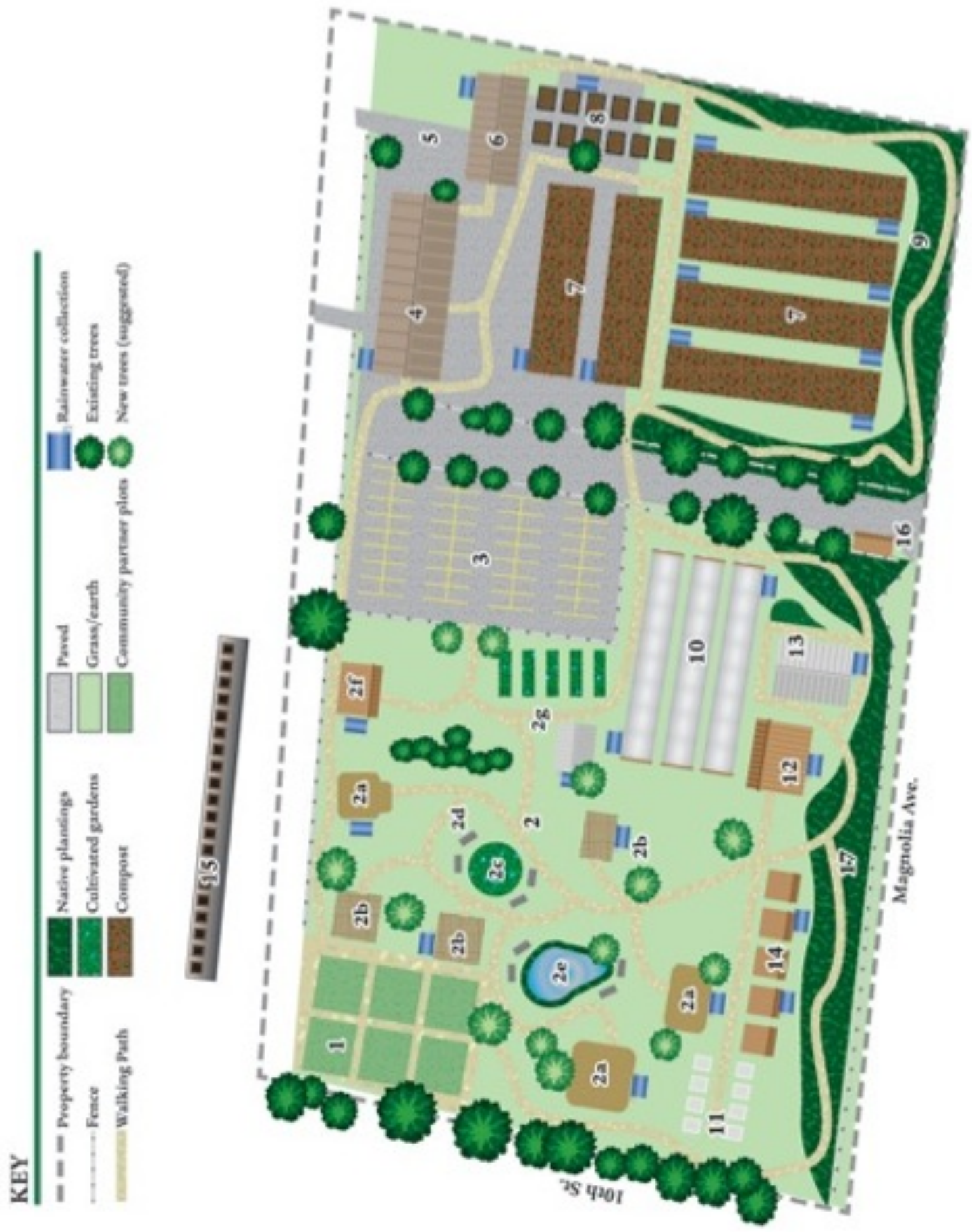
University of Louisville Sustainability Village - Map Key

1. Community partner areas

2. Sustainability Village
a. Cobb houses (3, various sizes)
b. Pallet houses (3, various sizes)
c. Circular herb garden
d. Parklike seating areas
e. Pond
f. Chicken coop and movable pen tractor shed
g. Sustainable Education Garden

3. Public parking

4. Vermiculture area

5. Asphalt de-paving area

6. Heavy equipment storage

7. Compost windrows

8. Compost dumpsters

9. Native planting areas with walking paths

10. Hoophouses (3)

11. Beekeeping 


\section{Workshop}

13. Existing house with artificial wetland

14. Sustainability construction stations

15. Mycoculture (in basement of adjacent building)

16. Compost drop-off and pick-up. station

17. Walking paths throughout property

*All buildings, dumpsters, and windrows feature rainwater collection

\section{Funding and Support}

This proposal presupposes an initial 5-year cycle and a second 5-year cycle. The structure outlined here is based upon suggestions made by $\mathrm{U}$ of $\mathrm{L}$ leadership concerning possible funding structures. This proposal operates off of the assumption that a five million dollar endowment is established to provide a $\$ 250,000$ operating budget to the site each year. The land will be owned by $U$ of $L$ and managed by the leadership of Sustainability Village and U of L's Special Assistant to the Provost for Sustainability Issues, Justin Mog, among other leadership.

This document proposes a direction for the first five year plan. The first two and a half years involve using the university endowment to pay operating costs and setting up partnerships and infrastructure. The next two and a half years, as those partnerships and the infrastructure progress, will see the organization move to a community-support model that is membership- and product-based. The organization, Sustainability Village, will ask stakeholders to pay monthly and annual memberships in an effort to become self-suffi- 
cient. Various other fees, space rentals, and product lines developed at Sustainability Village will fund the site and its paid employees by the end of the fifth year.

During the second five years, SV will privilege the support of community partnerships and solid educational projects for sustainability over the making of short-term profit. The organization will be oriented toward long-term profitability, but it is important that principles of sustainable operations are not violated at this property, since every move made will have to be justifiable in terms of core sustainability values. During the second five years, SV could work with $\mathrm{U}$ of L leadership to help manage the endowment in order to support other local sustainability initiatives. Once SV has satisfied its infrastructure concerns and has become self-sustaining, the management and distribution of the annual payout from the endowment to other local, educationally-oriented, sustainability organizations should become an additional priority.

The project will be plugged into the local sustainability community at a deep level, and so the social media of those organizations and individuals will help spread information about the operation. In addition, SV will actively fundraise year-round in order to secure support for various initiatives.

\section{Budget}

\section{Initial Materials}

Cost: $\$ 190,500$ 
- Pallets and fixtures for five pallet buildings of various dimensions. Pallets can be donated, but hardware and fixtures will have to be purchased. Pallet houses can be build for less than $\$ 10$ per square foot. $\$ 50,000$

- Materials and fixtures for five cobb buildings of various dimensions. Cobb buildings cost roughly $\$ 15$ per square foot to construct, assuming that some materials will be shipped to SV. In addition, many natural building materials can be donated and located on the property, but hardware and fixtures will have to be purchased. $\$ 75,000$

- Two decommissioned university vans. These are available at no cost, though some regular maintenance will be required, as well as insurance and gas. $\$ 1000$ per year.

- Two skid-steer earth movers. These cost roughly $\$ 10,000$ each. This price should include all maintenance for the first five years, particularly if the skid-steers are used at the time of purchase. One skid-steer alone will make for very slow work. Fuel will cost extra. $\$ 20,000$

- Six dry composting toilets: These will be made with repurposed materials, but some new construction is suggested. $\$ 300$ each for $\$ 1800$ total.

- Artificial wetland. This will be made from recycled and repurposed materials. $\$ 300$

- Green roofing materials. These materials can be donated.

- Kiosk for bucket donations: The kiosk will be built in the 1st wave of infrastructure. It can be built from pallets for less than $\$ 500$, assuming donated pallets and buckets. The buckets will be provided by a parter. The U of L Composting Project has had 
partners in the past who have provided donations of used buckets, and SV can locate a new community partner for this venture at no cost to the project for buckets.

- Rainwater catchment materials. Many of the necessary materials can be donated. Costs should be around $\$ 200$ per system for platforms and fixtures, though some will be far less. A working estimate for 20 systems is $\$ 3000$.

- Wood and other reclaimed materials for outdoor educational installations. These materials can be donated.

- Wood chipper $\$ 800$

- Seeds, plants, and other landscaping materials can be donated.

- Three hoop houses at $\$ 3000$ each, including labor. Grant funding is likely available for a portion of this expense. $\$ 9,000$

- Herb garden bricks can be donated.

- One dozen small solar pumps. $\$ 50$ each for $\$ 600$ total.

- Beekeeping materials will have to be constructed or purchased. These could cost $\$ 200$ each for 10 boxes. $\$ 2,000$

- Chickens and chicken coop/tractor startup costs: $\$ 3000$ inclusive for first 30 months

- New trees can be donated or granted through Metro government.

- Mycoculture setup, with beds, tables, and cultures, could cost $\$ 2000$.

- Vermiculture startup materials, including mechanical sifters and a harvesting machine. $\$ 10,000$ 
- Used tractor with front end loader, bush hog, backhoe, and post hole digger attachments $\$ 6500$

- Repurposed metal building (including heater) for vermiculture $\$ 5000$

Paid Labor - $\$ 140,000$ to $\$ 260,000$ per year

\section{1 full-time director at $\$ 60,000$}

The director should be able to manage all sustainable systems, develop reporting systems, perform community outreach, fundraise, teach about these systems, deeply understand the sustainability principles and relationships at Sustainability Village, and be able to jump in and help with any system in the absence of its manager. The director will hire paid staff, terminate working relationships at SV, coordinate volunteer labor, and enter into contracts. The director is also expected to source donations of materials for projects and to secure grant funding for the site of at least $\$ 50,000$ per year.

8 part-time (\$10 per hour for 20 hours per week for 50 weeks) work study students at $10 \mathrm{~K}$ each $=\$ 80,000$

These students will learn about basic systems and provide much of the labor as they work on the systems. So, a student could be turning compost with a skid-steer, sifting worm castings, planting trees, building pallet houses, cleaning compost buckets, or any other job that needs doing at SV. Student workers will take direction from SV leadership, as identified by the director.

6 specialists at $20 \mathrm{~K}$ per year $=\$ 120,000$ 
SV will be more successful in a shorter time period if the project chooses to hire parttime specialists for the operation of systems, instead of asking them to work as volunteers. Suggested local talent to fill the positions are in parentheses: a professional vermiculturist (Terry Johnson, owner of Rock'n M Ranch, has expressed interest in this position), a master gardener, a compost manager (Josh Orr, Composting Project assistant), a master beekeeper, a mycoculturist, and an education garden specialist (Alex Udis, builder of educational gardens at Americana Community Center).

\section{Generated Income}

(This proposal accounts for $\$ 2585$ per week after 30 months of operation. Sustainable systems take time to develop. This comes to $\$ 134,420$ per year at the halfway point of the first five year plan.)

The immediate goal of the operation is to begin earning $\$ 200,000$ per year by the end of the fifth year. While some monies may trickle in during the first 30 months, it seems unlikely that the revenue-producing systems at Sustainability Village will be mature enough to serve as stable revenue streams until well into the third year of operation. To bring in $\$ 200,000$ per year by the end of year five, one might focus on attaining $\$ 4,000$ per week. This proposal modestly demonstrates nearly $\$ 3000$ per week in grants, products, consulting, and memberships by the end of the 30th month of operation. Products can be delivered to area retailers as part of waste pickup routes, can be purchased on-site, or can be shipped to purchasers of Internet orders. SV would seek certifications as a Kentucky Proud retailer and all items will be $\mathrm{U}$ of $\mathrm{L}$ branded products. 
A total of $\$ 500$ in sales of honey per week to the The Root Cellar and other area retailers. Think of it as $12 \$ 5$ jars of honey per case, which is $\$ 60$ per case. Sustainable Village's goal would be 14 cases per week sold regionally. Sustainable Village would offer several sizes and types of honey-related food products, like comb, pollen, and honey candy. Containers will be returnable to SV, which will clean and refill them, saving packaging costs. Initial packaging can be donated from local retailers and stakeholders.

\$200 per week in vermicompost sales could be achieved by merchandising the worm castings at community partners' businesses, like Sunergos, Quills, Days, The Root Cellar, Bluegrass Green, and others. \$10 per bag is 20 bags per week. This merchandising method was successful for the partnership between Breaking New Grounds and Heine Bros. Coffee.

A total of \$250 in sales per week from partner coffee shops, Sunergos, Quills, and Days, among other future partners, for other bee-derived products. Following the model pioneered locally by Heine Bros. Coffee shops, SV will offer its other bee products, like soaps, candles, lip balms, etc. If one case of soap holds 12 bars at $\$ 3$ per bar, that's $\$ 36$. Each week, SV would need to sell seven cases of soap or similar products.

Consultancies could generate $\$ 100$ per week. During the course of the year, Sustainable Village will strive to develop an average of $\$ 400$ per month in sustainability consultancy at $\$ 50$ per hour.

Between aquaponically-grown specialty plants in two hoophouses and native plant products, like herbal teas, SV could generate $\$ 175$ per week total. Selling packaged teas, 
SV could expect to move 10 packages per week at $\$ 5$ per package, for $\$ 50$ per week in sales. If Sustainability Village goes to full production in one 40 -foot aquaponics greenhouse, assuming two 40-foot trays of edible mixed greens and 100 catfish left to harvest at maturity, local prices could provide $\$ 4$ per pound for the greens, of which SV could reasonably provide 100 pounds per month over ten months per year. This is 1,000 pounds of greens at $\$ 4$ per pound, or $\$ 4000$ pounds for 10 months, coming to $\$ 100$ per week. SV could also receive $\$ 10$ per catfish, for $\$ 1000$, or $\$ 25$ per week over the fish's 10 -month growing cycle.

Egg sales to local outlets like The Root Cellar and CSAs could generate $\$ 80$ per week. SV could produce 1 egg per chicken per day. If the flock is 40 chickens, that comes to 280 eggs per week, or 23 dozen. If SV gets $\$ 3.50$ per dozen eggs, that's $\$ 80$ per week.

Sustainability Village will strive for 150 individual memberships and 50 corporate memberships by the end of 30 months of operations. SV will request a donation from individuals of $\$ 10$ per month, and corporations will be asked to pay a scaled donation of $\$ 20$-\$50 per month. This could bring in $\$ 100$ per week.

Mycoculture could produce $\$ 180$ per week. Sustainable Village could sell four varieties of mushroom to begin: shiitake, portobello, oyster, and lion's mane. If these are sold for $\$ 3$ per pound, on average, the project could produce 15 pounds per week of each type of mushroom after 30 months of operation. $\$ 45$ per week for four mushroom types is $\$ 180$ per week in mushroom sales.

The director will be responsible for finding $\$ 1000$ per week in grant funding. 
Extra funds will be generated during the holiday season and at back-to-school.

Sustainability Village can also expect to gain revenue from having its products included in university gift baskets. The sale of boutique plants, while also likely, is not included in this proposal.

Profit sharing and/or rent will be negotiated from community partners inhabiting Sustainability Village monthly or annually, but the process and estimated income from this activity are not included in this proposal.

\title{
Other Financial Benefits
}

Kentucky provides a $50 \%$ tax credit for all composting-related purchases.

\section{Contact Information}

For further discussions regarding this proposal, please contact:

Brian Barnes: brian.barnes@,louisville.edu

\begin{abstract}
ABOUT THE AUTHOR
Brian Barnes, a Louisville native, has been teaching Business Ethics at least three times per year since 2004 at the University of Louisville; he is also working with U of L's College of Business to develop an ethics approach across the curriculum there. Since 2006, he has been offering Business Ethics at Quality Leadership University in Panama City, Panama, once or twice annually. Barnes also teaches Critical Thinking at $\mathrm{U}$ of $\mathrm{L}$ and is Visiting Scholar at The Foundation for Critical Thinking, which promotes the Paulian
\end{abstract}


conception of critical thinking and education reform. In addition to working in U of L's Philosophy Department, Barnes is or has been part-time faculty at Bellarmine University, at Indiana University's Southeast campus, and at Jefferson Community and Technical College, Northwood University, Strayer University, and Simmons College. He teaches a broad range of courses at these universities, including Sustainability and Eastern Philosophy.

Barnes holds a B.A. in Philosophy from Hanover College in Indiana, an M.A. in Philosophy from U of L, an Arabic language certificate from the Defense Language Institute in Monterey, $\mathrm{CA}$, and, at the time of this writing, is a $\mathrm{PhD}$. candidate in Interdisciplinary Humanities at $\mathrm{U}$ of $\mathrm{L}$. This document is one part of his requirements for that terminal degree. Barnes won an Outstanding Volunteer Service Medal in the Army, and he is the recipient of U of L's 2010 award for Community Engagement in the faculty category.

As a veteran of the US Army's Military Intelligence branch, Barnes was involved in operations during the first decade of the 21 st century that led to the occupation of Afghanistan and Iraq by US forces and corporations. He has worked for the National Security Agency and has been a contract translator for FBIS, CIA, and others. Barnes has also worked for American corporations, like Wild Oats Markets, in addition to his own entrepreneurial enterprises with several for- and non-profit corporations in Kentucky and the US.

Barnes has been a competitive fencer, coach, and referee. His is also a teacher of Hontai Yoshin Ryu jujutsu and related weaponry at Katsujinken Dojo in Louisville. 
Barnes is Coordinator of U of L's Eco-reps program, which promotes sustainability education and service to the Metro Louisville community. During the first few months of each year, you could find Barnes searching through the ruins of Waverly Hills Sanatorium, appreciating the architecture and looking for ghosts; so far, he's come up emptyhanded. Barnes is married to Mith Barnes, and they have one teenaged son, Iain.

\section{APPENDIX A \\ A REVIEW OF CRITICAL THINKING APPROACHES AS REPRESENTED IN PHILOSOPHY TEXTBOOKS}

This section critiques some contemporary critical thinking texts in order to demonstrate knowledge of the "critical thinking" as it applies to the discipline of Philosophy. The field of critical thinking in Philosophy appears to be broken into two camps when it comes to critical thinking: "Informal Logicians" and everyone else. Informal Logic dominates the textbooks that are sold as critical thinking texts, which is demonstrated by this literature review.

Richard Paul draws a line between what commonly passes for critical thinking at the university level, something he calls, "informal logic," and his version of critical thinking.

"I characterized one limited dimension of that struggle [the emergence of the critical thinking field] as having been played out by philosophy departments seeking and claiming priority rights to critical thinking, and by informal logicians as having tacitly attempted to reduce theory of critical thinking to theory of reasoning and argumentation. In a yet smaller and personal context, I described some of the ways in which my views on 
critical thinking have been informally and tacitly marginalized, mainly by informal logicians." 58

So, what counts as “informal logic”? According to Ralph Johnson and Anthony Blair,

"The term 'informal logic' in the sense in which we are dealing with it came into use in the late 60 's and early 70 s primarily to designate the anew kind of logic course: one whose overt purpose was to equip students to assess argument as these are found in the pages of the mass media." 59

Later, the authors also suggest that informal logic is involved in "the deeply felt need to rethink the nature of argument." ${ }^{60}$ Robert Fogelin offers that informal logic raises questions like, "What is the place of argument within language as a whole? In a given language, what words or phrases are characteristic of arguments? What tasks are arguments supposed to perform?"61 Also, Douglas Walton's “Informal Logic, A Handbook for Critical Argumentation” defines his goal of conveying informal logic as a way "to help the reader use critical methods to evaluate impartially and reasonably the strengths and weaknesses of arguments.” 62

${ }^{58}$ Richard Paul. "Reflections on the Nature of Critical Thinking, Its History, Politics, and Barriers, and on its Status across the College/University Curriculum, Part II." Inquiry: Critical Thinking Across the Disciplines. 27:1, 5.

59 Ralph H. Johnson and J. Anthony Blair. "Informal Logic: The Past Five Years 1978-1983”. American Philosophical Quarterly, 22:3, 1985. 181.

60 Ibid., 182.

${ }^{61}$ Robert J. Fogelin. Understanding Arguments: An Introduction to Informal Logic. Harcourt Brace Jovanovich, 1978, xxii.

62 Douglas N. Walton. Informal Logic, A Handbook for Critical Argumentation. Cambridge University Press, Cambridge, 1989. 3. 
What's common in these approaches to informal logic is an emphasis on approaching arguments in the real world. The textbooks reviewed for this dissertation have similar ideas about what activities are valuable for the thinker to consider, and nearly all of them are focused on analysis and dissection of arguments exclusively. This seems quite different from Richard Paul's approach:

"Critical thinking as a core value implies academics and insightful citizens with special skills and traits, namely, persons so educated that they can think multilogically, who can move up and back between theory and practice, and who, ultimately, can articulate the interrelations between pedagogic practice and practice that transfers beyond academics into the messy world of everyday human realities." ${ }^{63}$

Recall, above, that Paul suggests that critical thinking has been taken over by an emphasis on informal logic and argument, both of which are rarely mentioned in his approach.

The review that follows emphasizes this distinction and underscores the need for more Paulian or similar approaches to critical thinking. In the textbooks reviewed, the most common method for employing informal logic is the use of mathematical and symbolic methodologies from classical and modern logics to help the students solve logic puzzles and analyze arguments. The methods used are rarely integrated with one another in the texts reviewed, and few of the reviewed texts supply methods to readers

${ }^{63}$ Richard Paul. "Reflections on the Nature of Critical Thinking, Its History, Politics, and Barriers, and on its Status across the College/University Curriculum, Part I." Inquiry: Critical Thinking Across the Disciplines. 26:3, 6. 
for applying skills acquired in the informal logic context to problems outside the classroom, though many examples seek to analyze real-world arguments from the media and elsewhere.

In order to create a basis for comparing informal logic approaches to critical thinking and a Paulian approach, this section relies up the analysis of "Critical Thinking Polarities," articulated by Richard Paul in his keynote address at the 33rd International Critical Thinking Conference, hosted by The Foundation for Critical Thinking. ${ }^{64}$ These polarities are useful, since Paul sets up a defensible position regarding what a critical approach to thinking and teaching looks like, and each of the "critical" polarities contrasts with a logical opposite. Many of the opposites are demonstrated by the approaches that textbooks reviewed here take. Interestingly, none of the texts offered, with the sole exception of Nosich's, mentions Richard Paul, Linda Elder, or Nosich anywhere in the text or in their indices. Perhaps this indicates that the two camps of critical thinking in Philosophy are, in fact, deeply divided from one another. All of the reviewed texts, except Nosich's Learning to Think Things Through, are offered by their publishers for adoption at university Philosophy departments as critical thinking textbooks. Nosich's text was suggested for use in Philosophy department "Critical Thinking" courses by scholars at The Delphi Center for

${ }^{64}$ Richard Paul. "Keynote Address." 33rd International Conference on Critical Thinking and Education Reform. July, 2013. https://www.youtube.com/watch? v=p3R6hi0bY6Y\&list=PLAX3Qhlb9gdKknt5M9uvzp4wn5MqPFG2X 
Thinking and Learning at The University of Louisville.

The documents that follow are rated according to Paul's Critical Polarities. Each text is given a designation along the lines of the Polarities in Paulian Critical Thinking Theory. Each text is then classified on a qualitative scale from "Critical," to a "Strong Hybrid" of critical and didactic approaches, to a "Weak Hybrid" of critical and didactic approaches with much more emphasis on didactic methods, and "Didactic," which demonstrates only the didactic side of the Paulian Critical Polarities.

The reviewed sources are considered highly relevant to a philosophical understanding of critical thinking, which is what The Central Question is using. Other approaches to critical thinking, like Diane Halpern's work or Edward de Bono's “Six Thinking Hats," are based in Psychology and are not strictly applicable here, due to the differences in approach between psychological and philosophical understandings of critical thinking.

The Seven Critical Thinking Polarities - There is a pair of published instances of these in The Foundation for Critical Thinking literature. The first is in A Glossary of Critical Thinking Terms and Concepts. ${ }^{65}$ Paul offers "critical thinking forms and manifestations: the varieties, structures, or types of critical thinking that people use." Four of the polarities are here;

${ }^{65}$ Richard Paul. A Glossary of Critical Thinking Terms and Concepts. Foundation for Critical Thinking Press, 2009. 16-17. 
they are numbered as $1,2,3$, and 4 below. Six of the polarities are also mentioned in Inquiry, Volume 26, Number $3 .{ }^{66}$ That document includes all of the polarities except the final one, integrated versus fragmented. The full list is available on YouTube as Paul's 33rd International Conference Keynote. $^{67}$

Below, each polarity first expresses the critical manifestation of that aspect, and then it is compared with its didactic manifestation. A rationale for why these are opposite poles of criticality is suggested for each, and then each polarity is associated with a question that captures the distinction between the two poles for help in identifying critical aspects of these textbooks.

The first polarity is Explicit versus Implicit Thinking:

"Most faculty approach critical thinking in an implicit rather than an explicit manner. They believe that one can learn critical thinking best by working under mentors who model critical thinking in their reading, writing, speaking, and listening — without calling explicit attention to the fact that they are doing so." 68

A critical approach makes the thinking process explicit. The thinker

${ }^{66}$ Richard Paul. "Reflections on the Nature of Critical Thinking, Its History, Politics, and Barriers, and on its Status across the College/University Curriculum, Part I." Inquiry: Critical Thinking Across the Disciplines. 26:3, 2011. 6.

${ }^{67}$ Richard Paul. "Keynote Address". 33rd International Conference on Critical Thinking and Education Reform. July, 2013. https://www.youtube.com/watch? $\mathrm{v}=\mathrm{p} 3 \mathrm{R} 6 \mathrm{hi0bY6Y \& list=PLAX3Qhlb9gdKknt5M9uvzp4wn5MqPFG2X}$

${ }^{68}$ Richard Paul. "Reflections on the Nature of Critical Thinking, Its History, Politics, and Barriers, and on its Status across the College/University Curriculum, Part I." Inquiry: Critical Thinking Across the Disciplines. 26:3, 2011. 6. 
is thinking about his or her thinking as a part of the methodology being followed. Didactic methods, since they are focused on copying, are not interested in the thinker making his or her actual thinking about a topic explicit; doing so is beside the point of mere representation of ideas for the purpose of evaluation, which is what the didactic approach asks of its students. Critical approaches bring the thinking to the surface so that the thinking itself can be examined for quality, not merely engaging in an examination of thinking's products. When thinking is on the surface, it can be corrected, amended, and improved, independent of any content. The process should make the thinking of the user explicit in all of these ways in order to be considered "critical."

Here is a question that might be asked of a textbook claiming to be interested in criticality-Is the process of thinking about a person's own thinking made explicit as part of the instruction, or does any rigorous thinking process remain hidden in and by the content?

The second polarity is Global versus Specialized Thinking:

"There are concepts that apply to critical thinking across the disciplines. To the extent that there are, the nature or character of critical thinking in one discipline re-enforces the nature and character of critical thinking in the others. Nevertheless, there are also discipline-specific critical thinking concepts and principles, skills and abilities." 69

A critical method will give the thinker the ability to analyze, evaluate, and improve his or her thinking in any area. Strong sense critical

${ }^{69}$ Ibid. 
thinking has as its ultimate goal the creation of critical societies, which are societies in which human beings demonstrate and perpetuate the critical mode for all aspects of their living.

For Paulian Theory, critical methods will be applicable to people everywhere, for all kinds of thinking, and will be capable of improving thinking for its users in all areas. If a method is too specialized, thinkers will require uncommon techniques to employ it. Highly specialized techniques are also not suited to all activities of the mind without some significant modification and reinterpretation on the thinker's part before the methods can be used at all. Critical approaches will be applicable across the board in order to promote broad development of good thinking.

A question that probes whether a system is global might be-Is the critical thinking approach applicable to a variety of types of intellectual systems, or is it geared toward specific applications only?

The third polarity is $\underline{\text { Systematic versus Episodic Thinking: }}$

"One can approach critical thinking as a set of concepts and principles inherent in all thought within a discipline, on the one hand, or restrict it to periodic relevance, on the other. Those who approach critical thinking as episodic think of it as relevant only in special circumstances, usually when facing a difficult or complex problem. In such a case, critical thinking typically shows up in textbooks in stand-alone boxes, titled something like 'Critical Thinking Problem' or 'Critical Thinking Questions."'70

A critical approach will be systematic. Systems can be broken into their component parts, the parts can be analyzed, deficiencies in thinking

${ }^{70}$ Ibid. 
can be assessed and fixed, and the system can be reassembled to operate well, once again. If a critical thinking approach is systematic, it will be possible to deconstruct it in just this way. An episodic approach to CT will only be useful in one instance or in very narrow applications. It will not be connected with a larger body of theory, and it will not have characteristics or parts that can be disassembled and reassembled for improving thinking.

A question to probe the systematic or episodic nature of a CT approach might be-Can the thinking system be used across disciplines in an organized way, or can it only be used for isolated applications and, as a result, must be married with other material to be broadly effective for promoting understanding?

A fourth polarity is Socratic versus Sophistic Thinking:

"This distinction is crucial because humans often use their criticality to 'win' an argument or gain advantage over others. They are concerned with their vested interests above all else. In contrast, there are some people who develop as fair-minded thinkers and strive to face the truth, even if the truth does not put them in a favorable light. Socrates symbolizes this latter case (people with intellectual integrity and intellectual empathy). Most politicians are more likely to think habitually in a sophistic manner. Sophistry, in contrast, symbolizes those interested only in winning. We sometimes mark this distinction by the terms 'strong sense' or 'weak sense' critical thinking. For example, when philosophers attempt to persuade the faculty to restrict the teaching of critical thinking courses to those candidates with an advanced degree in philosophy, or claim that philosophers have a special competence in critical thinking (that makes them uniquely qualified to teach critical thinking), they use critical thinking (in my view) in a weak or sophistic sense. Highly skilled intellectuals can be self-deceived in their thought; as can, indeed, any given human whatsoever, when her or his vested interests are involved. If the danger of sophistic critical thinking is not recognized and combated, our communities and societies will continue to be dominated by sophistic thought. 
Where you stand in this polarity is, in my view, the most significant fact about your own criticality."71

As Paul indicates, The Foundation for Critical Thinking's Intellectual Traits are modeled primarily upon characteristics evident in the character of Socrates from Plato's dialogues. A Socratic approach uses methods that will discover truth in the situation. Sophistic methods, by contrast, are more interested in producing particular results, independent of the truth. Sophistic approaches are fond of techniques and devices that will produce desired outcomes without too much thinking on the thinker's part; they are intellectually labor-saving. Methods that seek the truth at all points are Socratic, and these methods help the student learn the truth of situations for him or herself.

Two appropriate questions that could be used to determine whether a system is Socratic or sophistic might be-Does the thinking approach prompt learners to find truths for themselves, or is the system dedicated to demonstrating truths for one approach at any cost? Does the system emulate the intellectual traits exemplified by Socrates, or is the system interested in manipulating the thinker for pre-determined ends?

The fifth polarity is Liberating or Constraining Thinking:

"We want our framework to be explicit, global, systematic, and Socratic, rather than implicit, specialized, episodic, and sophistic. That's not all, because we might want to ask ourselves, 'What implications for freedom of thought does this approach to critical thinking give us? How much

${ }^{71}$ Ibid. 
freedom do we have to think as the evidence leads us without worrying about stepping on the toes of the authority figures who may be relevant?' Wherever humans are existent and pursuing their ends, they are doing it under relative freedom. Some, very little freedom. It's all party-line, [and] intellectually justified. But what we want our students to do is think for themselves; follow the evidence; don't be intimidated by authorities who want you to come to a pre-decided conclusion. So, we want freedom for our students, rather than constraints, masks, covers, punishments."72

A critical thinking system that liberates thinking helps the thinker develop flexibility to broadly consider many topics and methods in thinking with one set of skills. A liberating system helps the thinker develop into a better thinker by merely thinking within that system. Constraining systems cause the thinker to become less flexible by introducing unnecessary rigidity into the thinker's intellectual processes, like the repressive political systems Paul references in his keynote. These artificial limitations cause the thinker to develop well within the particular system, but any artificially-limited intellectual approach eventually becomes a trap of biases and restricted thinking.

To probe whether a system liberates or constrains thinking, one may ask-Does the system help open up the thinking of the thinker so that he or she can become a better thinker in unrelated areas of content or application, or does learning to think well within this system limit the thinker's ability to adopt other points of view or intellectual methodologies?

\footnotetext{
${ }^{72}$ Richard Paul. "Keynote Address." 33rd International Conference on Critical Thinking and Education Reform. July, 2013. https://www.youtube.com/watch? $\mathrm{v}=$ p3R6hi0bY6Y\&list=PLAX3Qhlb9gdKknt5M9uvzp4wn5MqPFG2X. 38:49 to 40:59.
} 
The sixth polarity is Ordinary language versus Technical language:

"Critical thinking can be approached in terms of specialized or technical concepts and principles or, conversely, in terms of natural or non-technical concepts and principles. When it is approached as a specialized language, it has limited use. For instance, when it is understood in terms of formal logic, only those who understand formal logic can use it. When it is understood in terms of theory of argumentation, only those who study argumentation theoretically have access to it. When it is understood in terms of any specialized discipline, such as informal logic, analytic philosophy, rhetoric, cognitive psychology, and so on, only those people who study and think within these disciplines have entrée into it. Further, it is questionable as to how and to what extent any such approach can actually help people reason through life's real and often complex issues. (For instance, how many philosophers actually use formal logic formulas (or constructs in theory of argumentation) to figure out solutions to issues implicit in their personal relationships?) Conversely, when the concepts embedded in natural languages (such as English, Chinese, Arabic, Spanish, and so on) are used as foundations of critical thinking, all (potentially) who speak natural languages have access to them.."73

Further,

"In order to be available for thinkers on any topic, the words and phrases used in a critical thinking system should be easily accessible to ordinary users of the language. Didactic approaches, since they focus on memorization and regurgitation without deep understanding, can deploy highly technical terms that often add little to the understanding of users but do serve to clearly place the user in one academic or professional camp, as opposed to another. Highly technical language, outside of a few notable exceptions, like Chemistry or Medicine, typically serves to obscure meaning rather than illuminate it. By creating jargon that is weak on meaning but heavy on mystery, some thinking systems waste intellectual power on meaningless technicality, rather than helping adherents become better thinkers immediately by rendering its key concepts in common, wellknown vocabulary." 74

${ }^{73}$ Richard Paul. "Reflections on the Nature of Critical Thinking, Its History, Politics, and Barriers, and on its Status across the College/University Curriculum, Part I." Inquiry: Critical Thinking Across the Disciplines. 26:3, 2011. 6..

${ }^{74}$ Richard Paul. A Glossary of Critical Thinking Terms and Concepts. Foundation for Critical Thinking Press, 2009. 17. 
A question associated with the search for this kind of distinction is

-Does the system promote everyday words and phrases for its approach, or does it use heavy jargon?

The seventh and final Paulian critical thinking polarity is Integrated versus Fragmented Thinking:

"Many approaches to critical thinking give you lists of critical thinking concepts: do this; don't do that. But they don't integrate across the lists with key concepts that tie the lists together. To the extent that they are so structured, they are fragmented and do not represent our best thinking." 75

Critical thinking systems should possess parts that are integrated with one another so that the thinker can immediately apply one part of the theory to other parts of the theory without a great deal of difficulty or need for translation of one part into another. Many non-critical systems employ theories of thinking in which one part of the theory is largely isolated from another. When one part of the theory is not easily relatable to some other part of the theory, the thinker experiences a fragmentation in the process that requires bridging by other concepts.

A valuable question to determine whether a CT system is integrated or fragmented might be-Is it possible to incorporate different parts of the system into other parts, or are the aspects of this approach to thinking dif-

75 Richard Paul. "Keynote Address". 33rd International Conference on Critical Thinking and Education Reform. July, 2013. https://www.youtube.com/watch? $\mathrm{v}=$ p3R6hi0bY6Y\&list=PLAX3Qhlb9gdKknt5M9uvzp4wn5MqPFG2X. 42:39 to 43:35. 
ficult to link with other aspects of the approach?

In the analyses below, each textbook's approach to critical thinking is evaluated from the point of view of the seven polarities above. The findings of this section are summed up in Table 1.

\section{Bassham, Critical Thinking: A Student's Introduction, 4 th ed. ${ }^{76}$}

The first chapter, "Introduction to Critical Thinking" is excellent. For its eight "Intellectual Standards," six are explicitly Paulian, one is from Nosich's Learning to Think Things Through, and the other, "consistency," is an old Standard still listed among them on FCT's website. No mention of Paulian CT or Paul's work is present, however. The benefits of critical thinking listed in the chapter are almost verbatim rehashings of benefits in the Miniature Guide to CT and elsewhere, and the two "Barriers" are Paul's egocentrism and sociocentrism, infused with some classical fallacy theory. The list of characteristics of a critical thinker invoke Intellectual Standards and Traits from The Foundation for Critical Thinking, though no mention of any scholars from that organization is made in the index, acknowledgements, or elsewhere. The approach from this first chapter is solid.

The problem is, these Standards are not mentioned again, except after page 350 in some exercises about scientific reasoning. Most of the text is in-

76 GregoryBassham, et. al. Critical Thinking: A Student's Introduction. 4th ed. New York: McGraw-Hill Higher Education, 2011. 
formal logic and fallacy theory with some solid writing exercises thrown in that could very well be critical, though not explicitly so. The reasoning process, when systematic, uses highly technical language. The exercise sets are Socratic to the extent that they encourage students to work independently of the text, and there are many exercises of this type, but there is no discussion in the text about its methods helping readers free own their thinking through their use. Many of the exercises are global in their scope, but there is no explicit presentation of how they could be applied outside of the textbook. The listing of Standards and Traits early on does not tell the reader how to use them in any systematic way, and there is no attempt to integrate the traditional logical exercises present in most of the text with the more critical aspects of the thinking process.

This text makes critical thinking explicit as a process in only a small part, and it is largely didactic in its approach.

\section{Boss, Think: Critical Thinking and Logic Skills for Everyday Life ${ }^{77}$}

From page 4: "Critical thinking involves the application of the rules of logic as well as gathering evidence, evaluating it, and coming up with a a plan of action." This approach is way too vague to be useful, though it is quite global in its scope. She has some good principles in Chapter One that include

77 Judith Boss. Think: Critical Thinking and Logic Skills for Everyday Life. New York: McGraw-Hill, 2010. 
characteristics of a good critical thinker. The text also offers technical language for discussing thinking and lacks an integrated method for analyzing, evaluating, and improving thinking like the Paulian theory does. The critical thinking theory in this text is episodic and fragmented.

Most of the text is informal logic of the constrained type, which is mainly mathematical exercises, and it uses mostly technical language. This text presents a didactic model. If every chapter was like Chapter One, however, this would satisfy many more of the polarities.

\section{Boylan, Critical Inquiry: The Process of Argument ${ }^{78}$}

This textbook provides some easy-to-understand methods, but those methods are for writing a persuasive essay from a logical argument and related tasks, not for critical thinking. This text explicitly takes its method from an informal logic text from the 1980s, according to its Introduction, when the field of critical thinking was being organized. This text does not put forth an integrated or systematic approach, except where it is using heavily technical language and very constraining intellectual techniques.

The text is not explicit about a critical thinking approach in any way. It is highly specialized toward informal logical exercises. Many of the exercises encourage students to work on their own to develop their own under-

78 Michael Boylan. Critical Inquiry: The Process of Argument. Boulder, CO: Westview Press, 2010 . 
standings, so it displays a strong Socratic aspect. It is episodic and fragmented in the continuity it brings to its various methods. This text is highly didactic.

\section{Cohen, Critical Thinking Unleashed ${ }^{79}$}

This textbook contains formal and informal logic exercises from a traditional point of view. There is nothing else here; the title is a smokescreen and a simple rebranding that is senseless. This text is highly specialized, constrained in its approaches, highly technical in its language (even for a text of this type), and makes no efforts to integrate one of its methods with another. The text has lots of exercises that encourage the reader to do the work for him or herself, thus encouraging a Socratic approach. Didactic.

Damer, Attacking Faulty Reasoning: A Practical Guide to Fallacy-Free Arguments, 6 th ed. $^{80}$

This book explains how to avoid fallacies in the reader's reasoning. It gives some nice methods for self-reflectively checking oneself to avoid fallacies, but there is no discussion of a more flexible or broadly-applicable

79 Elliot Cohen. Critical Thinking Unleashed. Lanham, MD: Rowman \& Littlefield Publishers, 2009.

80 T. E. Damer. Attacking Faulty Reasoning: A Practical Guide to Fallacy-Free Arguments. 6th ed. Belmont, CA: Wadsworth/Cengage Learning, 2009. 
thinking process. This book spends most of its space identifying ways that fallacies hide in everyday language, and fallacious situations are identified in order to help readers recognize and avoid them. There is a systematic attempt at integration in the system by using fallacy theory as a core. Also, some discussion of argument theory is included, by way of rounding out the process. The integration of some traditional methods with fallacy theory increases the likelihood that students will be able to apply critical thinking to their lives. The process presented is explicit, but it's also highly specialized. Imposingly technical language is imposed throughout. This text is a Weak Hybrid.

\section{Hughes and Lavery, Critical Thinking: An Introduction to the Basic Skills.} $\underline{5 \text { th ed. }}{ }^{81}$

This textbook is informal logic with fallacy theory added on. Some explicit informal methods are provided to go with the formal methods, but it's all very technical in its approach. The text doesn't advocate for any Socratic methods in its exercises, it is highly constrained and specialized, and there is little effort made to integrate one logic method with another. There is no system here, only separate methods. Didactic.

81 William Hughes and Jonathan A. Lavery. Critical Thinking: An Introduction to the Basic Skills. 5th ed. Peterborough, ON: Broadview Press, 2008. 
Martin, There Are Two Errors in the Title of This Book: A Sourcebook of

Philosophical Puzzles, Problems, and Paradoxes. ${ }^{82}$

This text is all logic puzzles of various types, but with no deep discussion of process or suggestion of any integrated method for approaching the puzzles. There is simply no reasoning system presented in this text, so there is no way to address it with the polarities. The puzzles are presented in a classically didactic fashion.

\section{Moore and Parker, Critical Thinking. 10th ed..$^{83}$}

Brook and Parker have a good definition of critical thinking in the first chapter, and they go on to make an explicit checklist for reasoning. They don't discuss or offer a method for doing the reasoning the checklist indicates, however. They also say, later, that their book is "critical thinking because it offers guidance in critiquing thinking" (2). This is not the sense of "critical" that Richard Paul is using with his polarities, and that definition points directly to the deep divide among critical thinking theorists. After page three of this text, the authors move into argument theory, never to return. The text doesn't integrate any of its methods into a system that can be used for a variety of applications outside of the logic book, and it doesn't

$\underline{82}$ Robert M. Martin. There Are Two Errors in the Title of This Book: A Sourcebook of Philosophical Puzzles, Problems, and Paradoxes. Peterborough, ON: Broadview Press, 2011.

$\underline{\mathbf{8 3}}$ Brooke Moore and Richard Parker. Critical Thinking. 10th ed. New York: McGraw-Hill, 2012 . 
promote any liberated thinking. Rather, it constrains the thinking of its users with the restrictive and highly specialized methods it offers after Chapter One. Didactic.

\section{Nosich, Learning to Think Things Through: A Guide to Critical Thinking}

Across the Curriculum, 3 rd ed. ${ }^{84}$

This text is part of the Foundation for Critical Thinking canon, and it reflects many, if not all, of the core Paulian principles, including expanding the Paulian theory in ways too various to list here. The method is explained well, and this text follows all of the Polarities as expressed by Paul. Nosich makes the ways the thinking should be done explicit in his text. His approach is intended to cross disciplines, and it does, so it's global. All critical thinking techniques are intended to be used together in an integrated system. Much of the text helps readers think through the material themselves, and so it is both Socratic and liberated in its approach to reasoning, and Nosich is careful to use only ordinary language. This text is "critical" in the Paulian sense.

84 Nosich. Learning to Think Things Through, 2009. 
Ruggiero, Thinking Critically About Ethical Issues, 7 th ed. $^{85}$

This text covers topics in ethical analysis, but Ruggiero doesn't present an integrated method for ethical reasoning. He does present assignments that are geared to different knowledge levels and exercises that ask students to reconsider their answer from some other point of view, which is very Socratic. This is the "thinking critically" part of the text. However, the method is almost completely implicit where it offers advice on reasoning well. There is no apparently integrated or systemic approach. The language is all highly technical, and the techniques presented do not seem to liberate the thinker from his or her intellectual constraints; these methods only make those constraints deeper. The approach may be global, but it might also be so specialized as to be a hidden method. Didactic.

\section{Ruggiero, Beyond Feelings: A Guide to Critical Thinking, 9th ed. ${ }^{86}$}

This text presents several ideas immediately relatable to the Paulian Polarities and theory. Ruggiero's egocentric bias, sociocentrism, discussions of Intellectual Traits, and discussions of the process of becoming a critical thinker all bear strong resemblances to Paul's approach. None of this material appears in Ruggiero's book on ethical reasoning (prior entry.) Despite

$\underline{85}$ Vincent R. Ruggiero. Thinking Critically About Ethical Issues. 7th ed. Boston: McGrawHill Higher Education, 2008.

866 Vincent R. Ruggiero. Beyond Feelings: A Guide to Critical Thinking. 9th ed. New York: McGraw-Hill, 2012. 
their presence, the various critical thinking principles are not integrated or organized into an explicit system for the thinker's use. Beyond that, Ruggiero elevates intuition to a level not really valuable for logical reasoning processes. Though he discusses thinking a great deal, he presents no systematic methods of thinking, except for the jargon-laden and highly technical ones associated with informal logic when he slips into fallacy theory or informal argument analysis. These methods are not able to be immediately integrated with one another for rational discourse or a global method. All in all, Ruggiero undermines critical thinking in this text more than he strengthens it by suggesting that intuition presents a reliable and trainable method that should be part of a critical approach. He doesn't spend much space defining intuition or how it works for the thinker, though, and so that method isn't very helpful. This text could be classified as a Weak Hybrid.

\section{Salmon, Introduction to Logic and Critical Thinking: Instructor's Edition} 6th ed. ${ }^{87}$

This text is all traditional logic: argument forms, induction, and deduction. The formulaic approach lacks an explicitly Socratic element, it is very constrained in its applicability, and it uses highly technical language. This type of text does not liberate thinking; it constrains thinking within

$\underline{87}$ Merrilee H. Salmon. Introduction to Logic and Critical Thinking: Instructor's Edition 6th ed. Boston: Wadsworth, 2013. 
rigid methods, which are highly specialized. The approach is didactic.

Schick and Vaughn, How to Think About Weird Things: Critical Thinking for a New Age, 5 th ed. ${ }^{88}$

The methods given in the section "Case Studies in the Extraordinary" are based on scientific method, global. Despite that, Schick's and Vaughn's approach is intellectually liberating to the mind and possesses some degree of integration within itself. There are good principles to follow on page 5, providing a three-part reasoning process (which contains some of the book's most explicit instructions about reasoning), but the rest of the book falls back into formal logical reasoning, heavy on the fallacy theory, in order to fill out its page count. One this textbook's strengths is that its examples are quite interesting and more entertaining than most (aliens, Bigfoot, ghosts, conspiracy theories, and the like), but the examples are set up so demonstrate only the jargon-laden, technical, and specialized approaches Vaughn, a major theoretician in contemporary logic, is known for in the field. Much of the reasoning here is episodic and unconnected to other parts of the text. Also, the parts that are not based a formal structure provide only implicit, not explicit, reasoning; that is to say that the process is not on the surface to

$\underline{88}$ Theodore Schick and Lewis Vaughn. How to Think About Weird Things: Critical Thinking for a New Age. 5th ed. Boston: McGraw-Hill Higher Education, 2008. 
be analyzed, as it should be in a critical explication. This text is a strong hybrid.

Schick and Vaughn, How to Think About Weird Things: Critical Thinking for a New Age, 6th ed. ${ }^{89}$

For purposes of this study, there are no differences distinguishing the 5th edition from the 6th, reviewed in the previous entry. This text is also a strong hybrid.

Vaughn, The Power of Critical Thinking: Effective Reasoning About Ordinary and Extraordinary Claims: Instructor's Edition..$^{90}$

This approach is argument-based and relies upon the techniques of formal logic for much of its process. Vaughn also provides self-assessment quizzes and a lot of writing exercises, which makes the material more accessible and provides a modicum of integration, as well as a Socratic approach. Since it explains to instructors how to develop their own exercises and to apply many pieces of the text, there is a clear effort at global over specialized thinking present, too. The text is not very clear or explicit about how those writing exercises should be evaluated, though, except upon principles

$\underline{89}$ Theodore Schick and Lewis Vaughn. How to Think About Weird Things: Critical Thinking for a New Age. 6th ed. Dubuque, IA: McGraw-Hill, 2011.

90 Lewis Vaughn. The Power of Critical Thinking: Effective Reasoning About Ordinary and Extraordinary Claims: Instructor's Edition. New York: Oxford University Press, 2013. 
of argumentation and deductive form, which are highly technical, specialized, and constraining for the thinker. Fortunately, those methods are also Socratic. Vaughn presents a defense of scientific reasoning, but the method offered relies upon a training in formal logic just to use it. He does provide intellectual methods for other non-philosophers, non-mathematicians, and non-scientists, which is very useful and further promotes a global approach. This text is a Strong hybrid.

\section{$\underline{\text { Conclusions }}$}

These popular textbooks for critical thinking in the Philosophy do not reflect a critical approach to learning as defined by Paulian Polarities. Critical Thinking within Philosophy is clearly dominated by the Informal Logic approach, which has traditionally provided methods for improving thinking within the Western tradition. The Paulian critical thinking approach for the classroom is a system that students can learn which is explicit, global, systematic, Socratic, liberating for student thought, integrated with itself, and which uses ordinary language. This cannot be said for most of the texts reviewed.

Informal and formal logic puzzles only teach students to think in the narrow ways needed to solve those puzzles, which are designed to be discipline-specific and to produce very precise thinking patterns within the student's mind. These problem sets and approaches could easily undermine 
mental flexibility, particularly because the available texts rarely teach integration of intellectual methods. Most texts do not encourage students to apply their new skills to anything other than what they've already used them for. This also means they are not very useful in the real world. Students don't learn to be better thinkers generally from logical excises in the traditional formats any more than they learn to be better thinkers from playing Sudoku or Scrabble, doing crossword puzzles, or watching gameshows. Certainly, some intellectual work is being accomplished in these activities, but that work doesn't lead to the improvement of general reasoning skills across disciplines, as Paulian Theory trains the student to do. 


\section{APPENDIX B}

\section{A REVIEW OF THE BUSINESS ETHICS FIELD AS REPRESENTED IN PHILOSOPHY TEXTBOOKS}

The majority of these business ethics sources do not explicitly discuss systematic thinking processes for students to learn to use in line with a global, integrated approach to critical thinking. None of them approach the process of teaching thinking in the depth suggested by Richard Paul's work. The Business Ethics textbooks reviewed in this section are primarily in the discipline of Philosophy, and these are the sorts of sources that one would expect to find in a university-level business ethics class for undergraduates. The review also examines popular business ethics sources that might be appropriate as readings for a business ethics course. A few texts from the field of Management are also included in this list, since those sources contain significant text related to ethical theory, mimicking Philosophy's approach.

In reviewing these texts, all of which have been recommended by publishers for teaching Business Ethics, four major groups emerge. A 
"critical" business ethics text would be explicitly structured to teach students to think about their own thinking and to use specific rational tools to analyze, evaluate, and improve their ethical reasoning within various business contexts. That kind of text would teach thinking skills that are immediately transferable to reasoning about non-business applications. "Didactic" texts teach students the material without any reference to the intellectual processes needed to learn it; students are merely to absorb the material in any ways that they can. "Strong hybrid" approaches contain some important critical aspects about thinking in their texts, or they contain detailed or lengthy discussions of reasoning within ethics only, but without any methodology for the thinker. "Weak hybrids" contain trivial or ineffective critical features in their texts, or they may have implicit criticality and processes that are never made explicit by their authors. The summarized findings are contained in Table 2.

Of the twenty sources reviewed, eleven of them are classified as didactic. Many of the didactic sources are case readers that are only used to get the issues in front of interested eyes. The authors make no effort at improving the thinking of the readers concerning the subjects covered in the text by adding commentary or methodology for thinking about the materials. This is the model used by Allhoff and Vaidya in their Business in Ethical Focus anthology. ${ }^{91}$ No systems of reasoning are discussed, no best

91 Allhoff, Fritz and Anand Vaidya. Business in Ethical Focus. Broadview Press, 2008. 
practices or principles for working through the text are mentioned, and readers are left to rely upon whatever skills they approached the text with to navigate the articles. None of the articles discuss how ethical reasoning might be accomplished in business, though a majority of them suggest that ethical reasoning within business is important.

An identical story exists with Gini and Marcoux, ${ }^{92}$ Martin, Vaught, and Solomon, ${ }^{93}$ and Richardson. ${ }^{94}$ Lisa Newton and her various co-editors for the two versions of Taking Sides: Clashing Views on Business Ethics and Society ${ }^{95}$ reviewed here seem to have no interest in helping students think about the issues. They introduce each pair of conflicting essays with some general background about the issue that seems to be as objective as possible. When no lens on thinking is offered and when no best practices are demonstrated, then students will bring all of their biases and misconceptions into the classroom. Of course, if the text is intended to help students orally argue about the issues, that is quite praiseworthy from a critical point of view, since it encourages Socratic engagement.

${ }^{92} \mathrm{Al}$ Gini and Alexei Marcoux. Case Studies in Business Ethics. Pearson, 2009.

${ }^{93}$ Clancy Martin, Wayne Vaught, and Robert Solomon. Ethics Across the Professions: A Reader for Professional Ethics. Oxford University Press, 2010.

${ }^{94}$ John Richardson. Annual Editions: Business Ethics. McGraw-Hill, 2011.

${ }^{95}$ Lisa Newton. Taking Sides: Clashing Views on Business Ethics and Society, 11th Edition. McGraw-Hill, 2008, and Lisa Newton, Elaine Englehardt, and Michael Pritchard. Taking Sides: Clashing Views on Business Ethics and Society, 12th Edition. McGraw-Hill, 2012. 
A surprise in this review was Bill McKibben's Deep Economy. ${ }^{96}$ McKibben's organization, $\underline{350.0 r g}$, brings together disparate groups to educate them about activism around climate change. McKibben is wellknown for his activism and his calls to action that make national and international headlines, like him synchronizing climate change protests around the world for his "Day of Climate Action" in 2009 and other annual events that tap into the activist efforts of groups in more than 150 countries. In short, he's one of the heroes of the modern sustainability movement. McKibben presents the information to readers in order to help them think about climate change without giving his audience any tools to refine their thinking processes. He doesn't even try to articulate the ethical reasoning process, though he clearly wants people to have their thinking and their actions changed by his work. His book contains various calls to action, but there are no arguments about why this is the right way to think or how to change thinking, only that the author's approach is the right way to think, which amounts to an appeal to McKibben's authority. McKibben seems to believe that presenting the material alone will accomplish his goal, but that is not true. Those without evidence, but who are engaged in action for other reasons, need to be shown the value of using evidence and then argued to the side of the cause. The Paulian framework provides the

96 Bill McKibben, Deep Economy: The Wealth of Communities and the Durable Future. St. Martin's Griffin Press, 2008. 
tools to accomplish that. McKibben's work does not.

Other didactic approaches include Michael Sandel's What Money Can't Buy: The Moral Limits of Markets. ${ }^{97}$ Sandel, a professor of ethical and political philosophy at Harvard, has become a public figure in the area of arguing for morality over markets. His processes are available on YouTube in a number of places (in The Central Question, online videos are used to present Kant's materials.) In his “Justice" MOOC 98 from Harvard, he discusses the way we reason around the classical ethical thinkers of our tradition, but he does none of that here. Sandel doesn't discuss thinking process at all. He mentions some principles that could be useful, like fairness, but he doesn't explicitly advocate for them. Like McKibben, Sandel seems to believe that throwing business examples out there and discussing why readers should do this and that without talking about the reasoning process needed for such values, for real change, and for really deciding for ourselves "what money can’t buy."

Another big name with a similar approach is the Indian physicist and food activist, Vandana Shiva. Her Manifestos on the Future of Food \& $\operatorname{Seed}^{99}$ are inspiring if you are already certain about the issues, but it doesn't help readers discover how to have intellectual empathy, intellectu-

\footnotetext{
${ }^{97}$ Michael Sandel. What Money Can't Buy: The Moral Limits of Markets. MacMillan, 2012.

98 "Justice with Michael Sandel." www.justiceharvard.org

${ }^{99}$ Manifestos on the Future of Food \& Seed. Vandana Shiva, ed. South End Press, 2007.
} 
al courage, or intellectual perseverance, which she clearly possesses. Shiva could have expanded the introduction of her book to talk about strategies for acquiring the valuable Intellectual Traits that allow readers to connect with the essays she is offering.

Two other disappointing authors in this set are Joe DesJardins and William Shaw. Each are big names on the philosophy textbook side of business ethics, and each have multiple offerings in that discipline. I choose four books between the two authors that show up often in searches and lists of business ethics texts with a progressive agenda politically and ethically. All of them were offered to me for use in my business ethics courses by publishers. None of the textbooks discuss thinking processes at all. In fact, Shaw and Barry’s Moral Issues in Business ${ }^{100}$ doesn't even discuss the process of ethical reasoning for thinkers. If the goal is to present business ethics cases and theory to readers, it is very useful.

DesJardins is a little better, but still didactic. His Introduction to Business Ethics ${ }^{101}$ is a "strong hybrid," leading the textbook offerings. His effort in 2007, however, called Business, Ethics, and the Environment, ${ }^{102}$ is a lot like what Sandel, Shiva, and McKibben have to offer in this area.

\footnotetext{
${ }^{100}$ William Shaw and Vincent Barry. Moral Issues in Business. Cengage Learning, 2013. 101 Joseph DesJardins, Introduction to Business Ethics. McGraw Hill Higher Education, 2003. 102 Joseph DesJardins, Business, Ethics, and the Environment. McGraw Hill Higher Education, 2007.
} 
It's a shame that he couldn't take some of the space in this book to give as much attention to intellectual processes as he does in other texts. I guess, like Sandel, we are expected to see his other work. A critical textbook could be packaged in such a way that the reader teaches him or herself about business ethics while simultaneously practicing thinking about his or her own thinking at a high level.

"Weak Hybrids" abound in the list. These texts each explicitly suggest that students consider their own thinking processes in order to learn to be a better thinker about ethics in business contexts. Beyond that important critical aspect, these texts include primarily didactic methods. However, each of them alludes to critical thinking principles. A brief examination of this group's membership follows.

In Culture Jam: The Uncooling of America, ${ }^{103}$ Kalle Lasn gives lots of good advice for thinking. He advocates thinking through the votes we cast, the food we eat, and the media we consume. He advocates that we think differently about our clothes and our cultural biases, but he doesn't tell us how to do so. To his credit, he raises strong thinkers who do advocate methodologies of some sort, from the anarchist Guy DeBord, to the Zen master Takuan Soho, to the Canadian philosopher and activist Marshall McLuhan. Lasn doesn’t go into their methods, though; he appropri-

${ }^{103}$ Kalle Lasn. Culture Jam: The Uncooling of America. Excerpts published in The Guardian, April, 2000. Web. November 22, 2013. <http://www.guardian.co.uk/books/2000/apr/10/ex$\underline{\text { tract> }}$ 
ates their one-liners and memes for his tapestry, which is all about thinking, if mainly in the implicit sense. He is advocating good thinking, and he has clearly structured his text to engender that for some ethical stance regarding business, but he doesn't give the reader any process or system to develop or learn from.

Annie Leonard's work on The Story of Stuff ${ }^{104}$ media project raised awareness of climate change and the need for some types of sustainable action and citizen-based initiatives through animation on the Internet. Her book about the project by the same name, published in $2011,{ }^{105}$ promises in its title that it can help us "make it better." However, this document, while it raises lots of suggestions about what can be done and how a person might go about doing it, including large-scale social change, it doesn't talk about the thinking process someone might go through to determine for themselves what values are important. Leonard and Conrad (her coauthor) do a nice job criticizing contemporary paradigms around energy, food, and manufacturing, but they do not present any process to go along with the ethical approaches. In The Central Question, a reader could take this content (the video on YouTube is included in Chapter 11 of that text)

\footnotetext{
104 Annie Leonard. The Story of Stuff. Tides Foundation and Funders Workgroup for Sustainable Production and Consumption, 2007. YouTube. November 21, 2013. <http://www.youtube.com/watch? $\mathrm{v}=9$ GorqroigqM $>$

105 Annie Leonard. The Story of Stuff: The Impact of Overconsumption on the Planet, Our Communities, and Our Health-And How We Can Make It Better. Free Press, 2011.
} 
and apply rigorous standards of thinking to it to determine if the authors are being biased or fair-minded, for example. After having done that, a reader could decide precisely why he or she would want to adopt the author's thinking and how to do that. This document doesn't even mention thinking processes, though it spends dozens of pages attacking the fruits of one type of it.

Hartman's and DesJardins's book, Business Ethics: Decision Making for Personal Integrity and Social Responsibility ${ }^{106}$ has a lot of good suggestions for "social integrity," which they articulate into a positive intellectual trait in the Introduction. In a departure from his more popular Introduction to Business Ethics, ${ }^{107}$ however, DesJardins makes no contributions that explain a systematic process for developing social responsibility, integrity, or any other intellectual skills or characteristics. He makes no mention of thinking as a piece of this process at all, and so readers cannot learn to do it for themselves, except by guessing at how to fill in the blanks. The Central Question does accomplish these things where this text does not, creating a critical process for business ethics that teaches readers how to think through their own work in the discipline.

A similar outcome is produced by Hill's and Rae's The Virtues of

${ }^{106}$ Laura Hartman and Joseph DesJardins. Business Ethics: Decision Making for Personal Integrity and Social Responsibility. McGraw-Hill, 2011.

107 Joseph DesJardins, Introduction to Business Ethics. McGraw Hill Higher Education, 2003. 
Capitalism: A Moral Case for Free Markets, ${ }^{108}$ which makes lots of moral arguments and even spends a lot of text helping its reader think through his or her moral reasoning. The moral reasoning is largely based in biblical principles, however, and doesn’t pass muster as “evidence-based” from either the Paulian point of view or the standard for ethical theories in Chapter Two of The Central Question. It certainly does not look deeply into any reasoning process that would be transferrable to another area of life that is irreligious, like the diagnosing and fixing of a kitchen appliance. The Paulian method would be useful in many situations (Paul calls this the "global" polarity), and an evidence-based approach to ethical reasoning would allow readers of Hill's and Rae's text to evaluate competing systems on both non-economic and non-biblical criteria, skills their book does not teach.

Beauchamp's Ethical Theory and Business ${ }^{109}$ is an excellent text for learning to reason ethically from the point of view of classical texts in the tradition of western ethics. Beauchamp lays out those authors' reasoning, but he mentions nothing of the reader's reasoning. He has questions and discussions after the theoretical discussions that prompt a reader to look at his or her thinking about a theory or about an issue, but there is no discus-

108 Austin Hill and Scott Rae. The Virtues of Capitalism: A Moral Case for Free Markets. Northfield Publishing, 2010.

${ }^{109}$ Tom Beauchamp, Norman Bowie, and Denis Arnold. Ethical Theory and Business. Pearson Press, 2009. 
sion or explanation about how one goes about doing that.

Honest Work ${ }^{110}$ by Ciulla, Clancy, and Solomon are in the same vein as Beauchamp. The Central Question discusses ethical reasoning methods from different systems and how to apply them to business ethics, then how to think about your own thinking, and then how to combine the two to think about business ethics. There is an analogous approach by Solomon regarding process-oriented ethics and reasoning in Honest Work. On page 106, for example, Solomon presents a list of questions one might pose to oneself to determine whether the thinker is successful in achieving the purpose for his or her thinking. The list of questions is presented in a Socratic way, which Solomon does well in many textbooks, to help the reader teach him or herself by reading the words on the page and thinking through the steps. Exercises nearby in the text provide more reinforcement. Further, there is a brief ethical reasoning discussion in the Preface to Instructors, but that is lighter on process than the later section. The contribution from Solomon would place this text in the "Critical" category if there were more essays like this one, but there is no further mention of how to improve thinking, for business ethics or anything else, anywhere else in this massive textbook.

The "Strong Hybrids" are the best examples of critical thinking

110 Joanne Ciulla, Clancy Martin, and Robert Solomon. Honest Work. Oxford University Press, 2007. 
principles available in contemporary textbooks. The textbooks reviewed revealed no examples of "critical" business ethics texts, which would teach readers to think about their own thinking systematically, within the content of the course, and be structured to teach both business ethics reasoning and reasoning in general. The strong hybrids, on the other hand, teach quite a bit about reasoning within business ethics, but they do not present any methodology or integrated, systematic approach reminiscent of Paulian Critical Thinking.

Anita Allen's popular book The New Ethics ${ }^{111}$ has lots of suggestions about how to live ethically in and out of business. There is also advice for how to "be a good person," but there is no discussion about how reasoning gets us to these places of goodness. In other words, lots of principles are discussed, lots of cases presented, and much critique is offered from Allen, but there is no integrated process for the reader who uses her principles, and there is no system for including them in the reader's thinking process. Allen tells us what to do and why it's the ethical thing, but she doesn't teach us to emulate her reasoning.

DesJardins succeeds in terms of ethical reasoning where Allen fails. He discusses the need for understanding ethical reasoning in his preface and that the process should "involve students in thinking for

${ }^{111}$ Anita Allen. The New Ethics. Miramax Publishing, 2004. 
themselves". ${ }^{112} \mathrm{He}$ also cites his discussion questions as a major method for getting students involved in their own thinking process, and he encourages teachers to emphasize ethical reasoning in their classes, though he doesn't present integrated methods for doing this. Throughout four editions of his text, there are pockets of critical thinking and ethical reasoning processes outlined, but DesJardins's book is not designed to coalesce these methods and principles into a toolbox that students can use to think about their own thinking about business ethics, in the Paulian critical style. His first chapter is very detailed about how to do ethical reasoning in a general way, but those principles are never revisited later in the text or pointed to for a process-driven analysis.

Ghillyer's book ${ }^{113}$ is endorsed by the Better Business Bureau, and it is a great text for understanding business ethics cases as they relate to the law. Ghillyer combines ethics reasoning processes to great effect in each chapter, pointing out principles of fairmindedness, evidence, and accuracy throughout. They are not linked together, though, and no explicit system is offered, though Ghillyer has enough critical principles to present one. The text could be more critical with some contextualization of the thinking process outside of ethics, and the various principles should be integrated

112 Joseph DesJardins, Introduction to Business Ethics. McGraw Hill Higher Education, 2003. xvii.

${ }^{113}$ Andrew Ghillyer, Business Ethics Now. McGraw-Hill Publishers, 2003. 
into those examples.

In The Ethics of Management, ${ }^{114}$ Hosmer offers a four-part system of ethical reasoning that asks readers to self-reflect and consider their thinking about the business decisions of others. The reasoning that is advocated is essentially John Stuart Mill's style of utilitarianism contextualized for an office setting, but it's not very explicit. Frankly, there is no discussion of ethical reasoning outside of the case analyses, and there is little expectation on the part of the text that readers will use the material in their lives outside of a management setting. This is the most systematic approach, next to Solomon's essay in Honest Work above, in any of the business ethics texts reviewed.

Certainly, this list and analysis demonstrate the need for a business ethics text that teaches business students to think in an integrated way about existing business ethics concerns, while also helping them learn to update their own thinking for the innovations in business ethics that they will inevitably face in their various interactions with the market. There is no shortage of case readers and business ethics texts that are orientated toward a casual perusal of ethical theories and concerns. Very few of them, however, make any effort to teach students to think through the content in a critical fashion, such that that reader internalizes the deep principles of business ethics for any application.

${ }^{114}$ La Rue Hosmer. The Ethics of Management. McGraw-Hill Publishing, 2008. 


\section{APPENDIX C}

\section{CLAIMS OF ORIGINALITY}

This section addresses the dissertation's claims of original research and its contributions to the fields of business ethics, critical thinking, and interdisciplinary education. The claims are each verified by reference to literature searches in academic and popular databases. Below are sixteen claims of originality. Thirteen are related to the discipline of business ethics and three are related to critical thinking. Each claim is annotated to indicate its relevance and scope for the project, including the extent to which it is interdisciplinary. Search databases and vehicles are canvassed, and then one claim of originality is proposed at a time, along with the disclosure of search terms and the results of those searches offered for the claim. These efforts are summarized in Table 3. A conclusion is offered for each data search. The search engines and databases used are here:

\section{Academic Search Premier:}

"Academic Search Premier covers the expansive academic disciplines now being offered in colleges and universities. It provides comprehensive content, including PDF backfiles to 1975 or further for well over one hundred journals, and searchable cited references for more than 1,050 
titles"

(http://www.ebscohost.com/academic/ academic-search-premier).

Amazon Books: "Amazon.com carries tens of thousands of book

titles, mainly from contemporary, in-print sources" (http://www.amazon.-

com $/ \mathrm{s} / \mathrm{ref}=\mathrm{nb}$ sb noss 2?url=search-alias $\% 3$ Daps\&field-

keywords=books).

Business Source Premier:

"Business Source Premier is the industry's most popular business research database, featuring the full text for more than 2,200 journals. Full text is provided back to 1965, and searchable cited references back to 1998 . Journal ranking studies reveal that Business Source Premier's full-text coverage outshines its competitors in all business disciplines, including marketing, management, MIS, POM, accounting, finance and economics. Additional full text, non-journal content includes market research reports, industry reports, country reports, company profiles and SWOT analyses." (http://www.ebscohost.com/academ-ic/business-source-premier)

\section{EBSCOhost:}

"EBSCO Information Services provides a complete and optimized research solution comprised of research databases, e-books and e-journals [by offering] more than 375 full-text and secondary research databases and over 515,000 e-books plus subscription management services for 360,000 e-journals, e-journal packages, and print journals"

(http://www.ebsco.com/ about).

EconLit:

"The American Economic Association's electronic bibliography, EconLit, indexes over 120 years of economics literature from around the world. Compiled and abstracted in an easily searchable format, EconLit is a comprehensive index of journal articles, books, book reviews, collective volume articles, working papers and dissertations"

(http://www.aeaweb.org/econlit/.)

Google Books: This website indexes books and makes them 
searchable.

"Just enter the keyword or phrase you're looking for into the Google Books box. For example, when you search for [rock climbing] or for a phrase like 'one small step for man,' we'll find all the books whose contents match your search terms"

(https://support.google.com/books/answer/43724?hl=en). This part in-

spires confidence that the scope of the database will turn up hits if they

exists in published books:

"We're working with several major libraries to include their collections in Google Books and, like a card catalog, show users information about the book, and in many cases, a few snippets - a few sentences to display the search term in context" (http://books.google.com/googlebooks/library/).

"This is just one approach Google is taking to digitize all published work, and their collection currently boasts sophisticated partners carrying books in the disciplines most relevant to this study: business ethics, critical thinking, philosophy, management, and economics. These partners include Harvard University, Columbia University, The New York Public Library, University of California, Oxford, Stanford, and University of Virginia library collections."

\section{Google Scholar:}

This site indexes academic papers from "most major academic publishers and repositories worldwide, including both free and subscription sources," and "Google Scholar includes journal and conference papers, theses and dissertations, academic books, pre-prints, abstracts, technical reports and other scholarly literature from all broad areas of research."

The editors say they update the database twice weekly, although they are 6-9 months behind on updating publications. (http://scholar.google.com/ intl/en-US/scholar/help.html\#coverage). 


\section{GreenFILE:}

"This comprehensive resource draws on the connections between the environment and a variety of disciplines such as agriculture, education, law, health and technology. Topics covered include global climate change, green building, pollution, sustainable agriculture, renewable energy, recycling, and more. This collection of scholarly, government and general-interest titles includes content on the environmental effects of individuals, corporations, and local/national governments, and what can be done at each level to minimize these effects" (http://www.ebscohost.com/academic/greenfile.)

\section{JSTOR:}

"JSTOR currently includes more than 2,000 academic journals, dating back to the first volume ever published, along with thousands of monographs and other materials relevant for education. We have digitized more than 50 million pages and continue to digitize approximately 3 million pages annually"

(http://about.jstor.org.libproxy.bellarmine.edu/.)

\section{Philosopher's Index:}

“The Philosopher's Index is the world's most current and comprehensive bibliography of scholarly research in philosophy, serving the philosophical community worldwide. Today, The Index contains more than 540,000 journal articles and book citations drawn from over 1600 journals, originating from 139 countries in 37 languages. The literature coverage dates back to 1940 and includes print and electronic journals, books, anthologies, contributions to anthologies, and book reviews. Covering scholarly research in all major areas of philosophy, The Index features informative, author-written abstracts. The extensive indexing, which includes proper names along with subject terms, enhances the search capability"

(http://philindex.org/.)

\section{$\underline{\text { ProQuest }}$}

("http://www.proquest.com/") ProQuest is 
"a growing content collection that now encompasses 90,000 authoritative sources, 6 billion digital pages, and spans six centuries. It includes the world's largest collection of dissertations and theses; 20 million pages and three centuries of global, national, regional and specialty newspapers; more than 450,000 ebooks; rich aggregated collections of the world's most important scholarly journals and periodicals; and unique vaults of digitized historical collections from great libraries and museums, as well as organizations as varied as the Royal Archives, the Associated Press and the National Association for the Advancement of Colored People" (http://www.proquest.com/about/who-we-are.html).

\section{BUSINESS ETHICS CLAIMS}

\section{Original Contributions to the Discipline of Business Ethics, Claim \#1 of}

13: This is the only business ethics textbook explicitly concerned with criticality.

Methodology: The databases searched were JSTOR, Google Books, Google Scholar, Academic Search Premier, ProQuest, EBSCOhost, Business Source Premier, EconLit, GreenFILE, and the Philosopher's Index. The search terms were "Critical Thinking" and "Business Ethics." When searched in this way, JSTOR located 58 results. Of the 58 results, nine were investigated for challenges to the claim of originality by reading their provided abstracts. Integrity: Doing the Right Thing for the Right Reason $^{115}$ is a psychological text based in clinical practice that focuses on workaholism. There is no mention of critical thinking in its abstract. This

115 Barbara Killinger. Integrity: Doing the Right Thing for the Right Reason. McGill's Queen's University Press, 2010. 
is not a business ethics textbook, at any rate, so it does not challenge the claim.

Other texts which showed up in the search, including Martha Nussbaum's Not for Profit ${ }^{116}$, Values in Conflict, ${ }^{117}$ The Googlization of Everything (And Why We Should Worry), ${ }^{118}$ Researching the Social Economy, ${ }^{119}$ Human Rights in Our Own Backyard:Injustice and Resistance in the United States, ${ }^{120}$ and Growing Greener Cities: Urban Sustainability in the Twenty-First Century ${ }^{121}$ are not business ethics textbooks, so they do not challenge this claim.

The remaining two texts could be used as textbooks for business ethics classes, though neither says it is explicitly written for that. New World Order: Corporate Agenda and Parallel Reality ${ }^{122}$ is a themed essay anthology

116 Martha C. Nussbaum. Not For Profit:Why Democracy Needs the Humanities. Princeton University Press, 2012.

${ }^{117}$ Paul Axelrod. Values in Conflict. McGill Queen's University Press, 2002.

118 Siva Vaidhyanathan. The Googlization of Everything (And Why We Should Worry). University of California Press, 2012.

119 Laurie Mook, Jack Quarter, and Sherida Ryan. Researching the Social Economy. University of Toronto Press, 2010.

120 William Armaline, Davita Glasberg, and Bandana Purkayastha. Human Rights in Our Own Backyard:Injustice and Resistance in the United States. University of Pennsylvania Press, 2011.

121 Eugenie Birch and Susan Wachter. Growing Greener Cities: Urban Sustainability in the Twenty-First Century. University of Pennsylvania Press, 2011.

122 New World Order: Corporate Agenda and Parallel Reality, Gordaria Yovanovich, ed. McGill Queen's University Press, 2003. 
that could fall into a "Weak Hybrid" category, particularly for its Introduction, parts of its second essay, and, particularly, its last essay, "Higher Education in the New World Order" by Howard Vargo. These three pieces are concerned with intellectual processes, though there is no systematic or integrated approach mentioned by name. It also doesn't teach ethical theories in any of its business ethics essays, though it alludes to contemporary models for ethical business.

The last book is Creating Healthy Organizations: How Vibrant Workplaces Inspire Employees to Achieve Sustainable Success. ${ }^{123}$ The Introduction and Chapter One "The Healthy Organization" explicitly address business ethics, and the entire book is structured to teach a reader how to create a healthy organization by thinking it through. There is no explicit mention of critical thinking or any integrated thinking system here, however, and there is no effort made to put forth an integrated method for thinking through business ethics problems generally. This text falls into the "Strong Hybrid" category. It claims to be in the Management area of business ethics, however, and doesn't explicitly mention criticality or critical thinking in any of its chapters. This text does not challenge the claim of originality, since it does not explicitly discuss any critical approach, though it could have been designed with some unknown critical model in mind.

123 Graham Lowe. Creating Healthy Organizations: How Vibrant Workplaces Inspire Employees to Achieve Sustainable Success. University of Toronto Press, 2010. 
The Google Books literature search for "business ethics" and "critical thinking" returned 4,020 hits. Of these, ten more books appeared to present a serious challenge the claim that The Central Question is an original approach to creating a business ethics textbook, one that is overtly concerned with teaching content through critical thinking. Jones's and Dutcher's Business Ethics: Developing Analytical and Critical Thinking Skills, ${ }^{124}$ despite its title, doesn't do much to teach critical thinking or ethical reasoning. The purposes of the book is to supplement law school ethics courses and to help students develop core critical thinking skills, according to its "Message from the Authors." The text relies heavily upon industry-specific approaches to ethics that are based in current legal standards. Chapter Two of The Central Question explains why thinking about ethics in a legalistic way undermines the ethical reasoning process. That principle doesn't comes up for Jones and Dutcher.

The Seventh Chapter is three pages long and mentions a host of ethical theories, even a few that don't qualify for reason-based ethics, like "divine command theory." The entire entry on contractarianism, the topic of thirteen pages in The Central Question, is quoted here: "A social contract is the way to think about this theory. The guiding principle is that rational people will choose the most equitable and fairest result. Theorists: John Lock and

${ }^{124}$ Frederick D. Jones and Cristen Dutcher. Business Ethics: Developing Analytical and Critical Thinking Skills. Kendall-Hunt Publishing, 2013. 
John Rawls." There is no other mention of the theory or of its mentioned theorists, and no other resources or discussion for helping readers think through this ethical theory is provided. The authors' critical thinking theory is also in this chapter, and it is a set of twelve questions from Laura Nash, a philosopher from Fairfield University. As great as these twelve questions are, they aren't use or mentioned again, and neither is Nash. This approach cannot be expected to help people learn to reason ethically or to reason critically. This text, for our purposes, is useless, and does not challenge the claim of originality. This text is not explicitly concerned with criticality.

The Mortgage Broker and Loan Officer Core Education ${ }^{125}$ is not trying to teach readers to reason ethically at all. It is a professional guide for professional certifications and examinations in various aspects of the businesses related to the title. The text is geared only toward a Texas market, and it is also concerned with the legal standards far more than than anything having to do with ethics. It does have "Questions for Critical Thinking" at the end of each chapter, though, but these are not critical in nature. For example, from page 159: "Questions for Critical Thinking: 1. List the items that conforming conventional underwriting guidelines require from every borrower as documentation in every file," 126 and, from page 201, "Demonstrate

125 Professional Exam Review. The Mortgage Broker and Loan Officer Core Education. Cengage Learning, 2010.

${ }^{126}$ Ibid., 159. 
the difference between an ARM, a buy-down, and ..."127 These questions promote didactic use of the text. This book is no challenge to the claim of criticality.

In Linda Dyer's Critical Thinking for Business Students, ${ }^{128}$ there is a great bunch of critical thinking, though it tapers off into traditional logical exercises in a couple of spots. In Dyer's Preface, she writes,

"The handbook is intended for use as a supplemental text in undergraduate business courses. It teaches students to bring a critical perspective to their reading in various fields of business - evaluating authors' arguments, uncovering key assumptions, analyzing why certain texts are more persuasive than others, and practicing related critical thinking skills." 129

She uses a great critical thinking process that, while incomplete, is probably really effective for helping undergraduate business students break apart arguments and become better writers by that exercise. She has no discussion of ethical theorists for business or a process for how to reason ethically within business anywhere in the text, however, and so this is not a business ethics text that's concerned with teaching students to reason ethically. For this reason, it cannot challenge the claim of originality..

Shaw's Business Ethics: A Textbook with Cases $^{130}$ is no better than his effort with Barry, above. There is no discussion of a reasoning process for

127 Ibid., 201.

${ }^{128}$ Linda Dyer. Critical Thinking for Business Students .Captus Press, 2006.

${ }^{129}$ Ibid., vii.

${ }^{130}$ William Shaw. Business Ethics: A Textbook with Cases. Cengage Learning, 2010. 
ethics in this text, and there is no organized system of critical thinking introduced or suggested for reasoning within business. This textbook does not challenge the claim.

The anthology, Business Ethics: A Critical Approach: Integrating Ethics Across the Business World, ${ }^{131}$ has terrific and highly relevant business ethics essays. It has at least four essays that discuss methods of doing ethical reasoning, but the only systematic understanding of critical thinking is a threepart process that is articulated in the first and second essays by O'Sullivan. The three-part process presented is in levels. The first is descriptive, the second is normative (establishing how the subject should act), and the third is the critical moral reflection This process compares the descriptive level to the normative one in order to arrive at a judgment, but O'Sullivan doesn't offer any suggestions for how that critique should be undertaken or managed as a system by the thinker. O'Sullivan goes on to demonstrate that his understanding of "critical thinking" comes from his understanding of "critical theory," which informs social sciences and is essentially a methodology adopted from Karl Marx that challenges social norms with reality. This approach does not provide any other systematic structure, nor is the system explained in any greater detail in Chapter Two than it is from Chapter One, paraphrased above. This system, also, is not applied explicitly throughout

${ }^{131}$ Patrick O'Sullivan, Mark Smith, and Mark Esposito. Business Ethics: A Critical Approach: Integrating Ethics Across the Business World. Routledge Publishing, 2012. 
the text. The other mention of critical thinking in this anthology is in Josiena Gotzsch's essay, "Designing for a Better World," where she offers in the Introduction that,

"The design process is not a cure for all problems, but its creative approach can play a part in the search for solutions. Critical thinking [is] identifying the real problem spots and asking both fundamental and naive questions, [which] lead to understanding what is really needed. If this is combined with creativity, flexibility, and the objective to create solutions in sometimes unexpected ways, this may become a core competitive asset for a company." 132

This text may be written with criticality in mind in one sense, but it does not actually demonstrate that criticality throughout. The text is not obviously arranged to promote better thinking about the reader's thinking about business ethics issues. This text does not unseat the claim of originality, though it is quite a fine text and is a "strong hybrid."

\section{Ronald Sims's Teaching Business Ethics for Effective Learning ${ }^{133}$ is a} book for teachers, not for students, and so it does not qualify as a textbook. it is quite a fine text with many explicit principles, though it does not approach the global, integrated, explicit methods of Paulian Theory. It poses no challenge to the claim.

Finally, The Legal Environment of Business: A Critical-Thinking Ap-

132 Josiena Gotzsch. "Designing for a Better World," in Patrick O’Sullivan, Mark Smith, and Mark Esposito. Business Ethics: A Critical Approach: Integrating Ethics Across the Business World. Routledge Publishing, 2012.

${ }^{133}$ Ronald Sims. Teaching Business Ethics for Effective Learning. Springer, 2002. 
proach, ${ }^{134}$ presents robust critical thinking suggestions from a number of approaches, including from Paulian Theory, but it doesn't make any effort to teach students how to reason ethically, only legally, which is its stated goal. There is no challenge here to the claim of originality for business ethics textbooks.

Google Books and JSTOR cover the breadth of textbooks published in business ethics, so searching it demonstrated that the literature doesn't support a critical thinking approach to teaching business ethics. The online "Business Ethics: The Magazine of Corporate Social Responsibility"135 was searched with the same search terms. It returned only a single hit for "critical thinking," which is not a textbook.

Based upon the aforementioned evidence, the first claim, that "This is the only business ethics textbook overtly concerned with criticality," is true. The text that presented the greatest challenge to the claim during analysis was Business Ethics: A Critical Approach: Integrating Ethics Across the Business World. ${ }^{136}$

Original Contributions to the Discipline of Business Ethics, Claim \#2 of 13:

134 Nancy Kubasek. The Legal Environment of Business: A Critical-Thinking Approach. Prentice Hall, 1999.

${ }^{135}$ www.business-ethics.com.

136 Patrick O'Sullivan, Mark Smith, and Mark Esposito. Business Ethics: A Critical Approach: Integrating Ethics Across the Business World. Routledge Publishing, 2012. 
A business ethics textbook has never been published that is explicitly built around the central question technique.

Methodology: An identical EBSCOhost database search to that performed for the first claim was used, but using the search terms "central question" and "business ethics." There were discovered no matches. Next, the same search terms were used on Amazon Books, which would bring up contemporary textbooks for sale. There was one hit, but it is not a business ethics textbook; it is a book about being a leader and advisor in any industry. The claim is not challenged by it.

Google Books gave 766 hits for "central question" and "business ethics." The bottom line from all of those results is this: Nearly every author about business ethics believes that there is a central question he or she is addressing in the text or essay, and that central question is often related to culture or a specific industry of interest to the author. Any deviations found from this description, like Fundamentals of Ethics, ${ }^{137}$ On the (Im)Possibility of Business Ethics, ${ }^{138}$ Management Ethics: Contemporary Contexts, ${ }^{139}$ or Ethics Management: Auditing and Developing the Ethical

137 John Finnis. Fundamentals of Ethics. Georgetown University Press, 1983.

138 Minka Woermann. On the (Im)Possibility of Business Ethics: Critical Complexity, Deconstruction, and Implications for Understanding the Ethics of Business. Springer, 2013.

${ }^{139}$ Stewart Clegg and Carl Rhodes. Management Ethics: Contemporary Contexts. Routledge, 2006. 
Content of Organizations ${ }^{140}$ were not business ethics textbooks, so they present no direct challenge to the originality claim.

Searching EBSCOhost, Amazon Books, and Google Books should have provided published textbooks built around a central questions that were also in the discipline of business ethics. However, such claims were not made by any text reviewed, and it seems that the central question technique as explained and developed in The Central Question has not been adopted for any other business ethics textbook.

\section{Original Contributions to the Discipline of Business Ethics, Claim \#3 of}

13: No other business ethics textbook begins with The Milgram Experiments.

Methodology: Searches were conducted for "business ethics" and "Milgram experiments" in Google Books, Amazon Books, and EBSCOhost for books. When a business ethics text that contained the Milgram Experiments was located, it was examined to see where it falls structurally in the textbook being examined. The Central Question starts with Milgram, and that sets the tone for the rest of the text, particularly since the methodology continues to build upon and return to the $f \& p$ concepts from that first chapter throughout the text. Others might do the same, if the structure is

${ }^{140}$ S.P. Kaptein. Ethics Management: Auditing and Developing the Ethical Content of Organizations. Springer, 1998. 
similar.

Amazon's search produced Grote and McGreeney's Clever as Serpents:

Business Ethics and Office Politics, ${ }^{141}$ which is a business ethics textbook.

The Milgram Experiments, however, are not mentioned in this text. Bad

search algorithm!

Another search with the terms reversed produced several additional texts. The anthology Economics and Morality ${ }^{142}$ was promising, but that text relies heavily upon Lynne Milgram (one of the editors), not Stanley. On the other hand, Obstacles to Ethical Decision-Making ${ }^{143}$ does introduce Milgram in Chapter Three. This is not a business ethics textbook, however, and Milgram is not mentioned again, so the claim of originality holds.

Leadership and Business Ethics, ${ }^{144}$ doesn't mention Milgram until page 94, and Business Ethics Collection ${ }^{145}$ doesn't raise Milgram until a quarter of the way through the text. A search in Google Books turned up many of the same texts as the Amazon search. None of these that are business ethics

141 Jim Grote and John R. McGreeney. Clever as Serpents: Business Ethics and Office Politics. Michael Glazer, 1997.

142 Economics and Morality: Anthropological Approaches. Katherine Browne and B. Lynne Milgram, eds. Society for Economic Anthropology, 2009.

${ }^{143}$ Patricia H. Werhane, Laura Pincus Hartman, Crina Archer, Elaine E. Englehardt, and Micahel S. Pritchard. Obstacles to Ethical Decision-Making: Mental Models, Milgram, and the Problem of Obedience. Cambridge University Press, 2013.

${ }^{144}$ Leadership and Business Ethics. Gabriel Flynn, ed. Spring Science + Business Media, 2008.

${ }^{145}$ Business Ethics Collection. William Frey and Jose Cruz-Cruz, eds. Blackwell Press, 2009. 
textbooks begin with The Milgram Experiments. A search in Google Scholar's "books" field produced no Milgram Experiment chapters that showed up early in the development of the text.

An EBSCOhost search of all databases for book chapters with "Stanley Milgram" and "business ethics" produced only one result, Werhane's and Hartmann's use of Milgram experiments in Chapter Three of their text, as discussed above.

Since no contradictions to the claim that The Central Question is the only textbook that begins with The Milgram Experiments can be located in either the EBSCOhost book search, Google Books, Google Scholar book search, or Amazon Books, this claim stands.

\section{Original Contributions to the Discipline of Business Ethics, Claim \#4 of}

13: Advocating The Oxford Tutorial for business ethics instruction is original.

Methodology: The Amazon Books search produced no results, but many results for Oxford Publishing. The same search in EBSCOhost produced no results. Google Books produced no results that are business ethics texts. Google Scholar produced a few more hits, but none of them are business ethics textbooks. ProQuest, which is appropriate to use when searching for academic articles, rather than books, produced no results. Since no results were produced through the search protocols to demon- 
strate that any other published business ethics approach has explicitly incorporated the Oxford Tutorial, the claim stands that The Central Question is original by connecting The Oxford Tutorial and business ethics.

\section{Original Contributions to the Discipline of Business Ethics, Claim \#5 of 13:}

The particular sources and thinkers used in The Central Question have been arranged in a unique way for business ethics textbooks.

Methodology: Of the dozens of business ethics textbooks reviewed for this dissertation, none were found to possess an identical sequential ordering of ideas to the approach used in The Central Question. In the absence of any evidence to the contrary, the claim holds.

\section{Original Contributions to the Discipline of Business Ethics, Claim \#6 of 13:}

No other business ethics textbook includes its author's own original business proposal, as in Appendix Four of The Central Question.

Methodology: None of the business ethics textbooks reviewed for this dissertation possess any original business proposals from their authors. In addition, a search was performed in electronic databases to confirm that original business proposals are not present in an unreviewed text. The EBSCOhost search was first, and nothing that it produced out of 775 hits from all sources was a business ethics textbook.

JSTOR's 92 original results for "business ethics" AND "business 
plan" OR "business proposal" yielded seven that may have been business ethics textbooks. Upon inspection, five are worth pursuing. Geoffrey Heal's When Principles Pay: Corporate Responsibility and the Bottom Line ${ }^{146}$ does not contain an original business plan by the author, but it does contain an original plan for corporate governance. Managing for Stakeholders: Survival, Reputation, and Success ${ }^{147}$ does not contain any original business plans, though there is interesting material about developing business plans for entrepreneurs in chapters nine and ten. U.S. Corporate Governance ${ }^{148}$ does not possess an original business plan from the authors, either. This text contains lots of mentions of international business plans, but it puts forth none of its own.

No original business plans show up in the literature reviewed for this dissertation. The idea of including an original business plan of any type in a business ethics textbook seems original with The Central Question.

${ }^{146}$ Geoffrey Heal. When Principles Pay: Corporate Responsibility and the Bottom Line. Columbia Business School Publishing, 2008.

${ }^{147}$ R. Edward Freeman, Jeffrey Harrison, and Andrew Wicks. Managing for Stakeholders: Survival, Reputation, and Success. Yale University Press, 2007.

148 US Corporate Governance. Donald H. Chew and Stuart L. Gillan, eds. Columbia University Press, 2009. 
Original Contributions to the Discipline of Business Ethics, Claim \#7 of 13:

The central question, "When is it acceptable to profit from harm to others in business?" is original with this manuscript.

Methodology: The databases were searched with that question in quotation marks. Amazon Books provided no results for the search. The same result was had with EBSCOhost. The same result was reached with Google Books, the general Google search engine, and Google Scholar. ProQuest also came up empty on this search.

Since the central question, "When is it acceptable to profit from harm to others in business?" doesn't show up in any searches, it should be considered original for The Central Question.

Original Contributions to the Discipline of Business Ethics, Claim \#8 of 13: The use of The Corporation as the focal feature of a chapter in a business ethics textbook has not been accomplished prior to The Central Question. Methodology: Searches were conducted for "The Corporation documentary" and "business ethics." Within those results, tables of contents and abstracts of chapters were examined to determine whether this film was used as the topic of any chapters in other business ethics textbooks.

Amazon Books did not provide any useful results, and none of the hits on Google Scholar ended up being textbook chapters about the film. At least 
six textbooks that showed up in the Google Books search that hadn't already been reviewed, but none of them ended up containing significant material about the film, much less a chapter that uses it exclusively. The JSTOR search with 91 results for "business ethics" AND "the corporation" AND "documentary" produced no texts at all that relied upon The Corporation.

There was no mention of The Corporation documentary film as a serious part of any chapters in any of the two dozen sources reviewed from JSTOR. The use of this documentary film as the main subject matter in a chapter of a business ethics textbook is original.

Original Contributions to the Discipline of Business Ethics, Claim \#9 of 13: The linking of The Milgram Experiments, The Butterfly Effect, and The Small World Experiments as a way of teaching interdisciplinary thinking in business ethics is original with this text.

Methodology: The databases were searched for any documents where all three of these topics occur together.

Amazon Books produced nothing, and JSTOR did not produce any results. Neither did EBSCOhost or ProQuest. Google Books provided nothing relevant.

The first article in Google Scholar is closest, but its "Small World" is Disney's, not Milgram's. Since no information could be located in the data- 
bases to refute it, this claim of originality in combining those three theories into one assignment as a way to explain interdisciplinary reasoning is original in The Central Question.

Original Contributions to the Discipline of Business Ethics, Claim \#10 of 13: The community engagement student assignment of exploring food deserts and making student films about them is original with this text. Methodology: The databases were searched for hits combining "food desert" and "student film."

Methodology: Amazon Books didn't find anything. EBSCOhost couldn't even find any "student film" assignments for "business ethics," much less about food deserts. Google Books couldn't find anything, either, nor could Google Scholar. ProQuest located nothing.

Since none of the database searches found any results to these searches, this claim of originality is also bona fide.

Original Contributions to the Discipline of Business Ethics, Claim \#11 of 13: 
There are no published examples of the criticism of Friedman's thesis along the lines of U.S. free market culture creating the conditions whereby companies will break the law, pay the fine, and do it again, thereby leading to an undermining of the logicalness of Friedman's ethical thesis ("shareholder theory").

Methodology: The initial search focused on JSTOR. Searching for "Milton Friedman" and "Ethics" came up with 2,537 hits. Since equivocation is at the heart of the criticism, those hits were further refined with the term "equivocation," to arrive at 1,339 hits. Of these, 52 academic articles were reviewed (listed in the References.) None of them demonstrated an equivocation on the word "regulation," which is where the arguments in Chapter Five focus. This body of research went back to the 1960s, and only three of the 52 articles actually dealt with equivocation, though each equivocated on different words. This claim is original.

\section{Original Contributions to the Discipline of Business Ethics, Claim \#12 of}

13: The assignment for collecting personal trash and doing various things with it is new to business ethics as a classroom assignment in any "business ethics" textbook.

Methodology: Google Books found nothing in its database. Neither did Google Scholar. Neither did JSTOR. Nor did ProQuest. ESCOhost produced twelve results, but none of them was a textbook or a student assignment. 
Since no evidence can be found for a business ethics assignment that asks students to collect their personal trash, this claim stands as original.

Original Contributions to the Discipline of Business Ethics, Claim \#13 of

13: This textbook publishes answers to its questions solicited from local entrepreneurs and businesspeople to serve as examples to the students. Methodology: The databases were searched for "contributions from local business" and "business ethics."

Google Books found nothing, but thirty of the reviewed business ethics texts were searched for evidence of contributions to the text by local businesspeople. Nothing materialized. Amazon Books found nothing. Neither did EBSCOhost, nor did Google Scholar. ProQuest located nothing.

Since nothing could be discovered to indicate that other business ethics textbooks include contributions from local businesspeople, the claim stands as original.

Critical Thinking Claims

Three claims of original contributions to the field of critical thinking are also asserted. These are demonstrated below in identical ways to those above.

Original Contributions to the Discipline of Critical Thinking, Claim \#1 of 3: 
This is the first complete application of Paulian critical thinking theory to a business ethics textbook.

Methodology: Connections were sought between "business ethics" and "Richard Paul."

EBSCOhost has no results for this search. Nothing can be found on ProQuest. None of Google Scholar's hits on this search are for Richard Paul. For Google Books, there are two promising links, but each of them, Administrative Management: Setting People Up for Success ${ }^{149}$ and Supervision: Setting People Up for Success, ${ }^{150}$ mention him only in the index.

Since there is no evidence that any other business ethics textbook has integrated Paulian Critical Thinking into their approach at a deep level, this approach is original with this text.

Original Contributions to the Discipline of Critical Thinking, Claim \#2 of 3:

Application of the critical thinking technique of the central question for the

149 Charlene Cassidy, Bob Kreitner, and Susie VanHuss. Administrative Management: Setting People Up for Success. Cengage Learning, 2013.

${ }^{150}$ Charlene Cassidy and Bob Kreitner. Supervision: Setting People Up for Success. Cengage Learning, 2009. 
discipline of business ethics is original in this text.

This claim has already been proved by the methodology used to demonstrate that number two in the previous section is original.

Original Contributions to the Discipline of Critical Thinking, Claim \#3 of 3:

The connection made between Paulian critical thinking theory and Japanese cultural arts in Chapter Eleven is original.

Methodology: Using the databases above, no results were located on Amazon Books. There were no results on EBSCOhost. Three results were found on Google Books, but none were relevant. There were no results for Google Scholar and no results on ProQuest.

The originality of this claim is demonstrated.

\section{Conclusion}

Each of the thirteen claims made about original contributions to the discipline of business ethics have been demonstrated. In addition, three claims of original contributions to critical thinking have been demonstrated 


\section{APPENDIX D \\ THE AUTHOR'S EDUCATIONAL BACKGROUND AND PEDAGOGICAL DEVELOPMENT}

This document catalogs the various elements that qualify the author

for $\mathrm{ABD}$ in Humanities at $\mathrm{U}$ of $\mathrm{L}$, which indicates that he has finished all of the coursework and comprehensive examinations regarding this doctoral program. In addition, the author has taught Business Ethics (PHIL 225) at The University of Louisville thirty-two times since 2004, and he has taught it an additional fourteen times in Panama City, Panama, to international students at Quality Leadership University.

As professional development, the author has reviewed more than fifty textbooks published in a philosophical approach to business ethics, that is, an approach typically found taught through Philosophy departments, as opposed to business schools (see the Business Ethics literature review in Appendix A.) Since initial critical thinking training with U of L's Delphi 
Center in $2008,{ }^{151}, 152$ the author has deeply considered how a business ethics course should be designed to reflect maximum student engagement with the content of the course, which has led to the development of the structure of this project. Some of the author's prior didactic approaches to teaching business ethics have been praised in departmental reviews of teaching by U of L's Philosophy Department, and two of three U of L "Faculty Favorite" awards have been based upon students writing about the author's business ethics classes. The author was hired by U of L's College of Business for 2013-14 to help COB develop cases in business ethics that could be used across business disciplines for faculty and students untrained in applied ethics. This is related to aspects of COB's Quality Enhancement Program, which involves the development of ethical reasoning, top to bottom, for business school students and faculty. The prepared document is included in this dissertation as Appendix E.

Perhaps most relevantly to this dissertation's content, the author was approached at the end of the Fall, 2012, semester by Kendall-Hunt Publishers to write a business ethics textbook for use in his own classes. The text-

151 The University of Louisville offers a variety of professional development opportunities to adjunct and part-time faculty through The Delphi Center for Teaching and Learning and their critical thinking initiative, Ideas to Action: http://louisville.edu/ideastoaction/about.

152 Nationally, it is rare for part-time and other contingent faculty to receive educational benefits (and even more rarely, stipends) from university professional development programs. This is problematic from many business ethics points of view, since such a large percentage of university courses nationwide are taught by contingent faculty. The University of Louisville has been a local leader in such professional development and the offering of financial support for contingent faculty participants in that professional development. 
book has been reviewed and praised by Dr. Linda Elder, President and Fellow of The Foundation for Critical Thinking; as Visiting Scholar at The Foundation for Critical Thinking, the author submitted a pre-publication copy of the textbook to The Foundation for scholarly review. Any substantive changes suggested to the textbook during the dissertation process will be incorporated into the textbook's second edition, which is forthcoming from Kendall-Hunt in Fall semester of 2015. ${ }^{153}$

The following comments detail the author's teaching history in college and his pedagogical shift from didactic to critical approaches. Outlined here is also what has caused him to choose Paulian theory, as opposed to other methods of teaching.

Brian Barnes began teaching in the college environment in 1991 at Hanover College as an undergraduate assistant in the Physical Education Department. He had no academic interest in physical education, but he was hired to teach fencing all four years. During his last two years, he was hired for an additional course each semester as a self defense teacher. All of these courses were for-credit, and no member of the Physical Education Department showed up to those meetings. In fact, it was made explicit that no member of that department had any interest in teaching that material.

153 The second edition of The Central Question: Critical Engagement with Business Ethics, will reflect all of the paradigms outlined and elaborated upon in this document. Scholars wishing to use this dissertation as a key to the second edition of The Central Question textbook will find several opportunities to extend the paradigms and methods discussed in this dissertation to several new chapters and expanded content throughout. 
Barnes quickly discovered that he really was lost without a book, and he wasn't very good at improvising or coming up with his own answers to inevitable student questions. He was approaching his teaching duties from a didactic point of view, which is to say that he wanted the students to copy him as precisely as possible, whether they, or he, understood why they were doing whatever they were being asked to do.

Fortunately, academic work elsewhere at Hanover College was much more engaging. The faculty thrived on the Socratic approach, and Barnes was constantly challenged and engaged by small classes and teachers who knew his name on the street. Through conversation and a commitment to the examined life, his professors in Philosophy, Anthropology, and elsewhere helped him learn to interact with the world of ideas and how to deepen his own intellectual processes. These examples showed him the power of dialectical thinking and logical, evidence-based debate regarding ideas, and this foundation served him well as he moved toward graduate school in Philosophy at U of L.

Matriculating to and then from graduate school, he taught for a year past beyond his departmental fellowship in Logic. His training was almost entirely didactic, as these were all classes that could be taught from a logic book, letting it tell both the students and the teacher what was correct. His graduate work had been both masterfully didactic and powerfully Socratic, and Barnes grew to love a well-delivered lecture with lots of detail on an 
interesting topic as well as he loved an intellectual debate over bottles of wine. That many others didn't appreciate the strong lecture method was indication only that they weren't many very serious students, not that there was something wrong with a didactic classroom. Certainly, some students thrived in that environment. Graduate students, in his view, should be excited enough about their topic to go the extra mile to master content presented in any fashion.

His own observations of undergraduate classrooms, however, have shown him that something less than $10 \%$ of the students in his classes do the extra work required from a didactic format for them to develop deep meaning. So, Barnes estimates that $90 \%$ of his students struggle with this approach. By comparison, students in classes that are taught critically, particularly with a Socratic focus, are more often prepared to move on with their thinking about the course content independently by the end of the semester, more often engaged with the course content and their peers with regard to it, and they more often self-report that they have found critical approaches to the content valuable for their learning.

After his initial round of university teaching, Barnes moved on to language school, the US Army, and government service with the National Security Agency. Each of these environments had its own teaching methods, most of which encouraged doing (kinesthetic learning) over copying didactically. For example, didactic methods might rule an Army multiple-choice 
quiz regarding the digging of a fighting position during a firefight in a forest, but passing the quiz was only the precursor to actually digging the fighting position in question. Soldiers learned by doing as much as they did by memorizing.

Language school was total immersion in the target language in the classroom and in residential settings, like barracks and mealtimes. This created a high-stress learning environment in which the student had to constantly do his or her own thinking in and about the target language in order to accomplish even the most mundane tasks. In this way, language was acquired quickly, though inefficiently. All of the emphasis was on doing the work with the language in real-time and in real-life situations, however, and learning developed from that pressure-cooker method translated well into the pressure-cooker of live translation in combat zones and NSA SCIFs.

During that time, Barnes led dozens of educational presentations, but his students were never called upon to think for themselves during those presentations. These lectures were designed, at the request of leadership, for transmitting information only. The presenter held almost no responsibility for the receiver getting the content effectively, and required Powerpoint slides reinforced every presentation. Even "paying attention" was reduced to the lowest common denominator in those sessions, with "staying awake" praised as an acceptable substitute to internalizing the content. There were almost never questions posed after one of these presentations. Barnes now 
interprets their absence as a lack of caring on the part of the audience; none of the students wanted to be there, since they all knew that there were other opportunities for learning much of the material kinesthetically. These opportunities were far more fulfilling than "death by Powerpoint," as it was called. Barnes began to see the value in having learners do the work, since it caused them to internalize the material in a more useful way.

After government service, Barnes enrolled in The Brandeis School of Law at U of L. His year in law school demonstrated what effective and organized Socratic dialogue could produce, and it also highlighted various limits to that system of teaching. For example, it can be used in a sense of cooperative exploration or a sense of outright destruction (as can be seen from Plato's dialogues.) Barnes left law school disenchanted with the study of law but very certain that the next time he was in front of the classroom, he would engage the students Socratically. The next teaching job, however, wasn't interested in that kind of pedagogy.

Barnes was able to begin teaching as a part-timer in U of L's Philosophy Department again after law school, so he had a good chance to begin constructing a version of the positive Socratic approach he envisioned. Unfortunately, that one Business Ethics class didn't pay very much, so Barnes also took a job at Wild Oats Natural Marketplace. A large part of his attraction to that kind of learning environment involved the constant action of stocking shelves, building displays, and cleaning that was so much a part of 
learning there.

As he began teaching at $\mathrm{U}$ of $\mathrm{L}$ again, Barnes tried to update my methods, but he was doing so with no real ideas about how to address student concerns over real-world reasoning ("Professor, is there anything other than argument?') and precise intellectual processes. Barnes had basic philosophical background on many issues, but he didn't know much about what should happen in the "Critical Thinking" (PHIL-211) class that eventually joined Business Ethics, aside from the logical fallacies, sentence diagramming, and related material that was offered in the informal logic texts on the subject. Barnes really didn't know very much about how to teach people to think systematically, outside of those specialized and intellectually-constraining methods.

When he entered his first Delphi Center Part-Time Faculty Learning Community in 2008 , he was suddenly surrounded with people who really wanted to talk about their teaching, about what worked and what didn't, and how to get through to successfully reach student learners. It was out of this several month exploration of Paulian Critical Thinking and pedagogical best practices that he decided to restructure his Critical Thinking class to include what he had learned in the learning community. The next year, he was involved in another Delphi workshop on teaching methods, and the combination of the two workshops caused Barnes to completely redesign all of his teaching for critical thinking in the Paulian style. 
Barnes had always possessed teaching standards before, but many of those standards had begun to create huge amounts of work for him as a professor. As he taught more classes, the grading that came along with the work became a heavy burden each semester. Barnes wanted to know how the students were doing, but several hundred papers several times each semester, along with or replaced by essay exams, began to wear him out. The idea of students doing their own work in peer review and getting some intelligent feedback from one another, through the Oxford Tutorial, with explicit selfreflection regarding their own biases and intellectual processes, was an exciting and new paradigm. Barnes was skeptical that peer review and a few groups of vocabulary words and educational techniques (which is how he initially viewed Paulian Theory) would have the power to create student learning in his classroom as promised, but his experiments with Paulian theory since that time have produced much success in terms of student understanding of any content.

With Paulian Theory, a professor can point directly to aspects of student analysis and construction with the Elements of Thought, challenge and encourage students' assessments with Intellectual Standards, and demonstrate or oppose student or writer character with reference to Intellectual Traits. Paulian Theory gives teachers and students methods for pointing out specific flaws in reasoning that are not merely based in fallacy theory. Flaws in reasoning are also based in various types of bias, and Paulian Theory 
helped Barnes understand and disseminate that so that to his students.

Over the past few years, Barnes has deepened his training in Paulian Critical Thinking. His association with the Delphi Center and the Ideas to Action critical thinking team at $\mathrm{U}$ of $\mathrm{L}$ has provided the opportunity to discuss the meaning and value of Paulian Theory with a wide variety of partners. He's served on The Critical Thinking Poster Committee, and he's currently serving on a Digital Tools Development Subcommittee. His classes have also participated in a critical thinking student film festival at Rauch Planetarium, and he's been featured as a faculty exemplar for critical thinking at $U$ of L. Over the past year, Barnes has been offering informal critical thinking and business ethics instruction at U of L's College of Business to students and faculty, and, since 2012, he's been Visiting Scholar at The Foundation for Critical Thinking. Barnes has presented at the 32nd and 33rd International Critical Thinking conferences in Berkeley, once for $\mathrm{U}$ of $\mathrm{L}$ and once representing FCT. He is scheduled to present workshops at this year's 34th International Conference, as well. Barnes has also presented at FCT's Spring Workshop in 2013 and has traveled to facilitate nearly a dozen faculty development workshops for FCT over the past two years around the country at educational institutions, primarily for the purposes of developing a critical thinking framework for a university's Quality Enhancement Program. Barnes has been fortunate to spend a combined total of a month of additional training directly with Richard Paul, regarding Paulian theory and 
its applications. Also central to his training have been discussions and guidance from Linda Elder, Rush Cosgrove, and Gerald Nosich, all Fellows of The Foundation for Critical Thinking.

These additional experiences have caused Barnes to dig deeper into his thinking about teaching than ever before. He has spent many hours constructing his own class designs and those for FCT workshops with FCT's critical thinking principles in mind. In the classroom, Barnes is less willing to rely upon the tenacity of a handful of students who are excited about the material to carry the whole group, and so he lectures less than ever before. Barnes's classes engage in a variety of activities, like peer review, Oxford Tutorial, Socratic methods, close reading, critical writing, role play, and he also employs the flipped classroom model, because he has come to see his classroom as a laboratory for better learning, much more like basketball practice than a traditional lecture-based classroom. When students engage directly with him and with one another, they get another chance at the content in the course. The more chances they get at the content, the better chance there is that they will be able to use it in their thinking. The engagement techniques become even more powerful when the intellectual tools each student is using are focused and powerful. One consequence of using the Paulian approach is that Barnes now tries to bring all of the students along without dumbing down the content. He won't let students escape the implications of the conversation, comment, or presentation engaged in. This 
is not just renewed interest on Barnes's part; he is engaged, too, since he is modeling criticality through his own use of the Paulian methods and vocabulary. Students and colleagues have responded well to the way this process is developing for Barnes, and he has a number of critical thinking projects in addition to this dissertation on the way to release over the next year or so.

His upcoming projects include satisfying grants from The Delphi Center for a series of critical thinking comic books that teach the Paulian Theory (written and drawn by undergraduates) and a data set for researchers, hopefully accompanied by a published paper co-authored by Rush Cosgrove from FCT, about the likelihood of students developing critical thinking skills in the Paulian style over one traditional semester in a class that is only critical thinking, versus in a class that uses critical thinking to convey content, like Barnes's Business Ethics. He has received approval from U of L's IRB in order to collect data from his Critical Thinking and Business Ethics classes. The data collection involved students answering an identical pre-class and post-class question in each class that caused them to produce an essay that could be evaluated with Paulian Theory. Barnes and Cosgrove then used FCT's rubric for critical thinking instruction to evaluate the amount of critical thinking growth from the beginning to the end of the semester, as demonstrated through comparing pre and post responses. They expect to publish some results from this study in 2015. The intellectual flexibility, the precision, and the fair-mindedness cultivated as a consequence of 
serious adoption of Paulian critical thinking can only help students, help teachers, and help our communities improve in the direction of empathy, integrity, humility, courage, fairness, and confidence in an autonomous, reason-based processes.

Barnes likes the Paulian approach for Business Ethics, per se, because he likes the way it promotes self-reflection and lots of specific tools that students can use to optimize their own thinking about unfamiliar topics, like business ethics. He has not yet found another critical thinking approach that could be replicated to the same effect in a business ethics context. This is not to say that other approaches won't work for business ethics, but Barnes has not yet put any effort into formally organizing those approaches for this content. Once he was able to redesign his business ethics class for critical thinking, as suggested by Gerald Nosich at FCT, Barnes was able to see the value of Paulian Theory for training thinkers in any discipline, not just his own. Barnes continues to be attracted to the flexibility, the straightforwardness, the emphasis on ethical development, and the self-reflective aspect, and the emphasis on writing suggested by this approach. This is why Barnes is committed to continuing to develop Paulian Theory for himself and to advocate it for business ethics thinking at the university level and beyond.

Barnes has also been excited about Gerald Nosich's notion of a central question, and he's built Critical Thinking and Business Ethics classes 
around it. Nosich advocates for the central question method in How to Think Things Through, ${ }^{154}$ combining it with fundamental and powerful concepts and a concept map. This is the method that Nosich helped Barnes think through two years ago on Richard Paul's couch. They talked about how to adapt the concept map into a syllabus for a course that would build off of the central question like a spine. In this way, students could always locate the logic of an assignment or the course as a whole through tracing a string of fundamental and powerful concepts back to the central question whenever confusion arose for that thinker. Nosich's text and that conversation formed the basis for this textbook structure and the syllabus structure of Barnes's business ethics course.

Outside of the classroom, Barnes's approach has also developed toward the critical. He directs two educational programs on U of L's campus. One is the Eco-Reps sustainability education and service program through The Sustainability Council, and the other is The U of L Community Composting Project, sponsored by The Provost's Special Assistant for Sustainability Initiatives, Justin Mog. In both of these programs, Barnes is in a position to train students to do various tasks at worksites on- and off-campus. Barnes finds that he is more interested in having students do the work together and to develop a community with their peers in the activity than in

${ }^{154}$ Nosich, Gerald. Learning to Thinking Things Through: Critical Thinking Across the Curriculum, 3rd Edition. Prentice Hall, Upper Saddle River, NY, 2007. Pages 101-107. 
merely having them listen to him talk about what should be done. Often, Barnes will just demonstrate a task, make students aware of safety issues, and let them get the work done for themselves.

From the point of view of Paulian Polarities, this makes the students' work explicit, since they are the ones looking at their own processes and bringing those to the surface of the project. The students are able to make the process as global as they have the vision for, since they are discovering it on their own. This also means that the learning they are doing is liberating them to explore and discover for themselves in other ways related to the project; by having them do the work, Barnes creates a safe learning space with them. The process is Socratic, since it's aimed that them learning for themselves authentically, not with reference to quick tricks. Of course, some students will seek the sophistic route, but at least they do so autonomously. Both options for interpreting the project are available to them. Barnes breaks all the work down into ordinary language, even employing highly informal language, so that directions can be easily understood by any adult native English speakers. Finally, both organizations are organized around sustainable operating principles that are automatically integrated with one another and can be applied elsewhere.

Finally, Barnes has studied for 23 years in The Hontai Yoshin Ryu, a Japanese cultural arts system based outside Nishinomiya, Japan. The Hontai Yoshin Ryu is a koryu kobudo bujutsu, which is to say that it is a system of 
military and cultural arts that are ingrained in Japan's feudal history. The system was founded in the 17th century, and its members have transmitted the art orally from teacher to student for 19 generations. Barnes has received a large portion of this transmission during his time training in this system, and much of it has been received didactically. Hontai Yoshin Ryu members are encouraged to watch and copy movements of jujutsu or weapon techniques as closely as possible. Within the system, there is a recognition, however, that no copy is perfect.

The principle that no copy precisely captures its object was brought home to to Barnes after he had begun teaching the art around the turn of the millennium. Students didn't do exactly what he was asking them to do; he'd never really been cognizant of this fact with his own seniors and peers. Further, his own teacher was a dozen hours' drive away, and he often found himself needing to be corrected and adjusted in order to be brought back into the aesthetic of the system.

This training, despite Barnes's long tenure with the organization, is always deepened and intensified when he travels to Japan or Europe for a training event with the home dojo every few years. There, he is always reshaped in what feels like radical ways, but which prove invaluable after a little settling.

This is how Paulian Theory has struck Barnes. It is another craft, like a koryu bujutsu, in which a student must strive to copy basics as pre- 
cisely as possible, all the time knowing that he or she will fall short. Over time, it becomes necessary to improvise on the system to create something that is personal, though, hopefully, reflective of the original processes being copied. It is a long and tedious process of refinement in the personal study of critical thinking and bujutsu. Luckily for Barnes and for his students, he is also a student all the way, all the time, with seniors and exemplars, successes and failures, but, at his best, having genuinely surrendered to the deep principles of the art in hopes that it will shape him in positive ways, and that he will be skillful enough to reciprocate. This experience of learning and applying the skills of an intellectual craft to the surrounding world is something Barnes wants any of his students to gain from working with him; he suggests that the real world is where and when much of the truly important work happens. 
APPENDIX E

\title{
COB ETHICS FRAMEWORK PROPOSAL
}

\author{
A Business Ethics Primer \\ for \\ College of Business Faculty \\ at the \\ University of Louisville
}

\author{
Brian Barnes \\ Senior Lecturer, \\ Philosophy Department \\ brian.barnes@louisville.edu \\ (502) 338-1338
}




\section{Table of Contents}

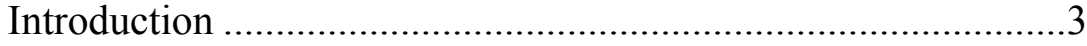

Thinking About Values and Biases .................................................

Sources of Values and Biases ......................................................

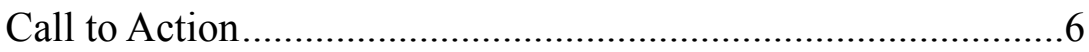

Sample Case ……………...................................................

The Disingenuous Mason ............................................................

The Business Ethics Theories and Analyses...................................

Psychological Egoism...............................................................

Psychological Egoism Analysis ...................................................10

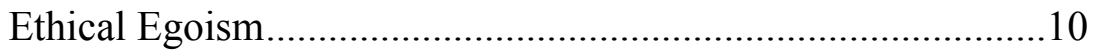

Ethical Egoism Analysis .........................................................11

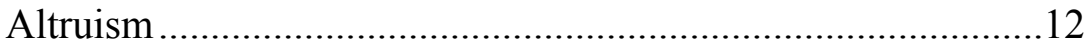

Altruistic Analysis ......................................................................12

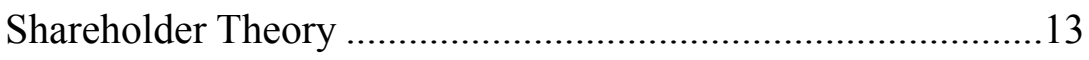

Shareholder Theory Analysis ....................................................13

Stakeholder Theory ...................................................................14

Stakeholder Theory Analysis .....................................................15 


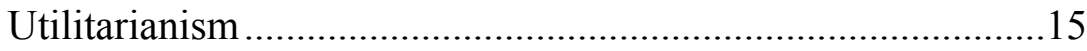

Utilitarian Analysis ............................................................... 16

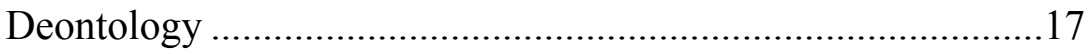

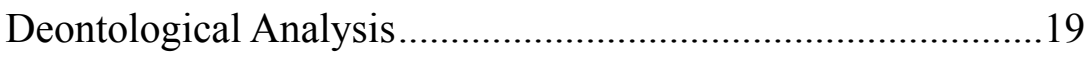

Paulian Analysis: Fairminded Critical Thinking ......................19

Critical Thinking Ethical Reasoning Analysis.........................22

Other Important Ethical Theories ........................................22 


\section{Introduction}

This document is intended to help professors in The University of Louisville's College of Business guide themselves and their students through ethical thinking about business issues. It contains a few introductory ideas about ethical thinking, a list of several well-known ethical theories and their key features, a sample case relevant to ethical thinking, and an analysis of that ethical case from the point of view of each ethical theory put forth in the earlier section, which is not exhaustive.

The layout of this document is intended to, first, help professors think generally about the ways ethics are at play in your business content areas. The theo-

ries are provided so that professors may examine the ethical theories outside of some particular context. If the method for applying a particular ethical theory is clear, professors should be able to begin applying some specific ethical theories to their own thinking about ethics and their own class material. The combination of problems to look for, precise theories, and sample case analyses provides professors the tools to create robust ethical analyses for cases in their own disciplines for every class. Please contact me directly with questions: Brian Barnes, brian.barnes@louisville.edu, 502-338-1338 (voice or text).

\section{Thinking About Values and Biases}

The first consideration is where the students' values are coming from. Not all of our values fall within the realm of ethical reasoning. If a student is engaged in ethical reasoning, there is a tendency toward using evidence for deciding whether an issue is "right" or "wrong". We shouldn't forget that any students could be reasoning from biases and not from evidence (examples of biasedbased reasoning include racism, misogyny, and homophobia).

This creates a problem. If students are not interested in using evidence for their reasoning about important ideas in business, then there is little chance students will learn to think about doing business fairmindedly. Popular attitudes about business can seem to provide little incentive for promoting fairness in our market-based culture. Only evidence can be used within the vehicle of argu- 
ment to help a student see reasons why he or she might want to change his or her mind. The student has to make the change, and the way he or she makes the change (in any discipline) is to consider evidence (the good reasons provided by reading, conversation, deep and careful consideration of ideas, and other methods for thinking things through), and by applying the evidence to a value system to determine what he or she should do or refrain from doing. As professors, we should not neglect the idea that we, too, have our own values and biases, any one of which could get in the way of our being able to use evidence to make well-reasoned, fairminded decisions. If we are going to teach students to think about their own thinking, we should be considering our own thinking, too. All of us must practice well in order to play well.

\section{Sources of Values and Biases}

In order to get to the ethical aspect of thinking about business issues, we need to consider where the ethical values come from. Four popular ways for us to develop our ethical values are from family and friends, from religion, from advertising, and from the law. It is important that we differentiate these aspects of valuation, and the economic one, from reasoned ideas about moral values. Briefly, the problem with these other standards is the ways they arrive at value: Family and friends tend to present their uncritical views of life, and we tend to accept them without thinking them through to see if they should be believed; religious thinking cultivates the tendency to believe what authorities tell us; advertising encourages us to accept points of view immediately and without questioning; and the law suggests that it is always morally correct, though it often is not (for example, laws supporting slavery or laws failing to protect the vulnerable from foreseeable harms.)

For clarification, each of the four potentially-biased sources are presented below, along with my main position against their use as an ethical standard. Feel free to substitute your own argument for mine, or you could suggest a counterargument. Whatever you do, please do it with the students' involvement or within student view, so that everyone can see how the new reasons are improvements on the old ones. It is in considering the transitions from one way of valuing to another that we learn how the ethics manifest, as opposed to the marketing, the management, the HR, the accountancy, etc. 
Social

When we take our values from family and friends, we often do so unconsciously and, therefore, uncritically. A critical process, one that examines the thinker's own thinking on an issue, has to be intentionally adopted for a situation. "Thinking" is not "critical thinking." Criticality requires an extra step, as does empathy.

If a child learns to dislike other races from his or her parent, that racism is perpetuated constantly, but it is not "chosen" in the sense of a conscious adoption of values. Instead, the child most often mimics the parent and adopts the parent's position as a function of authority. As the child learns to reason, he or she may mount attacks upon the parent's position, but often these attacks are unskillful, and the attacker falls prey to the biases and misunderstandings of the attacked in order to fit in with the order of things around the household.

Of course, this kind of authoritarian bias is not restricted to the home. Our social relationships outside the home, including those in the business world, can be riddled with uncritical sociocentric biases. When a newbie at the advertising firm is given direction to make ads that are exploitative, but not illegal, the newcomer may not ever consider whether this is right or wrong. Any initial concerns might be met with aphorisms like, "That's just how we do it here," or "This is the industry's standard." Accepting these explanations uncritically are no different from those accepted at home as children. The habit of unthinkingly accepting any reasons offered, "credulity," becomes a habit the more times it is engaged in. Often, of course, people merely accept authority in order to not rock the boat, to keep their chances for advancement open, or to be seen as a team player. None of these motivations are synonymous with reasoning through the ethics of the situation in order to determine the right thing to do. On the contrary, whatever is presented by the group or the authority figure is automatically presented as "the right thing to do." Accepting whatever values are presented without thinking them through is not ethical reasoning.

It should be recognized that sometimes families and friends give great advice that should be followed, and sometimes we are not in a position to verify this advice. Certainly, trust is powerful and useful in social life, as is loyalty. Misunderstandings, biases, inaccuracies, and fabrications are all too common, 
however, and our thinking will benefit from verification of facts more often than it benefits from blindly following authority.

\section{Religious}

Religious thinking offers a problem because it encourages believing something without verifiable evidence. Within business, verifiability is an important metric, and this kind of thinking overlooks that feature of everyday life in areas of great significance. This kind of thinking potentially encourages various ways of accepting other kinds of conclusions without reference to the evidence. If the use of evidence becomes merely one of many equal criteria for evaluating situations, instead of chief among all methods and the arbiter of disputes between the others, we become less likely to use evidence to update or improve our positions. When pressed to consider ethical issues in business or elsewhere, some students will retreat to deeply-entrenched religious positions to avoid considering the evidence of the situation at hand.

Certainly, the religious can be fine businesspeople and citizens. Their high personal standards are the foundation of many successful social experiments and religious considerations are at the deep foundations of social enterprises in the West. Care should be taken that lines between verifiable and unverifiable beliefs are not crossed in business contexts; the chance for irrelevant bias that leads to unintended ethical harm is high.

\section{Advertising}

Advertising attempts to connect consumers with products and services. Advertisers are interested in putting the best impression of the issue being advertised. As such, ethical judgments are often overlooked within advertising. Likewise, advertising is always telling one side of the story; other sides, however true, are silent in the advertisement. Without careful consideration of the message being sent by advertisers, consumers can find themselves unsure of values.

Advertising can play a valuable role for businesses wishing to sell products, and it has the potential to help consumers with their preferences. However, some advertising has historically been deceptive or manipulative. 


\section{Legal}

Our culture often believes that what is "legal" is the same as what is "right". The path of least resistance is often to go with what is legal whenever it is presented to us. In this way, the law becomes an easy stand-in for what is "right". The problem, of course, is that laws can be hijacked in order to favor the powerful. Our own democracy shows evidence of this kind of corruption historically, and the tendency of people to make laws along the lines of what is "the right thing to do" is easily overcome by people's tendency to take what is offered in their short-term interests.

Of course, laws are also fantastically important for order within society. As thinkers, we have a responsibility to consider for ourselves whether laws are right or wrong. We have mechanisms through democratic processes to alter the laws when they don't match our understanding of how things should be. In order to know whether laws are good or not, we must think them through, not merely accept them as reflecting the truth.

\section{Call to Action}

My goal in working with the COB Dean's Office on this project is to promote and provoke good thinking about ethical issues, particularly in business. I have no other agenda, and I wish to present the most rational tools available to my own particular approach (which, of course, is loaded with its own biases, one of which is toward evidence and the use of reason for deciding issues in business. You'll identify others as you read.)

I hope this document proves useful for your thinking. It is important that all of us consider the ethics of our actions before we find ourselves in a real life situation having to decide what happens to others in real time. We often don't have time to consider issues deeply when we are on a deadline, and so we should take the time to do it when we are not pressed. At the academy in a classroom setting is a great place to do training for the world of business; please help your students train their ethical thinking alongside your particular business content area. As I suggest in my business ethics textbook, The Central Question: Critical Engagement with Business Ethics (Kendall-Hunt, 2013), the ethical aspect is always present in business situations. If you can agree that the ethical aspect is always present in commerce, we should think and train to 
make sure we are as successful in that aspect of business as in any other aspect. I believe we all have a responsibility to train our students to think deeply about what it means to be "successful" in any aspect of our lives, including the ethical aspects.

By way of full disclosure, I am Visiting Scholar at The Foundation for Critical Thinking (www.criticalthinking.org), and I am deeply interested in perpetuating their approach to education and practical reasoning, which I find to be highly rational and evidence-based. Much of the reasoning about ethics I suggest in the following section of the document, though not all, can by found in The Miniature Guide to Understanding the Foundations of Ethical Reasoning by Richard Paul and Linda Elder. You could pick up a complimentary copy from The Delphi Center in the library (contact Judi Murray at 852-7611) if you'd like to dig deeper into the Paulian approach to critical and ethical thinking. To discuss any of these ideas in more depth, please feel free to email me at brian.barnes@louisville.edu. You could also text or call me at 502-338-1338.

\section{Sample Case}

\section{The Disingenuous Mason}

Several years ago CC. Inc. hired Chris Mason to work in its Sales Department. At the time of hiring, Mason indicated that Mason had earned a bachelor's degree in business from a well-known university and had four years of relevant sales experience. Upon accepting CC's offer, Mason easily adjusted to the new job and after only nine months quickly advanced in the Sales Department and became the most productive salesperson in the company. Mason remained the number one salesperson for the next three years, and CC credited Mason for increasing sales by at least $25 \%$ annually.

After a long and productive career CC's Sales Manager retired. (Mason was CC's logical candidate to become its new Sales Manager.) The requirements for Sales Manager included at least six years of practical experience and a bachelor's degree in business. Mason applied for the Manager position, and reported the requisite experience plus a bachelor's degree in business. CC selected Mason for the promotion which doubled Mason's salary and included other benefits. 
Mason soon created an efficient productive sales department with a top notch sales team. Sales jumped to record levels creating generous profits. After several years CC received an anonymous letter revealing Mason had not earned a bachelor's degree. Upon investigation, CC learned Mason had accumulated enough credit hours to graduate, but lacked the minimum GPA to qualify for the degree. Thus Mason falsely reported credentials to CC.

$\mathrm{CC}$ was ambivalent about what course of action to follow: if $\mathrm{CC}$ fires Mason, sales and profits may plummet. If CC does not fire Mason, other Masons may falsely present information to $\mathrm{CC}$.

Using multiple ethical principles presented in class, thoroughly examine CC's potential courses of action considering the parties and possible outcomes. Recommend CC's response to this situation.

\section{The Business Ethics Theories and Analyses}

The following theories may all be used to discuss ethics in business. My list is not exhaustive, but it provides many popularly-accessible theories applicable to business activities. Professors should feel free to add their own theories to the list or to ignore those that seem unrealistic. Each theory is intended to stand alone as an explanatory framework for the ethical actions of some agent, or "responsible moral actor."

"Key Features" must be adhered to for each theory if you are going to claim that a particular theory is in play for the ethical aspects of a situation. If any Key Features are violated, then you must select a different theory or you should claim that you are modifying the theory in a particular way. If your modification creates contradictions with other Key Features or leads to the undermining of the original theory, then it is not legitimate and should not be presented to students. "Logicalness" for a business ethics analysis should be maintained, since the removal of logical analysis from ethics removes our most useful persuasive tool for disseminating our position.

\section{Before we begin: It's all about accountability.}

Rights have to be paired with Duties, if we believe that rights are preserved by group enforcement, rather than from some other source. A common approach to ethics in the western tradition is to assert that duties are necessary to enforce rights. In other words, rights only exists to the extent that there is a power ca- 
pable of ensuring that I, a stakeholder of some kind, am able to exercise the rights that have been promised to me. If rights exists only in the abstract, and those rights cannot be protected in order that I can use them, then the rights do not exist, for all practical purposes. This interpretation of rights and duties could also be applied to markets.

What about duties? Moral agents are assumed to have those, as well as having rights. An important topic to consider prior to determining the ethical theory in play for you in a particular situation is who or what it is to which you believe you owe some duty. Is there anyone to whom you would hold yourself accountable, even if that person or thing didn't know you were taking on a duty toward them? What would such a set of duties to your bosses, your community, nature, your lovers, your children, or market competitors look like? Lastly, don't forget: multiple actors in the same situation will often employ different and contradictory theories of ethics in their background logic!

\section{Psychological Egoism}

Psychological egoism is NOT an ethical theory, but many students will try to invoke it, so it's good to be familiar with it. Psychological Egoism is a behavioral theory which states that all people always do what is in their own interests with no exceptions. This is an important theory for people to consider, since it asserts that no one has a choice to do anything except what is in his or her own interests. It is not possible for a psychological egoist to act for any interests other than his or her own, as he or she narrowly defines them. Any action done truly for the good of others is impossible, even if the actor believes that he or she intended it to help others.

Ethical theories will always recognize the ability of a person to choose freely ("agency"), will always use evidence in decision-making, and will always assert a judgment about right and wrong. Psychological egoism ignores at least the first and third criterion.

Key Features

- Psychological Egoism is NOT an ethical theory.

- Applies to everyone, everywhere, at all times. 
- It asserts that humans cannot choose to genuinely act in the interests of others.

- Any temptations to believe that someone is acting altruistically are mistake or deception.

\section{Psychological Egoism Analysis}

If CC's management believes that Psychological Egoism is a reality (which means that it applies to all people's actions all of the time), then the only fault in the situation lies with CC's hiring team.

Under Psychological Egoism, no one is free to act altruistically. Humans are simply unable to act in ways that demonstrate genuine care for others. In fact, all human beings always act in their own consciously or unconsciously calculated self-interest; there are no exceptions, not even for grandparents or saints. From this point of view, since everyone is always acting in his or her own self interest, there is no reason for anyone to believe that anyone else is doing anything other than being manipulative of them and their systems. Only the naive believe that there are other motivations, and so they get taken advantage of because they are unwary, which is what happened to CC's hiring team.

CC's hiring team failed to do its due diligence in this situation. Policies that check the credentials of new hires exist for a reason: if we don't check people's credentials, they might misrepresent themselves and put us in a position to hire a sub-standard employee. In Mason's case, CC got lucky, because the mistake on the part of the hiring team allowed a sensational employee to gain the position, to everyone's benefit.

$\mathrm{CC}$ should retain Mason. They should waive the requirement for him, but they should not help him get his credential; as long as he does not have his BA, he will be less likely to seek employment elsewhere. Mason's employment has only been a good thing for the company, and Psychological Egoism offers no reason why Mason should be disciplined. CC's hiring team should be disciplined, however, and the deficiency in the system that caused Mason's transcript to be overlooked should be corrected. While Mason proved to be a good hire, despite the policy, the policy is a good one that is in place to help the 
company hire qualified employees. It should be strengthened, and Mason should be retained.

\section{Ethical Egoism}

Ethical egoism is an ethical theory that states that all actions should be taken in the actor's own interests; these actions are always labeled as "good" or "right". A bad action under ethical egoism is an action which elevates the interests of others over interests for the self. Any action labeled as altruistic, then, is possible under ethical egoism, but it is always the wrong thing to do.

Key Features

- Ethical Egoism is an ethical theory.

- Good actions are done to promote the interests of the agent doing the acting.

- Bad actions are those that do not recognize the self-interests of the agent.

\section{Ethical Egoism Analysis}

Under Ethical Egoism, Mason did the right thing when he acted in his own interest by lying about his credentials. He was trying to maximize his own interest, which Ethical Egoism sees as a good thing. Mason had a choice about whether or not to be honest, but it was in his interest to do the thing that advantaged him the most.

There is a significant question about whether or not Mason should be retained under Ethical Egoism. Mason does have a choice about whether to act in his own interests or to play by the rules under this theory, and he clearly chose to take a chance at breaking the rules. CC should evaluate this example of Mason's character before they decide their course of action. While he's been very effective as a salesperson, how much of his success has come as a result of deception? Are there other areas where Mason's deceptive character might create problems for the company or its stakeholders? Should Mason be installed as a leader and exemplar for other employees?

If CC is comfortable that Mason's character at work is in line with its values and will only continue to benefit the company, then they should retain him. It 
is in the company's best interest, from the point of view of Ethical Egoism, to do so. It is possible, however, that Mason's deceptive character could create unforeseen problems for the company, and $\mathrm{CC}$ will want to determine whether Mason's sales and management skills are worth the risk to the company's reputation down the road. If they are not comfortable with this discovery about Mason's character and its potential implications for the company, they should

fire him. An Ethical Egoist is unlikely to change character; in fact, it's in his or her own interest to pretend to affect change when discovered, making confidence in the claim that genuine change has occurred more difficult to accept. At any rate, the hiring team should be disciplined for having disadvantaged the company by not doing their jobs, and the hiring oversight should be fixed.

\section{Altruism}

Altruism is an ethical theory which asserts that anyone is capable of acting in the interests of others or in the interest of him or herself, but the right thing to do is always to act in the interests of others. The wrong thing is always to act for one's own interests.

Key Features

- Altruism is an ethical theory.

- Good actions are done for the interests of others with no reference to self-interest.

- Bad actions undermine or ignore the interests of others.

\section{Altruistic Analysis}

Altruism insists that the right action is always the action taken for the sake of others. Bad or wrong actions are done in one's own self interest and do not recognize the interests of others. This standard always opposes standards that promote self interest.

So, if CC wishes to act in Mason's interest (remember that they can choose whether to or not), they will forgive Mason and continue to promote him as those opportunities become appropriate, because they are making their decision with his benefit (not theirs) squarely in mind. It would be best for Mason if his scheme to get a job without the appropriate credentials worked out. If 
Mason objectively examines the situation, he would also want to keep his job for the benefit of the company, without reference to himself, since he is so valuable to them as an employee.

Of course, it may seem that the altruistic company will have some reasons to fire Mason over his dishonesty, since it clashes with their core values. Altruism decides in the best interests of others, however, and so it would likely not be doing the best thing for Mason by firing him, particularly when he doesn't have the means to get a similar job without the college degree at issue.

Altruistic CC should also try to make the hiring process work out better in the future so that bad employees don't infiltrate the company. Altruistic organizations can still have standards that are intended to enhance the benefit for the organization's various stakeholders; a policy that checks credentials before hiring would do that. Though the individual applicant without the necessary degree would not be benefited, the greater good (measured by quantity of individuals receiving that good) would allow altruism to avoid hiring a poorlyqualified applicant. Certainly, in Mason's case, hiring the under qualified applicant produced much more benefit for those stakeholders than anticipated, but the company can't be guaranteed that future errors of this type will produce desirable outcomes.

\section{Shareholder Theory}

Milton Friedman's Shareholder Theory (Capitalism and Freedom, Chapter 8, "Monopoly and the Social Responsibility of Business and Labor" (1962), and the New York Times Review article,'The Social Responsibility of Business is to Increase its Profits" (1970)), also referred to as The Neo-Classical Model of Corporate Social Responsibility, states that the only ethical duty owed by an agent of any company (managers, in particular), is to make money for owners within the limits of the law or the ethical custom for the citizens involved. There are many modified versions of this theory, but any theory of this type maintains similar characteristics.

Shareholder theories tend to label what is "right" as whatever is good for the owners of the company. Bad actions are whatever takes away from value for the owners. For this reason, it has been embraced as the leading justification for the ethics of modern capitalism in free-market societies, since it always 
encourages the interests of those who would concentrate capital in private control.

\author{
Key Features
}

- Shareholder theories always focus on value for owners of a business.

- Value is not shared among many groups; it is concentrated narrowly as the owners' interests.

- Good actions benefit owners' interests.

- Bad actions elevate other interests to equal or greater value than those of the owners.

\title{
Shareholder Theory Analysis
}

Shareholder Theory says that the right thing to do is whatever maximizes profits for the owners of $\mathrm{CC}$ within the limits of the law or within accepted customs of behavior. Certainly, $\mathrm{CC}$ wants to retain their top salesperson in order to maximize shareholder value. Letting Mason go would jeopardize profits for shareholders, which is absolutely not acceptable under Shareholder Theory. The problem is that retaining Mason might upset the limits of the ethical theory, which involve the law or the ethical custom. So, did Mason do something illegal? Clearly, he engaged in deception, but doesn't the law typically allow the company to decide what the punishments should be for this type of infraction? So, if the company strictly follows all legal guidelines as its guiding ethics approach, Mason should be disciplined. It would be in CC's best interest to exclude termination from that punishment, which would seem to be acceptable by the theory.

Interestingly, this theory is often applied in such a way as to justify following ethical customs that ignore the law, as long as this choice benefits owners. If, as an internal matter, $\mathrm{CC}$ allows its executives and managers the latitude to decide which laws should be followed or ignored, as in this situation, then the ethical custom of that company or industry could be to break the law in instances where 1) no one will ever find out about the illegality, and 2) breaking that law will make shareholders a large return. If CC interprets Shareholder Theory in this soft way, Mason should be retained and given his promotion. If $\mathrm{CC}$ takes the orthodox interpretation of Shareholder Theory, breaking of the 
law cannot be tolerated without punishment, since this undermines fairness in the marketplace.

\section{Stakeholder Theory}

Any stakeholder theory is a modification of shareholder theory such that it provides the central value usually attributed to a for-profit company's ownership to a different group, or an expanded group, of stakeholders from the shareholders or owners alone. A stakeholder can be defined in many ways, but a useful way of defining the term for business ethics is "any person who has a vested interest in the success or failure of an enterprise."

Stakeholders can be determined as human (e.g., employees, neighbors, customers) or non-human (e.g., the biosphere, cattle, or coral reefs), depending on the focus of the enterprise. Shareholders may be one set of stakeholders, and so may have high value for the business, but they may not represent the singular or central value of a business. If this happens, the business is actually demonstrating a version of shareholder theory.

Key Features

- Stakeholder theories place groups other than shareholders at the central position.

- Shareholders may be one set of stakeholders, but not the only one or the primary one.

- Any interests other than those of shareholders may be the main interest of the business.

- Good actions benefit the decided-upon stakeholders' interests.

- Bad actions fail to achieve the stakeholders' interests.

\section{Stakeholder Theory Analysis}

The ethical interpretation of Stakeholder Theory in this instance would involve whether CC as a company promotes ethical values beyond value to shareholders. If CC uses this "stakeholder" rhetoric to only provide value for one group of stakeholders, the shareholders, then $\mathrm{CC}$ is actually practicing Shareholder Theory and just calling it "Stakeholder Theory". 
If CC has values other than promoting shareholder value that it cultivates and maintains, then we would need to know what those values are as an aspect of our analysis. Some stakeholders, like the environment, would be irrelevant to this case. Other stakeholders, like the employees on a whole, might be very relevant. I'll pursue the latter analysis.

If employees are understood to be an important stakeholder group beyond the value that $\mathrm{CC}$ gives to shareholders, then ensuring that the employees are not harmed for some company gain is of primary importance. This is because Stakeholder Theory (in this instance) sees them as a key stakeholder group. So, if it is possible that employees could be harmed by CC retaining Mason, then he should be fired, despite his value to shareholders. It is possible that keeping him in his position could hurt morale, but that it would also hurt morale to fire him, so the company will be justified in deciding how to deal with Mason based upon whatever is in the best interests of the employees.

\section{Utilitarianism}

Jeremy Bentham was an Enlightenment politician in Great Britain who believed in a radical approach to social reform. For Bentham, culture should embrace Utilitarianism, with its core idea the promoting the greatest "utility" (which is pleasure, broadly construed) for the greatest number of people. Bentham believed that human experience and living is dominated by various ways of cultivating long and short term pleasures, while simultaneously avoiding pains. Between two choices of action, Bentham believes the right thing to do is to promote the happiness for the most people possible in the situation. There are other technical features, but for business ethics the main point is that the way value is determined is not by reference to what's best for one person or for one group in isolation. Rather, the right thing to do is to consider all those affected by the situation and determine what would bring about the greatest benefit ("utility") for everyone in the group.

Bentham believes that any creature that consciously pursues pleasure and avoids pain should be included in the analysis. Reasoning is very highly valued from Bentham's point of view, since being able to reason about moral issues is the most reliable way we arrive at what we should pursue and what we should avoid. To go a step farther, most utilitarians believe that even if some creatures can't reason about moral issues (for example: some mentally handi- 
capped individuals, all very young children, most non-human animals, and many very elderly people), they still deserve protection from arbitrary harm, because they are capable of experiencing pleasure and pain, which is the most important natural criterion for consideration.

Bentham and the other utilitarians (J.S. Mill and Peter Singer, for example) are all concerned that individual self-interest will overcome fair-minded thinking about ethics. Bentham uses a mathematical system of determining utility in an attempt to avoid biased thinking; he believes that math inserts objectivity into any decision-making process. Later utilitarians believe that we have to cultivate fair-minded thinking in order to avoid biased decision-making when others are involved.

Key Features

- Many human actions involve others; these actions should be decided by bringing together multiple points of view.

- Any kind of Utilitarianism has as its goal the achieving of the greatest good for the greatest number of stakeholders.

- Relevant stakeholders for utilitarianism are able to feel pleasure and pain, are self-aware, and have a stake in the situation.

- A good action maximizes "utility" (which generates pleasure, broadly construed)

- A bad action will fail to maximize utility for those involved and/or will promote pain.

- Utilitarian deciders must be careful to avoid personal biases when deciding on behalf of others.

\section{Utilitarian Analysis}

Any version of Utilitarian thinking tries to achieve the greatest good for the greatest number of stakeholders in the situation. The reason why all stakeholders in the situation are measured is because Utilitarianism demands a complete analysis of the foreseeable impacts of the action in order to determine what the greatest good for the greatest number actually is.

$\mathrm{CC}$ has a variety of stakeholders, as businesses almost always will. Many of them can be excluded as irrelevant once their pleasure and pain are identified, 
however, since customers, partners, and landlords are quite remote from the situation. We would want to measure the pleasure and pain of all relevant stakeholders on the situation, which would include management, other employees, shareholders, and Mason.

The importance of Mason's contributions to the bottom line and his solid example of work ethic and productivity are positives for keeping him. It might be the case that letting him go would actually harm profits for the company and negatively impact the sales force. We might want to gauge Mason's actual onthe-ground leadership in the company to determine what the impact to other team members might be.

Losing Mason would send a clear signal that fraud is not tolerated at CC. There could be other positive effects within the company, like giving other salespeople the opportunity to succeed in the gap Mason's firing or demotion creates. Of course, to be consistent, those that failed to check Mason's credentials should also be punished by $\mathrm{CC}$.

The right decision regarding whether or not to fire Mason under Utilitarianism will rest on which of these two courses will produce the greatest good for the greatest number of relevant stakeholders to the situation. At first glance, it seems like the better action will be retaining Mason as an employee. To know for sure, a detailed analysis is required with more information about other stakeholders than we have in the case.

\section{Deontology}

The most famous duty-based ethical system belongs to Immanuel Kant, leading thinker of the 18th century German Enlightenment. Kant's position is that human beings have a certain amount of natural dignity, and this dignity causes humans to have the highest form of value available, "intrinsic" value. For Kant, we violate a duty to one another when we harm arbitrarily. It is always wrong to harm something with intrinsic value unless you have some excellent reasons for doing so. 


\section{Key Features}

- Humans are the most valuable creatures in existence. They have intrinsic value, which is value that is superlative and cannot be downgraded. It is the highest kind of value possible.

- The value of human beings comes from a combination of Rationality (the ability to use reason) and Autonomy (the ability to use one's free will), which is a unique combination in nature that is found only in human beings. Actions against the person that violate their Rationality or Autonomy will violate the human's intrinsic value, and so these are bad actions, whether they occur in business or anywhere else in life.

- All actions are not moral actions. The overwhelming majority of actions, particularly in business, contain only the actions we must take in order to get those things accomplished. To accomplish this kind of action or to change from one to another is not a moral decision, as far as Kant is concerned, since most actions are not moral in nature. For example, if I change from an Art major to an Economics major, or vice-versa, Kant sees no moral aspect to this choice. Following hypothetical imperatives is one way that humans exercise their autonomy, and selecting new ones should not be considered "wrong" in a moral sense.

- Categorical Imperatives are choices that contain moral features. A categorical imperative is something that must be done in order for the action to be considered "good".

- Kant believes that human beings have similar physical and mental structures that support thinking, and he thinks logic is the best way to navigate our rationality. A contemporary analogy would have our brains as a computer system's hardware with logic as the operating system. For Kant, as with the computer, we can use it well or poorly.

- If we examine moral questions like, "How should I behave in my business activities?" Kant believes there is one right answer. In fact, all moral questions have the same guiding principle, which must never be set aside if the action is to be considered "right". Kant's categorical imperative is "In all of our actions, we must act so that the value of our action can be made into a universal law." Any action that 
meets this standard is good; any action that violates this standard is a bad action.

- Kant believes that there is an immediately obvious inference from this categorical imperative. In other words, if the categorical imperative is true, then Kant thinks this other statement, his "First Corollary", is also true. It states: "We must always treat people, whether in the person of ourselves or others, as ends in themselves [creatures possessing intrinsic value] and never as means only." Like the categorical imperative, if we avoid violating the first corollary, then the action is a good action. If we violate it, then then the action is a bad one.

\section{Deontological Analysis}

Kant's Categorical Imperative does not allow lying. Deontology is very strict about the breaking of duties, like every human being's duty to never lie. Lying is not something that should be done for any kind of gain, since universalizing lying would lead to the undermining of a society that relies upon trivial truths ("Hey, buddy, do you have the time?") to significant truths, like the details of contracts, for its everyday functioning. Since lying cannot be universalized, it violates the categorical imperative; it cannot serve as an example to other human beings. Likewise, lying treats the person lied to as a means only and not a creature that is valuable in itself. By violating human dignity in this way, lying also violates the First Corollary to the Categorical Imperative.

Mason's lie is wrong and should be treated as such by company policy. The policy can decide whether or not he is retained, despite his lie, according to hypothetical imperatives (non-moral goals) set by the company. Certainly, Mason did the wrong thing and should be held accountable. To determine what that accountability looks like is a function of CC's corporate culture and the way it deals with non-moral goals, like how Mason's employment should be handled.

\section{Paulian Analysis: Fairminded Critical Thinking}

The Foundation for Critical Thinking has put forth an ethics theory in the Miniature Guide to Ethical Reasoning, referenced above. Theirs is an integrat- 
ed system of critical thinking, which contains various aspects to reasoning, including Elements of Though, Intellectual Standards, Intellectual Traits, and Egocentric and Sociocentric biases. Ethical thinking, for The Foundation, will avoid harm to others, avoid egocentric and sociocentric biases, and will promote the development of the Intellectual Traits: Intellectual Humility, Intellectual Courage, Intellectual Empathy, Intellectual Integrity, Intellectual Perseverance, Intellectual Autonomy, Confidence in Reason, and Fairmindedness. Thinkers reflect upon and attempt to cultivate these Intellectual Traits, which are reprinted here from Foundation for Critical Thinking documents:

Intellectual Humility (opposite is Intellectual Arrogance)

Having a consciousness of the limits of one's knowledge, including a sensitivity to circumstances in which one's native egocentrism is likely to function self-deceptively; sensitivity to bias, prejudice and limitations of one's viewpoint. Intellectual humility depends on recognizing that one should not claim more than one actually knows. It does not imply spinelessness or submissiveness. It implies the lack of intellectual pretentiousness, boastfulness, or conceit, combined with insight into the logical foundations, or lack of such foundations, of one's beliefs.

\section{Intellectual Courage (opposite is Intellectual Cowardice)}

Having a consciousness of the need to face and fairly address ideas, beliefs or viewpoints toward which we have strong negative emotions and to which we have not given a serious hearing. This courage is connected with the recognition that ideas considered dangerous or absurd are sometimes rationally justified (in whole or in part) and that conclusions and beliefs inculcated in us are sometimes false or misleading. To determine for ourselves which is which, we must not passively and uncritically "accept" what we have "learned." Intellectual courage comes into play here, because inevitably we will come to see some truth in some ideas considered dangerous and absurd, and distortion or falsity in some ideas strongly held in our social group. We need courage to be true to our own thinking in such circumstances. The penalties for nonconformity can be severe. 
Intellectual Empathy (opposite is Intellectual Narrow-mindedness)

Having a consciousness of the need to imaginatively put oneself in the place of others in order to genuinely understand them, which requires the consciousness of our egocentric tendency to identify truth with our immediate perceptions of long-standing thought or belief. This trait correlates with the ability to reconstruct accurately the viewpoints and reasoning of others and to reason from premises, assumptions, and ideas other than our own. This trait also correlates with the willingness to remember occasions when we were wrong in the past de-spite an intense conviction that we were right, and with the ability to imagine our being similarly deceived in a case-at-hand.

Intellectual Autonomy (opposite is Intellectual Conformity)

Having rational control of one's beliefs, values, and inferences. The ideal of critical thinking is to learn to think for oneself, to gain command over one's thought processes. It entails a commitment to analyzing and evaluating beliefs on the basis of reason and evidence, to question when it is rational to question, to believe when it is rational to believe, and to conform when it is rational to conform.

\section{Intellectual Integrity (opposite is Intellectual Hypocrisy)}

Recognition of the need to be true to one's own thinking; to be consistent in the intellectual standards one applies; to hold one's self to the same rigorous standards of evidence and proof to which one holds one's antagonists; to practice what one advocates for others; and to honestly admit discrepancies and inconsistencies in one's own thought and action.

Intellectual Perseverance (opposite is Intellectual Laziness)

Having a consciousness of the need to use intellectual insights and truths in spite of difficulties, obstacles, and frustrations; firm adherence to rational principles despite the irrational opposition of others; a sense of the need to struggle with confusion and unsettled questions over an extended period of time to achieve deeper understanding or insight.

\section{Confidence In Reason (opposite is Distrust of Reason and Evidence)}

Confidence that, in the long run, one's own higher interests and those of humankind at large will be best served by giving the freest play to reason, by encouraging people to come to their own conclusions by developing their own 
rational faculties; faith that, with proper encouragement and cultivation, people can learn to think for themselves, to form rational viewpoints, draw reasonable conclusions, think coherently and logically, persuade each other by reason and become reasonable persons, despite the deep-seated obstacles in the native character of the human mind and in society as we know it.

\section{Fairmindedness (opposite is Intellectual Unfairness)}

Having a consciousness of the need to treat all viewpoints alike, without reference to one's own feelings or vested interests, or the feelings or vested interests of one's friends, community or nation; implies adherence to intellectual standards without reference to one's own advantage or the advantage of one's group.

To the extent that a thinker is capable of authentically cultivating these Traits, while avoiding biases and foreseeable harms to others, the thinker has performed a good action. To the extent that the thinker behaves unfairly to others, cultivates the opposites of the Traits, and/or falls prey to biases in his or her thinking about moral issues, the thinker has done something wrong.

\section{Key Features}

- Good character comes from the cultivation of Intellectual Traits.

- Acting in accordance with those Traits habitually produces good actions.

- Habituating and acting upon negative Intellectual Traits should be avoided and is bad.

- Care should be taken to be self-reflective, to avoid foreseeable harms to others, and to avoid egocentric and sociocentric biases.

\section{Critical Thinking Ethical Reasoning Analysis}

Mason's thinking is the focus of this analysis. We don't know anything about Mason's thinking, so we can only use evidence from his past actions. Clearly, Mason displayed Intellectual Autonomy and Intellectual Courage by standing against the idea that he needed to actually meet the standards in order to do this job well. By deceiving the management, however, he also demonstrated Intellectual Arrogance and a lack of Intellectual Empathy for other job seekers when he gamed the system to get this job and his promotion. 
It's clear that Mason is highly rational, so he probably has some degree of Confidence in Reason. He also possesses a high degrees of Intellectual Perseverance, as his sales success demonstrates. Probably, though, Mason does not possess Intellectual Integrity through all aspects of his life. If he does, that would seem to indicate that he is comfortable being deceptive at any level. This could present a problem for $\mathrm{CC}$, and they should consider whether they want someone with this kind of character leading their sales force and acting as an exemplar to others employees.

The biggest problem from the point of view of Paulian Critical Thinking Theory, however, is that Mason does not demonstrate Fairmindedness. In other words, he is more interested in winning than he is in cultivating and participating in a level playing field in his communities and among his fellows. We have no compelling reasons to believe that Mason will become truly Fairminded, since he has been so successful as a deceiver. $\mathrm{CC}$ will have to decide whether it wants to take a risk that Mason's deception is limited to this one narrow aspect by placing him in a leadership position. Paulian CT Theory does suggest that it's possible that Mason could change if properly motivated or if he discovers the value of Fairmindedness, but, though Mason has a long way to go with his development of Intellectual Traits, CC may still want to take a chance on him, according to the values of its own corporate culture.

Other Important Ethical Theories

Theories like "Biospheric Justice", "Contractarianism", "Care Ethics", "Disaster Capitalism", "Sustainability", "Virtue Ethics", or “Animal Liberation" are valuable to consider for a number of business situations. Each of these could be analyzed following the examples above and their functional elements described in a checklist for the purposes of reasoning ethically with that theory. Other theories, like those from Buddhist, Jainic, or Confucian traditions, could also be relevant and insightful if we try to apply them to business situations. 


\section{APPENDIX F \\ COPYRIGHT AND COPYRIGHT PERMISSION TO REPRINT \\ "THE CENTRAL QUESTION: CRITICAL ENGAGEMENT \\ WITH BUSINESS ETHICS" \\ IN THIS DISSERTATION}

COPYRIGHT INFORMATION FOR THIS TEXTBOOK:

(Please note: Hyperlinks are active in the published version, but are inactive in this dissertation version. Please see links at the end of each chapter and the references.)

The Central Question: Critical Engagement withBusiness Ethics

\section{Brian G. Barnes}

This book has been printed from author prepared copy.

Cover image (C) T. Mithuiel Barnes

www.kendallhunt.com

Send all inquiries to:

4050 Westmark Drive

Dubuque, IA 52004-1840

Copyright (C) 2013 by Brian Barnes

ISBN 978-1-4652-2854-3

Kendall Hunt Publishing Company has the exclusive rights to reproduce this work, to prepare derivative works from this work, to publicly distribute this work, to publicly perform this work and to publicly display this work.

All rights reserved. No part of this publication may be reproduced,stored in a retrieval system, or transmitted, in any form or by any means, electronic, mechanical, photocopying, recording, or otherwise, without the prior written permission of the copyright owner.

Printed in the United States of America

$\begin{array}{llllllllll}10 & 9 & 8 & 7 & 6 & 5 & 4 & 3 & 2 & 1\end{array}$ 


\section{DOCUMENTATION OF COPYRIGHT PERMISSION}

The following is an email exchange between the author of this dissertation and senior staff at Kendall-Hunt Publishing. There are three emails in total.

\section{$\underline{\text { EMAIL } 1}$}

From: Brian Barnes [logician@hyrusa.com]

Sent: Wednesday, March 12, 2014 1:35 PM

To: David Mattaliano

Subject: Re: textbook links

Hi, David. I hope this email finds you well.

I am writing you today at the urging of my doctoral committee. I am preparing to finish my dissertation, and the business ethics electronic textbook I published with Kendall-Hunt is the major document in that process. The Graduate School at the University of Louisville requires written confirmation that they have permission to publish my dissertation, as such, in the university record, which is the university's policy. In addition, all formatting in the textbook (which my wife created and we submitted as one piece, text and formatting, to Kendall-Hunt) will be changed in accordance with university policy for dissertations. I would like Kendall-Hunt's written permission to allow The University of Louisville to use my published work with Kendall-Hunt in the ways outlined above. The graduate school's policy follows my signature.

Allow me to provide my point of view on the process of using this document as my dissertation. On page 11 in the Preface of the e-book, I disclose that this document is part of my dissertation. I also had a discussion with Glenn Hammersmith near the end of our publication process in which he verbally confirmed that there were no issues with the dissertation process using my work published by Kendall-Hunt. Due to my disclosure in the text, which was meticulously examined by both K-H editorial and legal staff, and my confirmation from Glenn, I have moved forward in good faith toward finishing the dissertation and submitting this textbook as part of it.

Please let me know if there is any difficulty with my request. Thank you for your time, and I hope to hear back from you soon.

Brian Barnes

502-338-1338 
Published Work

If students wish to use material that has been previously published under their names in their thesis/dissertation, they will need to contact the original publisher for permission.

The original publisher will indicate whether or not the material may be used in the dissertation, and if permission is granted, the publisher will give instructions on how the material should be documented in the student's thesis/dissertation. The permission approval must be formatted accordingly and added as an Appendix. Permission to use previously published material in a thesis or dissertation doesn't necessarily give the student permission to sell that material. The student may need to put a restriction on the sale and availability of his/ her work according to the publisher's wishes.

If using published work as part of thesis/dissertation, the content of the published work must be reformatted for adherence to the stylistic requirements outlined in this document.

\section{EMAIL 2}

-----Original Message-----

From: David Mattaliano

Sent: Thursday, March 13, 2014 9:08 AM

To: Caroline Kieler

Subject: FW: textbook links

Carolyn,

The email we just discussed.

Regards,

David M Mattaliano

Managing Editor

Kendall/Hunt Publishing Company

702 Notre Dame, Suite 104

Grosse Pointe, MI 48230

2485453059

dmattaliano@kendallhunt.com 
$\underline{\text { EMAIL } 3}$

Good Morning -

Kendall Hunt Publishing grants permission for the inclusion of your text The Central Question: Critical Engagement with Business Ethics in your dissertation. Please include the following credit line:

The Central Question: Critical Engagement with Business Ethics by Brian Barnes. Copyright (c) 2013 by Brian Barnes. Reprinted by permission of Kendall Hunt Publishing Company.

Thank you,

Caroline Kieler

Senior Permissions Editor

Kendall Hunt Publishing

4050 Westmark Drive

Dubuque, IA 52002

563-589-1147 / 563-589-1038 (fax)

ckieler@kendallhunt.com 


\section{CURRICULUM VITAE}

\section{Brian Barnes}

2654 Taylorsville Rd. I Louisville, Kentucky 40205 I phone: 502.338 .1338 e-mail: brian.barnes@louisville.edu

Primary Research Interests

Critical Thinking, Sustainable Systems, Business Ethics

Education

Ph.D., Interdisciplinary Humanities, University of Louisville

Candidacy, Spr., 2012

Area of Concentration: Philosophy as Cultural Enterprise

Area of Specialization: Dialectical Reasoning and Ethical Business

Brandeis School of Law, University of Louisville

2003-04

Basic Arabic Linguistics Course, Defense Language Institute

2000

Master of Arts in Philosophy, University of Louisville

1997

Thesis: "Dueling Intersubjectivities: Jean-Paul Sartre, Edith Stein, and the Husserlian Heritage"

Emphases: Phenomenology, Formal Logic

Bachelor of Arts in Philosophy, Hanover College

1995

Minor: Cultural Anthropology

Classroom Teaching Experience 
This list includes courses scheduled through Dec, 2013. All courses listed below have been taught with full responsibility for planning, instruction, and evaluation.

\section{International}

Quality Leadership University, Panama City, Panama

2006-present

I teach a full-credit course through $\mathrm{U}$ of $\mathrm{L}$ to international undergraduates in Panama City,

Panama, once or twice annually.

Business Ethics (PHIL 225) 14 classes

Introduction to Logic (PHIL 311) 3 class

\section{Domestic}

University of Louisville

1996-

2004-present

Business Ethics (PHIL 225) 32 classes

Critical Thinking (PHIL 211) 10 classes

Introduction to Logic (PHIL 311) 10 classes

Contemporary Ethical Problems (PHIL 222) 9 classes

Introduction to Philosophy (PHIL 205) 2 classes

Bellarmine University

1997-

2006-present

Philosophy Courses:

Introduction to Philosophy (PHIL 160) 11 classes

Ethics (PHIL 301) 1 class

Interdisciplinary Seminars:

Critical Thinking and Being Human/Honors Section (HONR 101) 3 classes

Water/Honors Section (HONR 101) 1 class

Exploring Critical Thinking (IDC 101) 4 classes

Introduction to Popular Culture \& Philosophy (IDC 101) 4 classes

The Japanese Sword (IDC 301) 1 class

Philosophies of Asia (IDC 301) 3 classes

Exploring Social Justice (IDC 401) 5 classes

Sustainable Action Workshop (IDC 401) 7 classes 
Introduction to Ethics (PHIL 140) 19 classes

Elementary Logic (PHIL 150) 5 classes

Introduction to Philosophy (PHIL 100) 12 classes

Introduction to World Religions: Eastern Religions (REL 153) 4

classes

Introduction to the Humanities (HUMA 101) 1 class

Multidisciplinary Honors Seminars:

The Japanese Sword (HON 307) 1 class

Critical Thinking and Being Human (HON 307) 1 class

Jefferson Community and Technical College

2007-present

Introduction to Philosophy (PHIL 120) 4 classes

Bioethics: Moral Issues in Healthcare (PHIL 110) 3 classes

Ethics (PHIL 130) 3 classes

Introduction to Logic (PHIL 150) 2 classes

Strayer Universi-

ty

2011

Introduction to Logic (HUM 200) 1 class

Introduction to Humanities: Renaissance to Modern (HUM 100) 1 class

Northwood University

2012-present

Introduction to Ethics (P3100) 2 classes

The Search for Meaning Through the Humanities (HUM 3110) 1

class

Professional Honors

Visiting Scholar, The Foundation for Critical Thinking

2012-present

Promoted to Senior Lecturer I, Philosophy Department, Arts \& Sciences, $\mathrm{U}$ of $\mathrm{L}$

Fall, 2011

UL Community Engagement Award

Oct, 2011 
Featured Faculty, "Lights, Camera, Ideas to Action” U of L Critical

Thinking Faire

Mar, 2011

Faculty Favorite, Delphi Center for Teaching and Learning,UL

2006, '08, '12

Joint Services Achievement Medal, Department of De-

fense

2003

National Security Agency Certificate of Achievement

2002

US Army Outstanding Volunteer Service Medal

2000

Professional Publications

The Central Question: Critical Engagement with Business Ethics

Business Ethics textbook forthcoming from Kendall-Hunt publishers, ISBN: 978-1-4652-2854-3

Grants Received

Head Grant Writer, J. Graham Brown Foundation

June, 2013

This $\$ 1,000,000$ grant to WaterStep funds infrastructure development.

SUN Grant, University of Louisville

January, 2013

This grant funds a research project that explores the extent to which students in Critical

Thinking and Business Ethics classes can learn to apply critical thinking skills during the span of one semester. $(\$ 3,000)$

SUN Grant, University of Louisville

July, 2012 
This grant funds a year-long project that guides students to create a series of critical thinking-based comic books. $(\$ 9,100)$

James Randi Education Foundation Grant January, 2012

This grant funds ongoing research into critical thinking and the paranormal $(\$ 500)$

Metro Louisville Operation Brightside Renewal Grant

Nov., 2010

Co-recipient with Dr. Robert Kingsolver of a local government grant for the construction of facilities for a food waste composting and urban gardening program on Bellarmine's campus. $(\$ 2,500)$

Hanover College Council for Curriculum Development Grant Apr., 2010

Co-recipient of a grant with Dr. John Ahrens of Hanover College to explore and document the epistemological limits of the Paul-Elder Framework for paranormal inquiry. $(\$ 5,000)$

Professional Conference Presentations

"The University of Louisville Composting Project"

Oct., 2013

Poster Presentation, AASHE 2013: Resiliency and Adaptation (Nashville, TN)

"Internalizing the Foundations of Critical Thinking" (with Dr. Richard Paul),

Jul., 2013

"Placing a Substantive Conception of Critical Thinking at the Heart of Teaching and Learning" (with Dr. Rush Cosgrove), "Critical Thinking and the Common Core

State Standards," and "Dialogue With Richard Paul on the Possibility of Cultivating Fairminded Critical Societies" (with Dr. Richard Paul) 
Presenter, 33rd International Conference on Critical Thinking and Education Reform, Berkeley, CA

"Placing Critical Thinking at the Heart of Teaching and Learning," "Critical

Mar., 2013

Thinking and the Common Core State Standards," and "Critical Thinking and Socratic Questioning" (with Dr. Richard Paul)

Presenter, FCT Spring Workshop on Critical Thinking, Berkeley, CA

"Critical Thinking for Student Engagement"

Nov., 2012

Invited Speaker at the "Moving the Needle" conference at St. Petersburg College

Center of Excellence for Teaching and Learning, St. Petersburg, FL.

"Composting for Community Engagement"

Nov., 2012

2012 Kentucky Engagement Conference at Western Kentucky University

"Evidence of Critical Thinking in Student Films"

Feb., 2012

2012 Celebration of Teaching and Learning at U of L: Envisioning Teaching and Learning in the Digital Age

"Thinking Critically About Sustainable Systems"

Nov., 2011

Northern Kentucky University Campus Community Partnerships for Sustainability Conference

“Considering Food: How Should We Think About What We Eat?"

Apr., 2011

2011 Hanover College Capstone Lecture Series Presentation

"Teaching Medical Ethics"

Oct., 2010

Society for Ethics Across the Curriculum, Union College, Schenectady, NY.

"Food Waste Composting at the University of Louisville"

Aug., 2010 
Bluegrass Bioneers Conference Presentation, Louisville, KY

"Food Composting Efforts at the University of Louisville"

Aug., 2010

Campus Community Partnerships for Sustainability Conference, Lexington, $\mathrm{KY}$

"Critical Thinking and Student Engagement"

Aug., 2010

Seneca High School Teachers' Summer Retreat, Louisville, KY

Presented "A Business Ethics Toolbox" and "Vermicomposting for Urban

Renewal"

Apr., 2008

National Forum for Black Public Administrators, 2008 National Conference,

hosted by the Executive Leadership Institute, University of Louisville

"HAMAS and Islamic Jihad: Historical and Political Perspectives"

2000

Center for Non-Proliferation Studies, Monterey, CA

Professional Workshops

Foundation for Critical Thinking Professional Development Workshops

Faculty and Staff Development Workshop for QEP

Aug., 2013

Broward Community College, Penbroke Pines, FL

Faculty Development Workshop

May, 2013

J. Sergeant Reynolds Community College, Goochland, VA

Students' Success is Michigan's Success (Keynote Speaker)

Mar., 2013

Michigan Developmental Education Consortium Annual Conference, Grand Rapids, MI

Faculty Development Work-

shop

Jan., 2013

Central City Value High School, Los Angeles, CA 
Faculty Development Work-

shop

Oct., 2012

St. Mary in the Woods College, Terra Haute, IN

"Helping Students Develop Intellectual Virtues"

Jul., 2012

Workshop at The 32nd International Conference for Critical Thinking, Berkeley, CA

Other Workshops

"Cultivating Critical Thinking"

Jan., 2013

A Fundamentals of Teaching Spotlight Session at Bellarmine University

Bellarmine IDC Annual Faculty Work-

shops

2010-12

Led workshops on applying critical thinking models and student participation strategies in the classroom for faculty of the Interdisciplinary Core Program (IDC) at Bellarmine University.

"Critical Thinking and Sustainability"

Mar, 2012

Universiy of Kentucky Sustainability Forum, Lexington, KY

Participant in Faculty Learning Community for Education Methods at UL

2011-12

Vermiculture Workshop and Education Sta-

tion

2011-12

Healthy Foods, Local Farms Conference, Louisville, KY 
Panel Chair, Forum on Sustainability Initiatives

Mar., 2011

Faculty Research Forum, University of Louisville

"Composting: The Life Cycle of Trash"

Sep., 2010

Presented a 35 x 25 foot educational art installation made entirely from trash as part of the Healthy Foods, Local Farms Conference hosted by Spalding University, Louisville.

Invited Participant, Kentucky Dept. of Education Focus Group

May, 2010

Participated in on environmental on education and the federal No Child Left Inside program at Western Kentucky University

IdeaFest, Louisville, KY

Sep., 2009

Vermiculture presenter at Will Allen's 3-day workshop, held at Breaking New Grounds.

Participant in Faculty Learning Committee for Critical Thinking at $\mathrm{U}$ of $\mathrm{L}$

2009-10

Invited Speaker, Education Roundtable, Hanover College

Feb., 2009

Invited Participant, Business Ethics Round-

table

2007

Kentucky Leadership Development Council, Lexington, KY

Academic Service Activities

Ideas to Action Digital Tools Subcommittee

2013-present

Consultant on development of Ethics QEP at U of L College of Business

2013-14 
University of Louisville Sustainable Education Commit-

tee

2013

Director, UL Eco-Reps Sustainability Education and Service Organization

2011-present

University of Louisville Garden Commons Advisory Board

2011-12

University of Louisville Sustainability Council

2011-present

Committee Member, Senior Honors Thesis in Psychology, University of Louisville

Apr., 2010

"The Paul-Elder Framework and Inter-Rater Reliability for Education" by Rachel Hall

Ideas to Action Poster and Faculty Development Committee 2010-2012

University of Louisville Faculty Senate Executive Committee

2009-11

Chair, UL Faculty Senate Committee for Committees \& Credentials

2010-11

UL Faculty Senate Part-Time Faculty Committee

2009-12

UL Faculty Assembly Representative, Arts and Sciences Division

2010-2011 
Manager, UL Sustainability Council Initiative on Composting Food Waste

2009-present

I have designed and implemented systems, in conjunction with $\mathrm{U}$ of L and Sodexo,

to create compost \& vermicompost from campus food waste.

Community Service Activities and Partnerships

WaterStep Water Purification Trainer and Grant Writer

2012-present

I lead training workshops in various aspects of water purification technology, hygeine practices, and related topics at the Louisville international headquarters. I also write grants for various WaterStep humanitarian relief and education projects.

20/20 Talk for Gray Street Farmers' Market and U of L School of Public Health

Jun., 2013

Fox Hollow Folk School

Fall, 2012

Vermiculture Workshop Presenter

Louisville Area Skeptics, Skepticamp Kentucky

Jun., 2012

"Overcoming Egocentric and Sociocentric Bias"

WaterStep Training School at Quality Leadership Universi-

ty

Dec, 2011

Planned, located funding for, and trained staff for a water purification and hygiene program housed at a $\mathrm{U}$ of L's partner university in Panama City, Panama, using technology

developed in Louisville by Edge Outreach. We partner with the Foundation for the Children of Darien to install water purification technology at rural schools in Darien Province outside Panama City. 
Hoophouse at Bluegrass Community and Technical College, Lex, KY

May, 2011

Planned and helped construct a hoophouse in collaboration with Bluegrass

Community and Technical College.

Chance School Food Waste Composting Sys-

tem

Apr., 2011

Designed and implemented food waste composting and gardening program for integration into a secondary school curriculum.

Planning Committee, Bluegrass Bioneers Conference

Mar., 2011-13

Americana Community Center Urban Garden.

2010-present

Designed, led others, built, and implemented an urban composting system, vermiculture system, and a hoophouse for a community garden on Southside Drive in Louisville, KY. Recipient of their Volunteer Appreciation Award.

Inducted into Distinguished Order of Kentucky Colonels

2009

Breaking New Grounds

2006-2012

Breaking New Grounds was a community-based Louisville non-profit composting organization.

BNG collected food waste from local businesses and turned it into nitrogen-rich vermicompost, saving approximately a ton of trash from the landfill weekly. As an early board member, I was active in many administrative and production aspects of BNG. www.breakingnewgrounds.org

Co-Volunteer of the Year

2009

Director of Vermiculture

2007-2009 
Advisory Board member

2008-2011

Executive Secre-

tary

2006

Board of Direc-

tors

2006-07

Chair, Kentucky Division, United States Fencing Association

2003-05

Popular Publications

"Ethically Speaking" and "Something to Think About" The Turret, Ft.

Knox, KY

2008, 2010

Bi-weekly print newspaper columns regarding applied ethics and sustainability. (The Turret

is the largest weekly print newspaper in Kentucky and in the US Armed Forces.)

Annual Hanover College Capstone Publica-

tion

2009

Copy-Editor for Global Climate Change

"Worms"

2008

Shudokan Martial Arts Association newsletter, Winter 2008, reprinted in "Best of SMAA, 2010."

"Tips for the Recreational Fencer"

2003

Published in American Fencing, the journal of the United States Fencing Association. 
"Suffering as Catharsis"

2001

Shudokan Martial Arts Association newsletter, Winter 2008, reprinted in "Best of SMAA, 2010."

Popular Media Coverage

"Project Green: U of L compost program digs in dumpsters to reduce waste"

Mar., 2011

Project Green feature segment by Ben Pine, WHAS11, Louisville, KY

(http://www.whas11.com/news/local/118788594.html)

"Garden Commons takes root at U of L"

Mar., 2011

Feature article by Elijah McKenzie, The Louisville Cardinal. (http:// www.louisvillecardinal.com/ 2.4743/features/ garden-commonstakes-root-at-u-of-1-1.2524280)

"Food composting comes to campus"

Mar., 2011

Feature article, UofL Today

"Trash into treasure: creating compost at Bellarmine"

Dec., 2010

Project Green feature segment by Ben Pine, WHAS11, Louisville, KY (http://www.whas11.com/community/Trash-into-treasure-creating-compost-at-Bellarmine-111404109.html)

Featured in The Louisville Cardinal

Feb., 2008

Article entitled "Prof. Leading by Example"

Student Conference Presentations and Honors

"Interdisicplinary Reasoning: An Assessment of the Paul-Elder

Critical Thinking Framework for Humanities"

Apr., 2010

Graduate Student Interdisciplinary Conference, University of Kentucky 
"Is the Paul-Elder Critical Thinking Framework Appropriate for Humanities?"

Apr., 2010

Association for Humanities Academics Graduate Student Conference, $\mathrm{U}$ of $\mathrm{L}$

"A Rite of Passage for Conrad's Secret Sharers"

Mar., 2008

Crossing Boundaries Interdisciplinary Conference on the Humanities Inducted into Golden Key International Honour Soci-

ety

2007

"Contributions of the Nile: A Cultural Survey" (Presented in Arabic.)

2000

International Language Day, Defense Language Institute, Monterey, CA.

Graduate Teaching Assistantship in Philosophy, University of Louisville

1996-97

Research Assistantship in Philosophy, University of Louisville

1995

Richter Grant, Hanover College (funded home stay in Japan)

1993

Government Employment

United States Army, Military Intelligence Branch

1997-2005

Served in operations Noble Eagle and Enduring Freedom.

Arabic Cryptologic Linguist for the US Army and National Security

Agency

1998-2003 
Information Systems Security Officer, National Security Agency 2002

Basic Cryptologic Linguist Certification, US Army Intelligence School 2000

Top Secret (TS/SCI) Security Clearance granted by US Government 1998

Professional Responsibilities in US Army

Squad Leader

2001-03

Hand-to-Hand Combat Instructor 1998-2002

Platoon Equal Opportunity Representative

2002

Platoon Arabic Tutor

2002

Junior Enlisted Training School Instructor 1998-2000

Professional Responsibilities at NSA

Lead/Training Operative

2002-03

Operative

2000-03

Other Government Projects 
Defense Intelligence Agency

2000

Designed Internet Search Protocols

Center for Non-Proliferation Studies (CNS) at the Monterey Institute of International Stud-

ies

2000

Consultant on Middle East Terrorism and Arabic Culture

Performed Open-Source and Classified Translation for FBIS, FBI, CIA, DIA, and NSA

1999-2000

Other Employment

Consultant for Raising Hope Organic Farm, Fisherville, KY

2012-13

Designed, built, and maintained hoophouses for agriculture and poulty, vermiculture systems, and black soldier fly habitats.

Wild Oats Natural Marketplace, Inc., Louisville

Customer Service Manager \& Regional Operations and Training Team

2006-07

Grocery Manager \& Regional Grocery Training Team

2004-06

Assistant Coach, Augusta Fencers' Club, Augusta, GA

2001-03

Certified coach and referee, USFA \& Fencing Officials Commission

2002-2007 
Owner, Katsujinken Dojo, an Authorized Branch of Hontai Yoshin Ryu, USA

1999-present

Senior instructor of traditional Japanese jujutsu and weaponry for Hontai Yoshin Ryu USA.

www.hyrusa.com

\section{References}

John Ahrens, Ph.D.

Chair of Philosophy

Department of Philosophy, Hanover College

812.866.7000•ahrens@hanover.edu

Graham Ellis, Ph.D.

Assistant Vice President for Academic Affairs

Director, Interdisciplinary Core

Associate Professor of Chemistry

College of Arts and Sciences, Bellarmine University

502.452.8218•gellis@bellarmine.edu

Osborne Wiggins, Ph.D.

Professor of Philosophy (Emeritus)

Department of Philosophy, University of Louisville

502.333.0645• opwigg01@gmail.com 